\title{
Regimes de Crescimento Econômico: uma síntese Kalecki-Pasinettiana
}

Pedro Celso Rodrigues Fonseca

\author{
Brasília
}

Fevereiro 2017 


\section{Pedro Celso Rodrigues Fonseca}

\section{Regimes de Crescimento Econômico: uma síntese Kalecki-Pasinettiana}

Tese apresentada ao Departamento de Economia da Universidade de Brasília como requisito à obtenção de título de Doutor em Economia.

Orientador: Prof. Dr. Ricardo Silva Azevedo Araújo

Brasília 


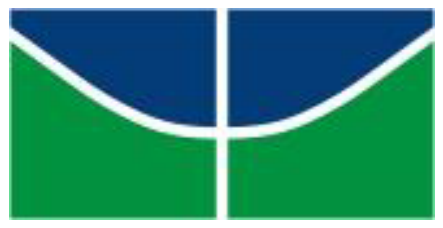

Regimes de Crescimento Econômico: uma síntese Kalecki-Pasinettiana.

Brasília, fevereiro de 2017.

Orientador: Prof. Dr. Ricardo Silva Azevedo Araújo - FACE/Unb

Prof. Dr. Joanílio Teixeira - FACE/Unb

Dr. Leopoldo Costa Júnior - Ministério do Planejamento, Desenvolvimento e Gestão

Dra. Keiti da Rocha Gomes - Secretaria do Tesouro Nacional

Dr. Jorge Thompson Araújo - Banco Mundial

Suplente: Profa. Dra. Daniela Freddo - FACE/Unb 


\section{DEDICATÓRIA}

Dedico esta tese a Mônica Maranha Paes de Carvalho e Antônio Celso Paes de Carvalho Fonseca. 


\section{AGRADECIMENTOS}

Após quatro anos percorrendo os corredores e salas de aula da Unb, muitas pessoas passaram na minha vida modificando-a de forma permanente e sem dúvida a engrandecendo.

Citá-las todas seria muito extenuante e provavelmente eu seria injusto ao me esquecer de alguém. Deste modo, vou me reter inicialmente àqueles que me acompanham desde que nasci e cuja criação e apoio incondicional aos projetos que proponho deram-me e dão forças para continuar adiante. Estes são meus pais Celso Silva Fonseca e Valéria Rodrigues Motta.

Neste ciclo familiar não posso deixar de referenciar meus irmãos, Luiz Gustavo, Ana Carolina, João Jorge e Maria Rita. Todos torcem fervorosamente pela minha felicidade, e apesar da distância física frente à Ana, devido às suas constantes viagens, no amor estamos sempre juntos.

No âmbito da Universidade só tenho a agradecer a essa excelente instituição que me acolheu na graduação e no doutorado expandido o meu conhecimento para horizontes aos quais eu não poderia alcançar sem os seus docentes e alunos. Entre os docentes cito o professor Ricardo Araújo que pacientemente me orientou e tornou este trabalho possível, e os professores Joanílio Teixeira, Adriana Amado, Maria de Lurdes e Luís Carlos. Em relação aos colegas, gostaria de agradecer a amizade e companheirismo, recheados de boas conversas nesses quatros anos, da Daniela Freddo, Keiti Gomes, Saulo Quadros e Pedro Garrido.

Por fim, discorro sobre a minha linda esposa Mônica Maranha Paes de Carvalho, seu esforço foi tão ou maior que o meu para que pudesse realizar esta tese, a ela devo tudo e foi dela que tive a impronunciável felicidade de ser pai. Ao nosso filho Antônio Celso Paes de Carvalho Fonseca, não devo somente agradecimentos, mas sim desculpas pela minha constante ausência (particularmente nos finais de semana) no seu primeiro ano de vida. Prometo que farei o possível para sanar essa falta nos próximos anos. A ambos dedico este trabalho.

Meus sinceros agradecimentos. 
“(...) yet it seems to me that is possible to build a unifying theory [...]. It is a theory the basic elements of which can be trance back to various stages in the development of economic thought; they can be found, here and there, in Smith, in Ricardo, in Malthus, in Marx, in Keynes, in Kalecki, in Leontief, in Sraffa, and in the recent models of economic growth and income distribution."

(Luigi L. Pasinetti, Structural Change and Economic Growth - A theoretical essay on the dynamics of the wealth of nations)

"Post-Keynesians can demonstrate the strength and the generality of their approach by embracing Sraffian multisectoral foundations. "

(Andrew B. Trigg, Future Directions for Heterodox Economics) 


\section{RESUMO}

O presente trabalho discorre sobre a pertinência ou não de se considerar a escola neoricardina como integrante da escola pós-keynesiana. Mostra-se que é possível aproximar as duas escolas a partir do modelo multissetorial de Pasinetti no âmbito da teoria do crescimento e distribuição. Sendo assim, realiza-se a síntese Kalecki-Pasinetti. Para tanto, no segundo capítulo discute-se os modelos keynesianos de crescimento apresentando os seus princípios, conclusões e limitações. Demonstra-se, em seguida, que o modelo kaleckiano supera as referidas limitações constituindo atualmente o modelo canônico pós-keynesiano de crescimento. No terceiro capítulo, apresenta-se o modelo neo-ricardiano destacando que é possível aproximá-lo do pós-keynesiano e, a depender da concepção de taxa de lucro normal, obtém-se os mesmos resultados de Bhaduri e Marglin, ou seja, a economia é caracterizada por regimes de crescimento wage-led ou profit-led. Nesse mesmo capítulo apresenta-se o modelo multissetorial de Pasinetti e mostra-se que, adotando o seu conceito de taxa de lucro natural, obtêm-se diferentes regimes de crescimento na economia. No quarto capítulo demonstra-se que, utilizando como ponte o modelo de Feldman, obtém-se o modelo kaleckiano de dois setores a partir do modelo de Pasinetti e vice-versa, de tal forma que é possível sintetizar os dois. Dado que Pasinetti havia endogeneizado a taxa de lucro natural, com a síntese é possível endogeneizar a taxa de utilização natural da capacidade. Nesse exercício mostram-se as condições para equalização da taxa de lucro intrassetor e interssetores, assim como o processo de transição do curto para o longo prazo. Nesse capítulo conclui-se que diferentes regimes de crescimento devem existir nos diferentes setores de uma dada economia. Ao final, demonstram-se algumas limitações do modelo. Observa-se que a superação dessas envolveria esforços analíticos realizados pela escola estruturalista latino-americana. No quinto capítulo, mostrou-se que, apesar da simplicidade é possível utilizar o modelo síntese na representação dos debates estruturalistas, e isso é realizado no debate da década de 1960 sobre o estagnacionismo.

Palavras-chaves: pós-keynesianos, neo-ricardianos, crescimento e distribuição, análise multissetorial, estruturalismo. 


\begin{abstract}
This work deals about the relevance of considering whether the neo-Ricardian school is inside or not of the post-Keynesian school. It shows that is true and for that we use Pasinetti multissectoral model to realize a Kalecki-Pasinetti synthesis. To get this synthesis in the second chapter we discuss the Keynesian growth and distribution models, their assumptions, conclusions and limitations. After it we demonstrate that the Kaleckian model overcome their limitations which result in the canonical postKeynesian growth model. In the third chapter, we handle with the neo-Ricardian model and we show how close are Kaleckians and neo-Ricardians. Especially, if we considerate the actual profit rate as the normal or Pasinettian natural, the economy shows two different regimes of growth, profit-led or wage-led. During the forth chapter, we utilize Feldman to show how similar are Pasinetti multissector model and kaleckian two sector model. As Pasinatti had endogeneized the natural profit rate, to comprehend long term investiment it is necessary to endogeneize the natural productive capacity. It is done in this chapter which shows how difficult it is to equalize the profit rate intrasector and intersector, so we conclude that inside the same economy there are many regimes of growth. At the end of the forth chapter, the restrictions of the synthesis models are discussed and we recognize that for overcoming them an extensive analysis would be necessary. Such analysis was applied by the Latin-America Structuralist School. Although the synthesis model is simple, it is able to demonstrate formally a debate about stagnationism of the structuralist school.
\end{abstract}

Keywords: post-Keynesians, neo-Ricardians, growth and distribution, multissetoral analysis, structuralism. 


\section{SUMÁRIO}

LISTA DE GRÁFICOS

CAPÍTULO 1 - INTRODUÇÃO

CAPÍTULO 2 - OS MODELOS DE CRESCIMENTO PÓS-KEYNESIANOS

E KALECKIANOS 16

2.1 INTRODUÇÃO 16

2.2 O PRINCÍPIO DA DEMANDA EFETIVA DE KEYNES: CONTRAPOSIÇÃO À TEORIA NEOCLÁSSICA

2.3 OS MODELOS DE CRESCIMENTO E DISTRIBUIÇÃO PÓSKEYNESIANOS 24

2.3.1 O MODELO DE HARROD (1939) E DOMAR (1946) 25

2.3.2 OS MODELOS DE KALDOR (1956) E PASINETTI (1962) 34

2.3.3 O MODELO DE CRESCIMENTO DE ROBINSON 41

2.4 O MODELO KALECKIANO DE CRESCIMENTO E DISTRIBUIÇÃO 47

2.5 RESUMO DO CAPÍTULO 57

CAPÍTULO 3 - A PERSPECTIVA NEO-RICARDIANA 60

3.1 INTRODUÇÃO 60

3.2 PREÇOS DE MERCADO E PREÇOS NATURAIS NOS CLÁSSICOS (SMITH, RICARDO E MARX)

3.3. O MODELO NEO-RICARDIANO 62

3.4 O MODELO MULTISSETORIAL PASINETTIANO 71

3.4.1 CARACTERÍSTICAS GERAIS 71

3.4.2 O MODELO DE PRODUÇÃO SEM PROGRESSO TECNOLÓGICO 75

3.4.3 O MODELO ECONÔMICO EM EXPANSÃO SEM PROGRESSO TECNOLÓGICO

3.4.4 O MODELO DE PRODUÇÃO PURO TRABALHO SEM PROGRESSO TECNOLÓGICO 
3.4.5 MODELO DE CRESCIMENTO CONSTANTE PURO TRABALHO SEM PROGRESSO TECNOLÓGICO …................................................................... 90

3.5 O MODELO KALECKIANO COM A TAXA DE LUCRO NATURAL ........... 92

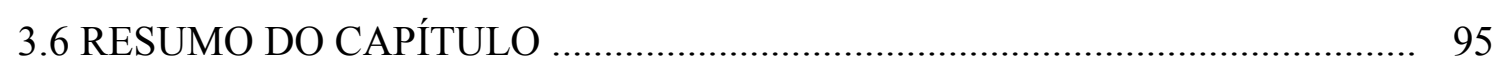

CAPÍtULO 4 - O MODELO KALECKIANO MULTISSETORIAL E A SÍNTESE DE PASINETTI ................................................................................... 98

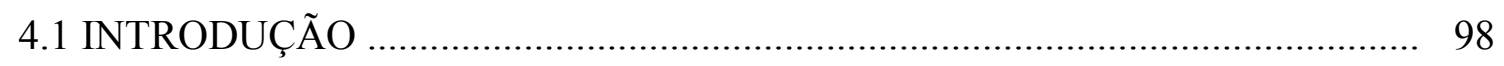

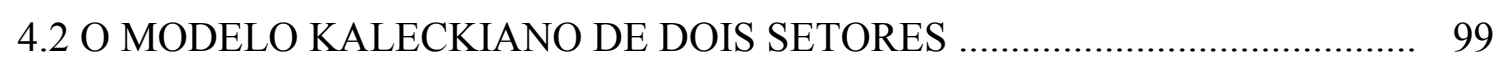

4.3 O MODELO PASINETTIANO DE CURTO PRAZO COM DOIS SETORES

SEM PROGRESSO TECNOLÓGICO …........................................................ 106

4.4 O MODELO PASINETTIANO DE CRESCIMENTO COM DOIS SETORES

SEM PROGRESSO TECNOLÓGICO _............................................................... 109

4.5 A ENDOGENIZAÇÃO DA TAXA NATURAL DE UTILIZAÇÃO DA

CAPACIDADE ….................................................................................. 114

4.5.1 ENDOGENIZANDO NO MODELO DE APENAS UM BEM ......................... 114

4.5.2 ENDOGENIZANDO NO MODELO DE DOIS BENS .................................... 117

4.5.3 ENDOGENEIZANDO NO MODELO MULTISSETORIAL ........................... 123

4.6 RESUMO DO CAPÍTULO .............................................................................. 133

CAPÍTULO 5 - UM BREVE EXERCÍCIO SOBRE HISTÓRIA DO PENSAMENTO ECONÔMICO: APLICAÇÃO DO MODELO SÍNTESE

KALECKI-PASINETTI ..................................................................... 136

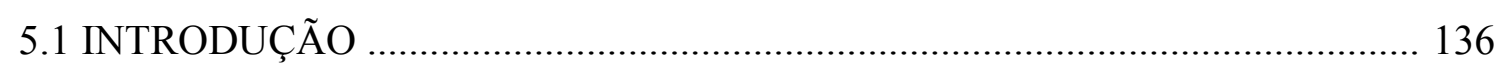

5.2 O ESTRUTURALISMO LATINO-AMERICANO ........................................... 137

5.3 A TESE DA TENDÊNCIA À ESTAGNAÇÃO ……............................................ 139

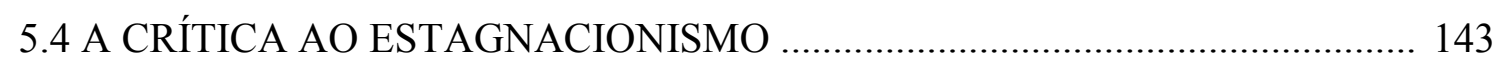

5.5 APLICANDO O MODELO SÍNTESE KALECKI-PASINETTI AO DEBATE

SOBRE O ESTAGNACIONISMO E POSSÍVEIS DESDOBRAMENTOS .......... 145

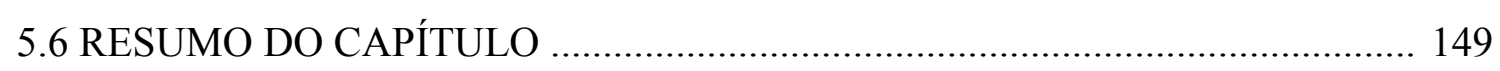

CAPÍTULO 6 - CONCLUSÃO ...................................................................... 151

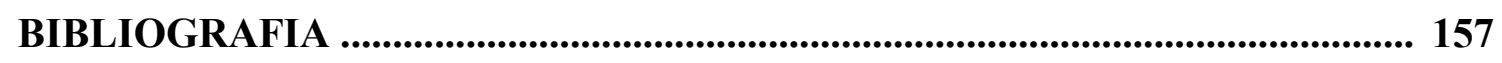




\section{LISTA DE GRÁFICOS}

Gráfico 2.1 - Determinação do produto e emprego em Keynes ............................... 22

Gráfico 2.2 - Instabilidade do modelo de Harrod ........................................................ 29

Gráfico 2.3 - Curvas de Robinson .................................................................... 43

Gráfico 2.4 - Instabilidade no modelo de Robinson ............................................... 44

Gráfico 2.5 - Paradoxo da poupança no modelo de Robinson .................................. 45

Gráfico 2.6 - Equilíbrio no modelo de Kalecki ....................................................... 54

Gráfico 2.7 (a) - Paradoxo da poupança ................................................................... 56

Gráfico 2.7 (b) - Paradoxo dos custos ............................................................. 56

Gráfico 3.1 - Paradoxo dos custos no modelo neo-ricardiano ................................ 67

Gráfico 3.2 - Regimes de crescimento profit-led e wage-led ................................ 70

Gráfico 3.3 - Fluxo das mercadorias no modelo de Pasinetti ................................... 76

Gráfico 4.1 - Taxa de crescimento natural e taxa de crescimento de curto prazo ...... 117

Gráfico 4.2 - Modelo multissetorial .................................................................. 124

Gráfico 4.3 - Taxas de lucro presentes no modelo verticalmente integrado de dois setores

Gráfico 5.1 - Estrutura de Furtado pré-industrialização ........................................... 145

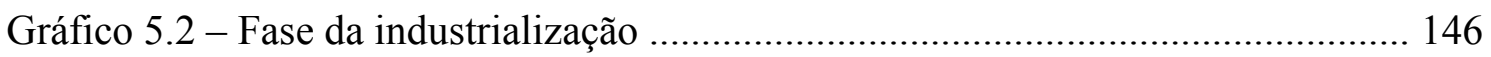




\section{CAPÍTULO 1 - INTRODUÇÃO}

A presente tese insere-se num amplo debate a respeito da pertinência ou não de se considerar a escola neo-ricardiana como parte da escola pós-keynesiana. Em linhas gerais a escola pós-keynesiana consiste na extensão e generalização das ideias seminais de John Maynard Keynes, e seu início foi exatamente na Universidade de Cambridge, na qual Keynes lecionou, com diversos pesquisadores como Roy Harrod, Nicholas Kaldor, Joan Robinson, Pierro Sraffa e Maurice Dobb. Posteriormente essa tradição se desenvolveu com Luigi Pasinetti, Geoffrey Harcourt, Wynne Godley, Paul Davidson e Victoria Chick. No âmbito da teoria do crescimento e distribuição, Kalecki contribuiu fundamentalmente para essa escola, sendo que o seu trabalho hoje representa o modelo canônico pós-keynesiano de crescimento.

A escola neo-ricardiana, por sua vez, desenvolve-se a partir dos trabalhos do economista italiano Pierro Sraffa com os seguintes pesquisadores: Garegnani, Sylos Labini, Roncaglia, Pasinetti, Baranzini, Pivetti entre outros. Como característica basilar desta escola encontra-se o objetivo de redescobrir e reavivar a tradição da economia política clássica cuja origem encontra-se em Smith, Ricardo e Marx. Nestes a premissa central é que a distribuição do produto não é regulada pelas forças de oferta e demanda, mas sim por processos históricos e institucionais que refletem os interesses de classes.

Os clássicos, diferentemente dos neoclássicos, não estavam preocupados com os determinantes das trocas de mercadorias, mas sim com as condições necessárias para a produção e reprodução destas. Os neoclássicos de tradição marginalista iniciam a análise econômica a partir dos aspectos estáticos da realidade, nos quais se pressupõem dados recursos naturais, dado número de indivíduos e preferência dos agentes pré-definidas. Diante destes pressupostos, o problema econômico seria encontrar os preços determinados no processo de troca, de tal forma que houvesse alocação ótima dos recursos. Esse procedimento parte do princípio de que há escassez de recursos na economia e foi eternizado por Lionel Robins (1932) quando definiu a economia como a ciência que estuda a alocação de recursos escassos entre fins alternativos. Os clássicos não negavam que esta abordagem fosse importante, mas não a consideravam a mais relevante. Para eles a economia consistia no estudo do modo pelo qual a sociedade produzia as mercadorias e como estas eram distribuídas entre seus membros. Nesta interpretação, os preços não são um índice de escassez, mas sim refletem o custo unitário de reprodução dos bens e serviços. 
A relevância do princípio da produção frente ao da escassez é acatada tanto pelos neoricardianos quanto pelos pós-keynesianos. No entanto, a partir dos anos 1980, autores como Dow (1988) e Downward (2000) advogavam a incompatibilidade entre as duas escolas. Segundo eles, a essência da metodologia pós-keynesiana são os sistemas abertos, isto é, sistemas nos quais os agentes não conhecem todas as variáveis, há incerteza na economia e os agentes possuem racionalidade limitada.

A conceituação de sistemas abertos não é consensual e autores como Lee (2002) afirmam que tal conceito está relacionado ao realismo crítico. Ou seja, trabalhar com sistemas abertos nada mais é do que adotar o princípio de que o pesquisador deve superar a superfície do fenômeno e adentrar na estrutura e nos mecanismos de causalidade que o explicam. Este por sua vez é exatamente o princípio metodológico dos neo-ricardianos. Por isso, autores como Lavoie (2015) e Mongiovi (2012) posicionam-se favoravelmente frente à compatibilidade entre as escolas, além de destacar outros pontos em comum, como a presença de desemprego involuntário, a importância da variação do produto e do emprego no ajuste macroeconômico e a efetividade da política econômica na estabilização da economia.

O presente trabalho tem o objetivo de mostrar que é possível aproximar as duas escolas no que se refere à teoria do crescimento e distribuição, a partir do modelo multissetorial de Pasinetti $(1983,1991)$. Destaca-se que ambas possuem princípios em comum como: a precedência do investimento frente à poupança; a relevância do princípio da demanda efetiva no curto e no longo prazo (em contraposição ao princípio da escassez); a importância crucial da distribuição do produto; a concepção do capital como mercadoria; integração vertical entre os setores etc. Mas, apesar destes, alguns elementos constituem o estereótipo da escola neo-ricardiana e são utilizados pelos partidários da incompatibilidade de síntese entre as duas correntes de pesquisa. Tais elementos são:

- A análise do longo período é importante, enquanto os problemas de curto prazo não;

- O núcleo de estudo da economia são os preços relativos e a distribuição social do produto;

- As posições de longo prazo consistem em aquelas em que os preços, o produto e o nível de utilização da capacidade produtiva encontram-se ao nível normal;

- As posições de longo prazo são determinadas ex-ante independentemente das variações das posições de curto prazo. 
De modo a analisar as afirmações elencadas, este trabalho utiliza os modelos de crescimento e distribuição kaleckiano e pasinettiano. O primeiro foca nas posições de curto prazo, em particular no caráter instável da economia a partir da instabilidade da função investimento; e, a depender das variáveis que determinam o investimento, permite identificar diferentes regimes de crescimento na economia. Por outro lado, o modelo de Pasinetti desenvolve-se por meio de um sistema de produção e preços investigam-se os pontos fundamentais, independentes dos aspectos institucionais da sociedade, que permitem manter a economia em equilíbrio com pleno emprego e sem desperdício de recursos em seus múltiplos setores.

No desenvolver deste trabalho mostra-se que, além dos pressupostos similares, como a integração vertical, é possível demonstrar fazendo uso do modelo de Feldman (1926) que as equações dos modelos kaleckiano e passinettiano são semelhantes de tal forma que é possível sintetizar os dois. Tal exercício elucida elementos interessantes: do ponto de vista passinettiano, percebe-se que os multissetores podem ser institucionalizados à la Kalecki, obtendo-se diferentes regimes de crescimento para cada setor; e, do ponto de vista kaleckiano, transfere-se a análise da economia agregada em um único setor para $n$ setores e permite-se analisar o comportamento da economia na transição do curto para o longo prazo. Nesta última observação, em particular, o presente trabalho destaca as condições para equalização da taxa de lucro intrassetor e interssetores.

No desenvolvimento dos argumentos mostra-se que para os neo-ricardianos: a análise de curto e longo prazo é importante; não apenas os preços relativos e a distribuição consistem no núcleo do estudo da economia, como também a definição da taxa de crescimento, os determinantes do investimento, o nível de emprego etc.; as posições de longo prazo dependem do comportamento da economia no curto prazo, há path dependence; as posições normais não são inalteráveis.

Com este trabalho pretende-se mostrar que as similaridades entre as teorias do crescimento e distribuição neo-ricardiana e kaleckiana permitem considerar a primeira como parte integrante da escola pós-keynesiana. Isso é importante para o fortalecimento e afirmação desta escola como alternativa ao mainstream.

Em geral, os economistas tendem a sobre enfatizar as suas contribuições, diferenciando-a das demais teorias, o que limita o debate e a abrangência dos argumentos teóricos e das proposições de política apresentadas. A presente tese não coaduna com esses princípios e mostra que o diálogo entre kaleckianos e passinetianos pode ser frutífero para ambos. 
De modo a atingir os objetivos citados, além desta introdução, no segundo capítulo expõem-se os modelos de crescimento de distribuição pós-keynesianos e kaleckianos. Mostrase que estes tinham como objetivo transpor a análise keynesiana do curto prazo para o longo prazo, analisando não apenas o nível do produto e emprego, mas também a taxa de crescimento do produto, a taxa de lucro e a taxa de utilização da capacidade. Como se trata de modelos que combinam os princípios clássicos de crescimento e distribuição com o princípio da demanda efetiva, demand led growth, inicialmente discute-se este princípio em Keynes e posteriormente apresentam-se os modelos pós-keynesianos de Harrod (1939), Domar (1946), Kaldor (1956), Pasinetti (1962), Robinson (1962) e o modelo kaleckiano.

No terceiro capítulo apresenta-se a escola neo-ricardiana, em particular o modelo de mudança estrutural de Pasinetti, autor expoente desta corrente de pensamento. Conforme mencionado nesta introdução pretende-se superar as divergências fundamentais entre os kaleckianos e os neo-ricardianos, de modo a expor os pontos de convergência e a possibilidade de síntese. Para isso, inicialmente apresenta-se o conceito de preço natural dos clássicos (Smith, Ricardo e Marx) e a forma como este é apropriado pelos neo-ricardianos permitindo a aproximação entre os modelos. Posteriormente, discutem-se as premissas, resultados e conclusões do modelo de Pasinetti, dentre as quais destaca-se o conceito de taxa de lucro natural, que é endogeneizada por Pasinetti. Ao final do capítulo verifica-se que interpretar a taxa de lucro kaleckiana como a taxa de lucro natural de Pasinetti não elimina a identificação dos dois regimes de crescimento.

No quarto capítulo realiza-se a síntese propriamente dita. Para tanto, inicialmente expõe-se a semelhança entre todas as equações do modelo kaleckiano de dois setores (PARK, 1995; DUTT, 1997) e o modelo de Pasinetti. Isto é, demonstra-se que é possível se deslocar de um modelo para o outro por meio de uma "ponte", que é o modelo de Feldman (1929). Em seguida, dado que Pasinetti havia endogeneizado a taxa de lucro natural e para que a transição entre o curto e longo prazo fosse completa, torna-se necessário endogeneizar a taxa natural de utilização da capacidade, o que é realizado para um modelo com um, dois e múltiplos setores. Nesta síntese apresentam-se as conclusões sobre os padrões de crescimento no longo prazo, assim como as condições para equalização da taxa de lucro intra e interssetores. Ao final discorre-se sobre as limitações do modelo apresentado.

Observa-se que, para eliminar as limitações do modelo, grande esforço analítico deveria ser realizado e isto envolveria características históricas e institucionais de cada país, o que foge ao escopo do presente trabalho. Sabe-se que esse esforço foi realizado ao longo do século XX pela escola estruturalista latino-americana. Deste modo, para mostrar a relevância 
e aplicabilidade do modelo síntese ora apresentado, no quinto capítulo mostra-se como a discussão historicamente datada sobre o estagnacionismo estruturalista é passível de ser representada no modelo. Assim, no início do capítulo apresentam-se algumas características gerais do pensamento estruturalista, seguidas da tese da tendência à estagnação e da crítica a esta tese. Posteriormente, mostra-se como o modelo síntese representa analiticamente o debate e os possíveis desdobramentos dessa análise, por exemplo, para a economia brasileira atual. Não se pretende neste capítulo esgotar o debate, assume-se apenas o caráter exemplificativo.

Ao final, no sexto capítulo apresentam-se as principais conclusões.

No que diz respeito à técnica de apresentação, busca-se formalizar os argumentos, não apenas por esta ser uma característica da discussão sobre crescimento e distribuição moderna, mas por se reconhecer que a utilização de modelos permite simplificar a realidade e restringir a discussão aos aspectos fundamentais. De modo a facilitar a compreensão, sempre que possível utiliza-se a estática comparativa e a representação gráfica. Além disso, como forma de exposição, ao início e final de cada capítulo faz-se uma breve introdução e conclusão dos argumentos apresentados.

É importante frisar que o modelo utilizado neste trabalho representa uma economia fechada sem governo e sem progresso tecnológico. O intuito destes pressupostos foi exatamente trabalhar no menor nível de complexidade para a realização da síntese proposta. 


\section{CAPÍTULO 2 - OS MODELOS DE CRESCIMENTO PÓS- KEYNESIANOS E KALECKIANOS}

\subsection{INTRODUÇÃO}

Dentre os objetivos da teoria pós-keynesiana destaca-se a combinação dos princípios clássicos de crescimento e distribuição com o princípio da demanda efetiva de Keynes e Kalecki. Esta combinação refere-se à extensão do modelo Keynesiano de curto-prazo para a análise do desenvolvimento de longo prazo; isto é, o foco passa do nível do produto e do emprego para a taxa de crescimento do produto, a taxa de lucro e a taxa de utilização da capacidade (HEIN, 2014). Busca-se assim estender a teoria pós-keynesiana às análises de acumulação de capital, progresso tecnológico, distribuição funcional da renda etc.

O objetivo deste capítulo é expor os modelos pós-keynesianos de Harrod (1939), Domar (1946), Kaldor (1956), Pasinetti (1962), Robinson (1962) e o modelo Kaleckiano de crescimento. Como todos esses modelos consideram a independência entre o investimento e a poupança, em particular a precedência do investimento frente a poupança, torna-se relevante expor o princípio da demanda efetiva de Keynes que é o ponto de partida dos modelos póskeynesianos. Isso é realizado na segunda subseção.

A terceira subseção adentra nas particularidades dos modelos pós-keynesianos, inicialmente discute-se o trabalho de Harrod no qual se destaca a sua concepção de crescimento em estado estacionário, e a instabilidade desta posição, em seguida aborda-se o modelo de Domar que apresenta as condições para que a economia esteja infinitamente em equilibrio. Posteriormente expõem-se os modelos de Kaldor e Pasinetti, relevantes por introduzirem a distribuição funcional da renda (classes sociais), mas frágeis por considerarem no longo prazo a plena utilização da capacidade produtiva. Nesta subseção o último modelo apresentado é o de Robinson, que explicita os determinantes do investimento e endogeniza a taxa de lucro.

Na quarta subseção apresenta-se o modelo de crescimento de Kalecki, o qual, assim como os keynesianos, tem por fundamento o princípio da demanda efetiva. Destaca-se que Kalecki abandona a hipótese de plena utilização da capacidade no longo prazo. No transcurso deste capítulo foca-se nos principais resultados de cada modelo, os quais são resumidos na quinta subseção. 


\subsection{O PRINCÍPIO DA DEMANDA EFETIVA DE KEYNES: CONTRAPOSIÇÃO À TEORIA NEOCLÁSSICA}

A teoria neoclássica baseia-se em uma economia de trocas em que toda a renda gerada no processo de produção retorna ao mercado como demanda por bens, sendo os excessos ou escassez destes determinados pelo sistema de preços. Tal concepção de economia foi denominada "paradigma da feira da aldeia" por Minsky (1975). Essa economia seria constituída por produtores e consumidores que trocariam os excedentes de sua produção pelos bens de sua necessidade; ou seja, os objetivos dos agentes econômicos se resumiriam ao consumo dos bens e serviços desejados: "as Ricardo wrote, productions are exchanged for productions, and productive effort is made only because agents need or want the additional product" (CARVALHO, 1992, p.39).

No paradigma da feira da aldeia, a moeda é apenas um meio utilizado pelos agentes para trocarem os produtos entre si, e não pode ser vista como um fim em si mesma. Tem-se, assim, a moeda neutra com possibilidade de ser não neutra apenas no curto-prazo, "when it is possible for agents to confuse it for real wealth" (CARVALHO, 1992, p.36).

O pressuposto da neutralidade da moeda resulta na aceitação da Lei de $\mathrm{Say}^{1}$, a qual foi resumida por James Mill por meio do seguinte ditado: a oferta cria sua própria demanda (DAVIDSON, 2002). Segundo a Lei de Say, todos os bens são trocados por outros bens, o que sob o sistema de mercado competitivo faz com que o produto e o emprego estejam sempre em seu nível máximo, pois toda a renda auferida pelas famílias é gasta na aquisição de bens.

Keynes $(2007$, 1936) por sua vez, afirma que a moeda não é apenas um meio de circulação, mas também uma forma de representação da riqueza. Em outras palavras, ela é um ativo que representa a forma pura de manutenção do poder de compra mantido durante vários períodos de tempo. E por ser ativo substituto aos demais, ela afeta o modo no qual os agentes decidem conservar a riqueza. Deste modo, a moeda não atua somente nas operações de curto prazo, mas também as trajetórias de longo prazo (FONSECA, P., 2010):

The theory which I desiderate would deal, in contradiction to this, is an economy in which money plays a part of its own and affects motives and decisions and is, in short, one of the operative factors in this situation, so that the course of events cannot be predicted, either in the long period or in the short, without a knowledge of the behavior of money between the first state and the last. And it is this which we ought to mean when we speak of

\footnotetext{
${ }^{1}$ Além da neutralidade da moeda, para que a Lei de Say seja válida é necessário que a se assuma constante a velocidade de circulação da moeda (FONSECA, P., 2010)
} 
monetary economy. (CWJMK ${ }^{2}$, XII, p. 408-409 apud CARVALHO, 1992, p. 37).

Na citação acima se percebe que Keynes ao adotar nova concepção para a moeda, abandona a teoria baseada na interação produtor-consumidor praticada no paradigma da feira da aldeia e introduz o conceito de economia monetária ou empresarial ou monetária de produção. Segundo Carvalho (1992), esta nova concepção de economia - na qual Keynes desenvolve uma teoria baseada na interação entre as firmas, as famílias e os bancos - pode ser resumida em seis princípios fundamentais:

1) Princípio da produção: a firma é reconhecida como um agente que tem como objetivo gerar lucro.

2) Princípio da estratégia dominante: na economia empresarial se reconhece a existência de diferentes graus de poderes entre os agentes da economia, ou seja, a distribuição dos recursos produtivos não é igual entre os agentes. Normalmente, as firmas possuem mais poder que os trabalhadores.

3) Princípio da temporalidade: a produção leva tempo, o que significa afirmar que ela é uma atividade especulativa, pois as firmas devem decidir as suas escalas de produção baseadas nas expectativas de demanda pelo bem a ser produzido.

4) Princípio da não-ergodicidade: o processo econômico não é estacionário, e, uma vez tomada a decisão, não há como voltar atrás (irreversibilidade do tempo).

5) Princípio da coordenação: a divisão do trabalho ocorre durante todo o processo produtivo, coordenando os planos de produção. No entanto, devido à possibilidade de falha de coordenação, os agentes desenvolvem instituições que socializam as perdas e reduzem os riscos de cada agente. Dentre essas instituições se destacam os contratos ${ }^{3}$.

6) Princípios das propriedades da moeda: para que o sistema de contratos seja aplicável é necessário que a moeda possua algumas características que a tornem líquida e que mantenham a sua capacidade de reter poder de compra e liquidar dívidas. Essas características são: elasticidade de produção e substituição nulas ${ }^{4}$.

O sexto princípio foi apresentado por Keynes no capítulo dezessete da Teoria Geral do

\footnotetext{
${ }^{2}$ Colleting Writtings of John Maynard Keynes.

${ }^{3}$ Paul Davidson $(1988,1994,2002)$ destaca-se entre os economistas que desenvolveram a teoria dos contratos, e o papel deste na solução das falhas de coordenação.

${ }^{4} \mathrm{~A}$ elasticidade de produção zero, indica que, se o preço da moeda em termos de unidade de salário subir, os empresários não podem aplicar, à vontade, trabalho para produzir dinheiro. A elasticidade de substituição zero indica que a elevação do valor de troca da moeda não significa a substituição da moeda por outro ativo. Isto é, quando o poder de compra da moeda sobe, os seus detentores são estimulados a guardá-la ainda mais, ao invés de gastá-la.
} 
Emprego, da Moeda e do Juro ${ }^{5}$. Por meio dessas características ele reconheceu que a moeda tinha "um rendimento nulo, um custo de manutenção insignificante, porém, um prêmio de liquidez substancial" (KEYNES, 2007, p.178). No mesmo capítulo, ele conclui que "a liquidez e os custos de manutenção são ambos questão de grau, e que é unicamente na importância da primeira em relação aos últimos que reside a peculiaridade da moeda”.

A peculiaridade da moeda para Keynes faz com que a Lei de Say não seja válida, pois como a moeda é um ativo como os demais, a renda obtida pelas famílias não necessariamente será totalmente alocada para o consumo. Em particular, Keynes identifica três motivos para a demanda por moeda:

- Motivo transação: necessidade de moeda para as trocas correntes, correspondendo à circulação industrial. Este motivo é subdividido por Keynes no motivo-renda e no motivo-negócio. Em relação ao primeiro, Keynes afirma que "uma das razões para conservar recursos líquidos é garantir a transição entre o recebimento e o desembolso da renda" (KEYNES, 2007, p. 157). Já em relação ao motivo-negócio, Keynes sustenta que “os recursos líquidos são conservados para assegurar o intervalo entre o momento em que começam as despesas e o recebimento do produto das vendas" (KEYNES, 2007, p.157).

- Motivo precaução: aqui a moeda seria demandada para "atender às contingências inesperadas e às oportunidades imprevistas de realizar compras vantajosas" e "conservar um ativo de valor fixo em termos monetários para honrar uma obrigação estipulada em dinheiro" (KEYNES, 2007, p. 157).

- Motivo especulação: aqui a moeda é demandada dada à possibilidade de obtenção de lucros por meio da expectativa de variação da taxa de juros. Para Keynes este motivo era o "menos compreendido" necessitando de um estudo detalhado dado a sua importância na transmissão dos efeitos de uma variação na quantidade de moeda. Segundo ele, não existe uma relação quantitativa definida entre a taxa de juros e a demanda especulativa por moeda, "o que importa não é o nível absoluto da taxa de juros, mas, sim, o seu grau de divergência quanto ao que se considera um nível razoavelmente seguro dessa taxa" (KEYNES, 2007, p. 161). Isto é, se para certo agente econômico o nível seguro da taxa de juros (ou taxa de juros normal) for superior à taxa de juros corrente, esse agente reterá

\footnotetext{
${ }^{5}$ Os demais princípios encontram-se não apenas na Teoria Geral, como também em outras obras como o Tratado sobre a Moeda (1930).
} 
moeda pelo motivo especulação. Para esse agente é melhor guardar moeda para, no futuro, adquirir outros ativos a um preço menos elevado, já que ele espera uma taxa de juros mais elevada que a atual. O contrário ocorreria se a taxa de juros natural do agente fosse menor que a taxa de juros corrente.

Em relação aos dois primeiros motivos acima, Keynes afirma serem "em circunstâncias normais (...) o resultado da atividade geral do sistema econômico e do nível de renda normal em termos monetários" (KEYNES, 2007, p. 157). Tratando-se do terceiro motivo, Keynes identifica dois tipos de agentes, uns seriam os ursos, isto é, aqueles que apostam na alta do juro, retendo moeda no presente (estes são aqueles que consideram a taxa de juros normal superior à taxa de juros corrente), os outros seriam os touros, os quais apostam na baixa do juro e, por isso, aplicariam os seus saldos monetários na aquisição de títulos etc. (estes são aqueles que consideram a taxa de juros normal inferior à taxa de juros corrente). A interação entre os dois agentes é responsável pela definição da taxa de juros corrente, e é por este motivo que Keynes considera "ser mais exato dizer que a taxa de juros seja um fenômeno altamente convencional do que basicamente psicológico, pois o seu valor observado depende sobremaneira do valor futuro que se lhe prevê" (KEYNES, 2007, p. 162)

Pelo exposto, observa-se que a teoria da preferência pela liquidez explica não só a demanda por moeda, mas também a taxa de juros, dando sustentação à tese da não neutralidade da moeda e, consequentemente, a rejeição da Lei de Say. Ao negá-la Keynes conclui que o nível do produto e emprego de longo prazo não é determinado pelos recursos disponíveis, mas sim pelo nível de demanda efetiva.

A demanda efetiva corresponde ao nível de renda (e correspondente nível de emprego) decorrente da interseção das funções de demanda agregada e de oferta agregada. Como Possas (1987) observa, esse nível é determinado no curto prazo, pois se assume como dados as expectativas de longo prazo, a técnica, os salários nominais e os custos unitários de produção. Em Keynes, o curto prazo envolve as decisões de produzir associadas ao "período de produção" e o longo prazo está associado às decisões de investir, "período de investimento".

O "prazo", como se sabe, diz respeito mais propriamente à natureza e ao horizonte do respectivo cálculo capitalista do que à duração do tempo cronológico, embora via de regra o "longo prazo" seja mais extenso que o "curto", pela própria durabilidade e iliquidez dos ativos fixos envolvidos no cálculo relativo ao investimento. (POSSAS, 1987, p.76).

Em Keynes, as funções de demanda e oferta são determinadas pela renda agregada esperada frente ao nível de emprego agregado. Esta renda corresponde ao preço do produto vezes a quantidade produzida menos o custo de produção (custo dos fatores). Asimakopulos 
(1991) destaca que é preferível lidar com as expectativas de renda ao invés dos preços, pois a renda pode ser agregada para todas as indústrias, enquanto o preço é específico para cada produto.

The advantage of dealing with expectation of proceeds rather than prices is that the former, being in identical money-value units, can be aggregated over all industries, while the latter are product-specific (ASIMAKOPULOS, 1991, p. 42).

Assim, a curva de oferta agregada de Keynes corresponde à renda agregada esperada pelos produtores que é suficiente para arcar com os custos de produção e permitir a manutenção de certo nível de emprego.

Keynes defines 'the aggregate supply price of the output of a given amount of employment [as] the expectation of proceeds which will just make it worth the while of the entrepreneurs to give that employment' (ASIMAKOPULOS, 1991, p. 42).

Utilizando a notação de Keynes (2007), sendo Z o preço de oferta agregada e N a quantidade de trabalhadores empregados, a função de oferta agregada é dada por $Z=\varphi(N)$. Mas, como Asimakopulos (1991) observa, é N a variável dependente e não Z, pois N depende das expectativas de renda dos produtores.

In spite of Keynes's unconventional notation, it is clear that it is the expectation of proceeds which is the independent variable, while the employment offered is the dependent variable (ASIMAKOPULOS, 1991, $\mathrm{p}$. 42).

A função de demanda agregada por sua vez corresponde à expectativa de receita proveniente da venda do consumo final, consumo e investimento, para dado nível de emprego. Seguindo a notação de Keynes, D representa o "produto que os empresários esperam receber do emprego de $\mathrm{N}$ homens" (KEYNES, 2007, p. 38), assim $\mathrm{D}=\mathrm{f}(\mathrm{N})$ representa a função de demanda agregada. A representação gráfica é: 
Gráfico 2.1 - Determinação do produto e emprego em Keynes

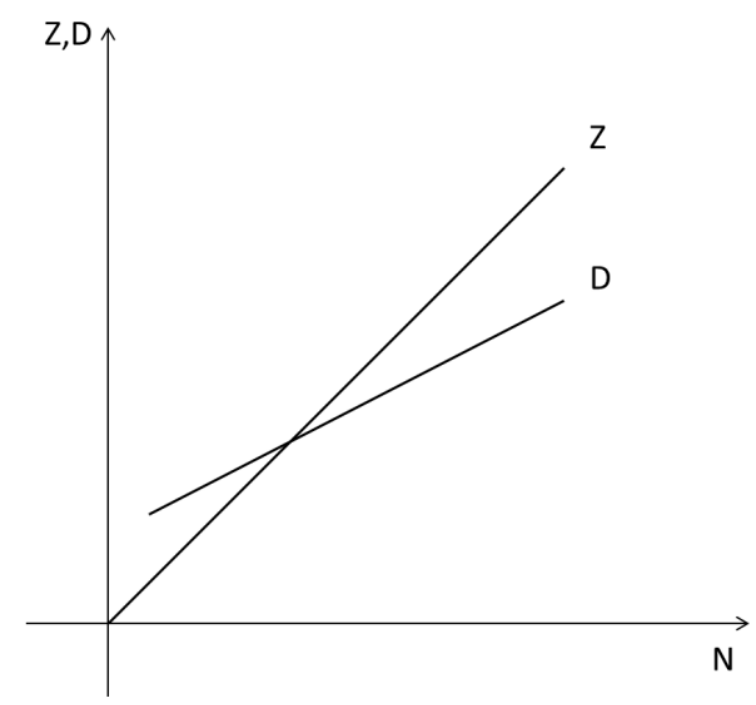

O ponto de intersecção entre as duas funções como afirmado é denominado por Keynes de demanda efetiva, o qual determina o volume de emprego frente à renda esperada.

(...) o volume de emprego é determinado pelo ponto de intersecção da função da demanda agregada e da função da oferta agregada, pois é nesse ponto que as expectativas de lucro dos empresários serão maximizadas. Chamaremos demanda efetiva o valor de $\mathrm{D}$ no ponto de interseção da função da demanda agregada com o da oferta agregada (KEYNES, 2007, p. 38).

Isto é, a demanda é efetiva não por pressupor a venda de tudo o que é produzido, mas sim por empregar os recursos na atividade produtiva à medida que a receita é antecipada. Disto percebe-se, que a renda realizada ex post não necessariamente é a prevista ex ante, a igualdade pode ocorrer por simples acaso, e se ocorrer significa que os produtores "anteciparam corretamente o montante e a composição da demanda final" (POSSAS, 1987, p. $80)$.

Keynes denominou o ponto de demanda efetiva de ponto de equilíbrio, que como visto trata-se de equilíbrio virtual, pois o sistema econômico não é atraído para este ponto. A cada decisão de produção no curto prazo, novo ponto de demanda efetiva é determinado, de tal forma que todos eles são pontos de equilíbrio e nenhum pressupõe a existência de pleno emprego na economia. O processo de decisão do produtor consiste em acertos e erros, os quais são percebidos ex post com a demanda final, variável esta que os produtores não têm controle.

In Keynes's theory of employment, there are many possible positions of short-period equilibrium, each corresponding to different values for the 
volume of investment and/or the economy's consumption function. (ASIMAKOPULOS, 1991, p. 46).

Entrepreneurs have to endeavor to forecast demand. They do not, as a rule, make wildly wrong forecasts of the equilibrium position. But, as the matter is very complex, they do not get it just right; and they endeavor to approximate to the true position by a method of trial and error. Contracting where they find that they are overshooting their market, expanding where the opposite occurs. It corresponds precisely to the haggling of the market by means of which buyers and sellers endeavour to discover the true equilibrium position of supply and demand (KEYNES, 1937, apud ASIMAKOPULOS, 1991, p. 48).

O princípio da demanda efetiva em Keynes mostra que ex post a determinação do produto e do nível de emprego é dado pelo consumo e o investimento ${ }^{6}$, que representam decisões de gasto dos trabalhadores e dos investidores e, portanto, estão diretamente relacionadas à preferência pela liquidez dos agentes econômicos.

Observa-se também que o princípio da demanda efetiva em Keynes foi desenvolvido para explicitar a determinação do produto e do emprego no curto prazo e não para expor o processo de acumulação de capital de certa economia. No entanto, para compreender este último, o princípio da demanda efetiva é fundamental e por isso foi utilizado por Harrod, Kaldor e Robinson, autores que discutimos nas próximas seções. Sabendo que o investimento depende da renda esperada e que a renda realizada afeta o investimento, estes autores buscaram integrar os princípios do acelerador e do multiplicador para explicar o processo de crescimento de longo prazo $^{7}$. Ou seja, eles partem do fato de que o investimento afeta o produto e este, posteriormente, induz a mudanças no investimento.

Robinson, no seu famoso Acumulação de Capital (1956), foi uma das primeiras póskeynesianas a realizar a formalização do curto para o longo prazo da Teoria Geral de Keynes, assim como Harrod, Kaldor e Pasinetti. No entanto, é interessante notar que os elementos monetários da teoria keynesiana não foram considerados por esses autores para explicar a acumulação de capital e o crescimento (HEIN, 2008). Lembra-se, conforme descrito, que a moeda é fundamental no programa de pesquisa de Keynes, e o seu papel na economia faz parte dos fundamentos para rejeição da Lei de Say.

Desconsiderar os elementos monetários na explicação do processo de crescimento torna os modelos dos primeiros pós-keynesianos suscetíveis a diversas críticas (LAVOIE,

\footnotetext{
${ }^{6} \mathrm{Na}$ quarta subseção mostra-se que Kalecki obteve resultado semelhante a partir de argumentos mais simples.

${ }^{7}$ Possas (1987) afirma ser um equivoco supor que a transposição para o longo prazo do multiplicador keynesiano e do principio da aceleração tenham inaugurado a área de investigação teórica do crescimento econômico. Neste trabalho não se adota essa afirmativa, mas se reconhece que os primeiros modelos de crescimento adotaram a interação dos dois princípios.
} 
2012) referentes à ausência do setor financeiro, especificamente a origem dos recursos que financiam o investimento. Autores como Hein (2008), Hein e Ochsen (2003) e Hein e van Treeck (2008) procuram remediar essa ausência. Entretanto, este não é o objetivo deste trabalho, e deste capítulo em particular ${ }^{8}$. Aqui iremos discutir os primeiros modelos que se baseiam na interação do efeito multiplicador e acelerador.

\subsection{OS MODELOS DE CRESCIMENTO E DISTRIBUIÇÃO PÓS-KEYNESIANOS}

O ponto de partida dos primeiros modelos pós-keynesianos (ou neo-keynesianos) é a independência entre as decisões de investimento e poupança, de tal forma que o investimento precede logicamente a poupança. A poupança se ajusta ao investimento devido à relação bilateral entre o último e o produto (renda) (ARAÚJO, J.T., 1998):

\section{$\mathrm{I} \rightarrow \mathrm{R} \rightarrow \mathrm{S}$}

Isto é, seguindo a teoria de Keynes, o investimento ex-ante determina o nível de renda (R) e este ex-post determina a poupança (S).

This Independence was considered by Robinson to be the hallmark of keynesian models, because they 'project into the long period the central thesis of the General Theory, that firms are free, within wide limits, to accumulate as they please, and that the rate of saving of the economy as a whole accommodates itself to the rate of investment that they decree' (ASIMAKOPULOS, 1991, p. 139).

Outras duas características fundamentais destes modelos de primeira geração são: a) assumir as empresas em ambiente de concorrência imperfeita (oligopolista) ${ }^{9}$; b) adotar no longo prazo a taxa plena de utilização da capacidade, isto é, igual a 1. Como veremos esta última hipótese é fundamental para diferenciar os primeiros modelos pós-keynesianos e os modelos kaleckianos.

\footnotetext{
${ }^{8}$ No seção 2.4 discute-se o modelo de crescimento e distribuição kaleckiano e mostra-se que neste o papel do financiamento está subtendido, sendo a moeda endógena.

${ }^{9}$ No modelo de Kalecki a ser discutido adiante, a estrutura de mercado oligopolizada é melhor explicitada.
} 


\subsubsection{O modelo de Harrod (1939) e Domar (1946)}

O modelo seminal pós-keynesiano foi o de Harrod (1939), que explicitamente buscou direcionar para o longo prazo a teoria keynesiana por meio de uma teoria dinâmica, isto é, um instrumento no qual ciclo e tendência fazem parte do mesmo processo.

Como característica fundamental do trabalho de Harrod, verifica-se a determinação das condições necessárias para o equilíbrio entre poupança e investimento ao longo de vários períodos. Esse equilíbrio proporcionaria o crescimento estacionário, este é aquele em que o produto cresce de forma constante e a variação do investimento é proporcional à variação do estoque de capital.

A steady advance is defined as one in which the ratio of the increment of output to the previous level is constant (...) the proportionate increase of net investment on the given day over net investment on the day preceding is equal to the proportionate addition to the stock of capital goods available for use on the given day. The experience of the given day will be the primary test as to whether the advance is likely to remain. (HARROD, 1936, p. 88).

As principais hipóteses de Harrod são (JONES, 1975):

i) economia produz um único bem ou vários bens cujo preço relativo é mantido constante;

ii) a poupança (S) é função simples e proporcional da renda agregada (Y), S = sY, 0 $<\mathrm{s}<1$, onde s é a propensão média e marginal agregada a poupar;

iii) a força de trabalho (L) cresce a taxa constante e exógena $\eta, \frac{\dot{L}}{L}=\eta$;

iv) não há progresso tecnológico e o estoque de capital não se deprecia;

v) a tecnologia é descrita por uma função de produção de Leontieff, $\mathrm{Y}=\min \left\{\frac{K}{v}, \frac{L}{\mu}\right\}$, onde $v$ é a relação capital-produto e $\mu$ o requisito de mão-de-obra por unidade de produção.

Observa-se a partir da hipótese v que $\mu$ representa a razão constante do trabalho pelo produto total $(\mathrm{L} / \mathrm{Y})$, isso significa que a produção de qualquer nível de produto requer $\frac{L}{\mu}$ unidades de trabalho. Deste modo, dada a hipótese iii, deduz-se que a taxa de crescimento do produto, $\frac{\Delta Y}{Y}$, não poderá exceder a taxa de crescimento da força de trabalho. Harrod, no entanto, assumiu que o produto não é limitado pelo trabalho, mas sim pelo capital. Isto é:

$$
\mathrm{Y}=\frac{K}{v} \text {, isto é, } \mathrm{K}=v \mathrm{Y}
$$


Consequentemente tem-se,

$$
\Delta K=v \Delta Y
$$

A respeito da razão capital-produto, v, Harrod adota dois conceitos: a) v efetiva, que representa o montante dos bens de capital, K, necessários para o aumento unitário do produto; b) $v_{R}$, que representa o montante de capital esperado pelos empresários para o futuro nível de produto, o que equivale a taxa da relação capital-produto esperada.

Dado que o estoque de capital não se deprecia devido à hipótese iv, pode-se afirmar que a taxa de mudança no estoque de capital, $\Delta K$, é igual ao investimento agregado na economia $^{10}$, I. Assim, (2.2) pode ser reescrita por:

$$
I=v \Delta Y
$$

A equação (2.3) representa o princípio do acelerador.

The acceleration principle is reflected in his theory by the assumption that investment in a subsequent time period is affected by the relation between the change in output over the present and the concurrent change in productive capacity (ASIMAKOPULOS, 1991, p. 146).

O objetivo de Harrod era verificar as condições necessárias para a manutenção do equilíbrio a cada período, e, em particular o que ocorre caso haja desequilíbrio. Sabendo que o equilíbrio é dado por $\mathrm{S}=\mathrm{I}$, tem-se que:

$$
s Y=v \Delta Y
$$

Isto é,

$$
\frac{\Delta Y}{Y}=\frac{s}{v}
$$

A equação (2.5) foi definida por Harrod como equação fundamental, pois ela mostra o que é necessário para que o produto cresça a taxa efetiva constante $G_{a}=\frac{\Delta Y}{Y}$. No entanto,

\footnotetext{
${ }^{10}$ Em tese a taxa de mudança do estoque de capital deveria se igualar a taxa de mudança do investimento na economia. No entanto, como não há depreciação do capital, a taxa de variação do capital é acumulada ao longo do tempo de tal forma que representa o investimento agregado.
} 
Harrod observa que a relação capital-produto esperada $\left(v_{R}\right)$ pelos empresários pode ser diferente da efetiva, assim, tem-se que:

$$
G_{w}=\frac{\Delta Y}{Y}=\frac{s}{v_{R}}
$$

$G_{w}$ foi denominada de taxa de crescimento garantida. Esta é a taxa que torna os empresários satisfeitos por terem produzido exatamente a quantidade correta ${ }^{11}$. Nesse sentido, a taxa garantida representa o equilíbrio em crescimento estacionário, de tal forma que satisfaz as decisões de produção e investimento dos empresários, o que mantém o equilíbrio no mercado de bens, mas não necessariamente no mercado de produto ${ }^{12}$.

The warranted rate, on the other hand, expresses the equilibrium of steady growth, in the sense that entrepreneurs are satisfied with their production and investment decisions, so that the market for goods (but not necessarily the labor market) is in equilibrium (BOIANOVSKY, p. 6, 2015).

Importante observar que nada garante a igualdade entre $G_{w}$ e $G_{a}$, pois não é possível assumir que $v_{R}=v$.

Não há, claramente, nenhuma razão particular pela qual devamos esperar que a economia cresça na verdade à taxa garantida, uma vez que a taxa verdadeira de crescimento é o resultado de expectativas, decisões e erros de um número grande de tomadores de decisão. (JONES, 1975, p. 63).

Além disso, é importante destacar que o produto não pode crescer mais do que a oferta de trabalho, isto é, a taxa efetiva de crescimento da economia não poderá exceder a taxa de crescimento da força de trabalho, $G_{a} \leq \eta$. Neste caso, a manutenção do pleno emprego na economia exigiria que:

$$
\frac{s}{v}=G_{a}=G_{w}=\frac{s}{v_{R}}=\eta
$$

A taxa de crescimento da economia a pleno emprego foi denominada por Harrod (1939) de taxa de crescimento natural, e por Robinson (1962) de idade de ouro. Dado que é improvável a ocorrência de $G_{a}=G_{w}$, o mesmo vale para $G_{a}=G_{w}=\eta$. Isso ocorre, pois $\frac{s}{v} \mathrm{e}$

\footnotetext{
11 “(...) the warranted rates of growth, (...), refers to entrepreneurial equilibrium in the sense that it is the entrepreneurs (or producers) who, on balance, consider that the increase in output in the period justified the investment they made in that period" (ASIMAKOPULOS, 1991, p. 151).

${ }^{12}$ Percebe-se claramente o papel do princípio da demanda efetiva no modelo de Harrod. Ver seção anterior.
} 
$\frac{s}{v_{R}}$ são determinados independentemente ${ }^{13}$. Esta ausência de mecanismo no modelo que assegure o pleno emprego ficou conhecido na literatura como primeiro problema de Harrod.

Ainda que o crescimento em estado estável a pleno emprego seja possível no modelo do tipo Harrod de crescimento econômico, tal "idade dourada" é altamente improvável dadas as variáveis constitutivas independentes na igualdade necessária da taxa garantida de crescimento $\frac{s}{v_{R}}$, à taxa natural de crescimento $\eta$. (JONES, 1975, p. 64).

Segundo Harrod (1939), a taxa de crescimento garantida representaria o estado estacionário da economia, o "steady advance" mencionado anteriormente ${ }^{14}$. A manutenção deste crescimento estaria relacionada a três postulados (ASIMAKOPOLOS, 1991): a) a existência de um único valor para a taxa de crescimento garantida; b) os fatores que geram nos empresários o sentimento de terem tomado a decisão correta; c) a hipótese de que o alcance da taxa garantida irá induzir os empresários a continuarem nela. A partir destes postulados, percebe-se que implicitamente Harrod assume a existência um único valor de equilíbrio para a taxa de lucro na economia. Mas este valor varia a cada momento em que se modificam as expectativas dos empresários.

Apesar de reconhecer a existência do estado estacionário, Harrod mostra que a manutenção deste é altamente instável, pois depende do modo como os empresários irão reagir frente às diferenças entre $v_{R}$ e $v$. De (2.7) obtém-se que:

$$
\frac{G_{a}}{G_{w}}=\frac{v_{R}}{v}
$$

Logo, se $G_{a}>G_{w}$ então $v_{R}>v$, ou seja, a taxa de capital requerida pelos empresários será maior do que a efetiva, isto é, os empresários acharão que o crescimento do estoque de capital foi inferior ao que eles esperavam frente ao crescimento do produto e da renda. Deste modo, no próximo período o investimento irá se elevar o que consequentemente aumentará a taxa de crescimento efetiva, assim a economia se distancia mais da condição de

\footnotetext{
13 "There is no tendency in Harrod's model for the warrant and natural rates to coincide, since their determinants differ”. (ASIMAKOPULOS, 1991, p. 151).

14 "[A] unique warranted line of growth [that] is determined jointly by the propensity to save and the quantity of capital required by technological and other considerations per unit increment of total output. Only if producers keep to this line will they find that on balance their production in each period has been neither excessive nor deficient" (ASIMAKOPULOS, 1991, p. 151).
} 
equilíbrio dada por $G_{a}=G_{w}$. O efeito oposto ocorre se $G_{a}<G_{w}$. Este argumento demonstra o quanto fundamentalmente instável é a taxa garantida de crescimento ${ }^{15}$.

If the aggregated result of trial and error by numerous producers gives a value for $\left[G_{a}\right]$ which is different from $G_{w}$, there will not be any tendency to adapt production towards $G_{w}$, but, on the contrary, a tendency to adapt production still farther away from it, whether on the higher or lower side. (HARROD, 1948, p. 87).

A instabilidade do crescimento balanceado de Harrod fez com que Solow (1956) cunhasse o termo "equilíbrio sob o fio da navalha". Essa instabilidade ficou conhecida na literatura como segundo problema de Harrod e pode ser verificada no Gráfico 1.2. Neste representa-se a linha de steady advance e as trajetórias assumidas pela economia caso $G_{a}>G_{w}$ e $G_{a}<G_{w}$.

Desvios da taxa verdadeira de crescimento numa economia do tipo Harrod da taxa garantida, $\frac{\mathrm{s}}{v_{\mathrm{R}}}$, longe de serem autocorretivos, são cumulativos de fato. (JONES, 1975, p. 69).

Gráfico 2.2 - Instabilidade do modelo de Harrod

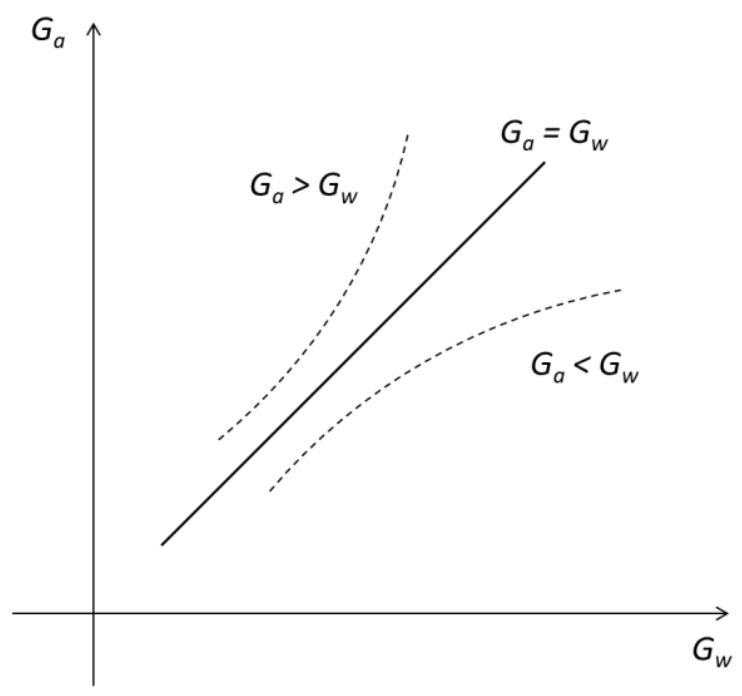

Harrod reconheceu as críticas de Solow, mas afirmou que apesar da improbabilidade de $G_{a}=G_{w}$, apenas desvios elevados levariam a economia para uma trajetória instável. Em geral, por meio do processo de tentativa e erro, a economia cresceria ao longo do estado estacionário.

\footnotetext{
15 "Harrod argued, however, that is not the value of $G_{w}$ that matters, but disequilibrium departures of $G_{a}$ from $G_{w}$ and their influence on production decisions" (BOIANOVSKY, 2015, p. 8)
} 
It would be almost a miracle if the aggregate of decisions resulted in an actual growth rate equal to the warranted growth rate. There are likely to be some deviations all the time. But if they are of moderate dimensions, I would not suppose that they would bring the instability principle into operation. That is why I so much object to the knife-edge idea. It requires a fairly large deviation, such as might be caused by a revision of assessments across the board in some important industry, like the motor car industry, to produce a deviation sufficient to bring instability into play. (HARROD, 1973, p. 33).

Solow não foi o único a identificar problemas no modelo de Harrod (1939). Possas (1987) afirma que este modelo é logicamente inconsistente, pois todas as variáveis encontram-se no mesmo período de tempo, ou seja, trata-se de modelo dinâmico sem tempo. Em resumo, o problema, estaria na ausência de defasagens, em particular na determinação do investimento.

Outra crítica ao modelo de Harrod diz respeito à função do acelerador utilizada, (2.3), esta projeta sobre o investimento o efeito do crescimento da renda, mas não considera os efeitos da taxa de utilização da capacidade produtiva sobre as decisões de investimento ${ }^{16}$.

Sen (1970) também identificou o problema das defasagens no modelo de Harrod e propôs a reinterpretação deste com o objetivo de torná-lo dinâmico, além de reproduzir as trajetórias de instabilidade apresentadas no modelo original. As variáveis utilizadas por Sen são (Jones, 1975):

- $\quad Y_{t}^{E}$ : fluxo de renda e produto esperado pelos empresários no período t;

- $Y_{t}$ : fluxo efetivo do produto e da renda no período t;

- $G_{t}^{E}=\frac{Y_{t}^{E}-Y_{t-1}}{Y_{t}^{E}}$ : taxa esperada de crescimento do produto e da renda entre os períodos t-1 e t;

- $G_{t}=\frac{Y_{t}-Y_{t-1}}{Y_{t}}$ : taxa efetiva de crescimento do produto e da renda entre os períodos t-1 e t;

- $\quad$ s: propensão marginal e média a poupar;

- $\quad$ : razão capital-produto.

A partir do princípio do multiplicador e do acelerador tem-se que:

$$
\begin{gathered}
Y_{t}=\frac{I_{t}}{s} \\
I_{t}=v\left(Y_{t}^{E}-Y_{t-1}\right)
\end{gathered}
$$

\footnotetext{
${ }^{16}$ Os efeitos da capacidade produtiva sobre o investimento serão discutidos no modelo kaleckiano.
} 
Substituindo (1.10) em (1.9) e dividindo por $Y_{t}^{E}$, obtém-se:

$$
\frac{Y_{t}}{Y_{t}^{E}}=\frac{v}{s}\left[\frac{Y_{t}^{E}-Y_{t-1}}{Y_{t}^{E}}\right]
$$

Ou seja,

$$
\frac{Y_{t}}{Y_{t}^{E}}=\frac{v}{s} G_{t}^{E}
$$

A equação (2.12) representa a taxa de crescimento garantida de Harrod, pois se o produto esperado é igual ao produto efetivo, então $\frac{Y_{t}}{Y_{t}^{E}}=1, \operatorname{logo} G_{t}^{E}=\frac{s}{v}$. Este resultado é similar à equação fundamental de Harrod, (2.5).

Dos conceitos adotados por Sen (1970) para $G_{t}^{E}$ e $G_{t}{ }^{17}$ é possível isolar $Y_{t}^{E}=\frac{Y_{t-1}}{\left(1-G_{t}^{E}\right)}$ e $Y_{t}=\frac{Y_{t-1}}{\left(1-G_{t}\right)}$, substituindo estes valores em (2.12) obtém-se:

$$
G_{t}=1-\frac{s}{v} \frac{\left(1-G_{t}^{E}\right)}{G_{t}^{E}}
$$

A partir da equação (2.13) percebe-se que a taxa de crescimento efetiva somente será igual à taxa de crescimento esperada, $G_{t}=G_{t}^{E}$, se e somente se, a taxa de crescimento esperada for igual à taxa de crescimento garantida, $G_{t}^{E}=\frac{s}{v}$.

Neste modelo de Sen (1970) também é possível identificar a instabilidade presente na análise de Harrod, pois se $G_{t}^{E}>\frac{s}{v}$ então $G_{t}$ será maior do que $G_{t}^{E}$. Ou seja, a taxa de crescimento efetiva será superior à esperada pelos empresários, portanto, pressupõe-se que para o próximo período eles ampliarão o investimento, o que reforça a trajetória de divergência da taxa de crescimento efetiva em relação à taxa de crescimento garantida. Resultado semelhante é obtido na direção contrária quando $G_{t}^{E}<\frac{s}{v}$.

\footnotetext{
${ }^{17}$ Possas (1987) e Jones (1975) observam que a definição adota por Sen (1970) é não convencional, pois o correto seria $G_{t}^{E}=\frac{Y_{t}^{E}-Y_{t-1}}{Y_{t-1}}$ e $G_{t}=\frac{Y_{t}-Y_{t-1}}{Y_{t-1}}$. No entanto, adotando-se a definição correta obtém-se que $G_{t}^{E}=\frac{\frac{s}{v}}{1-\frac{s}{v}}$ e não $G_{t}^{E}=\frac{s}{v}$, ou seja, a taxa de crescimento garantida é diferente da proposta por Harrod.
} 
O modelo de interação do efeito multiplicador e acelerador proposto por Harrod foi de extrema importância para o desenvolvimento da teoria do crescimento que segue a tradição keynesiana. O próprio Keynes se manifestou sobre este modelo criticando a proposta de existência de uma taxa de crescimento garantida. Esta crítica foi acatada por Kaldor e Robinson, os quais rejeitam a hipótese implícita de existência de um único valor de equilíbrio para a taxa de lucro na economia. Apesar disso, Keynes escreveu em 1939 em carta a Pigou que:

In the final result, I do not find myself in agreement [with the Harrod's model], but I do think that he has got hold of a very interesting point which, subject to the necessary qualifications, is of real importance (KEYNES, 1939, apud ASIMAKOPULOS, 1991, p. 165).

Domar (1956) assim como Harrod definiu a dinâmica econômica em termos de taxa de crescimento, no entanto, o seu objetivo não era expor a instabilidade do equilíbrio dinâmico, mas sim analisar os fatores que mantêm infinitamente a economia em equilíbrio. Esta posição foi denominada por Domar de equilíbrio móvel.

For Domar, modeling economic growth involved a new concepto for equilibrium in time (...). Domar called it "moving equilibrium" in the notes he made for his second Oxford lecture (...): 'The essence of our approach [is] a moving equilibrium, not a return to a previous position. Emphasize this' (BOIANOVSKY, 2015, p. 2).

O objetivo de Domar não era apresentar uma teoria do crescimento econômico, mas um modelo que expusesse as condições para o crescimento balanceado entre a oferta e demanda ${ }^{18}$. Os pressupostos do modelo de Domar são:

i) o nível geral de preços é constante;

ii) a poupança e o investimento se referem ao produto do mesmo período;

iii) o investimento é líquido de depreciação;

iv) a depreciação não se refere aos custos históricos, mas sim ao custo de reposição do bem de capital por outro de mesma capacidade produtiva;

v) são dadas a distribuição do produto, as preferências dos consumidores, as taxas de salários, os preços relativos, a estrutura da indústria etc;

vi) a capacidade produtiva da economia é aquela que corresponde ao nível de pleno emprego.

A partir do segundo pressupostos, percebe-se que Domar (1956) incorre na mesma crítica apresentada à Harrod, isto é, todas as variáveis encontram-se no mesmo tempo, em

\footnotetext{
18 "Domar problem, according to Svennilson, 'is not why and how growth takes place', as he 'investigates only the balance of growth' between capacity and demand over time" (BOIANOVSKY, 2015, p. 14).
} 
particular o investimento. Além disso, no último pressuposto observa-se que Domar assume no longo prazo a plena utilização da capacidade produtiva.

O lado da oferta corresponde à capacidade produtiva, U, que como destacado se refere ao nível do produto de pleno emprego. Domar assume que U é função linear do estoque de capital, K, e da produtividade média, s. Logo, $\mathrm{U}=\mathrm{Ks}$. Definindo $\sigma$ como a produtividade potencial média do investimento, Domar diferencia $\sigma$ de s, pois: a) $\sigma$ é a elevação da capacidade produtiva que acompanha o investimento; b) $\sigma$ se refere à ampliação da capacidade potencial; c) $\sigma$ é a ampliação da capacidade produtiva da sociedade em conjunto, e não da taxa esperada de investimento; d) s é o maior nível ao qual $\sigma$ pode alcançar.

Assumindo que s e $\sigma$ são constantes, a oferta é dada por:

$$
\dot{U}=I \sigma
$$

A demanda, por sua vez, nada mais é do que o multiplicador keynesiano no modelo de Domar. Sendo $\alpha$ a propensão média a poupar e I variável independente. Desta forma têm-se:

$$
\dot{Y}=\frac{\dot{I}}{\alpha}
$$

Interessante observar que Domar, diferentemente de Harrod, trabalha com o tempo contínuo, mas assim como este assume o investimento dado, ou seja, não discute os determinantes do investimento. Isto é intrigante, dado que Domar reconhece o papel do investimento na ampliação da capacidade produtiva e que nem sempre a ampliação do investimento resulta na ampliação do produto.

Puesto que el sistema keynesiano considera a la inversion unicamente como um instrumento de geracion de ingresso, no toma en cuenta el hecho sumamente essencial, elemental y bien conocido de que la inversion incrementa también la capacidade productiva (DOMAR, 1956, apud SEN, 1970, p. 65).

A manutenção do pleno emprego em equilíbrio móvel é dada pela igualdade entre a oferta e a demanda, (2.14) e (2.15):

$$
I \sigma=\frac{\dot{I}}{\alpha}
$$

Cuja solução é: 


$$
\mathrm{I}=I_{0} e^{\alpha \sigma t}
$$

Assim, para que a economia cresça a pleno emprego é necessário que o investimento cresça à taxa $r=\alpha \sigma$. Como Boianovsky (2015) observa o destaque deste modelo dá-se nas diferentes formas de fechá-lo, pois não há relação pré-definida entre as variáveis citadas. Desta forma se $r$ e $\sigma$ forem dados, a propensão média a poupar será $\alpha=\frac{r}{\sigma}$. Por outro lado, se $\alpha$ e r forem dados, a relação capital produto média da sociedade será dada por $\sigma=\frac{r}{\alpha}$.

O modelo de Domar é interessante, mas não constitui nas suas próprias palavras uma teoria, de toda forma contribuiu metodologicamente para o estudo do crescimento econômico ao desenvolver um sistema lógico solucionável, o que foi apropriado pelos demais modelos de crescimento e distribuição keynesianos.

\subsubsection{Os modelos de Kaldor (1956) e Pasinetti (1962)}

Os modelos de Kaldor (1956) e Pasinetti (1962) são importantes no desenvolvimento da teoria do crescimento econômico pós-keynesiana, pois introduziram explicitamente a distribuição funcional da renda. Certamente, grande parte da controvérsia moderna sobre acumulação, ciclo e crise gira em torno do papel da distribuição funcional da renda.

Kaldor (1956) observa que Keynes nunca se interessou pelo problema da distribuição de renda, apesar do princípio do multiplicador permitir tais implicações. Segundo Kaldor, isso se deve à preocupação de Keynes com a teoria do emprego, em particular, a possibilidade de equilíbrio no longo prazo com subemprego.

El análisis del multiplicador no se desarrolló como una teoría de la distribución porque fue concebido para los fines de una teoría del empleo, para explicar por qué puede permanecer en equilibrio un sistema económico con estado de subempleo (o de subutilización general de los recursos) (KALDOR, 1956, apud OCAMPO, 1988, p. 78).

No intuito de inserir a distribuição do produto na teoria keynesiana, Kaldor afirma que o princípio do multiplicador pode ser aplicado de duas formas: a) na determinação dos preços e salários, caso o nível do produto seja dado; b) na determinação do nível do produto, caso a distribuição (preços e salários) seja dada. Para Kaldor, isso significa que o item b representa o modelo estático de curto prazo, no qual se determina o produto e o emprego, e o item a representa o modelo dinâmico de longo prazo, no qual se determina a distribuição de renda. 
Por tratar-se de um modelo de longo prazo, Kaldor considera dado o nível de produto. Percebe-se, assim, que no modelo está assumida a plena utilização da capacidade produtiva, que por sua vez corresponde à posição de pleno emprego. A partir desta análise as hipóteses do modelo são:

i) estado de pleno emprego com produto total dado;

ii) o produto é divido entre salários $(\mathrm{W})$ e lucros $(\mathrm{P})$;

iii) há diferença entre a propensão marginal ao consumo entre os assalariados $\left(s_{W}\right) \mathrm{e}$ capitalistas $\left(s_{P}\right)$.

Destas hipóteses obtêm-se as seguintes identidades fundamentais:

$$
\begin{gathered}
\mathrm{Y}=\mathrm{W}+\mathrm{P} \\
\mathrm{I}=\mathrm{S} \\
\mathrm{S}=S_{W}+S_{P}
\end{gathered}
$$

A equação (2.18) representa a divisão do produto entre salários e lucros e a (2.20) representa a divisão da poupança entre a poupança dos trabalhadores $\left(S_{W}\right)$ e capitalistas $\left(S_{P}\right)$. Como o produto (renda) está dado, o objetivo do modelo é verificar as condições necessárias para manter o pleno emprego, isso é representado pela equação (2.19). Importante observar que a análise de Kaldor foca no equilíbrio do mercado de bens, pois assim como Harrod, neste modelo não há restrições no mercado de trabalho.

Since Harrod and Domar, following Keynes, believe that the market mechanism is not able to attain the full employment of labour, they [post Keynesian] focus their attention only on the equilibrium on the goods market - which holds when the savings are equal to the desired investment - rather than the general equilibrium on the goods and labour markets (D'AGATA, A.; FRENI, G., 2003, p. 15).

Assumindo que $S_{W}=s_{W} \mathrm{~W}$ e $S_{P}=s_{P} P$, onde $s_{W}$ é a propensão a poupar dos assalariados e $s_{P}$ a propensão a poupar dos capitalistas, por hipótese $s_{P}>s_{W}$. Substituindo em equilíbrio tem-se:

$$
\mathrm{I}=s_{W} \mathrm{~W}+s_{P} P=s_{W}(Y-P)+s_{P} P=\left(s_{P}-s_{W}\right) \mathrm{P}+s_{W} \mathrm{Y}
$$

Então, 


$$
\frac{P}{Y}=\frac{\frac{I}{Y}-s_{W}}{s_{P}-s_{W}}
$$

De modo semelhante à Harrod, no modelo de Kaldor (1956) o investimento independe da poupança. Esta dedução é importante para se interpretar a equação (2.22), pois significa que $\frac{I}{Y}$ é independente de variações em $s_{W}$ e $s_{P}$. Verifica-se, assim, que neste modelo a participação dos lucros na renda, $\frac{P}{Y}$, independe de parâmetros microeconômicos, mas somente de variáveis macroeconômicas.

The most famous feature of the neo-Keynesian model of growth and distribution is that the rate of profit does not depend on microeconomic technical conditions or on relative physical endowments, but solely on macroeconomic variables, namely the rate of growth of the economy and some variable related to the propensity to save out of profits (LAVOIE, 2014, p. 348).

Diante do produto dado e do investimento independente, a equação (2.22) pode ser interpretada da seguinte forma: suponha a elevação do investimento, o nível de preços irá elevar-se, o que reduz o salário real e consequentemente reduz a participação dos salários na renda, por outro lado eleva-se a participação dos lucros na renda, a qual posteriormente eleva a poupança. Ou seja, a poupança ajusta-se à variação do investimento e, assumindo a flexibilidade dos preços, tem-se que a economia sempre estará em pleno emprego ${ }^{19}$. Isto é, o crescimento com pleno emprego na economia é mantido por meio de ajustes na taxa de poupança decorrentes da variação na distribuição da renda.

Nas palavras de Possas (1987, p. 105):

(...) aumentando-se o investimento, os preços deverão aumentar mais rapidamente que os salários, de tal forma que redistribuam a renda em favor dos lucros no montante necessário para que a consequente redução no consumo (já que os capitalistas têm por hipótese maior propensão a poupar) compense exatamente o acréscimo no investimento, mantendo finalmente a renda no nível de pleno emprego.

A hipótese de que $s_{P} \neq s_{W}$ e $s_{P}>s_{W}$ é fundamental para a estabilidade do modelo de Kaldor. Se $s_{P}<s_{W}$ e houvesse queda nos investimentos, isso resultaria em queda nos preços e diminuição geral da demanda agregada, incentivando nova queda nos preços em processo cumulativo. Não haveria, assim, o ajuste entre a poupança e o investimento. Processo cumulativo semelhante ocorreria diante da elevação do investimento.

\footnotetext{
${ }^{19}$ Este argumento presente no modelo de Kaldor é semelhante à barreira inflacionária de Robinson, a ser discutida na próxima subseção.
} 
O caso particular do modelo de Kaldor é dado por $s_{W}=0$, assim:

$$
P=\frac{I}{s_{P}}
$$

Dividindo (2.23) pelo estoque de capital (K) obtêm-se a renomada equação de Cambridge, $\frac{P}{K}=\frac{\frac{I}{K}}{s_{P}}$, a qual demonstra que a taxa de investimento determina a taxa de lucro ${ }^{20}$. Em resumo, verifica-se que no modelo de Kaldor o investimento determina a taxa de lucro, a participação dos lucros na renda e consequentemente a participação dos salários na renda. Isto é, participação dos salários na renda é variável residual da distribuição ${ }^{21}$.

A principal fragilidade do modelo de Kaldor, que permeia todos os primeiros modelos pós-keynesianos $^{22}$, é a adoção da hipótese de pleno emprego no longo prazo. Esta hipótese está relacionada ao reconhecimento de plena utilização da capacidade produtiva. Interpreta-se a partir desta hipótese que o princípio da demanda efetiva é válido somente no curto prazo, no qual o investimento e o consumo (decisões de gasto) determinam o produto, sob preços e salários fixos. No longo prazo retornaria à validade a Lei de Say, "não deixa de ser irônico invocar o multiplicador de Keynes, a pretexto de que fora formulado num marco 'estático', para 'dinamizar' a lei de Say” (POSSAS, 1987, p. 104) 2324.

Pasinetti (1962) propõe uma reconsideração lógica do modelo de Kaldor, pois considera errôneo supor que a poupança dos trabalhadores decorre apenas dos salários. Segundo Pasinetti, o investimento determina a poupança dos capitalistas e dos trabalhadores, ou seja, Pasinetti assume que os trabalhadores também são proprietários de capital e por isso poupam, $s_{W}>0$. Desta forma, os lucros devem ser divididos entre capitalistas $\left(P_{P}\right)$ e trabalhadores $\left(P_{W}\right)$.

De forma semelhante à Kaldor, Pasinetti adota as hipóteses i, ii e iii. Assim, as equações fundamentais de seu modelo são (2.18), (2.19), (2.20) e:

\footnotetext{
${ }^{20}$ De forma semelhante à Kalecki (a ser discutido na próxima seção), Kaldor obtém que os capitalistas ganham o que gastam.

${ }^{21}$ Esta característica diferencia os modelos pós-keynesianos dos modelos clássicos de Smith, Ricardo e Marx. Nestes a taxa de lucro é a variável residual uma vez que os salários são dados pelo nível de subsistência.

${ }^{22}$ A mesma fragilidade será identificada nos modelos de Pasinetti (1962) e Robinson (1956).

23 “(...) o modelo de Kaldor é inteiramente análogo ao de Pigou: ambos supõem flexibilidade de salários e preços e o ajuste da renda ao pleno emprego através da propensão a poupar - só que um utiliza a distribuição, e o outro os saldos ou encaixes reais" (POSSAS, 1987, p. 107).

${ }^{24}$ Veremos nas próximas seções que essa fragilidade aqui apresentada é superada no modelo kaleckiano, o qual endogeniza a taxa de utilização da capacidade no longo prazo.
} 


$$
\mathrm{P}=P_{P}+P_{W}
$$

O pressuposto de que trabalhadores poupam transforma a função de poupança destes para $S_{W}=s_{W}\left(W+P_{W}\right)$, e a função de poupança dos capitalistas continua $S_{P}=S_{P} P_{P}$. Deste modo, para manter o equilíbrio em pleno emprego ao longo do tempo é necessário que:

$$
\mathrm{I}=s_{W}\left(W+P_{W}\right)+s_{P} P_{P}=s_{W}\left(Y-P_{P}-P_{W}+P_{W}\right)+s_{P} P_{P}=s_{W} Y+\left(s_{P}-s_{W}\right) P_{P}
$$

Isto é,

$$
\frac{P_{P}}{Y}=\frac{\frac{I}{Y}-s_{W}}{s_{P}-s_{W}}
$$

A equação (2.26) é similar à (2.22) de Kaldor e interpretada da mesma forma, uma vez que o investimento independe da poupança é ele que determina a participação dos lucros dos capitalistas na renda. Caso os trabalhadores não poupassem, $s_{W}=0$, a partir de (2.26) obteríamos a equação de Cambridge, $\frac{P_{P}}{Y}=\frac{\frac{I}{Y}}{S_{P}}$.

Multiplicando (2.26) por $\frac{Y}{K}$ obtém-se:

$$
\frac{P_{P}}{K}=\frac{\frac{I}{K}-s_{W} \frac{Y}{K}}{s_{P}-s_{W}}
$$

A diferença de (2.27) frente à (2.26) é que nesta o investimento está determinando a taxa de lucro e não a participação dos lucros na renda. Segundo Pasinetti (1962), (2.26) e (2.27) representam o core da teoria pós-keynesiana da distribuição e do produto.

As condições de estabilidade são semelhantes à Kaldor, $s_{P} \neq s_{W}$ e $s_{P}>s_{W}$. Em particular $s_{P}>\frac{I}{Y}$, o que exclui da posição de equilíbrio a participação negativa dos salários, e $s_{W}<\frac{I}{Y}$, que exclui a possibilidade de participação negativa dos lucros em equilíbrio.

A diferença do modelo de Pasinetti frente ao de Kaldor reside exatamente no reconhecimento da existência de $P_{W}$. Dado que o investimento determina o estoque de capital 
da economia, parte deste capital será direcionado aos trabalhadores $\left(K_{W}\right)$ e irá compor seu o lucro.

Para manter clara a divisão de classes do modelo, no sentido de que os capitalistas são os proprietários dos meios de produção, Pasinetti (1962) supõe que os trabalhadores emprestam o seu capital $\left(K_{W}\right)$ aos capitalistas pela taxa de juros i. A partir desta hipótese, torna-se possível obter a participação total do lucro na renda e a taxa de lucro total da economia, $\frac{P}{Y}=\frac{P_{P}}{Y}+\frac{P_{W}}{Y}$ e $\frac{P}{K}=\frac{P_{P}}{K}+\frac{P_{W}}{K}$, respectivamente. Assim de (2.27) tem-se:

$$
\frac{P}{K}=\frac{\frac{I}{K}-s_{W} \frac{Y}{K}}{s_{P}-s_{W}}+i \frac{K_{W}}{K}
$$

Em equilíbrio sabe-se que $\frac{K_{W}}{K}=\frac{S_{W}}{S}=\frac{s_{W}\left(W-P_{P}\right)}{I}$, assim, substituindo $\frac{K_{W}}{K}$ em obtém-se:

$$
\frac{P}{K}=\frac{\frac{I}{K}-s_{W} \frac{Y}{K}}{s_{P}-s_{W}}+i\left(\frac{s_{W} s_{P}}{s_{P}-s_{W}} \frac{Y}{I}-\frac{s_{w}}{s_{p}-s_{w}}\right)
$$

Multiplicando por $\frac{K}{Y}$,

$$
\frac{P}{Y}=\frac{\frac{I}{Y}-s_{W}}{s_{P}-s_{W}}+i\left(\frac{s_{W} s_{P}}{s_{P}-s_{W}} \frac{K}{I}-\frac{s_{w}}{s_{p}-S_{w}} \frac{K}{Y}\right)
$$

Com (2.29) e (2.30), Pasinetti obtém os almejados lucros totais. No entanto, para poder interpretar esse resultado, é necessário estabelecer o comportamento da taxa de juros. Neste ponto, Pasinetti diferencia-se de Keynes, pois não considera a taxa de juros variável monetária determinada pela preferência pela liquidez, mas sim variável real que no longo prazo é igual o lucro, $\frac{P}{K}=\frac{P}{Y}=i$.

Substituindo i em (2.30):

$$
\frac{P}{K} \frac{s_{P}\left(I-s_{W} Y\right)}{I}=\frac{I-s_{W} Y}{K}
$$

Como $I-s_{W} Y \neq 0$, 


$$
\frac{P}{K}=\frac{\frac{I}{K}}{s_{P}}
$$

De forma semelhante substituindo em (2.30), tem-se:

$$
\frac{P}{Y}=\frac{\frac{I}{Y}}{s_{P}}
$$

As equações (2.32) e (2.33) mostram que Pasinetti obtém o mesmo resultado de Kaldor. Apesar de supor a existência de poupança por parte dos trabalhadores, no longo prazo é a poupança dos capitalistas que determina a taxa de lucro e a participação dos lucros no produto. Essa conclusão confere maior generalidade ao modelo pós-Keynesiano de primeira geração.

Este é o memorável teorema de Pasinetti: numa tendência de crescimento balanceado, a taxa de lucro parece depender somente da taxa de crescimento e da propensão a poupar dos capitalistas e é independente da propensão a poupar dos trabalhadores, $s_{W}$. (JONES, 1975, p. 167).

Pelo exposto, percebe-se que Kaldor (1956) e Pasinetti (1962) expandiram o modelo neo-Keynesiano iniciado por Harrod introduzindo a distribuição funcional da renda e ambos concluem que o investimento precede os lucros, de tal forma que nessa relação somente a poupança dos capitalistas possui importância. Ambos os autores não assumem a hipótese implícita de um único valor de equilíbrio para a taxa de lucro presente no modelo de Harrod, para eles a divisão do produto entre lucros e salários pode assumir diversas feições. No entanto, no longo prazo, o crescimento estará sempre caracterizado pela plena utilização da capacidade produtiva.

As diversas combinações entre lucro e salários presentes na economia de Kaldor e Pasinetti evita o segundo problema de Harrod, denominado por Solow de crescimento no fio da navalha. Isso ocorre, pois se assume que os lucros e salários variam para manter a igualdade entre a taxa efetiva e garantida de crescimento, as quais são dadas no longo prazo.

Os modelos citados não discorrem sobre a determinação da função investimento, que como destacado detém papel fundamental na teoria econômica e na teoria Keynesiana em particular. Robinson (1962) discorreu sobre as variáveis que fundamentam o investimento, por isso seu modelo é discutido na subseção seguinte. 


\subsubsection{O modelo de crescimento de Robinson}

Nos modelos de Kaldor e Pasinetti é a taxa de investimento que precede a taxa de lucro, (2.23) e $(2.33)^{25}$. Robinson, por sua vez, afirma que tanto a taxa de crescimento quanto de lucro são endogenamente determinadas. Essa endogeneização é realizada ao assumir que a taxa de investimento depende da taxa de lucro esperada pelas firmas. Existe, assim, dupla relação entre a taxa de lucro e a taxa de crescimento, por um lado a taxa de lucro depende da taxa de investimento determinada pelas firmas, por outro lado, a taxa de investimento depende da taxa de lucro esperada ${ }^{26}$.

As hipóteses iniciais do modelo de Robinson são:

i) assume-se como dados a quantidade e qualidade da força de trabalho, a tendência de crescimento da força de trabalho, o estado das artes industriais, os recursos naturais etc. Não há na economia recursos escassos;

ii) o investimento em capital produtivo é determinado pela decisão das empresas. $\mathrm{O}$ crescimento depende do animal spirit do capitalista;

iii) a poupança é determinada pelo investimento;

iv) os salários são constantes no modelo, mas podem variar em duas situações: a) há demanda excedente de mão de obra; b) a taxa de investimento está tão pequena que deprime a taxa de salário real;

v) a política monetária possui pequeno papel, pois se assume que os investimentos são em sua maior parte financiados por lucros retidos ou por financiamentos bancários;

vi) em equilíbrio o nível de bens de capital deve ser aquele esperado pelos empresários para dada estrutura de custos;

vii) os trabalhadores não poupam, somente os capitalistas;

viii) no longo prazo não há excesso de capacidade.

A partir das hipóteses acima, reescreve-se as equações (2.23) e (2.32), equação de Cambridge, para expor formalmente o modelo de Robinson:

$$
\mathrm{r}=\mathrm{g} / \mathrm{s}_{\mathrm{p}} \text { ou } g^{S}=\mathrm{s}_{\mathrm{p}} \mathrm{r}
$$

\footnotetext{
${ }^{25}$ Para outros autores, como os marxistas, é a taxa de lucro que determina a taxa de crescimento, ou seja, a causalidade é inversa (LAVOIE, 2014). Essa divergência é superada ao se endogeneizar a taxa de investimento conforme realizada por Robinson.

${ }^{26}$ Para alguns autores, o modelo de Robinson é classificado como modelo pós-kaleckiano de primeira geração, pois se endogeniza a taxa de investimento a partir da taxa de lucro (ARAÚJO, R; TEIXEIRA, J; 2013)
} 
Em que I = investimento bruto; $\mathrm{s}_{\mathrm{p}}=$ poupança dos capitalistas; $\Pi=$ lucro bruto, $\mathrm{r}=$ $\Pi / \mathrm{K}, \mathrm{g}=\mathrm{I} / \mathrm{K}$ e $g^{s}$ pode ser interpretada como a taxa de crescimento da oferta de poupança, ou taxa de crescimento realizada pelo investimento, uma vez que o investimento determina a poupança. A taxa de investimento por sua vez é:

$$
g^{I}=\alpha+\beta r^{e}
$$

Onde $r^{e}=$ taxa esperada de lucro ${ }^{27}$ e $\alpha>0$ e $\beta>0$.

Em equilíbrio a taxa de crescimento esperada (induzida pela taxa de lucro), $g^{I}$, é igual à taxa de crescimento realizada (resultado da taxa de acumulação), $g^{s}$. Assim, no equilíbrio de longo prazo a taxa de crescimento desejada é igual à taxa de crescimento realizada. Isto é, no equilíbrio as expectativas das firmas com respeito ao futuro estão de acordo com a experiência presente.

Robinson's use of the double-sided relation between the rate of profit and the rate of accumulation allows her to derive the desired rate of accumulation. This is the rate of accumulation which results in a rate of profit that induces this particular rate of accumulation. It is her entrepreneurial equilibrium growth rate (ASIMAKOPULOS, 1991, p. 175176)

Formalmente, o ponto de equilíbrio é dado por:

$$
\begin{aligned}
& \mathrm{g}^{*}=\frac{s_{p} \alpha}{\left(s_{p}-\beta\right)} \\
& \mathrm{r}^{*}=\frac{\alpha}{\left(s_{p}-\beta\right)}
\end{aligned}
$$

Graficamente, o ponto de equilíbrio é representado por:

\footnotetext{
${ }^{27}$ Alguns autores como Lavoie (1992) qualificam o comportamento de $r^{e}$. Para o objetivo deste capítulo não será necessário qualificar $r^{e}$.
} 
Gráfico 2.3 - Curvas de Robinson

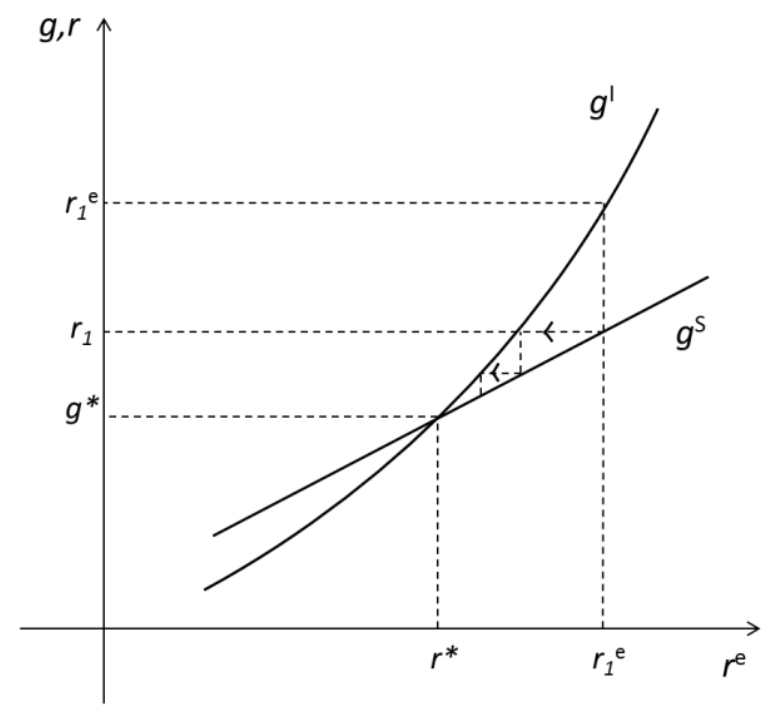

Neste gráfico representa-se a relação entre g e $\mathrm{r}$ a partir das curvas $g^{S}$ e $g^{I}$. Suponha que a taxa de lucro esperada seja de $r_{1}^{e}$, nesse caso a taxa de lucro realizada será $r_{1}$, onde $r_{1}<$ $r_{1}^{e}$. Espera-se, assim, que no próximo período as firmas reduzam o investimento, isso significa que a economia tende para a posição $\left(\mathrm{r}^{*}, \mathrm{~g}^{*}\right)$ de equilíbrio.

Percebe-se que a estabilidade exige que as decisões de investimento sejam menos sensíveis a mudança na taxa esperada de lucro do que a poupança dos capitalistas, $s_{p}>\beta$. A situação contrária é representada no Gráfico 2.4, neste suponha a taxa de lucro esperada seja de $r_{1}^{e}$, nesse caso a taxa de lucro realizada será $r_{1}$, onde $r_{1}>r_{1}^{e}$. Assim, no próximo período as firmas aumentarão o investimento, isso significa que a economia tende a se distanciar da posição ( $\left.\mathrm{r}^{*}, \mathrm{~g}^{*}\right)$ de equilíbrio. 
Gráfico 2.4 - Instabilidade no modelo de Robinson

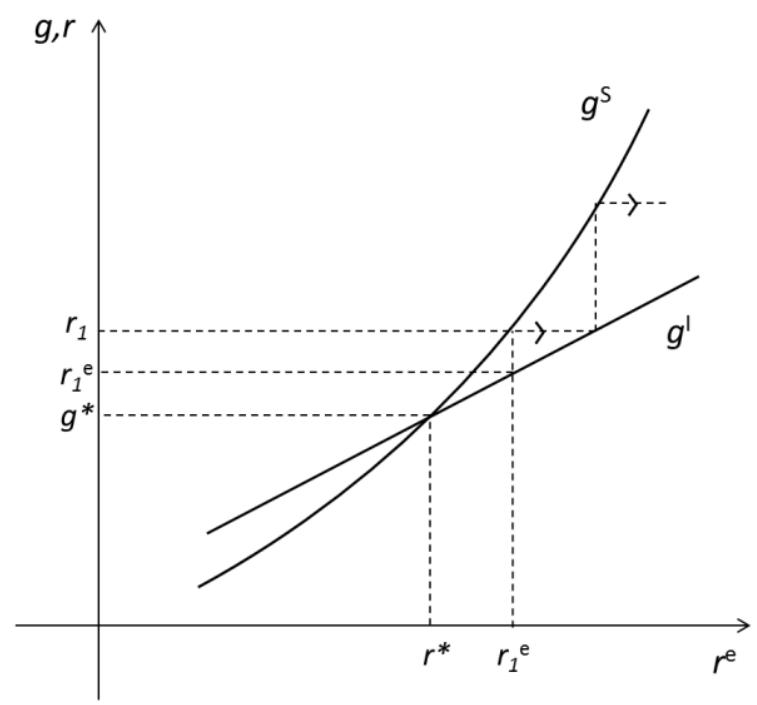

A respeito da posição (r*, $\left.\mathrm{g}^{*}\right)$ Robinson (1956, p. 67) afirma que:

That at every moment entrepreneurs expect the future of profit obtainable on investment to continue indefinitely at the level ruling at that moment; that they expect the rate of technical progress (which may be nil) to be steady: and that they fix amortization allowances for long-lived plant accordingly. When something occurs which causes a change, we assume that expectations are immediately adjusted, and that no further change is expected.

Apesar de reconhecer que as expectativas são ajustadas de modo a direcionar a economia para a posição ( $\left.\mathrm{r}^{*}, \mathrm{~g}^{*}\right)$ de equilíbrio, Robinson (1962) observa que não é garantida a manutenção da igualdade entre a taxa de acumulação desejada e a efetiva, devido aos seguintes motivos:

1. Há lapso temporal entre a aferição dos lucros e os gastos dos capitalistas (decisões de investimento);

2. As taxas de acumulação deixam resíduos sobre o estoque de capital, isto afeta as decisões de investimento.

O reconhecimento de que há lapso temporal no âmbito das decisões de investimento, evita que o modelo de Robinson seja atingido pela crítica de Possas (1987) ao modelo de Harrod exposto na subseção 2.3.1. Isto é, modelo de Robinson é logicamente consistente, pois todas as variáveis não se encontram no mesmo período de tempo, em particular, as referentes à determinação do investimento. 
Um importante resultado do modelo de Robinson é o famoso paradoxo da poupança de Keynes. Isto é, a elevação na propensão a poupar promove a redução da taxa de crescimento e da taxa de equilíbrio dos lucros. Este resultado é obtido a partir de (2.36) e representado por:

$$
\frac{d g^{*}}{d s_{p}}=-\frac{\beta}{\left(s_{P}-\beta\right)^{2}}<0
$$

O resultado (2.38) é visualizado no Gráfico 2.5. Após a elevação da propensão a poupar dos capitalistas, a curva $g^{S}$ desloca-se para a direita, $g^{S \prime}$. Devido à redução do consumo, a taxa de lucro será inferior. Desta forma, as firmas irão revisar as suas expectativas e a nova taxa de acumulação será (r', g').

Gráfico 2.5 - Paradoxo da poupança no modelo de Robinson

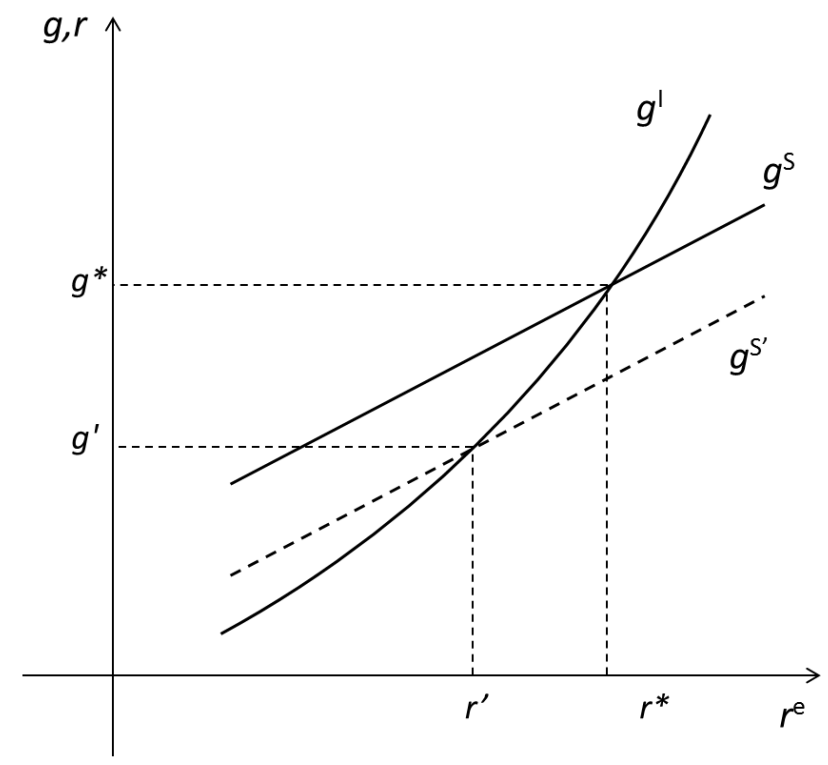

É importante observar que, conforme destacado nas hipóteses iniciais, Robinson assim como Kaldor assume no longo prazo plena utilização da capacidade produtiva. Isso significa que a elevação da propensão a poupar, apesar de reduzir a taxa de crescimento, não afeta o fato de se supor pleno emprego no longo prazo. Segundo Lavoie (1992) esta hipótese possui as seguintes consequências: a) mudanças na distribuição de renda ocorrem por meio de alterações nos preços relativos; b) existe relação inversa entre a taxa de salário real e a taxa de lucro $^{28}$.

\footnotetext{
${ }^{28}$ Consequências que também estão presentes no modelo de Kaldor e Pasinetti.
} 
O item b) acima é explicitado a partir da identidade entre o valor do produto e a soma entre salários e lucros.

$$
\mathrm{pq}=\mathrm{wL}+\mathrm{rpK}
$$

Sendo $\mathrm{p}=$ nível de preços; $\mathrm{q}=$ nível de produto real; $\mathrm{w}=$ taxa de salário nominal; $\mathrm{L}=$ nível de emprego; $r$ = taxa de lucro; $\mathrm{K}=$ estoque de capital. Dividindo por q, tem-se:

$$
\mathrm{p}=\mathrm{w}\left(\frac{L}{q}\right)+\operatorname{rp}\left(\frac{K}{q}\right)
$$

Define-se $v=\mathrm{K} / \mathrm{q}$ e $y=\mathrm{q} / \mathrm{L}$, deste modo rearranjando (2.39) tem-se:

$$
\frac{W}{P}=y(1-r v)
$$

Se $y$ e $v$ são fixos no longo prazo, a equação (2.41) mostra que quanto maior $\frac{W}{P}$, menor $r^{29}$. Para compreender os efeitos de (2.41) no modelo de Robinson, suponha a elevação do animal spirit dos empresários de tal forma que o investimento aumenta e consequentemente a taxa de lucro $r$. Como a economia encontra-se sob pleno emprego, a elevação de $r$ significa queda no salário real. Agora, suponha que exista um salário real mínimo aceito pelos trabalhadores, nesse caso a elevação da taxa de lucro somente se efetivará se houver ampliação do nível de preços. Trata-se assim da barreira inflacionária presente no modelo de Kaldor e Robinson.

The case of inflation barrier costs rests on the negative relationship between the real wage and the rate of growth. This is evidently true if one assumes that the economy always lies on the wage/profit frontier; that is, if one assumes that in long run analysis the rate of utilization of capacity is fixed at its normal on full capacity level (LAVOIE, 1992, p. 296).

A existência da barreira inflacionária, que é decorrente da hipótese de plena utilização da capacidade produtiva no longo prazo, traz à tona a fragilidade evidenciada no modelo de Kaldor (subseção anterior). Isto é, o principio da demanda efetiva atua no curto prazo, mas no

\footnotetext{
29 "The level of real-wage rates at which the inflation barrier is established depends very much on the levels of real-wage rates achieved in the past, the degree of organization of workers, and on class relations between workers and employers, in general. This is one of the important areas where historical and social factors affect the analysis, because sharp class antagonisms that keep bringing the inflation barrier into play, would impede accumulation and growth" (ASIMAKOPULOS, 1991, p. 171).
} 
longo prazo vale a Lei de Say. Retomando o argumento desenvolvido no parágrafo anterior, a validade da Lei de Say torna-se evidente, pois caso se eleve a poupança dos capitalistas haverá maior taxa de crescimento para dada taxa de lucro.

When there is a real wage resistance on the part of workers, a higher propensity to save on profits is favorable to the economy since it allows a higher rate of growth at a given rate of profit, that is, at a given real wage rate. (LAVOIE, 2014, p. 358)

A dicotomia de ajuste na quantidade no curto prazo, e nos preços no longo prazo é surpreendente em Robinson, pois ela assume que a estrutura de mercado é oligopolista com preços não flexíveis (LAVOIE, 2014).

Essa fragilidade presente nos primeiros modelos pós-Keynesianos é superada pelo modelo Kaleckiano, apresentado na próxima seção.

\subsection{O MODELO KALECKIANO DE CRESCIMENTO E DISTRIBUIÇÃO}

Kalecki, assim como Robinson, discordava da hipótese do investimento exogenamente determinado. Devido à importância do investimento na dinâmica econômica, para Kalecki era fundamental identificar os determinantes da taxa de investimento. Em linhas gerais o modelo é denominado kaleckiano se possuir as seguintes características (Lavoie, 2014):

1. Função de investimento que depende de diversas variáveis, em particular a taxa de utilização da capacidade produtiva;

2. Os preços dependem dos custos de produção e são dados;

3. A poupança proveniente do trabalho é nula;

4. A capacidade produtiva não é plenamente utilizada.

No modelo discutido nesta seção as hipóteses iniciais são: economia capitalista formada por empresas em grande número que produzem diversos bens e serviços; economia composta por trabalhadores e capitalistas; as empresas são verticalmente integradas; adota-se empresa representativa; o governo e o mercado externo são negligenciados; o mercado interno é imperfeito; o nível de produção depende da disponibilidade de força de mão de obra; a demanda dos bens e serviços finais consiste em: a) demanda dos capitalistas por bens de consumo e bens de investimento; b) demanda dos trabalhadores por bens de consumo; os trabalhadores não poupam e o seu nível de demanda varia com a produção; a produtividade do trabalho é dada e constante (não há retornos marginais decrescentes do trabalho).

Kalecki $(1983,1954)$ assume indústrias verticalmente integradas no sentido que elas não compram insumos uma das outras (LOPES, J., ASSOUS, M, 2010), desta forma o valor 
total da produção pode ser decomposto em salários mais lucro bruto. Assim, o produto nacional bruto calculado pela ótica da renda e do produto fornece:

$$
\begin{gathered}
\text { Lucros }+ \text { Salários }=\text { Investimento Bruto }+ \text { Consumo dos capitalistas }+ \text { Consumo dos } \\
\text { trabalhadores }
\end{gathered}
$$

Sob a hipótese de que os trabalhadores não poupam, tem-se que o consumo dos trabalhadores é igual aos salários. Deste modo:

$$
\text { Lucros }=\text { Investimento Bruto }+ \text { Consumo dos capitalistas }
$$

A partir desta equação, Kalecki $(1983,1954)$ deduz o princípio da demanda efetiva. Uma vez que os capitalistas possuem a autonomia de decisão sobre os seus gastos e não os seus ganhos, tem-se que é o investimento e o consumo que determinam os lucros e não o contrário. Isto é, os capitalistas ganham o que gastam. Importante destacar que a condição prévia para a validade do princípio da demanda efetiva é a elasticidade positiva da produção em relação à demanda. Deste modo, o deslocamento da demanda não irá se transferir integralmente para os preços.

A equação acima pode se escrita como:

$$
\text { Investimento Bruto }=\text { Lucros }- \text { Consumo dos capitalistas }
$$

De modo simplificado tem-se:

$$
\mathrm{I}=\underline{\mathrm{s}_{\mathrm{p}}} \Pi
$$

Sendo que $\mathrm{I}=$ investimento bruto; $\mathrm{s}_{\mathrm{p}}=$ poupança dos capitalistas; $\Pi=$ lucro bruto.

Dividindo (2.45) pelo estoque de capital da economia $\mathrm{K}$, obtém-se a equação de Cambridge $^{30}$ semelhante às equações (2.32) e (2.33) dos autores keynesianos discutidos na seção anterior:

$$
\mathrm{r}=\mathrm{g} / \mathrm{s}_{\mathrm{p}} \text { ou } \mathrm{g}=\mathrm{s}_{\mathrm{p}} \mathrm{r}
$$

\footnotetext{
${ }^{30}$ Robinson (1962), Kaldor (1956) e Pasinetti (1961).
} 
Em que $\mathrm{r}=\Pi / \mathrm{K}$ e $\mathrm{g}=\mathrm{I} / \mathrm{K}$.

A equação (2.46) determina a taxa de lucro pelo lado da demanda, ou seja, é a taxa de acumulação da economia, g, que determina a taxa de lucro ${ }^{31}$, argumento semelhante ao dos keynesianos. A taxa de lucro também pode ser mensurada pelo lado da oferta, a partir da identidade fornecida pelas contas nacionais.

$$
\text { Produto nacional }=\text { Salários }+ \text { Lucros }
$$

De modo simplificado, a identidade acima é expressa por (2.39), que dividido por $\mathrm{q}$ resulta em (1.40). Define-se, $1=\mathrm{L} / \mathrm{q}, \mu=\mathrm{q} / \mathrm{q}_{\mathrm{fc}}$ e $v=\mathrm{K} / \mathrm{q}_{\mathrm{fc}}$, sendo que $\mathrm{q}_{\mathrm{fc}}=$ nível de produto sobre plena capacidade produtiva. Observe que $\mu$ corresponde ao grau de utilização da capacidade produtiva e v a razão entre o capital e o produto. Assim:

$$
\mathrm{p}=\mathrm{wl}+\mathrm{rp}(\mathrm{v} / \mu)
$$

Isolando $r$,

$$
\mathrm{r}^{\mathrm{PC}}=\frac{\mu}{v}\left[1-\left(\frac{w}{p}\right) l\right]
$$

A equação (2.49) foi denominada por Rowthorn (1981) de profit cost curve.

A partir de (2.49) infere-se que a taxa de lucro depende da taxa de salário real e do grau de utilização da capacidade produtiva. Kalecki, como destacado nas hipóteses iniciais, diferencia seu modelo das primeiras abordagens sobre crescimento e distribuição keynesiana, pois assume o grau de utilização da capacidade produtiva inferior a unidade. Isto faz com que no modelo kaleckiano haja espaço para que o conflito distributivo entre capital e trabalho gere efeitos sobre o salário real e a participação do salário na renda.

De modo contrário ao obtido pelos neo-keynesianos, no modelo kaleckiano ao comparar-se (2.46) e (2.49) percebe-se que não há relação estabelecida entre a taxa de acumulação e o salário real. Isto é, a mesma taxa de salário real é compatível com diferentes taxas de acumulação.

\footnotetext{
31 “(...) são suas (dos capitalistas) decisões quanto ao investimento e consumo que determinam os lucros e não vice-versa" (POSSAS; M; BALTAR, P; p. 114; 1981).
} 
The result is that a higher rate of growth can be achieved without the real wage being smaller. Differences in the rate of accumulation (...) do not require changes in the real wage rate (CICCONE, 1986, p. 299).

Outra importante constatação do modelo kaleckiano é a endogeneidade do grau de utilização da capacidade, a qual é representada pela seguinte equação:

$$
\mu=\frac{g\left(\frac{v}{s p}\right)}{1-\left(\frac{w}{p}\right) l}
$$

Esta equação mostra que a taxa de utilização da capacidade produtiva depende da taxa de investimento, da relação capital-produto, da propensão marginal a poupar dos capitalistas, da taxa de salário real e da relação trabalho-produto.

Kalecki fundamenta microeconomicamente a sua teoria de crescimento por meio da citada hipótese de mercados imperfeitos e oligopólio. Em particular, Kalecki focou na formação dos preços e margens de lucro em condições de mercados oligopolistas, por isso a importância do conceito de grau de monopólio (exposto abaixo) no modelo kaleckiano.

(...) each firm in an industry arrives at the price of its product by marking up its direct cost, consisting of average costs of wages plus raw materials, in order to cover overheads and profits (KALECKI, 1971, p. 99 apud LEE, 1999, p. 145).

(...) o conceito de grau de monopólio exprime não só a concorrência entre capitalistas, como também o confronto entre estes e os trabalhadores, contém em si o processo pelo qual se dá a distribuição de renda entre lucros e salários a nível de empresa (POSSAS, M; BALTAR, P; 1981, p. 123).

De modo formal, Kalecki (1983) determina os preços de cada firma por:

$$
\mathrm{p}=\mathrm{mu}+\mathrm{n} \bar{p}
$$

Sendo, $\mathrm{p}=$ preço determinado pela firma; $\mathrm{u}=$ custo unitário de produção; $\bar{p}=$ média dos preços dos produtos similares na indústria em questão; $m$ e $n=$ parâmetros positivos.

Considerando todas as firmas na indústria em questão, tem-se:

$$
\bar{p}=\frac{\bar{m}}{1-\bar{n}} \bar{u}
$$


Onde, $\bar{m}, \bar{n}$ e $\bar{u}$ são médias e $\frac{\bar{m}}{1-\bar{n}}$ representa o grau de monopólio das firmas. Lopes e Assous (2010) justificam esta abordagem:

(...), this different microeconomic foundation is not based on an optimizing behavior, simple because under uncertain conditions firms do not have the requisite information to follow an optimizing procedure (p. 74)

No modelo kaleckiano proposto neste trabalho adota-se de forma simplificada a seguinte equação dos preços:

$$
\mathrm{p}=(1+\theta) \mathrm{wl}
$$

Em que $\theta$ corresponde ao mark up sobre os custos, os quais são constituídos somente pelos custo referentes a força de trabalho ${ }^{32}$. Substituindo (2.53) em (2.49):

$$
\mathrm{r}^{\mathrm{PC}}=\frac{\theta}{1+\theta}\left(\frac{\mu}{v}\right)
$$

Esta equação representa a determinação da taxa de lucro pela firma representativa de Kalecki. Dado que $r=\Pi / K$, de (2.54) obtém-se que:

$$
\frac{\theta}{1+\theta}=\frac{\Pi}{q}
$$

Isto é, $\frac{\theta}{1+\theta}$ consiste na participação dos lucros na renda (profit share). Denominando $\mathrm{h}=\frac{\theta}{1+\theta}$, tem-se que a curva de profit cost é reescrita por:

$$
\mathrm{r}^{\mathrm{PC}}=\mathrm{h}\left(\frac{\mu}{v}\right)
$$

This led Kalecki to posit that the distribution of income is determined by the price/unit cost ratio, on degree of monopoly, a term summarizing a variety of oligopolistic and monopolistic features (LOPES, J; ASSOUS, M., 2010, p. 68).

\footnotetext{
${ }^{32}$ Muitos autores segmentam a força de trabalho entre trabalhadores fixos e trabalhadores variáveis. Neste trabalho de modo a simplificar a análise adota-se como Hein (2008) apenas a força de trabalho como uma variável agregada. Este procedimento visa também facilitar a comparação com o modelo de Pasinetti a ser discutido no próximo capítulo.
} 
Cumpre destacar, que apesar do profit share depender do grau de monopólio, como exposto, os lucros são determinados pelos gastos dos capitalistas. Isso significa que para completar o modelo é necessário expor como a taxa de acumulação é determinada, isto é como o investimento é determinado.

Profits do not only need to be produced, the also need to be realized. This will only occur when there is a similar amount of higher capitalist expenditure. If capitalist expenditure remains unchanged, profits will remain constant too (LOPES, J., ASSOUS, M, 2010, p. 77).

A função investimento proposta por Kalecki foi modificada ao longo dos anos pelo autor no âmbito da sua teoria do ciclo econômico. Nos modelos de 1939 e 1943 Kalecki adota uma função investimento não linear, pois assume que a taxa de lucro corrente dependeria das expectativas dos lucros. Posteriormente, Kalecki adota novamente ${ }^{33}$ a função de investimento linear. Segundo Lopes e Assous (2010) isso ocorreu, pois Kalecki havia se convencido que choques erráticos poderiam manter o ciclo econômico.

Neste modelo simplificado seguiremos Rowthorn (1981), Lavoie (1992) e Hein (2008), os quais afirmam que a função investimento padrão depende de duas variáveis: a) a taxa de lucro corrente, $r$, que serve como indicador dos lucros futuros ${ }^{34}$ e provê os fundos para reinvestimento; b) o grau de utilização da capacidade, $\mu$, que é inferior a unidade uma vez que as firmas mantém capacidade produtiva para atender a demanda futura.

Formalmente,

$$
\frac{I}{K}=\mathrm{g}(\mathrm{r}, \mu)
$$

Assim,

$$
\mathrm{g}=\alpha+\beta r+\gamma \mu
$$

Assume-se que $\beta>0, \gamma>0$ e $\alpha>0$. Este último representa o componente autônomo da acumulação de capital, isto é, o animal spirit do investidor.

Igualando a poupança ao investimento, (2.58) a (2.46), obtém-se a curva de realização dos lucros:

\footnotetext{
${ }^{33}$ No modelo de 1933 Kalecki adota uma função investimento linear (LOPES,J; ASSOUS, M., 2010)

${ }^{34}$ Este ponto é importante, pois evidencia certa semelhança entre o modelo de Robinson e de Kalecki. Ela explicita a taxa de lucro futura na determinação da função investimento, Kalecki considera como proxy desta a taxa de lucro corrente.
} 


$$
\mathrm{r}^{\mathrm{ED}}=\frac{\gamma}{s_{p}-\beta} \mu+\frac{\alpha}{s_{p}-\beta}
$$

A independência do investimento frente à poupança ${ }^{35}$ pressupõe que as firmas possuem acesso ao crédito para financiamento à produção. Isso significa que o volume de crédito (fluxo) e a quantidade de moeda (estoque) são endógenos ao processo de acumulação.

Endogenous credit and money are prerequisites for the principle of effective demand to hold (HEIN, 2008, p. 43).

Dado que o investimento cria automaticamente a sua poupança, a taxa de juros não é determinada pela oferta e demanda de capital. Kalecki (1952) afirma que a taxa de juros de curto prazo é determinada pelo valor das transações e pela oferta monetária por parte dos bancos, o que a faz variar de forma significativa. No entanto, o objetivo de Kalecki era compreender as causas do ciclo econômico no longo prazo, período em que a taxa de juros pouco afetaria o investimento.

Efetivamente, em vista do fato de que a taxa de juros de longo prazo, (...), não apresenta flutuações cíclicas pronunciadas, dificilmente poderia ser considerada como um elemento importante no mecanismo do ciclo econômico (KALECKI, 1952, p. 71).

De modo semelhante aos modelos pós-keynesianos ${ }^{36}$, não considerar a taxa de juros como determinante do investimento é ponto relevante da teoria de Kalecki ${ }^{37}$, e passível de críticas (LAVOIE, 1992). Como destacado anteriormente não é o objetivo deste trabalho remediar esta ausência.

Deste modo, o modelo pode ser resumido a partir das equações:

$$
\begin{gathered}
\mathrm{r}^{\mathrm{PC}}=\mathrm{h}\left(\frac{\mu}{v}\right) \\
\mathrm{r}^{\mathrm{ED}}=\frac{\gamma}{s_{p}-\beta} \mu+\frac{\alpha}{s_{p}-\beta}
\end{gathered}
$$

Rowthorn (1981) destaca que no modelo kaleckiano, assim como nos keynesianos, a causalidade inicia-se no investimento. Este determina a renda, a qual por sua vez determina a

\footnotetext{
${ }^{35} \mathrm{O}$ princípio da demanda efetiva pressupõe a independência do investimento frente a poupança, pois como visto o investimento é gasto capitalista, o qual por natureza é autônomo. (POSSAS, M; BALTAR, P; 1981).

${ }^{36}$ Exceção feita ao modelo de Pasinetti apresentado na subseção anterior.

37 Este fato demonstra o quanto Kalecki estava preocupado em compreender o ciclo e as variáveis que o determinam.
} 
poupança. Deste modo, em qualquer situação de equilíbrio, a economia deve se situar sobre a curva de realização dos lucros, $\mathrm{r}^{\mathrm{ED}}$.

Igualando $\mathrm{r}^{\mathrm{ED}}$ a r ${ }^{\mathrm{PC}}$ obtém-se, as posições de equilíbrio:

$$
\begin{aligned}
\mu^{*} & =\frac{\alpha v}{h\left(s_{p}-\beta\right)-\gamma v} \\
\mathrm{r}^{*} & =\frac{h \alpha v}{h\left(s_{p}-\beta\right)-\gamma v} \\
\mathrm{~g}^{*} & =\frac{s_{p} h \alpha v}{h\left(s_{p}-\beta\right)-\gamma v}
\end{aligned}
$$

Graficamente,

Gráfico 2.6 - Equilíbrio no modelo de Kalecki

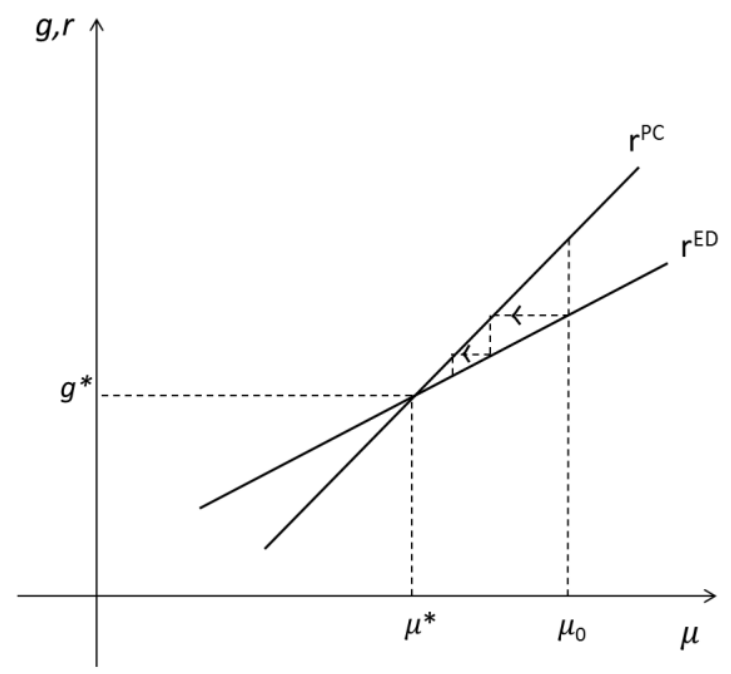

A condição de estabilidade do modelo é dada por $\mathrm{s}_{\mathrm{p}}>\beta+\frac{\gamma v}{h}$, o que garante a inclinação positiva de $\mathrm{r}^{\mathrm{ED}}$ inferior à inclinação de $\mathrm{r}^{\mathrm{PC}}$. A convergência à posição de equilíbrio é explicada de modo semelhante ao modelo de Robinson. Suponha que a taxa de utilização da capacidade seja $\mu_{0}$, neste patamar, a taxa de lucro realizada será inferior à taxa de lucro necessária para cobrir os custos de produção, $r_{0}^{E D}<r_{0}^{P C}$, deste modo no próximo período os investidores irão reduzir o investimento (e consequentemente a produção), de tal forma que a economia tenda para $\mu^{*}$. 
O modelo kaleckiano apresentado fornece os seguintes importantes resultados a partir de exercícios de estática comparativa:

$$
\begin{gathered}
\frac{d g^{*}}{d s_{p}}=-\frac{\left(h^{2} \alpha v \beta+\gamma v\right)}{\left[h\left(s_{p}-\beta\right)-\gamma v\right]^{2}}<0 \\
\frac{d \mu^{*}}{d h}=-\frac{\alpha v-\left(s_{p}-\beta\right)}{\left[h\left(s_{p}-\beta\right)-\gamma v\right]^{2}}<0 ; \frac{d r^{*}}{d h}=-\frac{\alpha h v^{2}}{\left[h\left(s_{p}-\beta\right)-\gamma v\right]^{2}}<0 ; \frac{d g^{*}}{d h}=-\frac{s_{p} \alpha h v^{2}}{\left[h\left(s_{p}-\beta\right)-\gamma v\right]^{2}}<0
\end{gathered}
$$

O resultado (2.63) mostra o famoso paradoxo da poupança, quanto maior a poupança dos capitalistas menor a taxa de acumulação da economia. O resultado (2.64), por sua vez, mostra o paradoxo dos custos, pois quanto maior o profit share, menor a taxa de acumulação. Isto é o mesmo que afirmar que quanto maior o wage share (custos de produção), maior será a taxa de crescimento.

Ambos os resultados são visualizados nos gráficos abaixo. Suponha a elevação da taxa de poupança, isso significa que haverá um deslocamento de $r^{E D}$ para $r^{E D \prime}$. Ao nível $\mu^{*}$ de utilização da capacidade, taxa de realização dos lucros é inferior aos custos de produção, isso é representado no gráfico pela diferença $g^{\prime}<g^{*}$. Neste caso, os empresários são induzidos a reduzir os investimentos e consequentemente a economia tende ao novo nível produtivo dado por $\left(g_{1}, \mu_{1}\right)$, inferior a $\left(g^{*}, \mu^{*}\right)$.

Thus in the Kaleckian model, the paradox of thrift holds, meaning that a higher propensity to save leads to a lower growth rate, and this will be accompanied by lower rates of profit and of capacity utilization. In contrast to the neo-Keynesian model, however, all this happens without any change in the costing margins or in real wages (LAVOIE, 2014, p. 365). 
Gráfico 2.7 (a) - Paradoxo da poupança

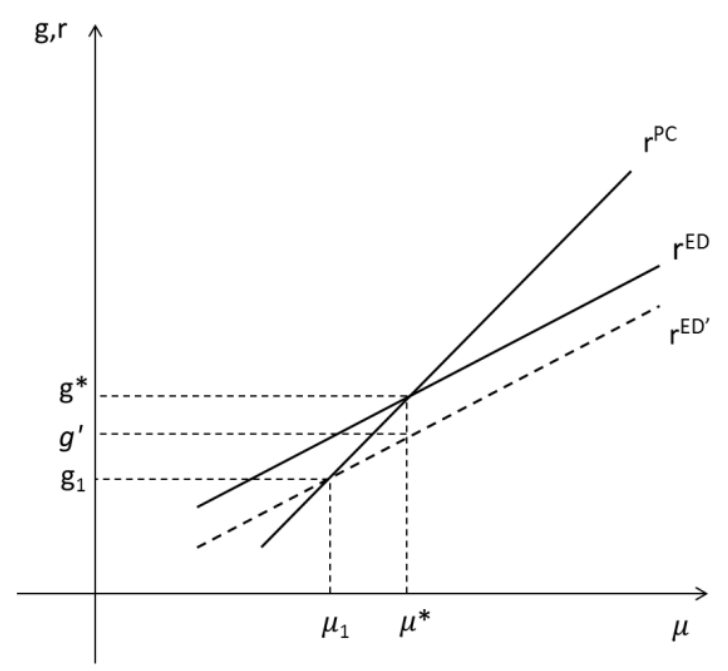

Gráfico 2.7 (b) - Paradoxo dos custos

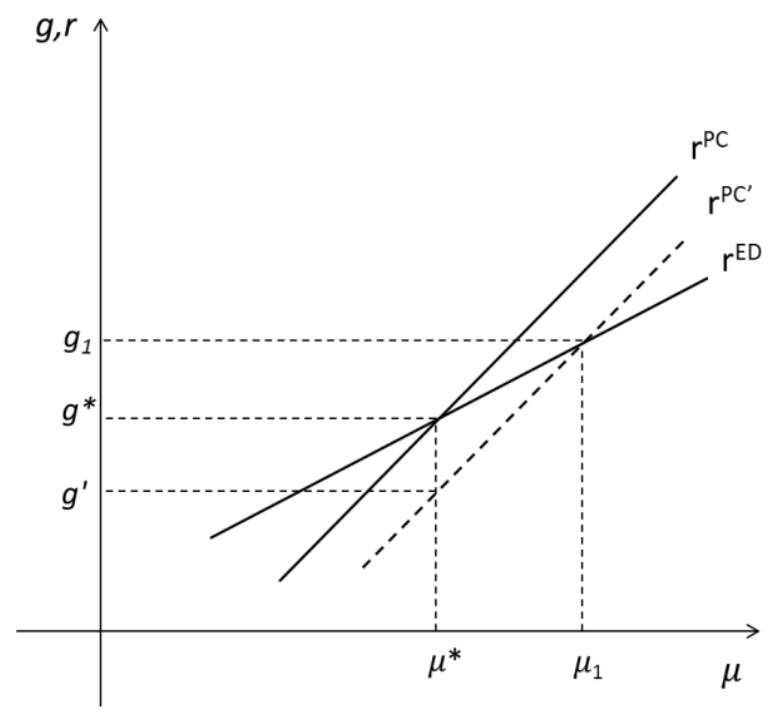

Suponha agora uma redução na taxa de participação dos lucros na economia, isso resulta no deslocamento da curva de profit-cost para a direita, $r^{P C^{\prime}}$, conforme o Gráfico 2.7 (b). Assim, Ao nível $\mu^{*}$ de utilização da capacidade, taxa de realização dos lucros é superior aos custos de produção, isso é representado no gráfico pela diferença $g^{\prime}<g^{*}$. Neste caso, os empresários elevarão a capacidade produtiva ao novo nível produtivo dado por $\left(g_{1}, \mu_{1}\right)$, superior a $\left(g^{*}, \mu^{*}\right)$.

O paradoxo dos custos é interessante, pois mostra que, se todas as firmas da economia elevarem a participação dos salários no produto, isto é elevarem os salários reais, a taxa de lucro da economia, ao invés de reduzir, aumenta. 
If a single firm raises real wages and reduces its costing margins, everything else being equal, it will obviously make less profit and it will face a reduction in its profit rate (unless there are wage efficiency effects). But if all firms increase their real wages together, this will generate a higher rate of capacity utilization for the whole economy, and, through the induced effects, linked to a sort of accelerator effect, it will lead to a higher macroeconomic profit rate. (LAVOIE, 2014, p. 367).

Importante frisar que tanto os paradoxos da poupança quanto dos custos somente existem quando não se assume no longo prazo a plena utilização da capacidade produtiva, hipótese inicial dos keynesianos.

\subsection{RESUMO DO CAPÍTULO}

No intuito de apresentar os modelos de crescimento pós-keynesianos inicialmente expõe-se o princípio da demanda efetiva de Keynes. Mostra-se que a dedução de Keynes deste princípio é realizada no âmbito da rejeição da Lei de Say, fato este estritamente relacionado às características peculiares da moeda.

Destaca-se que o ponto de demanda efetiva de Keynes é resultado da intersecção entre as curvas de oferta e demanda, as quais dependem da expectativa de lucro dos empresários. $\mathrm{O}$ ponto de demanda efetiva é de equilíbrio, mas não é único no sentido de que a economia é atraída ao seu encontro. A todo o momento este é modificado devido à alteração nas expectativas.

A partir do principio da demanda efetiva e da independência do investimento frente à poupança decorrente deste, Harrod propôs um modelo de crescimento baseado na interação do multiplicador e do acelerador keynesiano. O objetivo de seu modelo era determinar as condições necessárias para o equilíbrio entre poupança e investimento ao longo de vários períodos, o que resultaria no estado de equilíbrio estacionário. No entanto, a partir desse modelo mostrou-se que não é possível garantir: 1) o crescimento estacionário em pleno emprego; 2) a estabilidade do crescimento.

Domar, por sua vez, não almejou desenvolver uma teoria do crescimento, mas sim apresentar um modelo que contivesse as condições necessárias para manutenção infinita da igualdade entre demanda e oferta à pleno emprego. As fragilidades do modelo de Domar são semelhantes ao modelo de Harrod. De toda forma, a metodologia por ele utilizada foi importante para o desenvolvimento da teoria keynesiana de crescimento e distribuição.

Kaldor e Pasinetti expandem os modelos de tradição keynesiana introduzindo a distribuição funcional da renda. Ambos deduzem o que ficou denominado de equação de 
Cambridge, esta afirma que a taxa de lucro e a participação dos lucros no produto (profit share) são determinados pelo investimento. O resultado de Pasinetti é particularmente interessante, pois, ao contrário de Kaldor, ele assume que os trabalhadores possuem participação nos lucros ${ }^{38}$. No entanto, no longo prazo é somente a poupança dos capitalistas que influencia na determinação da taxa de lucro e do profit share, resultado semelhante ao obtido por Kaldor.

Robinson adiciona aos modelos de tradição keynesiana a função investimento, nos autores citados anteriormente o investimento é dado. De modo original, Robinson resolve a seguinte circularidade: o investimento determina a taxa de lucro, mas é determinado pela própria taxa de lucro. A solução de Robinson consistiu em adotar o investimento como função da taxa de lucro esperada pelos empresários, ou seja, ela endogenizou a taxa de lucro.

Uma das peculiaridades dos modelos de Kaldor, Pasinetti e Robinson é assumir o produto de longo prazo dado, isto é, eles assumem a plena utilização da capacidade produtiva. Assim, apesar dos modelos apresentarem o paradoxo da poupança, no longo prazo como a economia encontra-se em pleno emprego, a Lei de Say retoma a validade. Este resultado é extremamente curioso para ocorrer em modelos de tradição keynesiana.

A fragilidade dos modelos keynesianos é superada nos modelos kaleckianos, os quais incluem a utilização da capacidade como determinante da taxa de investimento. Isto é, endogeniza-se a taxa de utilização da capacidade, o que abre a possibilidade de não haver plena utilização da capacidade produtiva no longo prazo. Diante dessa hipótese mostraram-se dois importantes resultados do modelo kaleckiano: 1) paradoxo da poupança; 2) paradoxo dos custos.

Apesar de esses paradoxos serem compatíveis com a teoria keynesiana é interessante observar as diferenças e semelhanças entre os modelos. Em ambos percebe-se que a curva de "oferta" está relacionada aos custos de produção. No caso de Keynes, esta corresponde à renda esperada que é suficiente para arcar com estes custos. Conforme destaca Asimakopulos (1991), Keynes utiliza a renda, pois esta é agregada, já os preços são específicos para cada produto. Kalecki, por sua vez, não utiliza variáveis expectacionais, ao contrário, adota uma firma representativa em mercado de concorrência imperfeita e assume que os preços são determinados por mark up sobre os custos. Com relação à curva de demanda, novamente em ambos vê-se que ela depende do investimento, o qual para Keynes é determinado pela receita

\footnotetext{
${ }^{38}$ Kaldor (1956) também assume a possibilidade da poupança dos trabalhadores ser positiva, no entanto, não reconhece que isto levaria aos trabalhadores serem proprietários de bens de capital juntamente com os capitalistas.
} 
esperada e para Kalecki é determinado pelo lucro (receita) e pela taxa de utilização da capacidade.

Retornando a discussão proposta na introdução deste trabalho, percebe-se que no modelo kaleckiano não há menção a preços normais e taxas normais de lucro, as quais determinariam a taxa de utilização normal da capacidade. Além disso, as posições de longo prazo propostas por Kalecki não correspondem a estágios estacionários determinados ex-ante. A cada modificação em $s_{p}$ e $h$, a demanda efetiva varia e consequentemente altera-se a taxa de crescimento da economia. Não há, portanto centro de gravitação predeterminado da economia.

As conceituações do centro de gravitação provêm dos autores clássicos (Smith, Ricardo e Marx) sendo retomado na escola neo-ricardiana. No próximo capítulo discute-se esse conceito e destaca-se que a aproximação entre os modelos neo-ricardianos e Kaleckianos dependerá da interpretação da taxa de lucro. 


\section{CAPÍTULO 3 - A PERSPECTIVA NEO-RICARDIANA}

\subsection{INTRODUÇÃO}

A escola neo-ricardiana é conhecida por retomar os princípios clássicos de produção e realização do excedente. Em geral, o foco de sua análise é o comportamento da economia no longo prazo, em particular, como se promove e se sustenta a acumulação e de que modo se distribui entre as classes sociais a renda gerada na economia. $\mathrm{Na}$ introdução deste trabalho estão elencados os argumentos que compõem o estereótipo da teoria neo-ricardiana.

O presente capítulo pretende expor os princípios em que os modelos kaleckianos e neo-ricardianos são convergentes, de modo a analisar à possibilidade de síntese entre ambos. Nesse intuito, discute-se o modelo de mudança estrutural de Pasinetti, importante autor neoricardiano. A expansão da análise de modelos unissetoriais para multissetoriais incorpora resultados que serão apropriados neste e nos demais capítulos.

Além desta breve introdução, a segunda seção deste capítulo apresenta o conceito de preço natural introduzido pelos clássicos e apropriado pelos neo-ricardianos. A terceira seção discute como os preços naturais são interpretados por diversos autores neo-ricardianos. Verifica-se que existem interpretações que se aproximam do modelo kaleckiano e outras que se distanciam deste, nestas últimas se destacam a interpretação das variáveis normais como correspondente à expectativa dos agentes econômicos. Na apresentação formal desta interpretação verifica-se que a taxa de lucro normal pode ser representada pela participação dos lucros no produto, que resulta no modelo pós-kaleckiano.

A quarta seção discorre sobre o modelo multissetorial de Pasinetti. Inicialmente apresentam-se suas características gerais destacando o caráter pré-institucional, a integração vertical e o sistema econômico natural. Posteriormente seguem-se quatro subseções que discorrem sobre o modelo de produção estático e em crescimento constante, e o modelo de puro trabalho estático e com crescimento. Não se discute o papel do progresso tecnológico neste capítulo, pois o mesmo não foi considerado na exposição do modelo kaleckiano realizada no capítulo anterior. Dentre os importantes resultados obtidos deste modelo multissetorial destaca-se a qualificação apresentada por Pasinetti para a taxa de lucro natural.

$\mathrm{Na}$ quinta seção apresenta-se o comportamento do modelo kaleckiano caso a taxa de lucro fosse interpretada pela taxa de lucro natural de Pasinetti. Por fim, na sexta seção são apresentados os principais resultados deste capítulo. 


\subsection{PREÇOS DE MERCADO E PREÇOS NATURAIS NOS CLÁSSICOS (SMITH, RICARDO E MARX)}

Segundo Smith, os preços das mercadorias são determinados pela soma dos salários, lucros e renda da terra, sendo a taxa média de lucros e salários determinada pelas condições gerais da sociedade. A taxa média da renda da terra por sua vez é determinada pela fertilidade da terra. Tais taxas médias para Smith consistem nas taxas naturais de lucro, salário e renda da terra, as quais variam de acordo com a alteração das condições gerais da economia.

Essas taxas comuns ou médias podem ser denominadas taxas naturais dos salários, do lucro e da renda da terra, no tempo e lugar em que comumente vigoram (SMITH, A., 1983, p.83).

Sob a taxa natural, a mercadoria seria vendida pelo seu preço natural. Smith reconhece que, apesar do preço de mercado, determinado pela oferta e demanda, poder ser diferente do preço natural, existe tendência à convergência, de tal forma que o preço de mercado gravita em torno do preço natural.

(...) o preço natural é como que o preço central ao redor do qual continuamente estão gravitando os preços de todas as mercadorias. Contingências diversas podem, às vezes, mantê-los bastante acima dele, e noutras vezes, força-los para baixo desse nível. Mais, quaisquer que possam ser os obstáculos que os impeçam de fixar-se nesse centro de repouso e continuidade, constantemente tenderão para ele. (SMITH, A., 1983, p. 85).

Dado que as taxas naturais variam, Smith observa que os preços naturais também variam:

O próprio preço natural varia conjuntamente com a taxa natural de cada um dos componentes: salários, lucro e renda da terra; e em cada sociedade, essa taxa varia de acordo com as circunstâncias, sua riqueza ou pobreza, sua condição de economia e progresso, estacionária ou declinante. (SMITH, 1983, p. 89).

Ricardo apesar de tecer críticas à determinação dos $\operatorname{preços}^{39}$ (teoria do valor) em Smith concorda plenamente com a sua conceituação do preço natural: "no capítulo VII de $A$

\footnotetext{
39 "Adam Smith, que definiu com tanta exatidão a fonte original do valor de troca, e que coerentemente teve que sustentar que todas as coisas se tornam mais ou menos valiosas na proporção do trabalho empregado para produzi-las, estabeleceu também outra medida de valor, e se refere a coisas que são mais ou menos valiosas segundo sejam trocadas por maior ou menor quantidade dessa medida-padrão. Como medida-padrão ele se refere algumas vezes ao trigo, outras ao trabalho; não à quantidade de trabalho empregada na produção de cada objeto, mas à quantidade que este pode comprar no mercado (.....). Se isso fosse verdadeiro, se a remuneração do trabalhador fosse sempre proporcional ao que ele produz, a quantidade de trabalho empregada numa mercadoria e a quantidade de trabalho que essa mercadoria compraria seriam iguais, e qualquer delas poderia medir com precisão a variação de outras coisas. Mas não são iguais. A primeira é, sob muitas circunstâncias, um padrão invariável, que mostra corretamente as variações nas demais coisas. A segunda é sujeita a tantas flutuações quanto as mercadorias que a ela sejam comparadas. [É correto dizer] que a quantidade comparativa de
} 
Riqueza das Nações, tudo o que se refere a essa questão é tratado com muita competência" (RICARDO, 1983, p. 70).

Assim como Smith, Ricardo identificava os preços naturais como centros em tornos dos quais gravitariam os preços de mercado. No entanto, Ricardo explicita que a tendência à convergência dar-se-ia devido à concorrência entre os capitalistas. Naqueles setores em que o preço de mercado fosse superior ao natural, haveria atração de capital ${ }^{40}$ de tal forma que o preço de mercado tenderia a cair.

(...), é desejo de todo capitalista transferir seus fundos de uma atividade menos lucrativa, o que impede o preço das mercadorias de permanecer por algum tempo muito acima ou muito abaixo do preço natural. (RICARDO, 1983, p. 78-79).

Essa tendência à equalização da taxa de lucro entre os diversos setores da economia em Ricardo é acatada por Marx (1984). De acordo com Marx, independentemente da forma de determinação dos preços de mercado, é a lei do valor trabalho que determina a sua tendência.

A suposição de que as mercadorias das diversas esferas de produção se vendem por seus valores só significa, naturalmente, que seu valor é o centro de gravitação em torno do qual giram seus preços e em relação aos quais suas contínuas altas e baixas se compensam. (MARX, 1984, p. 138).

Essa tendência dos preços gravitarem em torno de seus valores naturais é apropriada dos clássicos pelos neo-ricardianos.

\subsection{O MODELO NEO-RICARDIANO}

A partir da teoria clássica, os neo-ricardianos trabalham com os conceitos de preço natural, taxa de utilização natural da capacidade e taxa de crescimento natural. Tais taxas naturais, como visto, seriam o centro de gravitação ao qual a economia tenderia, isto é, elas possuiriam força de atração.

Thus, all that theory can do to account for market prices - i.e the objectively observable prices - is to account for the natural prices which represent their centers of gravitation. This amounts to accounting for the basic trend in

\footnotetext{
mercadorias que o trabalho produzirá é que determina o valor relativo delas, presente ou passado, e não as quantidades comparativas de mercadorias que são entregues ao trabalhador em troca de seu trabalho" (RICARDO, 1983, p. 44-46).

${ }^{40}$ Ricardo pressupõe que o mesmo capital pode ser deslocado e inserido em outros processos produtivos. Os neokeynesianos e neo-ricardianos, apesar de pressuporem a equalização da taxa de lucro entre os diversos setores no longo prazo, não admitem que o mesmo capital possa ser inserido em diversos processos, pelo contrário, para eles cada setor é único. No entanto, as diferentes rentabilidades fazem com que o volume de investimentos em cada setor equalize as taxas de lucro.
} 
market prices, if so we may call that component of their trend that does not tend to correct itself in the course of time (VIANELO, 1989, p. 98).

(...) approximate compensation for divergences of market from natural prices will inevitably be observed, on the one direction that a sufficiently long observation period is allowed for (VIANELO, 1989, p. 104).

Sob essa perspectiva, a economia tenderia à posição de equilíbrio em que os preços seriam os preços naturais ${ }^{41}$, a taxa de utilização da capacidade produtiva seria a natural e os lucros seriam os naturais. Nesta posição de pleno ajuste (VIANELO, 1985), o produto é determinado pelo princípio da demanda efetiva e varia de modo a ajustar a poupança ao investimento. Não há, portanto, papel a ser desempenhado pela taxa de utilização da capacidade produtiva no longo prazo (WHITE, 1989).

Esta interpretação corresponde a assumir $\mu=1$ conforme praticado pelos primeiros pós-keynesianos. Nesse caso, há sistêmica relação inversa entre a taxa de acumulação e o salário real. Por exemplo, suponha que ocorra aumento da demanda, como $\mu=1$ haverá elevação dos preços, consequentemente queda do salário real e elevação das taxas de lucros. Esta é a reconhecida fronteira entre lucros e salários dos sraffianos proveniente da barreira inflacionária $^{42}$ (KURZ, 1986).

Kurz (1986) qualifica $\mu=1$ como a posição que resulta do sistema de minimização dos custos por parte dos empresários.

The normal position of the economy is defined in terms of the costminimizing system of production of given levels of output (KURZ, 1986, p. 44).

A abordagem neo-ricardiana apresentada claramente diverge do modelo kaleckiano proposto no capítulo anterior. Como exposto, para Kalecki a taxa de utilização da capacidade é variável endógena no longo prazo. Deste modo, não pode ser dada ex-ante. Esta endogeneidade, como destacado, decorre de dois elementos institucionais (AMADEO, 1986): a) reconhecimento de que as firmas operam em mercados oligopolizados e por isso tendem a evitar a variação dos preços; b) em mercados oligopolizados as firmas tendem a utilizar a taxa de utilização da capacidade como variável central para as decisões de curto prazo e longo prazo.

Quando Kalecki assume a existência de mercados oligopolizados, não significa que as firmas não minimizam os custos. A adoção de $\mu<1$ não está relacionada à técnica utilizada

\footnotetext{
${ }^{41}$ Este preço seria aquele necessário para estimular a produção e venda da mercadoria. Segundo Marx (1983), o preço natural é aquele que abaixo dele no longo prazo a produção da mercadoria é descontinuada.

${ }^{42}$ Esta barreira inflacionária é semelhante à proposta por Robinson, conforme descrito no capítulo anterior.
} 
na produção, mas sim faz parte das estratégias das firmas frente à possível elevação da demanda e também como barreira à entrada.

Tem-se, assim, que as propostas de Kurz (1986), Vianelo (1989) e White (1989) distanciam o modelo neo-ricardiano do kaleckiano, e por sua vez aproximam-se do modelo pós-keynesiano, o que não é o objetivo deste trabalho. Esta divergência é remediada por Ciccone (1986), que, apesar de reconhecer o longo prazo como centro de gravitação dos preços e quantidades, afirma que os preços e quantidades realizados diferem daquelas em que as expectativas são realizadas. Ou seja, para Ciccone (1986) as variáveis normais correspondem às expectativas dos agentes computadas a partir do que é definido por cada agente como preço, taxa de utilização e lucro normal.

Nesse interim, o longo prazo representa o período de tempo necessário para que os preços e quantidades gravitem em torno dos seus valores normais (esperados). Esta definição torna-se explícita ao se definir a taxa de utilização normal da capacidade. Para Ciccone (1986) esta corresponde à taxa de utilização da capacidade esperada para uma nova planta produtiva a ser instalada, que por sua vez depende dos lucros esperados para determinados níveis de demanda.

The degree of utilization that is relevant for long-period prices seems to be that expected for newly installed capacity which need not necessarily coincide with the degree of utilization actually realized with the existing stock of capacity (CICCONE, 1986, p. 24).

Como a taxa de utilização da capacidade determina os lucros realizados, se aquela for diferente da normal, esta também será. Assim, dado que as expectativas variam ao longo do tempo, há path dependence no que diz respeito aos preços e quantidades normais.

In short, the profits realized per unit of capital depend not only on the level of real wage and on technical conditions, but also on the actual utilization of capacity (CICCONE, 1986, p. 34).

(...) it is plausible that the average expected utilization for equipment of the desire size is to a large extent estimated on the basis of the utilization of capacity experienced in the past (CICCONE, 1986, p. 36).

Elimina-se assim, a hipótese de existência da taxa normal de longo prazo prédeterminada.

In general, the actual degree of capacity utilization influences the path of productive capacity and output: whenever the current and the normal degree of capacity utilization differ, ex post realized profits will be affected, and this will affect financing conditions, which in turn may affect investment expenditures, and hence the expansion of productive capacity, as well as technology (...) on the other hand, the current level of investment expenditures will affect aggregate demand, and hence the current level of capacity utilization (RONCAGLIA, 1995, p. 119). 
A interpretação de Ciccone (1986) e Roncaglia (1995) aproxima-se das críticas que Dupertuis e Sinha (2009) fazem à noção de centro de gravitação. Para esses autores a economia não tende as taxas naturais pelos seguintes motivos: a) dada a complexa estrutura de insumos e produtos, não há como prever que os lucros irão variar de acordo com os preços; b) o mecanismo clássico de ajuste apenas inicia-se depois que os preços tenham atingido o seu máximo e mínimo devido aos excessos iniciais de demanda e oferta; c) mesmo que a oferta se ajuste à demanda, nada garante que as taxas de lucro serão as mesmas em todos os setores.

A aproximação de Ciccone e Roncaglia com o modelo kaleckiano do capítulo anterior é evidente. No entanto, percebe-se que para os neo-ricardianos é a distribuição que determina a acumulação e não o contrário, conforme proposto pelos keynesianos. Além disso, não é a taxa de lucro atual kaleckiana que possui impacto na taxa de acumulação, mas sim a taxa de lucro normal para cada setor.

Representando formalmente o modelo neo-ricardiano têm-se as equações (2.46), (2.49), (2.54) e (2.56). Observa-se que a curva de profit-cost é semelhante a do modelo kaleckiano, isso ocorre, pois se adota os mesmos pressupostos: validade do princípio da demanda efetiva, firma representativa, mercado oligopolizado e preços determinados pelo mark up dos custos.

Como o investimento depende do lucro esperado a preços normais tem-se:

$$
\mathrm{g}=\alpha+\beta r_{n}+\gamma \mu
$$

Onde $r_{n}=$ lucro normal ${ }^{43}$. A partir de (3.1) percebe-se que para os neo-ricardianos a curva de realização dos lucros, $\mathrm{r}^{\mathrm{ED}}$, é diferente da obtida no modelo kaleckiano, pois agora a taxa de lucro realizada depende da taxa de lucro normal (esperada) pelos empresários. Esta curva é obtida ao se igualar (2.46) e (3.1):

$$
r^{E D}=\frac{\alpha}{s_{p}}+\frac{\beta r_{n}}{s_{p}}+\frac{\gamma \mu}{s_{p}}
$$

Igualando (3.2) a (2.56) tem-se em equilíbrio:

\footnotetext{
${ }^{43}$ Alguns autores, como Amadeo (1986), com o intuito de integrar as escolas keynesiana/kaleckiana com a neoricardiana, faz uso da função investimento $\mathrm{g}=\alpha+\gamma\left(\mu-\mu_{n}\right)$, pois, como observado, variações em $\mu$ afetam $\mathrm{r}$ de maneira semelhante. No entanto, esta não é boa abordagem, pois devido ao path dependance espera-se que $\mu_{n}$ varie com $\mu$. Além disso, a função não faz sentido se $\mu<\mu_{n}$, pois neste caso pode ocorrer $\mathrm{g}<\alpha$.
} 


$$
\begin{gathered}
\mu^{*}=\frac{\alpha+\beta r_{n}}{s_{p}\left(\frac{h}{v}\right)-\gamma} \\
\mathrm{r}^{*}=\frac{\left(\frac{h}{v}\right)\left[\alpha+\beta r_{n}\right]}{s_{p}\left(\frac{h}{v}\right)-\gamma} \\
\mathrm{g}^{*}=\frac{s_{p}\left(\frac{h}{v}\right)\left[\alpha+\beta r_{n}\right]}{s_{p}\left(\frac{h}{v}\right)-\gamma}
\end{gathered}
$$

Assim como no modelo da seção anterior, a condição de estabilidade é dada por $s_{p}>$ $\frac{\gamma v}{h}$. O exercício de estática comparativa resulta em:

$$
\begin{gathered}
\frac{d g^{*}}{d s_{p}}=-\frac{\gamma \frac{h}{v}\left(\alpha+\beta r_{n}\right)}{\left[s_{p} \frac{h}{v}-\gamma\right]^{2}}<0 \\
\frac{d g^{*}}{d r_{n}}=\frac{s_{p}\left(\frac{h}{v}\right) \beta\left[s_{p}\left(\frac{h}{v}\right)-\gamma\right]}{\left[s_{p}\left(\frac{h}{v}\right)-\gamma\right]^{2}}>0
\end{gathered}
$$

O paradoxo da poupança continua válido, (3.5.1), e o resultado (3.5.2) nos fornece que, quanto maior a taxa de lucro normal, maior será a taxa de acumulação. Ou seja, neste modelo não há garantia de validade do paradoxo dos custos. Assim, se todos os empresários aumentarem o wage share, a consequente redução do profit share fará com que a taxa de lucro normal (esperada) da economia se reduza, tal fato reduzirá consequentemente a taxa de realização dos lucros. Lembra-se que para os neo-ricardianos é a taxa de lucro que determina a taxa de acumulação.

A ausência do paradoxo dos custos é visualizada no Gráfico 3.1. Suponha a ampliação do wage share, a elevação do consumo fará com que aumente a taxa de utilização da capacidade produtiva. Isso resulta no deslocamento das duas curvas, a de profit cost e a efective demand. A primeira desloca-se para a direita, $r^{P C^{\prime}}$, devido à ampliação dos custos de produção, e a segunda desloca-se para baixo, devido à redução da taxa de lucro normal, $\mathrm{r}^{\mathrm{ED}}$ '. No caso, (3.5.2) mostra que o deslocamento de $\mathrm{r}^{\mathrm{ED}}$ ' será superior ao de $r^{P C \prime}$. Assim, o novo nível de equilíbrio $\left(g_{1}, \mu_{1}\right)$ inferior será inferior ao nível inicial $\left(g^{*}, \mu^{*}\right)$. 
Gráfico 3.1 - Paradoxo dos custos no modelo neo-ricardiano

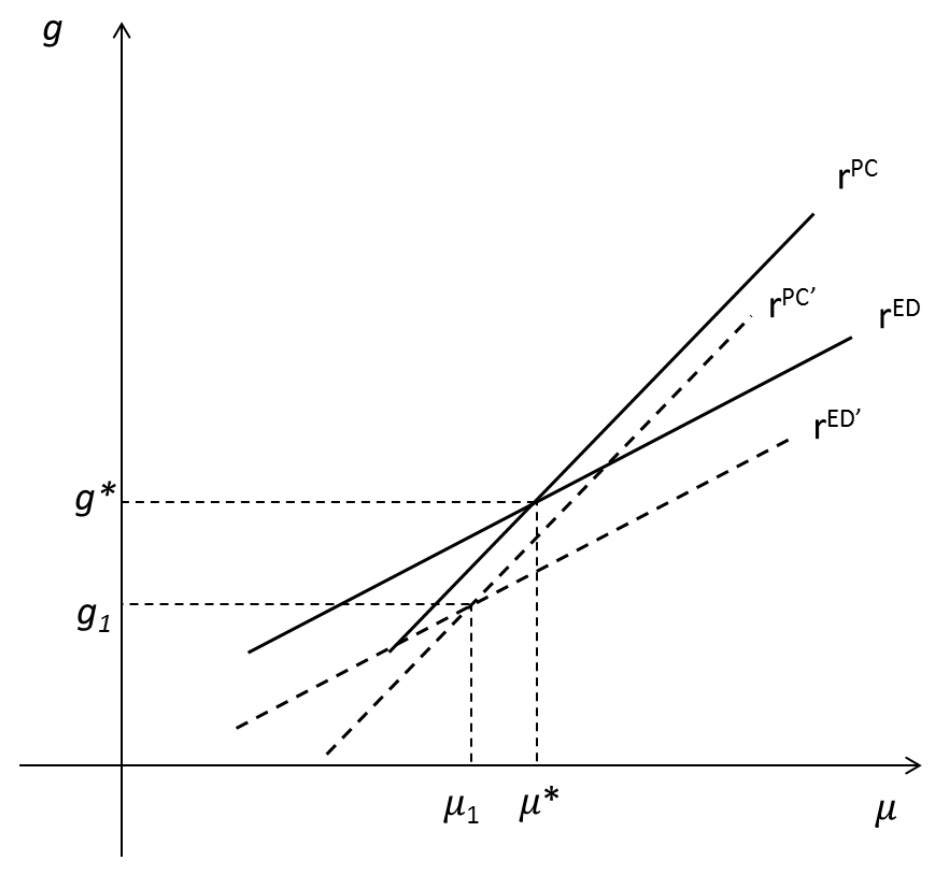

No argumento descrito para explicar o Gráfico 3.1 utiliza-se da relação entre o profit share e a taxa de lucro normal. Como a taxa de lucro normal é a taxa de lucro esperada pelos neo-ricardianos, na verdade está se considerando que a taxa de lucro normal corresponde à participação dos lucros na economia a partir da taxa normal de utilização da capacidade.

The normal rate of profit is the profit rate that will be achieved for a given mark-up (and thus for a given profit share in an economy without overhead labor costs) when the economy is running at its normal rate of capacity utilization (LAVOIE, 2014, p. 372).

The justification for this is that entrepreneurs cannot make future plans under the assumptions that capacity will be perpetually overutilised (LAVOIE, 1995, p. 796).

Utilizando a notação do capítulo anterior tem-se:

$$
r_{n}=\frac{\Pi}{K}=\frac{\Pi}{q} \frac{q}{q_{f c}} \frac{q_{f c}}{K}=\mathrm{h}\left(\frac{\mu}{v}\right)
$$

Se interpretar-se $r_{n}=\left(\frac{h}{v}\right)$, a taxa de lucro normal será igual à margem de lucro (profit share) e o modelo neo-ricardiano torna-se semelhante ao proposto por Bhaduri e Marglin (1990), no qual: 


$$
\mathrm{g}=\alpha+\beta h+\gamma \mu
$$

O objetivo de Bhaduri e Marglin era reconciliar o argumento do esmagamento dos lucros (profit squeeze) com o princípio da demanda efetiva ${ }^{44}$. O primeiro é decorrente da combinação entre a elevação dos salários e a queda da produtividade. Esta queda dos lucros por sua vez gera dois efeitos sobre o crescimento do estoque de capital (investimento): 1) redução da renda acumulada; 2) redução dos lucros esperados pelos empresários.

O segundo argumento está relacionado ao paradoxo da poupança no modelo kaleckiano. Devido ao princípio da demanda efetiva, a ampliação dos salários elevará o gasto dos trabalhadores e consequentemente ampliará a taxa de utilização da capacidade, deste modo o efeito negativo do esmagamento dos lucros sobre o investimento poderá ser sobreposto pelo efeito positivo da ampliação da capacidade produtiva.

Para promover essa reconciliação, Bhaduri e Marglin (1990, 1995) utilizam-se da equação (3.7) em que o investimento é função da participação dos lucros no produto e da taxa de utilização da capacidade produtiva. $\mathrm{O}$ argumento dos autores envolve a equação (3.6), pois, se a taxa de lucro (r) for constante, certa elevação na taxa de utilização da capacidade $(\mu)$ implica necessariamente na redução da participação dos lucros no produto $(\mathrm{h})^{45}$. No entanto, é de se esperar que a queda no profit share afete negativamente as decisões de investimento, e, em algumas situações, este efeito negativo pode se sobrepor ao efeito positivo decorrente da ampliação da taxa de utilização da capacidade produtiva.

Bhaduri e Marglin, as well as Vianello, argue that kaleckians have omitted the depressing costs effects on economic activity [...], if the rate of profit is to be taken into consideration in addition to the rate of capacity utilization, it should be calculated at the normal rate of utilization (LAVOIE, 1995, p. 798).

Diante desta interpretação, os novos pontos de equilíbrio são obtidos a partir de (3.2), (2.56), (3.6) e (3.7):

$$
\begin{gathered}
\mu^{*}=\frac{\alpha+\beta r_{n}}{s_{p} r_{n}-\gamma} \\
\mathrm{r}^{*}=\frac{r_{n}\left[\alpha+\beta r_{n}\right]}{s_{p} r_{n}-\gamma}
\end{gathered}
$$

\footnotetext{
${ }^{44}$ Bhaduri e Marglin observaram que nos países desenvolvidos, a partir da década de 1970 a massa de salários na economia estava aumentado, mas isso não estava resultando em crescimento econômico.

${ }^{45}$ Dado $v$ unitário.
} 


$$
\mathrm{g}^{*}=\frac{s_{p} r_{n}\left[\alpha+\beta r_{n}\right]}{s_{p} r_{n}-\gamma}
$$

A condição de estabilidade é dada por $s_{p}>\frac{\gamma}{r_{n}}$, e os exercícios de estática comparativa nos fornecem:

$$
\begin{gathered}
\frac{d g^{*}}{d s_{p}}=-\frac{\gamma r_{n}\left(\alpha+\beta r_{n}\right)}{\left[s_{p} r_{n}-\gamma\right]^{2}}<0 \\
\frac{d g^{*}}{d r_{n}}=\frac{s_{p}\left(\beta r_{n}-\mu \gamma\right)}{s_{p} r_{n}-\gamma} \geq 0
\end{gathered}
$$

A equação (3.10.1) mostra que, assumindo a taxa de lucro normal igual ao profit share, o paradoxo da poupança continua válido, no entanto, o resultado interessante é fornecido por (3.10.2), pois esta equação não possui resultado pré-definido. Se $\beta r_{n}>\mu \gamma$, a ampliação da margem de lucro eleva a taxa de acumulação, agora, se $\beta r_{n}<\mu \gamma$, a ampliação da margem de lucro reduz a taxa de acumulação.

Os dois possíveis resultados indicados por (3.10.2) são visualizados no Gráfico 3.2. Suponha a elevação de $r_{n}$, isso significa que a curva de profit cost irá se elevar, e, portanto, se deslocará para a esquerda, de $r^{P C}$ para $r^{P C \prime}$. Mas, como $r_{n}$ afeta positivamente a curva de realização dos lucros, a curva $r^{E D}$ também irá se deslocar para a esquerda. Se for para $r^{E D \prime}, o$ novo ponto de equilíbrio $\left(g_{1}, \mu_{1}\right)$ é inferior ao nível inicial $\left(g^{*}, \mu^{*}\right)$. Isso significa que $\beta r_{n}<\mu \gamma$. Mas, se o deslocamento for para $r^{E D \prime \prime}$, o novo ponto de equilíbrio $\left(g_{2}, \mu_{2}\right)$ será superior ao nível inicial $\left(g^{*}, \mu^{*}\right)$, ou seja, $\beta r_{n}>\mu \gamma$. 
Gráfico 3.2 - Regimes de crescimento profit-led e wage-led

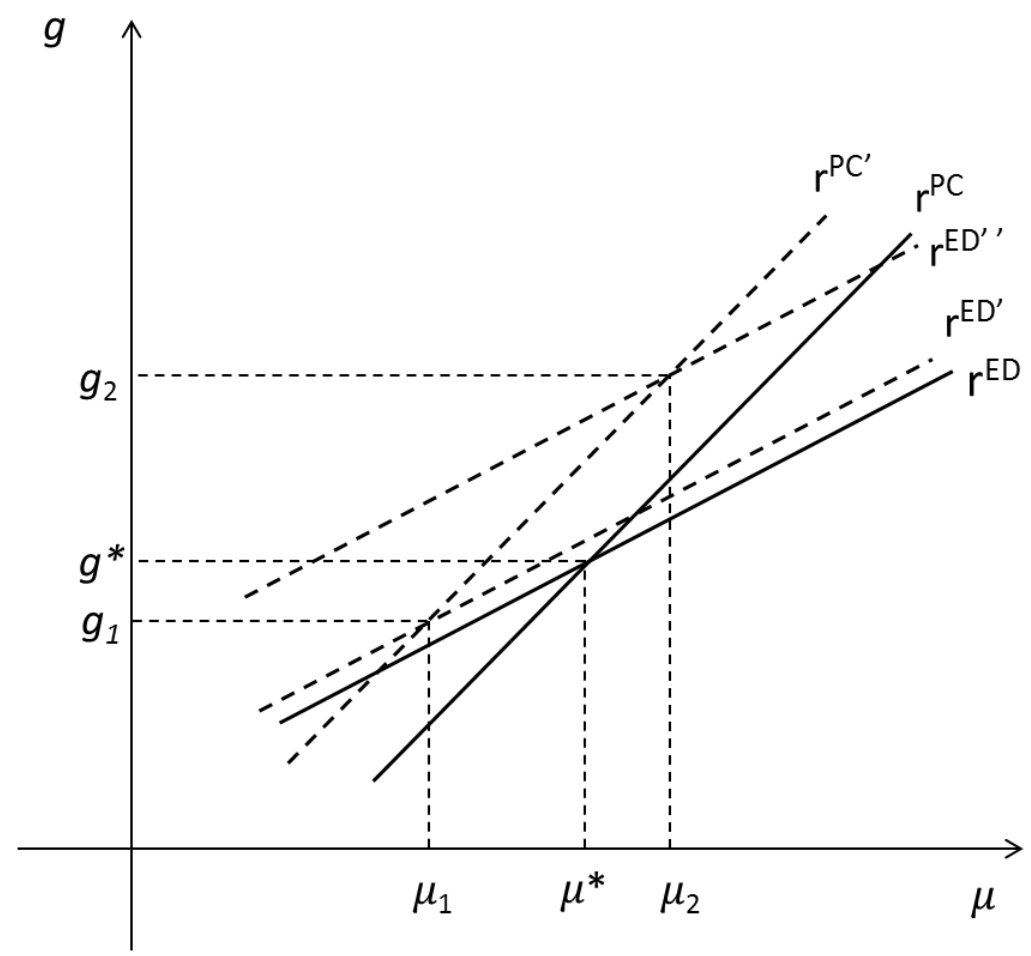

Esses diferentes efeitos foram classificados por Bhaduri e Marglin (1990) nos seguintes regimes:

- Aceleracionista (Exhilaration): a ampliação do profit share afeta positivamente a taxa de utilização da capacidade produtiva e a taxa de crescimento do produto, caso $\left(g_{2}, \mu_{2}\right)$ do Gráfico 3.2.

- Estagnacionista (Conflicting stagnationism): a ampliação do profit share afeta negativamente a taxa de utilização da capacidade produtiva e a taxa de acumulação da economia, caso $\left(g_{1}, \mu_{1}\right)$ do Gráfico 3.2.

Na literatura (LAVOIE, 2015; LAVOIE e STOCKHAMMER, 2013; HEIN, 2015) esses dois regimes são denominados respectivamente de wage-led e profit-led, classificação a ser utilizada neste trabalho.

Interpretar a taxa de lucro normal como a participação dos lucros na renda, a partir dos preços e quantidades normais, é importante iniciativa de integração dos modelos kaleckianos e neo-ricardianos.

Those who say that the share of profit [h], rather than the actual rate of profit [r], should enter the investment function in addition to the rate of utilization of capacity are making an argument that is no different from the assertion that the normal rate of profit $\left[r_{n}\right]$, rather than the actual one, 
should be included in the investment function in addition to the rate of utilization capacity (LAVOIE, 2014, p. 372).

Essa interpretação, no entanto, suscita diversas críticas, pois para muitos autores não há relação direta entre o profit share e a expectativa de lucro. Em particular observa-se que para Kalecki ${ }^{46}$ o investimento depende dos lucros retidos e do financiamento, deste modo é de se esperar a taxa de lucro realizada como melhor indicador para a obtenção de empréstimo e não o profit share. Essas críticas direcionam-se ao encontro da conclusão de White (1989), para o qual é necessário relacionar a dinâmica da demanda e a formação de expectativas de longo prazo para desenvolver a integração dos modelos. Na próxima seção mostra-se que o modelo multissetorial de Pasinetti promove a integração entre a variação da demanda e a dinâmica de acumulação de capital no sistema econômico natural.

Independentemente das diferenças, cumpre observar importantes semelhanças entre o modelo kaleckiano e o neo-ricardiano, com destaque o reconhecimento do path dependence. Ou seja, os preços e quantidades normais não são variáveis pré-determinadas para as quais a economia tende. Isso significa que para os neo-ricardianos a análise do curto prazo é tão importante quanto a do longo prazo. Além disto, no modelo vale o princípio da demanda efetiva tão caro aos kaleckianos.

\subsection{O MODELO MULTISSETORIAL PASINETTIANO}

\subsubsection{Características gerais}

A economia capitalista é caracterizada por crescimento desbalanceado, alteração da composição da demanda e taxas de progresso tecnológico heterogêneo entre as diversas indústrias (DEPREZ, 1990). Pasinetti (1981, 1993) busca compreender essa dinâmica por meio de modelo multissetorial no qual mudanças nas magnitudes macroeconômicas estão associadas a variações na composição da economia. Isto é, associadas à dinâmica estrutural que é marcada por mutações permanentes e irreversíveis.

O modelo de Pasinetti possui três elementos fundamentais para a sua compreensão: 1) caráter pré-institucional; 2) sistema econômico natural; 3) integração vertical para representação dos diversos setores econômicos (GARBELLINE; WIKIERMAN, 2014).

A concepção pré-institucional não significa que se trata de modelo pré-industrial, ao contrário, a proposta de Pasinetti é compreender a natureza do processo de produção em

\footnotetext{
${ }^{46}$ Modelo descrito no segundo capítulo deste trabalho.
} 
qualquer sistema industrial, por isso a abstração das instituições. Tal fato demonstra o foco de Pasinetti nas características primárias e naturais ${ }^{47}$ do sistema econômico (GARBELLINE; WIKIERMAN, 2014).

It is my purpose [...] to develop first of all a theory which remains neutral with respect to the institutional organization of society. My preoccupation will be that of singling out, to resume Ricardo's terminology, the 'primary and natural' features of a pure production system (PASINETTI, 1981, p. 25).

It is a distinctive feature of the present theoretical scheme to begin by carrying out the whole analysis at the level of investigation which the classical economists called 'natural', that is to say at a level of investigation which is so fundamental as to be independent of the institutional set-up of society (PASINETTI, 1981, p. 25).

Bortis (1996) relaciona a adoção da economia pré-institucional à opção feita por Pasinetti pelo realismo metodológico. Isto é, foca-se na identificação dos princípios que resumem a essência dos fatos e não na compreensão de regularidades empíricas observadas na economia $^{48}$. Assim, o objetivo é compreender causas que movem o sistema econômico, independentemente dos desvios transitórios.

This [realism] process is, as a rule, initiated by empirical observation; subsequently, however, pure reason plays the most important role, the aim being to bring into line systematic thinking about some phenomenon with its essence as closely as possible (BORTIS, 1996, p. 139).

A proposta de representar os aspectos fundamentais da economia faz com que Pasinetti concentre-se no processo social de produção ${ }^{49}$, o modelo de 1981 estuda as relações naturais associadas à dinâmica estrutural de produção de mercadorias por meio de capital e trabalho, e o modelo de 1993 trata da economia de puro trabalho ${ }^{50}$. Abstrair das instituições não é tarefa fácil, por isso Pasinetti restringe sua análise aos requisitos físicos necessários a produção e reprodução das mercadorias (GARBELLINE; WIKIERMAN, 2014).

Conforme mencionado, o objetivo de Pasinetti é desenvolver as características naturais do sistema econômico, as quais ele denomina de "natural features of a growing economic

\footnotetext{
${ }^{47}$ Pasinetti denomina de características naturais o que os clássicos descritos na segunda seção chamavam de normais.

${ }^{48}$ Isso demonstra que Pasinetti não estava interessado em compreender fatos estilizados.

${ }^{49}$ Bortis (2013) recorrendo à Marx mostra que o processo social de produção consiste na etapa de agregação de valor existente na economia monetária de produção (ver Capítulo 2). Nesta economia o ciclo de acumulação é representado por: $\mathrm{M}-\mathrm{C}$..............' $-\mathrm{M}^{\prime}$ ', onde P: processo social de produção, M: moeda e C: mercadoria, sendo C'> C e M'> M.

${ }^{50}$ Os modelos são apresentados nas subseções seguintes.
} 
system" que consistem em: (i) estrutura de preços das mercadorias; (ii) estrutura de produção; (iii) comportamento da taxa de salários e da taxa de lucro ${ }^{51}$.

Na exposição dessas estruturas, Pasinetti destaca que a atividade humana, trabalho, constitui o elemento básico da riqueza das nações, pois é o aprendizado e o conhecimento que afetam o processo de produção e consumo ${ }^{52}$.

(...) in modern societies (and primarily in industrial societies) the wealth of a nation is found principally on the human ability to learn and to apply knowledge to the production and consumption process (PASINETTI, 2001, p. 3)

Segundo Pasinetti, a representação dos preços naturais em termos de trabalho consiste na representação "justa" 53 do valor das mercadorias:

The natural interest appears to be just, because it is precisely that particular amount of purchasing power that, once added to the amount of the loan, makes the latter capable to by inter-temporally (that is, at each point of time) the same quantities of labour as the corresponding ones that were lent at the beginning (PASINETTI, 2001, p. 6)

Dado o caráter pré-institucional e o foco nas características naturais ${ }^{54}$, Gurlezi (1996) observa que o modelo multissetorial de Pasinetti resulta no sistema que lida exclusivamente com os requisitos para o pleno emprego, de tal forma que a mudança estrutural é analisada no âmbito de um modelo de crescimento em equilíbrio. No entanto, é importante qualificar o conceito de crescimento em equilíbrio de Pasinetti, pois dadas as mudanças estruturais o equilíbrio não representa a "posição normal" para o qual a economia tende para o longo prazo, mas sim, como será destacado nas próximas seções, consiste na posição em que ocorre pleno emprego e pleno gasto da renda.

Equilibrium growth, however, entails neither the identification of a "normal position' towards which the system tends in the long run - since the very structural dynamics of the economic system makes it impossible to identify a 'normal position' persistent enough to the continuous changes in the system's proportions - nor a logical secession of temporary equilibria spontaneously realized (GARBELLINE; WIKIERMAN, 2010, p. 47).

\footnotetext{
${ }^{51}$ Estes três componentes do sistema natural são apresentados na próxima subseção que trata do modelo formal proposto por Pasinetti.

52 O reconhecimento da essência do trabalho na representação da riqueza faz com que Pasinetti (1993) desenvolva o modelo de puro trabalho. Nesta tese, para os objetivos propostos, trabalhamos com os dois modelos.

${ }^{53}$ Essa discussão sobre o preço justo é realizada por Pasinetti em resposta à Malinvaud (2002), que discute validade ou não do pagamento de juros de acordo com a doutrina da igreja.

54 “(...) how important it is not to confuse the type of problems that concern the natural economic system and the type of problems that relate to the institutional mechanism which characterize any society. The former deal with logical relations, or end results, valid in themselves, independently of anything else." (PASINETTI, 1981, p. 153).
} 
Tem-se, assim, que o pleno emprego é atributo do sistema natural e não condição metodológica. Isso diferencia o sistema natural de Pasinetti dos clássicos apresentados na primeira seção, pois nestes a posição natural estaria associado ao longo prazo e à concorrência entre as firmas ${ }^{55}$ (GURLEZI, 1996).

A terceira característica fundamental do modelo de Pasinetti é a integração vertical dos diversos setores econômicos. Esta é utilizada como forma de apresentação do sistema econômico, no qual o ponto de referência é o vetor de demanda final e todas as interpelações precedentes se resumem aos coeficientes físicos de trabalho e de capacidade produtiva ${ }^{56}$. $\mathrm{O}$ primeiro refere-se à integração vertical do trabalho aplicado na produção das mercadorias e o segundo à integração vertical dos bens de capital (vertical integrated productive capacity). Os últimos representam uma mercadoria composta por diferentes proporções dos bens de capital utilizados na produção de uma unidade do bem de consumo final.

There is therefore a specific physical unit of productive capacity for each final good that is produced in the economic system. Of course a unit of productive capacity is, in an ordinary sense, a very composite physical commodity: it is made up of different types of physical goods in different proportions (PASINETTI, 1981, p. 36).

Importante frisar que a integração vertical é utilizada por Pasinetti como forma de representação da realidade e não descrição desta. Além disso, a integração vertical não consiste na segunda etapa após a compreensão das relações interindustriais. Como Pasinetti (1990) observa, o conceito de integração vertical é independente das variações tecnológicas interindustriais.

For many problems, we may well carry out vertically integrated investigations without having to bother about their inter-industry relations background. The important implication is that any change (owing to technical progress) of the inter-industry relations [...] does not invalidate the vertically integrated concepts (PASINETTI, 1990, p. 67).

Dado que o objetivo da análise da mudança estrutural é identificar as relações causais entre as variáveis fundamentais da economia, a integração vertical facilita esse processo, pois permite selecionar os diversos subsistemas que compõem o sistema econômico e assim identificar as transações intermediárias entre os setores produtivos e precisar as mercadorias (estoques) e a renda (fluxo) que compõem o excedente gerado na economia.

The identification and analytical utilization of subsystems are essential steps in the analysis of the transformation process of any given economic

\footnotetext{
${ }^{55}$ É importante lembrar que a concorrência entre as firmas é uma característica institucional da economia.

56 "It takes each physical quantity in the final demand vector as the point of reference, and collapses all the interrelations that are behind it simply into a physical labor coefficient and a physical unit of productive capacity" (PASINETTI, 1990, p.65).
} 
structure, since the consideration of subsystems makes it possible to deal analytically with a casual mechanism in which different parts of the economic system get transformed at different speeds, while the repercussions of change are transmitted from one subsystem to another (SCAZZIERI, 1990, p. 26).

Outra vantagem da integração vertical é a possibilidade de trabalhar com várias unidades agregadas de capital desde que haja bens finais no sistema econômico. Elimina-se assim a dificuldade encontrada para mensuração do capital, uma vez que este não é independente da distribuição da renda e do progresso tecnológico.

These physical units of capital by being expressed in terms of productivity capacity for the corresponding final goods, can be used without any restriction and with no problem whatever in the analysis of dynamics paths at the level of the final goods (PASINETTI, 1990, p. 68).

Diante destas características fundamentais passa-se à descrição formal do modelo de mudança estrutural de Pasinetti (1981, 1993). Inicialmente discute-se o sistema em que os insumos são trabalho e bens de capital e, posteriormente, o sistema de produção de puro trabalho. Mostrar-se-á que nestes modelos a mudança estrutural está relacionada com a evolução dos coeficientes técnicos e de demanda. Apesar de Pasinetti reconhecer o progresso tecnológico como o "primum movens" da sociedade industrial, neste capítulo discorre-se sobre o modelo sem progresso tecnológico, dado o objetivo de compará-lo e sintetizá-lo junto ao modelo kaleckiano (visto no primeiro capítulo) e neo-ricardiano (discorrido na seção anterior).

\subsubsection{O modelo de produção sem progresso tecnológico}

As hipóteses adotadas no modelo são:

- Economia desenvolvida, fechada e sem governo;

- Trabalhadores uniformemente qualificados (recebem o mesmo salário);

- $\quad N$ setores na economia, sendo o $n$-ésimo a força de trabalho;

- A economia produz bens de capital e bens de consumo;

- Na produção de bens de capital utiliza-se apenas o trabalho como insumo (esta hipótese é importante, pois permite reduzir todos os insumos a trabalho economia de puro trabalho);

- Para cada bem de consumo final existe um bem de capital específico; 
- Não há depreciação do estoque de capital ${ }^{57}$.

Como destacado, Pasinetti assume o processo produtivo verticalmente integrado, no sentido de que todos os insumos são reduzidos a trabalho e estoques de capital (estes também reduzidos a trabalho, dada a hipótese citada acima). Deste modo, no sistema produtivo existem dois fluxos: a) o fluxo de oferta de trabalho do $n$-ésimo setor para os $i$-ésimos setores produtores de bens de capital e bens de consumo final; b) o fluxo de mercadorias provenientes dos $i$-ésimos setores para o $n$-ésimo. Ou seja, existem $n$ - 1 setores que demandam trabalho e ofertam produtos e o setor $n$ que oferta trabalho e consome todas as mercadorias produzidas. O Gráfico 3.3 abaixo permite visualizar os fluxos a) e b) do modelo.

Gráfico 3.3 - Fluxo das mercadorias no modelo de Pasinetti

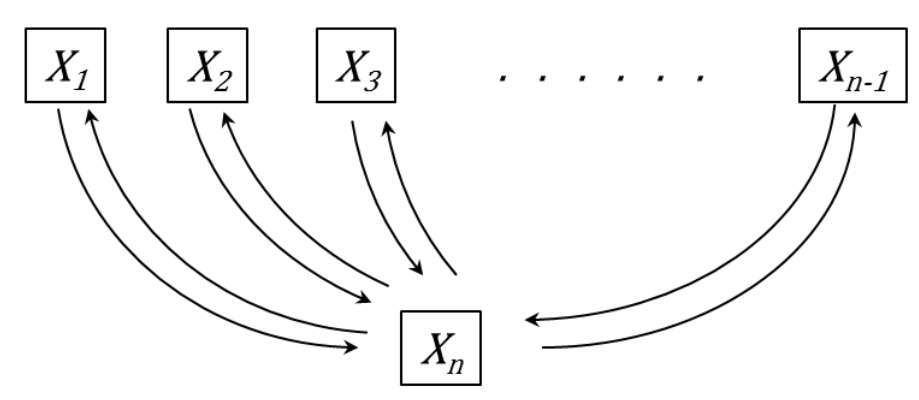

As variáveis utilizadas no modelo são:

- $X_{i}$ : quantidade produzida do bem final i;

- $X_{n}$ : quantidade total de trabalhadores utilizados na produção;

- $X_{i n}$ : quantidade demandada do bem final i pelo n-ésimo setor;

- $X_{n i}$ : quantidade de trabalho fornecido ao setor $\mathrm{i}$;

- $a_{n i}=X_{n i} / X_{i}$ : coeficiente de produção (inverso da produtividade) per capita no setor de bens finais;

- $a_{i n}=X_{i n} / X_{n}$ : coeficiente de consumo (demanda) per capita;

- $p_{i}$ : preço do bem final do setor $\mathrm{i}$;

- w: salário nominal;

- $X_{k i}$ : quantidade produzida do bem de capital no setor $\mathrm{i}$;

- $X_{n k i}$ : quantidade de trabalho necessária à produção do bem de capital no setor i;

- $X_{\text {kin }}$ : quantidade de bem de capital consumida pelo n-ésimo setor;

\footnotetext{
${ }^{57}$ Esta hipótese não é adota por Pasinetti (1981), no entanto para facilitar a compreensão do modelo e atingir o objetivo deste capítulo a utilizamos.
} 
- $a_{n k i}=X_{n k i} / X_{k i}$ : coeficiente de produção (inverso da produtividade) per capita no setor de bens de capital;

- $a_{k i n}=X_{k i n} / X_{n}$ : coeficiente de consumo (demanda) per capita;

- $r_{i}$ : taxa de lucro no setor $\mathrm{i}$;

- $p_{k i}$ : preço do bem de capital $\mathrm{k}$ do setor $\mathrm{i}$;

A partir das hipóteses iniciais e das variáveis acima descritas, Pasinetti apresenta o sistema de produção de mercadorias e o modelo de preços das mercadorias, ambos compostos por: a) série de $n-1$ estoques de bens de capital: $\left.\mathrm{k}_{1}, \mathrm{k}_{2}, \ldots . ., \mathrm{k}_{\mathrm{n}-1} ; \mathrm{b}\right)$ série de $2(\mathrm{n}-1)$ coeficientes técnicos: $a_{n 1}, a_{n 2}, \ldots \ldots ., a_{n n-1}, a_{n k 1}, a_{n k 2}, \ldots . . ., a_{n k(n-1)}$; c) série de n-1 coeficientes de consumo de bens finais: $a_{1 n}, a_{2 n}, \ldots . ., a_{(n-1) n} ;$ d) série de n-1 coeficientes de consumo de bens de capital: $a_{k 1 n}, a_{k 2 n}, \ldots \ldots, a_{k(n-1) n}$.

Assumindo a existência de apenas 1 período e que $a_{k i n}>0$ e $a_{n k i}>0$, para $\mathrm{i}=1, \ldots, n$. Tem-se:

$$
\begin{gathered}
\left\{\begin{array}{c}
\mathrm{X}_{\mathrm{i}}-\left(\mathrm{a}_{\mathrm{in}}\right) \mathrm{X}_{\mathrm{n}}=0 \\
X_{\mathrm{ki}}-\left(\mathrm{a}_{\mathrm{kin}}\right) \mathrm{X}_{\mathrm{n}}=0 \\
\mathrm{X}_{\mathrm{n}}-\sum_{\mathrm{i}=1}^{\mathrm{n}-1} \mathrm{a}_{\mathrm{ni}} \mathrm{X}_{\mathrm{i}}-\sum_{\mathrm{i}=1}^{\mathrm{n}-1} \mathrm{a}_{\mathrm{nki}} \mathrm{X}_{\mathrm{ki}}=0
\end{array}\right. \\
\left\{\begin{array}{c}
\mathrm{p}_{\mathrm{i}}-\mathrm{a}_{\mathrm{ni}} \mathrm{w}-r_{i} p_{k i}=0 \\
\mathrm{p}_{\mathrm{ki}}-\mathrm{a}_{\mathrm{nki}} \mathrm{w}=0 \\
\mathrm{w}+\sum_{i=1}^{n-1} a_{i n} p_{k i} r_{i}-\sum_{\mathrm{i}=1}^{\mathrm{n}-1} \mathrm{a}_{\mathrm{in}} \mathrm{p}_{\mathrm{i}}-\sum_{\mathrm{i}=1}^{\mathrm{n}-1} \mathrm{a}_{\mathrm{kin}} \mathrm{p}_{\mathrm{ki}}=0
\end{array}\right.
\end{gathered}
$$

Ambos os sistemas de produção (3.11) e de preços (3.12) podem ser representados na forma matricial por:

$$
\left[\begin{array}{cccccccccc}
-1 & 0 & 0 & & \ldots & \cdots & \ldots & \ldots & \mathrm{a}_{1 \mathrm{n}} \\
0 & -1 & 0 & & \ldots & \ldots & \ldots & \ldots & \mathrm{a}_{2 \mathrm{n}} \\
\vdots & 0 & -1 & & 0 & \ldots & \ldots & \ldots & \vdots \\
\vdots & \ldots & \ldots & \ddots & & 0 & & \ldots & \ldots & \mathrm{a}_{(\mathrm{n}-1) \mathrm{n}} \\
\vdots & \ldots & \ldots & \ldots & & \ddots & & 0 & \ldots & \mathrm{a}_{\mathrm{k} 1 \mathrm{n}} \\
\vdots & \cdots & \ldots & \ldots & & \ldots & & \ddots & \ldots & \vdots \\
\vdots & \cdots & \ldots & \ldots & & \ldots & \ldots & -1 & \mathrm{a}_{\mathrm{k}(\mathrm{n}-1) \mathrm{n}} \\
\mathrm{a}_{\mathrm{n} 1} & \mathrm{a}_{\mathrm{n} 2} & \ldots & \mathrm{a}_{\mathrm{n}(\mathrm{n}-1)} & \mathrm{a}_{\mathrm{n} 1} 1 & \ldots & \mathrm{a}_{\mathrm{nk}(\mathrm{n}-1)} & -1
\end{array}\right]\left[\begin{array}{c}
\mathrm{X}_{1} \\
\mathrm{X}_{2} \\
\vdots \\
\mathrm{X}_{\mathrm{n}-1} \\
X_{\mathrm{k} 1} \\
\vdots \\
X_{\mathrm{k}(\mathrm{n}-1)} \\
X_{\mathrm{n}}
\end{array}\right]=\left[\begin{array}{c}
0 \\
0 \\
\vdots \\
0 \\
0 \\
\vdots \\
0 \\
0
\end{array}\right]
$$




$$
\left[\begin{array}{cccccccccc}
-1 & 0 & 0 & & \ldots & \cdots & \ldots & \ldots & \mathrm{a}_{\mathrm{n} 1} \\
0 & -1 & 0 & & \ldots & \ldots & \ldots & \ldots & \mathrm{a}_{\mathrm{n} 2} \\
\vdots & 0 & -1 & & 0 & \ldots & \ldots & \ldots & \vdots \\
\vdots & \ldots & \ldots & \ddots & & 0 & & \ldots & \ldots & \mathrm{a}_{\mathrm{n}(\mathrm{n}-1)} \\
\vdots & \ldots & \ldots & \ldots & & \ddots & & 0 & \ldots & \mathrm{a}_{\mathrm{nk} 1} \\
\vdots & \cdots & \ldots & \ldots & & \ldots & & \ddots & \ldots & \vdots \\
\vdots & \cdots & \ldots & \ldots & & \ldots & \ldots & -1 & \mathrm{a}_{\mathrm{nk}(\mathrm{n}-1)} \\
\mathrm{a}_{1 \mathrm{n}} & \mathrm{a}_{2 \mathrm{n}} & \ldots & \mathrm{a}_{(\mathrm{n}-1) \mathrm{n}} & \mathrm{a}_{\mathrm{k} 1 \mathrm{n}} & \ldots & \mathrm{a}_{\mathrm{k}(\mathrm{n}-1) \mathrm{n}} & -1
\end{array}\right]\left[\begin{array}{c}
p_{1} \\
\mathrm{p}_{2} \\
\vdots \\
p_{\mathrm{n}-1} \\
p_{\mathrm{k} 1} \\
\vdots \\
p_{\mathrm{k}(\mathrm{n}-1)} \\
w
\end{array}\right]+\left[\begin{array}{c}
r_{1} p_{k 1} \\
r_{2} p_{k 2} \\
\vdots \\
r_{n-1} p_{k(n-1)} \\
0 \\
\vdots \\
0 \\
\sum_{i=1}^{n-1} a_{i n} p_{k i} r_{i}
\end{array}\right]=\left[\begin{array}{c}
0 \\
0 \\
\vdots \\
0 \\
0 \\
\vdots \\
0 \\
0
\end{array}\right]
$$

Pasinetti (1983) observa que ambos os sistemas, (3.11) e (3.12), são lineares e homogêneos. Deste modo, para que possuam solução não trivial (quantidades e preços iguais à zero) é necessário que o determinante da matriz dos coeficientes, dados em (3.11.1) e (3.12.1), seja igual a zero. Este determinante em ambos os sistemas é:

$$
\sum_{\mathrm{i}=1}^{\mathrm{n}-1} \mathrm{a}_{\mathrm{in}} \mathrm{a}_{\mathrm{ni}}+\sum_{\mathrm{i}=1}^{\mathrm{n}-1} \mathrm{a}_{\mathrm{kin}} \mathrm{a}_{\mathrm{nki}}=1
$$

Antes de discorrer sobre a importância do resultado determinado por (3.13) é importante relembrar da subseção anterior que os setores são verticalmente integrados, sendo cada bem de capital específico para a produção de determinado bem final. Isso significa que cada bem exige a definição de uma unidade de medida particular, a qual é composta pela soma de dois componentes: a) os insumos diretos utilizados na produção do bem final; b) os insumos diretos e indiretos necessários à produção dos bens intermediários utilizados na produção do bem final e na expansão da capacidade produtiva do setor ${ }^{58}$.

Retornando a (3.13), Pasinetti $(1981,1993)$ denominou essa equação de condição de equilíbrio macroeconômico, isto é, a condição para que a economia se reproduza com pleno emprego. As expressões $a_{i n} a_{n i}$ e $a_{\text {kin }} a_{n k i}$ representam a relação entre o produto final gerado em cada setor i e os gastos em consumo nesse setor. Assim, se (3.13) é satisfeita, tudo o que é produzido é consumido, ocorrendo pleno gasto da renda e plena utilização da força de trabalho na economia.

A condição de equilíbrio macroeconômico, caso satisfeita, resulta nas seguintes soluções para os sistemas (3.11) e (3.12):

\footnotetext{
${ }^{58}$ Se existisse depreciação dos bens de capital neste modelo, além dos itens a) e b) seria necessário incluir os insumos diretos e indiretos utilizados para a reposição dos bens de capital (GARBELLINE; WIKIERMAN, 2014).
} 


$$
\begin{gathered}
\mathrm{X}_{\mathrm{i}}=\mathrm{a}_{\mathrm{in}} X_{\mathrm{n}} \\
\mathrm{X}_{\mathrm{ki}}=\mathrm{a}_{\mathrm{kin}} \mathrm{X}_{\mathrm{n}} \\
\mathrm{p}_{\mathrm{i}}=\mathrm{a}_{\mathrm{ni}} \mathrm{w}+r_{i} p_{k i} \\
\mathrm{p}_{\mathrm{ki}}=\mathrm{a}_{\mathrm{nki}} \mathrm{w}
\end{gathered}
$$

As equações (3.14) e (3.15) representam a solução do sistema de quantidades físicas para cada setor verticalmente integrado e mostram que a produção de mercadorias depende exclusivamente da demanda, pois são proporcionais aos coeficientes de consumo. Por sua vez, (3.16) e (3.17) representam a solução do sistema monetário e mostram que os preços são diretamente proporcionais à quantidade de trabalho requerida para a sua produção.

Percebe-se a partir desse sistema dual ${ }^{59}$ que Pasinetti integra a teoria clássica do valor trabalho com a teoria keynesiana da demanda efetiva no âmbito de um modelo multissetorial (HISHIYAMA, 1996). Segundo Halevi (1996), Pasinetti reabilitou a noção marxista de trabalho abstrato, mas foi além dos clássicos, pois não relacionou o salário ao nível de subsistência dos trabalhadores.

Tem-se, portanto, assim como no modelo kaleckiano e dos demais neo-ricardianos, que é a demanda que determina o montante a ser produzido na economia. Deste modo, se $\sum_{\mathrm{i}=1}^{\mathrm{n}-1} \mathrm{a}_{\mathrm{in}} \mathrm{a}_{\mathrm{ni}}+\sum_{\mathrm{i}=1}^{\mathrm{n}-1} \mathrm{a}_{\text {kin }} \mathrm{a}_{\mathrm{nki}}<1$, no sistema dual isso significa que: a) $\sum_{i=1}^{n-1} \mathrm{a}_{\mathrm{ni}} X_{\mathrm{i}}<X_{n}$, ou seja, o emprego total gerado na economia é inferior ao trabalho disponível na economia, há subemprego; b) $\sum_{i=1}^{n-1} \mathrm{a}_{i n} p_{\mathrm{i}}<p_{n}$, ou seja, o gasto médio per capita é inferior à renda recebida pelos trabalhadores, há subconsumo. Por outro lado, se $\sum_{\mathrm{i}=1}^{\mathrm{n}-1} \mathrm{a}_{\mathrm{in}} \mathrm{a}_{\mathrm{ni}}+\sum_{\mathrm{i}=1}^{\mathrm{n}-1} \mathrm{a}_{\text {kin }} \mathrm{a}_{\text {nki }}>1$, conclui-se que: a) $\sum_{i=1}^{n-1} \mathrm{a}_{\mathrm{ni}} X_{\mathrm{i}}>X_{n}$, ou seja, o emprego demandado na economia é superior à força de trabalho disponível; b) $\sum_{i=1}^{n-1} \mathrm{a}_{i n} p_{\mathrm{i}}>p_{n}$, isto é, o gasto médio per capita é superior à renda recebida pelos trabalhadores, há sobreconsumo.

\footnotetext{
${ }^{59}$ A dualidade aqui não se encontra no sentido centro-periferia ou setor moderno e setor primário. No caso, faz referência aos dois sistemas presentes no modelo, o que representa as quantidades físicas e o que representa os preços.
} 
Em resumo, (3.13) expressa a proporção total de trabalho empregado na economia e a proporção total da renda gasta ${ }^{60}$, de tal forma que a condição de equilíbrio macroeconômico independe do número total de setores presentes na economia.

It is important to note immediately the macro-economic character of condition [3.13]: it does not depend on the number of sectors that exist in the economy. [3.13] is just one condition referring to the economic system as a whole, no matter how many (or how few) sectors may be considered (PASINETTI, 1981, p. 34).

Outro resultado interessante obtido por meio da condição de equilíbrio macroeconômico e dado pela substituição de (3.17) em (3.16):

$$
\mathrm{p}_{\mathrm{i}}=\left(\mathrm{a}_{\mathrm{ni}}+r_{i} a_{n k i}\right) w
$$

A equação (3.18) mostra que os preços das mercadorias no sistema de Pasinetti dependem dos custos de produção, em particular, os custos da quantidade de trabalhadores empregados em cada setor e os custos necessários à produção de bens de capital acrescidos da taxa de lucro incidente sobre os mesmos. Esta equação é semelhante à equação de preços de Kalecki, (2.49), caso seja considerado o custos de produção igual ao mark up ${ }^{61}$. No entanto, é fundamental frisar que o mark up está relacionado ao pressuposto de uma estrutura de mercado oligopolizada e no modelo de Pasinetti não há instituições, de tal forma que (3.18) serve para qualquer economia inclusive a kaleckiana.

Pasinetti ao apresentar o conceito de equilíbrio macroeconômico almejou demonstrar o quanto é difícil manter o pleno emprego da economia, pois se (3.13) é atingida em determinado período não significa que no período seguinte o equilíbrio se repetirá. Isso significa que a manutenção do pleno emprego não é um problema somente do curto prazo, mas também do longo prazo.

In this theoretical framework, therefore, the attainment of equilibrium in a given period of time does not mean at all that all problems have been solve (PASINETTI, 1983, p. 49).

It [the theoretical scheme] shows that the problems connected with employment are not confined to any single period of time (i.e to the short run), but are constantly present in a sequence of periods of time, when the complex structural dynamics of the

60 Conclui-se também que não é possível haver poupança neste sistema econômico caso a condição macroeconomia seja satisfeita. Segundo Pasinetti (1981), é possível que algum indivíduo poupe, mas esta deve ser sobreposta pelo gasto de outro indivíduo de modo a manter o equilíbrio.

${ }^{61} \mathrm{Na}$ última subseção desta seção a respeito do modelo de acumulação de Pasinetti discorre-se sobre uma proposta de interpretação da taxa normal de lucro a partir da taxa de lucro natural. Nessa ocasião demonstra-se que o mark up de Kalecki corresponde à taxa de lucro de Pasinetti. Este tema é aprofundado no Capítulo 4 deste trabalho. 
production economic system unfolds itself. In fact, it shows, in extremely clear turns, the existence of a permanent problem of coordination at the level of the economic system considered as a whole (PASINETTI, 1993, p. 59).

Gaberlline e Wikierman (2014) observam que a condição macroeconômica de Pasinetti, no momento em que representa o pleno emprego e o pleno gasto da renda, corresponde à condição de equilíbrio em fluxo, mas, ao indicar a plena utilização da capacidade produtiva, está representando o equilíbrio em estoques. Dado que o sistema é verticalmente integrado, a condição subjacente ao modelo que assegura o equilíbrio em estoques é:

$$
K_{i}=X_{i}
$$

A equação (3.19) afirma que o estoque de capital no início do período deve ser igual ao estoque de bens de consumo final produzidos no período, assim se (3.19) ocorrer, (3.13) representará o equilíbrio em fluxo e estoques.

A dificuldade de manutenção do equilíbrio é percebida com maior facilidade ao se introduzir o tempo no modelo que até o momento é estático. Isto é realizado na próxima subseção.

\subsubsection{O modelo econômico em expansão sem progresso tecnológico}

Para introduzir o crescimento econômico o primeiro item a ser introduzido é o tempo, assim será possível transpor para diversos períodos o modelo de produção ${ }^{62}$. Segundo Pasinetti (1981) existem duas noções de tempo que podem ser consideradas: a) o tempo como sucessão de períodos finitos, de tal forma que as mudanças estruturais ocorrem entre os períodos; b) o tempo é contínuo, neste caso os períodos finitos são infinitesimais.

De modo a manter o modelo simplificado, Pasinetti adota a noção de tempo contínuo. Dado que seu objetivo é discorrer sobre a evolução das variáveis econômicas ao longo do tempo, a primeira hipótese adicional introduzida por Pasinetti é a variação da população $\left(X_{\mathrm{n}}\right)$, o que consequentemente resulta na variação da demanda efetiva $\left(a_{i n}\right)$, pois se supõe que os consumidores alteram o seu padrão de consumo entre os setores.

As demais hipóteses adicionadas ao do modelo são:

\footnotetext{
${ }^{62}$ Considerar o tempo é fundamental para comparar os modelos neo-Ricardianos junto aos Kaleckianos e Keynesianos.
} 
- No tempo zero há pleno emprego da força de trabalho e plena utilização da capacidade produtiva;

- A população cresce a taxa constante $\eta$ e a população total é igual à população trabalhadora;

- Não há progresso tecnológico, desta forma os coeficientes técnicos $\mathrm{a}_{\mathrm{ni}}$ e $\mathrm{a}_{\text {nki }}$ são constantes;

- O padrão de consumo altera-se a taxa $\varphi$.

Analiticamente, essas hipóteses são representadas por:

$$
\begin{gathered}
X_{n_{(\mathrm{t})}}=X_{n_{(0)}} \mathrm{e}^{\eta \mathrm{t}} \\
\mathrm{a}_{\mathrm{in}(\mathrm{t})}=\mathrm{a}_{\mathrm{in}(0)} \mathrm{e}^{\varphi_{\mathrm{i}} \mathrm{t}} \\
\mathrm{a}_{\text {kin }(\mathrm{t})}=\mathrm{a}_{\text {kin }(0)} \mathrm{e}^{\varphi_{\mathrm{i}} \mathrm{t}} \\
\mathrm{a}_{\text {ni(t) }}=\mathrm{a}_{\text {ni(0) }} \\
\mathrm{a}_{\text {nki( }(\mathrm{t})}=\mathrm{a}_{\text {nki(0) }}
\end{gathered}
$$

A equação (3.20) mostra que a população cresce ao longo do tempo a taxa constante $\eta$; (3.21) e (3.22) mostram que os coeficientes de consumo final e de bens de capital variam para cada setor a taxa $\varphi$; e (3.23) e (3.24) mostram que os coeficientes técnicos (de produção) no setor de bens finais e no setor de bens de capital são constantes.

Diante dessas novas hipóteses, o sistema dual de produção de mercadorias e de preços é dado por:

$$
\begin{gathered}
\left\{\begin{array}{c}
\mathrm{X}_{\mathrm{i}(\mathrm{t})}-\mathrm{a}_{\mathrm{in}(0)} \mathrm{X}_{\mathrm{n}(0)} \mathrm{e}^{\left(\varphi_{\mathrm{i}}+\eta\right)(\mathrm{t})}=0 \\
X_{\mathrm{ki}(\mathrm{t})}-\mathrm{a}_{\mathrm{kin}(0)} \mathrm{X}_{\mathrm{n}(0)} \mathrm{e}^{\left(\varphi_{\mathrm{i}}+\eta\right)(\mathrm{t})}=0 \\
\mathrm{X}_{\mathrm{n}(\mathrm{t})}-\sum_{\mathrm{i}=1}^{\mathrm{n}-1} \mathrm{a}_{\mathrm{ni}(0)} \mathrm{X}_{\mathrm{i}(\mathrm{t})}-\sum_{\mathrm{i}=1}^{\mathrm{n}-1} \mathrm{a}_{\mathrm{nki}(0)} \mathrm{X}_{\mathrm{ki}(\mathrm{t})}=0
\end{array}\right. \\
\left\{\begin{array}{c}
\mathrm{p}_{\mathrm{i}(\mathrm{t})}-\mathrm{a}_{\mathrm{ni}(0)} \mathrm{w}-r_{i(t)} p_{k i(t)}=0 \\
\mathrm{p}_{\mathrm{ki}(\mathrm{t})}-\mathrm{a}_{\mathrm{nki}(0)} \mathrm{w}=0 \\
\mathrm{w}+\sum_{i=1}^{n-1} a_{i n(0)} p_{k i} r_{i} \mathrm{e}^{\varphi_{\mathrm{i}}(\mathrm{t})}-\sum_{\mathrm{i}=1}^{\mathrm{n}-1} \mathrm{a}_{\mathrm{in}(0)} \mathrm{p}_{\mathrm{i}} \mathrm{e}^{\varphi_{\mathrm{i}}(\mathrm{t})}-\sum_{\mathrm{i}=1}^{\mathrm{n}-1} \mathrm{a}_{\operatorname{kin}(0)} \mathrm{p}_{\mathrm{ki}} \mathrm{e}^{\varphi_{\mathrm{i}}(\mathrm{t})}=0
\end{array}\right.
\end{gathered}
$$


No formato matricial tem-se a expressão (3.25.1):

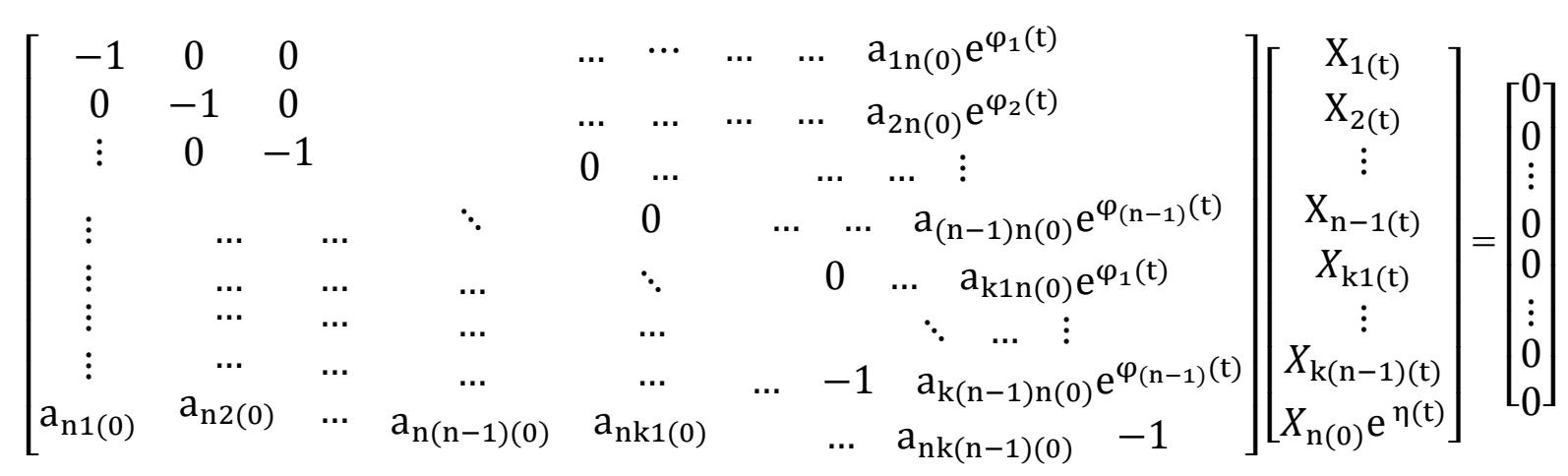

Da mesma forma obtém-se a expressão (3.26.1):

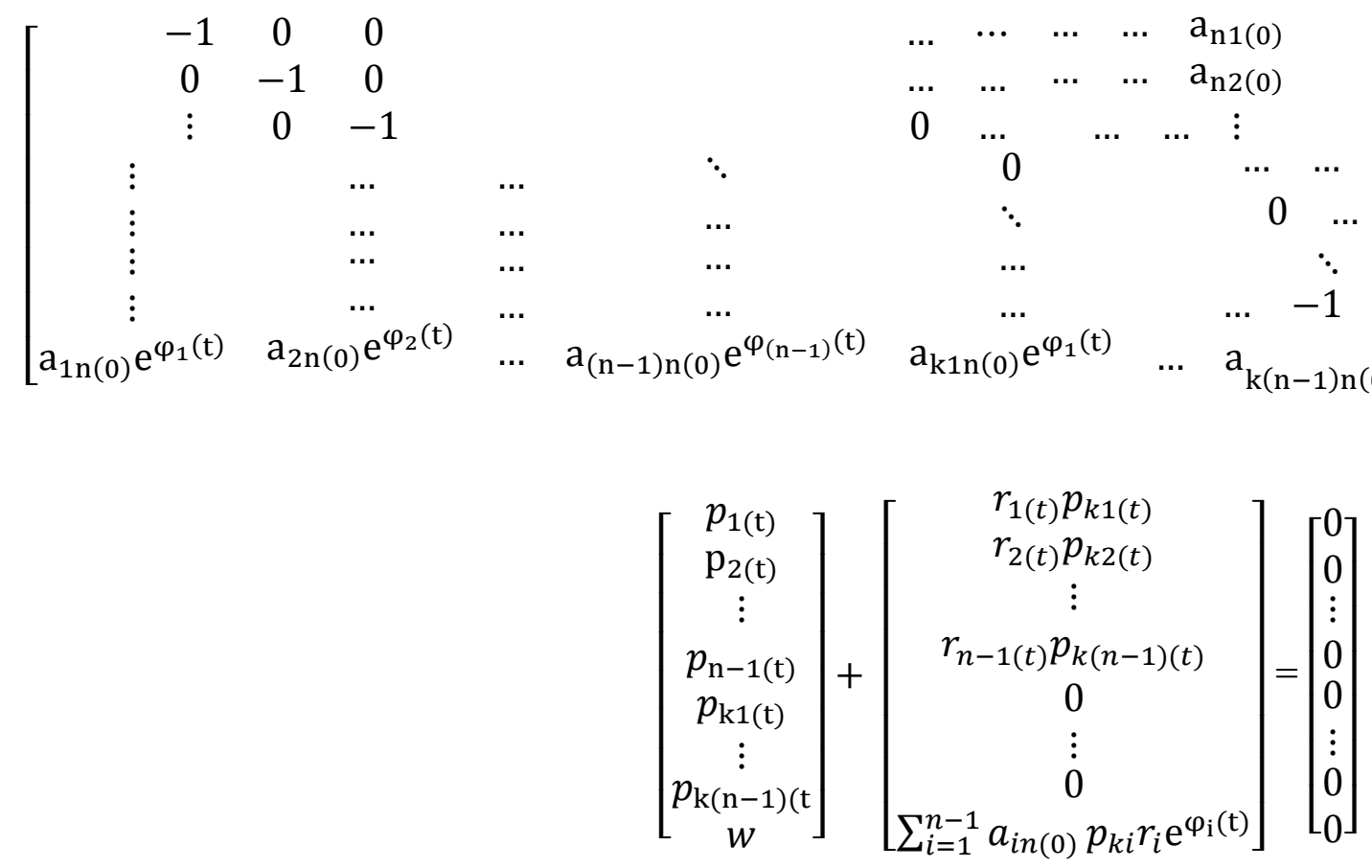

De modo semelhante ao modelo estático da subseção anterior, no modelo atual de crescimento para que a solução do sistema não seja a trivial é necessário que o determinante da matriz dos coeficientes de (3.25.1) e (3.26.1) seja igual à zero. Assim obtém-se:

$$
\sum_{\mathrm{i}=1}^{\mathrm{n}-1} \mathrm{a}_{\mathrm{in}(\mathrm{t})} \mathrm{a}_{\mathrm{ni}(0)}+\left(\theta+\varphi_{\mathrm{i}(\mathrm{t})}\right) \sum_{\mathrm{i}=1}^{\mathrm{n}-1} \mathrm{a}_{\text {kin }(\mathrm{t})} \mathrm{a}_{\mathrm{nki}(0)}=1
$$


A equação (3.27) representa a condição de equilíbrio macroeconômico ao longo do tempo. Como no modelo estático, esta condição indica que haverá pleno emprego e pleno gasto da renda, este é o equilíbrio em fluxo de Garbelline e Wikierman (2014).

The economic meaning of [3.27] is again that total expenditure must be equal to total potential gross national income if full employment and full capacity utilization are to be attained (PASINETTI, 1981, p. 54).

Caso o equilíbrio macroeconômico seja satisfeito, as soluções serão:

$$
\begin{gathered}
\mathrm{X}_{\mathrm{i}}=\mathrm{a}_{\mathrm{in}} X_{\mathrm{n}}=\mathrm{a}_{\mathrm{in}(0)} X_{n_{(0)}} \mathrm{e}^{\left(\varphi_{\mathrm{i}}+\eta\right) \mathrm{t}} \\
\mathrm{X}_{\mathrm{ki}}=\mathrm{a}_{\mathrm{kin}} \mathrm{X}_{\mathrm{n}}=\mathrm{a}_{\mathrm{kin}(0)} X_{n_{(0)}} \mathrm{e}^{\left(\varphi_{\mathrm{i}}+\eta\right) \mathrm{t}} \\
\mathrm{p}_{\mathrm{i}}=\mathrm{a}_{\mathrm{ni}(0)} \mathrm{w}+r_{i} p_{k i} \\
\mathrm{p}_{\mathrm{ki}}=\mathrm{a}_{\mathrm{nki}(0)} \mathrm{W}
\end{gathered}
$$

As equações (3.28) e (3.29) mostram que a produção de bens finais e bens de capital são determinados pela demanda e crescem de acordo com a soma da taxa de variação da demanda e da taxa de crescimento populacional. Em complemento, as equações (3.30) e (3.31) mostram que os preços dos bens intermediários e dos bens finais são determinados exclusivamente pela quantidade de trabalho utilizada na sua produção.

Por sua vez, a condição de equilíbrio macroeconômico pressupõe também o equilíbrio em estoques, o qual está intrinsicamente relacionado à integração vertical adotada no modelo, e de modo semelhante ao modelo de produção estático exige ao longo do tempo $K_{i}=X_{i}$, isto é:

$$
K_{i}=\dot{X}_{l}, \text { para } \mathrm{i}=1,2, \ldots, \mathrm{n}-1^{63}
$$

Substituindo (3.28) e (3.29) em (3.32) tem-se $\mathrm{a}_{\mathrm{kin}(0)} X_{n_{(0)}} \mathrm{e}^{\left(\varphi_{\mathrm{i}}+\eta\right) \mathrm{t}}=\left(\varphi_{\mathrm{i}}+\right.$ ๆ) $\mathrm{a}_{\mathrm{in}(0)} X_{n_{(0)}} \mathrm{e}^{\left(\varphi_{\mathrm{i}}+\eta\right) \mathrm{t}}, \operatorname{logo}$ :

\footnotetext{
${ }^{63}$ A priori, a equação (2.32) parece errônea dado que se igua-la à variação do produto com o estoque de capital, mas isso é factível, pois se assume ausência de depreciação. Isto é, o estoque de capital irá se acumular a medida que amplia a produção de bens finais.
} 


$$
a_{\text {kin }(t)}=\left(\varphi_{i}+\eta\right) a_{i n(t)}
$$

Este resultado mostra que, para a manutenção do equilíbrio em estoques, a demanda por bens de capital em cada setor deverá ser igual à demanda pelo bem final multiplicada pela soma da taxa de crescimento e da taxa de variação da demanda de cada setor. Isso significa que a demanda por novos bens de capital deve ser exatamente igual ao crescimento da capacidade produtiva de cada setor.

[...] for any specific composition of final demand for consumption, the equilibrium amount of gross investment is univocally determined by the technique in use and by the dynamics of population and of final consumption demand itself(PASINETTI, 1981, p. 25).

Se as equações (3.27) e (3.30) forem respeitadas, o sistema econômico proposto estará em equilíbrio de preços e estoques, com a população crescendo, mas mantendo-se em pleno emprego. De modo semelhante ao modelo de produção sem crescimento, a condição (3.27) independe da quantidade de setores e nada garante que ela será respeitada ao longo do tempo, em particular, a dificuldade de sua obtenção é elevada frente à equação (3.13), pois agora há o crescimento populacional e a variação da demanda.

A priori, como não há progresso tecnológico, deve-se pressupor a ausência de mudança estrutural, e de fato Pasinetti (1981, 1993) somente considera o seu modelo dinâmico a partir da relação entre o progresso tecnológico e variação da demanda. No entanto, neste modelo de crescimento constante é possível supor a alteração exógena dos padrões de consumo para cada setor, consequentemente há variação exógena da demanda ao longo do tempo. Para identificar os efeitos dessa variação é necessário primeiramente observar o valor do produto setorial e do emprego setorial.

O produto setorial é dado por:

$$
V_{i(t)}=\mathrm{p}_{\mathrm{i}(\mathrm{t})} \mathrm{X}_{\mathrm{i}(\mathrm{t})}
$$

E o emprego setorial é dado por:

$$
E_{i(t)}=\mathrm{a}_{\mathrm{ni}(\mathrm{t})} \mathrm{X}_{\mathrm{i}(\mathrm{t})}
$$

Substituindo (3.26), (3.28), (3.30) em (3.34) e (3.35) obtém-se: 


$$
\begin{gathered}
V_{i(t)}=\left(\mathrm{a}_{\mathrm{in}(0)} \mathrm{a}_{\mathrm{ni}(0)}+r_{i} \mathrm{a}_{\mathrm{in}(0)} \mathrm{a}_{\mathrm{nki}(0)}\right) \mathrm{X}_{\mathrm{n}(0)} w \mathrm{e}^{\left(\varphi_{\mathrm{i}}+\eta\right) \mathrm{t}} \\
E_{i(t)}=\mathrm{a}_{\mathrm{ni}(0)} \mathrm{X}_{\mathrm{n}(0)} \mathrm{e}^{\left(\varphi_{\mathrm{i}}+\eta\right) \mathrm{t}}
\end{gathered}
$$

Assim, percebe-se que tanto a taxa de variação do produto quanto do emprego no tempo é dada por:

$$
\frac{V_{l(t)}^{\dot{v}}}{V_{i(t)}}=\frac{E_{i(t)}}{E_{i(t)}}=\varphi_{\mathrm{i}}+\eta
$$

A equação (3.36) mostra que a soma da taxa de crescimento da demanda e da população em cada setor determina a taxa de crescimento do produto e do emprego. Observe que esse resultado é aquele que garante a manutenção do equilíbrio em estoques no modelo, (3.33). Por tratar-se de modelo de crescimento, há proporcionalidade entre a taxa de lucro e a taxa de crescimento de cada setor (ARAÚJO, R.; TEIXEIRA, J., 2003), isso conduz ao que Pasinetti denominou de taxa natural de lucro; isto é, a taxa que estimula a produção e mantém os níveis de demanda necessários para atender o crescimento populacional e as alterações do padrão de consumo.

$$
r_{i}^{N A}=\eta+\varphi_{\mathrm{i}}
$$

Substituindo (3.37) e (3.31) em (3.30) obtém-se o preço natural ao longo do tempo. Este é o nível de preços que permite a manutenção do pleno gasto da renda no modelo em que há crescimento populacional e crescimento do consumo:

$$
p_{i(t)}^{N A}=\left[\mathrm{a}_{\mathrm{ni}(0)}+\left(\eta+\varphi_{\mathrm{i}}\right) a_{n k i(0)}\right] w
$$

A taxa de lucro natural (e consequentes taxa de preço e de crescimento naturais) consiste em importante resultado obtido por Pasinetti $(1981,1993)$ no âmbito do modelo de produção pré-institucional, pois este conceito qualifica a definição de taxa de lucro normal dos clássicos. Conforme descrito na segunda seção deste capítulo, para os clássicos a taxa de lucro normal estava associada à taxa média de lucros determinada pelas condições gerais da sociedade, estas mesmas condições determinariam os preços e salários normais. Percebe-se que essa definição não é precisa e provavelmente a dificuldade em formalizá-la se deve ao 
caráter institucional da teoria clássica, em particular assume-se que a concorrência entre as firmas resultaria no deslocamento dos bens de capital e posterior equalização da taxa de lucro em seu nível normal, ou seja, haveria somente uma taxa de lucro normal na economia no qual as demais gravitariam.

Pasinetti, ao abandonar as instituições e analisar a economia que produz mercadorias por meios de mercadoria, define de forma precisa o que representa a taxa de lucro normal. Taxa esta que varia de setor para setor ${ }^{64}$.

$\mathrm{Na}$ segunda seção deste capítulo expôs-se também que diversos neo-ricardianos utilizam a taxa de lucro normal dos clássicos na construção dos modelos de crescimento e distribuição com apenas um setor (e uma mercadoria que é ao mesmo tempo insumo e bem final). Além disso, mostrou-se que esta taxa de lucro pode ser interpretada como o profit share, o que resulta no modelo pós-kaleckiano, o qual possui interesse do ponto de vista empírico ao permitir identificar os regimes de crescimento wage-led e profit-led (LAVOIE, 2014). Críticos da interpretação pós-kaleckiana à taxa normal de lucros, afirmam que a síntese entre o modelo neo-ricardiano e kaleckiano dependerá da correta relação entre a taxa de lucro e a variação da demanda. Pois bem, é exatamente essa relação que Pasinetti deriva de seu modelo multissetorial pré-institucional.

A formalização desta síntese será apresenta na próxima seção, antes se apresenta o modelo multissetorial Pasinetti com integração hiper vertical.

\subsubsection{O modelo de produção puro trabalho sem progresso tecnológico}

Pasinetti (1993) no livro "Structural economic dynamics $-A$ theory of the economic consequences of human learning" reproduz o modelo de produção sem progresso tecnológico apresentado em 1981, mas retira da modelagem os bens de capital. Uma vez que os bens de capital são produzidos somente por trabalho ${ }^{65}$, Pasinetti resolve eliminar os bens de capital e assumir como único insumo o trabalho, pois "is aimed at grasping basic features of the industrial economics of our time" (PASINETTI, 1993, p. 13). Este passo consiste em hiper integrar os setores da economia.

As hipóteses do modelo de puro trabalho sem progresso tecnológico são semelhantes às do modelo de produção da subseção 3.4.2 com pequenas alterações, de forma didática estas são reproduzidas a seguir:

\footnotetext{
${ }^{64}$ A questão referente à equalização da taxa de lucro entre os setores será discutida no próximo capítulo.

${ }^{65}$ Hipótese adotada na subseção 3.4.2.
} 
- Economia desenvolvida, fechada e sem governo;

- Trabalhadores uniformemente qualificados (recebem o mesmo salário);

- $\quad N$ setores na economia, sendo o $n$-ésimo a força de trabalho;

- A economia produz apenas bens de consumo, ou seja, não há bens intermediários;

- Cada indivíduo trabalha na confecção de apenas um bem de consumo final;

- A quantidade total de população trabalhadora é igual à quantidade total da população.

De forma semelhante ao modelo de produção (ver Gráfico 3.3), continuam existindo dois fluxos no sistema de puro trabalho, o fluxo de oferta de trabalho no $n$-ésimo setor para os $i$-ésimos setores produtores de mercadorias, e o fluxo das mercadorias para o $n$-ésimo setor.

As variáveis utilizadas no modelo são:

- $X_{i}$ : quantidade produzida do bem final i;

- $X_{n}$ : quantidade total de trabalhadores utilizados na produção;

- $p_{i}$ : preço do bem final do setor $\mathrm{i}$;

- w: salário nominal;

- $l_{i}$ : quantidade de trabalho empregado em cada setor (nada mais é do que o coeficiente de produção $\left.a_{n i}=X_{n i} / X_{i}\right)^{66}$;

- $c_{i}$ : coeficiente de consumo per capita (nada mais é do que o coeficiente de consumo $\left.a_{\text {in }}=X_{\text {in }} / X_{n}\right)$

A partir das hipóteses e das variáveis, Pasinetti apresenta o sistema de produção de mercadorias e de preços, ambos contém: a) série de (n-1) bens finais, $X_{1}, X_{2}, \ldots ., X_{n-1}$; b) série de (n-1) coeficientes de consumo, $c_{1}, c_{2}, \ldots . ., c_{n-1}$; c) série de (n-1) coeficientes de trabalho: $l_{1}, l_{2}, \ldots . ., l_{n-1}$.

Assume-se que $l_{i}>0$ e $c_{i}>0$, para $\mathrm{i}=1, \ldots, n$, assim o sistema dual é dado por:

$$
\begin{gathered}
\left\{\begin{array}{c}
\mathrm{X}_{\mathrm{i}}-c_{i} \mathrm{X}_{\mathrm{n}}=0 \\
\mathrm{X}_{\mathrm{n}}-\sum_{\mathrm{i}=1}^{\mathrm{n}-1} \mathrm{l}_{\mathrm{i}} \mathrm{X}_{\mathrm{i}}=0
\end{array}\right. \\
\left\{\begin{array}{c}
\mathrm{p}_{\mathrm{i}}-l_{i} \mathrm{w}=0 \\
w-\sum_{\mathrm{i}=1}^{\mathrm{n}-1} \mathrm{c}_{\mathrm{i}} \mathrm{p}_{\mathrm{i}}=0
\end{array}\right.
\end{gathered}
$$

${ }^{66}$ Poder-se-ia nesta descrição do modelo manter a nomenclatura utilizada na subseção 2.3.2, no entanto, resolveu-se alterá-la por três motivos: 1) respeitar a apresentação proposta por Pasinetti (1993); 2) a nova nomenclatura é de fácil compreensão; 3) no terceiro capítulo deste trabalho essa nomenclatura é de grande utilidade. 
Na representação matricial tem-se:

$$
\begin{gathered}
{\left[\begin{array}{cccccc}
1 & 0 & & \ldots & 0 & -c_{1} \\
0 & 1 & \ldots & \ldots & -c_{2} \\
\vdots & \vdots & \ddots & \vdots & \vdots \\
0 & 0 & \vdots & 1 & -c_{(n-1)} \\
-l_{1} & -l_{2} & \ldots & -l_{(n-1)} & 1
\end{array}\right]\left[\begin{array}{c}
\mathrm{X}_{1} \\
\mathrm{X}_{2} \\
\vdots \\
\mathrm{X}_{(\mathrm{n}-1)} \\
\mathrm{X}_{\mathrm{n}}
\end{array}\right]=\left[\begin{array}{c}
0 \\
0 \\
\vdots \\
0 \\
0
\end{array}\right]} \\
{\left[\begin{array}{cccccc}
1 & 0 & & \ldots & 0 & -l_{1} \\
0 & 1 & \ldots & \ldots & -l_{2} \\
\vdots & \vdots & \ddots & \vdots & \vdots \\
0 & 0 & \vdots & 1 & -l_{(n-1)} \\
-c_{1} & -c_{2} & \ldots & -c_{(n-1)} & 1
\end{array}\right]\left[\begin{array}{c}
\mathrm{p}_{1} \\
\mathrm{p}_{2} \\
\vdots \\
\mathrm{p}_{(\mathrm{n}-1)} \\
w
\end{array}\right]=\left[\begin{array}{c}
0 \\
0 \\
\vdots \\
0 \\
0
\end{array}\right]}
\end{gathered}
$$

Assim como no modelo com bens de capital, os sistemas são lineares e homogêneos, logo, para que possuam solução não trivial, é necessário que o determinante da matriz dos coeficientes seja igual à zero. De (3.39.1) e (3.40.1) obtém-se que:

$$
\sum_{i=1}^{n} c_{i} l_{i}=1
$$

A equação (3.42) consiste na condição de equilíbrio macroeconômico no sistema hiper verticalmente integrado. De forma semelhante a (3.13), se (3.48) for atingida significa que todos os bens produzidos estão sendo consumidos e que toda a força de trabalho está sendo empregada, representando o equilíbrio em fluxos e estoques ao mesmo tempo ${ }^{67}$. Diante de (3.39) as soluções do sistema serão:

$$
\begin{gathered}
\mathrm{X}_{\mathrm{i}}=c_{i} \mathrm{X}_{\mathrm{n}} \\
\mathrm{p}_{\mathrm{i}}=l_{i} \mathrm{w}
\end{gathered}
$$

Onde (3.43) mostra que as quantidades de bens finais produzidas em cada setor dependem da quantidade demanda, e (3.44) mostra que os preços das mercadorias são diretamente proporcionais à quantidade de trabalho utilizada na sua produção. Vê-se, portanto, que no modelo de puro trabalho (assim como no modelo com bens de capital) é a

\footnotetext{
${ }^{67}$ Devido à ausência de bens de capitais, o equilíbrio em estoques não exige considerações da ordem de (3.19).
} 
demanda que determina a produção, sendo esta restrita somente pela quantidade de trabalho disponível na economia.

De (3.42) percebe-se também que, se $\sum_{i=1}^{n} c_{i} l_{i}>1$, nesta economia a demanda supera as capacidades de produção e se $\sum_{i=1}^{n} c_{i} l_{i}<1$, as soluções (3.43) e (3.44) não são atingidas evidenciando subemprego na economia. Novamente, como (3.13), a solução (3.42) independe da quantidade de setores na economia e, mesmo que seja alcançada em um período, não significa que no próximo o mesmo ocorrerá, por isso a dificuldade de manutenção do pleno emprego na economia.

\subsubsection{Modelo de crescimento constante puro trabalho sem progresso tecnológico}

Para transformar o modelo puro trabalho em modelo de crescimento constante Pasinetti (1993) introduz o tempo, igual ao modelo de produção com bens de capital adota-se o tempo contínuo, no qual os períodos são infinitesimais. As hipóteses adicionais são:

- No tempo zero há pleno emprego da força de trabalho e plena utilização da capacidade produtiva;

- A população cresce a taxa constante $\eta$ e a população total é igual à população trabalhadora;

- O padrão de consumo altera-se a taxa $\varphi$.

A representação analítica dessas hipóteses é dada por:

$$
\begin{gathered}
X_{n_{(\mathrm{t})}}=X_{n_{(0)}} \mathrm{e}^{\eta \mathrm{t}} \\
c_{i_{(\mathrm{t})}}=c_{i_{(0)}} \mathrm{e}^{\varphi_{\mathrm{i}} \mathrm{t}} \\
l_{i_{(\mathrm{t})}}=l_{\mathrm{i}(0)}
\end{gathered}
$$

A equação (3.45) mostra que a população cresce à taxa constante $\eta$, (3.46) mostra que o coeficiente de consumo varia de acordo com a taxa $\varphi_{\mathrm{i}}$ para cada setor e (3.47) evidencia a ausência de progresso tecnológico, pois o coeficiente de produção é constante. A partir destas equações tem-se que o sistema dual é dado por: 


$$
\begin{gathered}
\left\{\begin{array}{c}
X_{i(t)}-c_{i(0)} X_{n(0)} e^{\left(\varphi_{i}+\eta\right)(t)}=0 \\
X_{n(t)}-\sum_{i=1}^{n-1} l_{i(0)} X_{i(t)}=0
\end{array}\right. \\
\left\{\begin{array}{c}
p_{i}-l_{i(0)} \mathrm{W}=0 \\
w-\sum_{i=1}^{n-1} c_{i n(0)} p_{i} e^{\varphi_{i}(t)}=0
\end{array}\right.
\end{gathered}
$$

No formato matricial tem-se:

$$
\begin{gathered}
{\left[\begin{array}{cccccc}
1 & 0 & & \ldots & 0 & -c_{1(0)} \mathrm{e}^{\varphi_{1}(\mathrm{t})} \\
0 & 1 & \ldots & \ldots & -c_{2(0)} \mathrm{e}^{\varphi_{2}(\mathrm{t})} \\
\vdots & \vdots & \ddots & \vdots & \vdots \\
0 & 0 & \vdots & 1 & -c_{(n-1)(0)} \mathrm{e}^{\varphi_{(\mathrm{n}-1)}(\mathrm{t})} \\
-l_{1} & -l_{2} & \ldots & -l_{(n-1)} & 1
\end{array}\right]\left[\begin{array}{c}
\mathrm{X}_{1(\mathrm{t})} \\
\mathrm{X}_{2(\mathrm{t})} \\
\vdots \\
\mathrm{X}_{(\mathrm{n}-1)(\mathrm{t})} \\
\mathrm{X}_{\mathrm{n}(0)} \mathrm{e}^{\eta(\mathrm{t})}
\end{array}\right]=\left[\begin{array}{c}
0 \\
0 \\
\vdots \\
0 \\
0
\end{array}\right] \quad(3.48 .1)} \\
{\left[\begin{array}{ccccccc}
0 \\
0 & 1 & 0 & & \ldots & \ldots & -l_{1} \\
0 & & \vdots & \ddots & \vdots & -l_{2} \\
-c_{1(0)} \mathrm{e}^{\varphi_{1}(\mathrm{t})} & -c_{2(0)} \mathrm{e}^{\varphi_{2}(\mathrm{t})} & \ldots & -c_{(n-1)(0)} \mathrm{e}^{\varphi_{(\mathrm{n}-1)}(\mathrm{t})} & -l_{(n-1)} \\
1
\end{array}\right]\left[\begin{array}{c}
\mathrm{p}_{1} \\
\mathrm{p}_{2} \\
\vdots \\
\mathrm{p}_{(\mathrm{n}-1)} \\
w
\end{array}\right]=\left[\begin{array}{c}
0 \\
0 \\
\vdots \\
0 \\
0
\end{array}\right]}
\end{gathered}
$$

Sabe-se que a solução não trivial do modelo existirá se o determinante da matriz dos coeficientes for igual a 1. Deste modo, de (3.48.1) e (3.49.1) obtém-se:

$$
\left(\varphi_{\mathrm{i}}+\eta\right)_{(t)} \sum_{i=1}^{n} c_{i(0)} l_{i(0)}=1
$$

A equação (3.50) representa a nova condição de equilíbrio macroeconômico em fluxo e estoques do modelo de puro trabalho proposto por Pasinetti (1993). Novamente nada garante que esta condição será atingida, e pelo contrário devido à variação da demanda e ao crescimento populacional é possível que se dificulte a sua existência. Se o lado direito for inferior a 1 haverá subemprego ${ }^{68}$ e se for superior a 1 há sobre demanda, isto é, a capacidade produtiva da economia não atende à demanda existente.

De toda forma, se (3.50) for satisfeita as soluções do modelo serão:

$$
X_{i(t)}=c_{i(0)} X_{n(0)} e^{\left(\varphi_{i}+\eta\right)(t)}
$$

\footnotetext{
${ }^{68} \mathrm{O}$ subemprego em Pasinetti pode ser interpretado também como o exercito industrial de reserva de Marx.
} 


$$
\mathrm{p}_{\mathrm{i}}=l_{i(0)} \mathrm{W}
$$

Destes obtém-se respectivamente o produto total setorial e o emprego total setorial:

$$
\begin{gathered}
V_{i(t)}=\mathrm{p}_{\mathrm{i}(\mathrm{t})} \mathrm{X}_{\mathrm{i}(\mathrm{t})}=l_{i(0)} \mathrm{X}_{\mathrm{n}(0)} \mathrm{e}^{\eta(\mathrm{t})} w \\
E_{i(t)}=\mathrm{c}_{\mathrm{i}(\mathrm{t})} \mathrm{X}_{\mathrm{i}(\mathrm{t})}=\mathrm{c}_{\mathrm{i}(0)} \mathrm{X}_{\mathrm{n}(0)} \mathrm{e}^{\left(\varphi_{\mathrm{i}}+\eta\right)(\mathrm{t})}
\end{gathered}
$$

A partir destes resultados percebe-se diferença entre o modelo de produção com trabalho e capital e o modelo puro trabalho. No último, o crescimento do produto setorial é determinado em última instância pela taxa de crescimento da população, $\frac{V_{i(t)}}{V_{i(t)}}=\eta$, e não pela taxa de crescimento do emprego, $\frac{E_{i(t)}}{E_{i(t)}}=\varphi_{\mathrm{i}}+\eta$. Este resultado é interessante, pois demonstra que a variação da demanda altera a participação do emprego em cada setor, mas não modifica a taxa de crescimento total da economia que será dada exogenamente pela taxa de crescimento da população. No modelo com bens de capital mostrou-se que a taxa de crescimento do produto depende não somente do crescimento populacional, mas também da taxa de crescimento da demanda, pois para a manutenção do crescimento constante é necessário que a demanda por bens de capital acompanhe a demanda por bens finais, equação (3.36), no caso de puro trabalho há apenas a demanda por bens finais, a qual está diretamente relacionada ao crescimento populacional.

Percebe-se que o modelo de crescimento de puro trabalho é uma simplificação do modelo que envolve bens de capital, mas em geral mantém a essência do modelo anterior que é identificar as características naturais da economia multisetorial pré-institucional.

Na próxima seção, verifica-se que a partir do conceito de taxa de lucro natural de Pasinetti é possível reinterpretar o modelo kaleckiano.

\subsection{O MODELO KALECKIANO COM A TAXA DE LUCRO NATURAL}

Conforme apresentado no primeiro capítulo, o modelo de crescimento e distribuição kaleckiano é institucional, onde se adota uma firma representativa que produz apenas 1 bem final, o qual é ao mesmo tempo insumo de si mesmo. Supõe-se o mercado oligopolizado e 
hiper verticalmente integrado, de tal forma que as firmas definem os preços a partir do mark up sobre os custos de produção.

Para adaptar o modelo kaleckiano ao modelo multissetorial de Pasinetti (1981, 1993), considera-se que cada setor seja determinado pela economia de Kalecki, e que a taxa de lucro normal dos neo-ricardianos seja a taxa de lucro natural de Pasinetti. Trata-se, portanto, de nova proposta de interpretação da taxa de lucro natural (TEIXEIRA, J.; ARAÚJO, R., 2014). Na seção 3.3 viu-se que os pós-kaleckianos interpretam a taxa de lucro normal sendo o profit share, Pasinetti por sua vez a considera com a soma da taxa de demanda setorial e a taxa de crescimento populacional.

Nesse caso o investimento setorial será determinado por:

$$
g_{i}=\alpha+\beta\left(\varphi_{i}+\eta\right)+\gamma \mu_{i}
$$

De modo a simplificar a análise adota-se $\alpha, \beta$ e $\gamma$ iguais para os $i=1,2, \ldots n-1$ setores produtivos da economia. Observa-se que se considera a existência somente dos $n$-1 setores produtivos e não se inclui o $n$-ésimo setor que é representado pela população conforme proposto por Pasinetti. Nesta seção objetiva-se primeira aproximação a partir do conceito de taxa de lucro natural e não se almeja a formulação do ciclo de produção fechado ${ }^{69}$.

Igualando (2.41) a (3.55) obtém-se a curva de realização de lucros do modelo kaleckiano:

$$
r_{i}^{E D}=\frac{\alpha}{s_{p}}+\frac{\beta\left(\varphi_{i}+\eta\right)}{s_{p}}+\frac{\gamma \mu_{i}}{s_{p}}
$$

Para se obter as soluções de equilíbrio deve-se igualar (3.56) à curva de profit-cost setorial dada por $r_{i}^{P C}=h_{i}\left(\frac{\mu_{i}}{v_{i}}\right)$, na qual $h_{i}$ que representa o profit share setorial dado por $h_{i}=\frac{\theta_{i}}{1+\theta_{i}} 70$. Interessante observar que o mesmo profit share é obtido a partir do modelo fechado de crescimento de Pasinetti. Abaixo se utiliza as variáveis de Pasinetti para demonstrar esta afirmação:

$$
r_{i}^{P C}=\left(h_{i}\right)\left(\frac{1}{v_{i}}\right)\left(\mu_{i}\right)=\left(\frac{r_{i} p_{k i} \mathrm{X}_{\mathrm{ki}}}{\mathrm{p}_{\mathrm{i}} \mathrm{X}_{\mathrm{i}}}\right)\left(\frac{X_{i}^{*}}{X_{k i}}\right)\left(\frac{X_{i}}{X_{i}^{*}}\right)=\frac{r_{i} p_{k i}}{p_{i}}=r_{i}\left(\frac{a_{n k i}}{a_{n i}+r_{i} a_{n k i}}\right)=r_{i}\left(\frac{1}{\frac{X_{n i}}{X_{n k i}}+r_{i}}\right)=\frac{r_{i}}{1+r_{i}}
$$

\footnotetext{
${ }^{69}$ No terceiro capítulo realiza-se o ciclo de produção fechado.

${ }^{70}$ Ver o primeiro capítulo deste trabalho.
} 
O resultado (3.57) é obtido, pois se assume que $X_{n i}=X_{n k i}$, isto é, a quantidade de trabalhadores utilizada na produção do $i$-ésimo bem final é igual à quantidade de trabalhadores requerida para a produção do $i$-ésimo bem de capital específico para aquele bem. Isto não é uma hipótese absurda, pois no modelo de crescimento de Pasinetti, no qual os setores são verticalmente integrados, como visto, necessariamente o setor de bens de capital deve crescer a mesma do setor de produção de bens finais. Ao se comparar (3.57) e o profit share do modelo de Kalecki, percebe-se que o mark up, $\theta$, corresponde à taxa de juros, r, do modelo de Pasinetti.

Os novos pontos de equilíbrio são obtidos a partir de (3.56), (2.56) e (3.57):

$$
\begin{gathered}
\mu_{i}^{*}=\frac{\alpha+\beta\left(\varphi_{i}+\eta\right)}{s_{p}\left(\varphi_{i}+\eta\right)-\gamma} \\
r_{i}^{*}=\frac{\left(\varphi_{i}+\eta\right)\left[\alpha+\beta\left(\varphi_{i}+\eta\right)\right]}{s_{p}\left(\varphi_{i}+\eta\right)-\gamma} \\
g_{i}^{*}=\frac{s_{p}\left(\varphi_{i}+\eta\right)\left[\alpha+\beta\left(\varphi_{i}+\eta\right)\right]}{s_{p}\left(\varphi_{i}+\eta\right)-\gamma}
\end{gathered}
$$

A condição de estabilidade é dada por $s_{p}>\frac{\gamma}{\left(\varphi_{i}+\eta\right)}$, e os exercícios de estática comparativa nos fornecem:

$$
\begin{gathered}
\frac{d g_{i}^{*}}{d s_{p}}=-\frac{\gamma\left(\varphi_{i}+\eta\right)\left[\alpha+\beta\left(\varphi_{i}+\eta\right)\right]}{\left[s_{p}\left(\varphi_{i}+\eta\right)-\gamma\right]^{2}}<0 \\
\frac{d g_{i}^{*}}{d \varphi_{i}}=\frac{s_{p}\left(\beta T_{i}-\gamma \Omega_{i}\right)}{\left[s_{p}\left(\varphi_{i}+\eta\right)-\gamma\right]^{2}} \lesseqgtr 0
\end{gathered}
$$

Sendo $T_{i}=s_{p}\left(\varphi_{i}+\eta\right)^{2} \geq 0$ e $\Omega_{i}=\alpha+2 \beta\left(\varphi_{i}+\eta\right) \geq 0$. O resultado (3.60.1) mostra que o paradoxo da poupança continua válido, e (3.60.2) mostra que a ampliação da taxa de crescimento da demanda resulta na elevação da taxa de lucro natural, a qual dependendo dos valores de T e $\Omega$ pode resultar na elevação ou redução da taxa de crescimento do setor. Isto é, na nomenclatura adota neste trabalho, mantém-se a possibilidade de manutenção de dois regimes de crescimento, o wage-led, se $\beta T_{i}<\gamma \Omega_{i}$, ou o profit-led, se $\beta T_{i}>\gamma \Omega_{i}$. 
Conforme exposto, Pasinetti qualifica o conceito de taxa de lucro normal dos neoricardianos deduzindo a partir do modelo multissetorial de crescimento. Entretanto, sabe-se que em geral as economias crescem de forma desbalanceada e não necessariamente o equilíbrio alcançado é de pleno emprego e pleno gasto da renda. Por isso, considerar cada setor da economia de Pasinetti como sendo os setores verticalmente integrados de Kalecki é relevante. Esta importância é evidenciada nos seguintes pontos: 1) introduz-se o caráter institucional ausente no modelo de Pasinetti; 2) introduz-se a possibilidade de equilíbrio com ausência de plena utilização da capacidade produtiva.

O segundo ponto acima merece esclarecimento, pois considerar a taxa de lucro de Kalecki como a taxa de lucro natural não significa a obtenção do pleno emprego e pleno gasto da renda representado pela condição de equilíbrio macroeconômico multissetorial, (3.27). A partir das equações (3.33) e (3.36) verifica-se que a taxa de lucro natural representa a condição necessária para que a produção de bens de capital acompanhe a expansão da produção de bens finais de consumo, mantendo a taxa de crescimento do produto e do emprego constantes em cada setor, o que por sua vez não está relacionado à satisfação do pleno emprego na economia como um todo. O modelo de Kalecki por adotar a economia verticalmente integrada faz com que o princípio representado por (3.33) esteja presente, logo é possível interpretar a taxa de lucro normal a partir da taxa de lucro natural.

A análise proposta nesta seção não permite verificar o processo de mudança estrutural, isto é, não responde às seguintes perguntas: a) quais os efeitos de divergências entre as taxas de lucro entre os setores? b) Há tendência a equalização da taxa de juros entre os diversos setores? c) Há deslocamento de bens de capital para os setores com maior taxa de lucro?

Para responder essas perguntas é necessário expandir a análise iniciada neste capítulo para o modelo kaleckiano com mais de um setor verticalmente integrado. Este é o objeto de estudo do próximo capítulo.

\subsection{RESUMO DO CAPÍTULO}

O objetivo deste capítulo foi expor a interpretação neo-ricardiana sobre os modelos de crescimento e distribuição, e nesse intuito introduziu-se o modelo de mudança estrutural Pasinetti, não apenas por ser o autor importante representante da escola neo-ricardiana, mas também por esse modelo possuir características que o diferenciam dos demais modelos neoricardianos e que trazem importantes resultados para este e os demais capítulos deste trabalho. 
O primeiro ponto a ser discutido é o conceito de variáveis naturais. Mostra-se que para os clássicos estas eram variáveis de longo prazo determinadas pelas condições gerais da economia. Tais variáveis seriam o centro de gravitação de todas as demais variáveis, como preços, lucros, taxa de crescimento e taxa de utilização da capacidade. Autores neoricardianos como Vianelo (1985) interpretam o estado natural como a posição de pleno ajuste da economia, na qual a taxa de utilização da capacidade produtiva é unitária, o que aproxima esta interpretação dos modelos dos primeiros pós-keynesianos discutidos no primeiro capítulo. Por outro lado, autores como Ciccone (1986) interpretam as taxas naturais de longo prazo como taxa esperadas pelos agentes econômicos, deste modo a taxa normal de longo prazo não é pré-determinada e varia a cada alteração das expectativas, o que evidencia também o path dependence no que diz respeito aos preços e quantidades normais. Esta segunda interpretação se aproxima do modelo kaleckiano, e também se evidenciam outras semelhanças como: a) adoção do princípio da demanda efetiva; b) importância das análises de curto prazo assim como as análises de longo prazo; c) path dependence.

Introduzindo-se a taxa de lucro normal no modelo kaleckiano verifica-se que o paradoxo da poupança continua válido, mas não há garantida sobre a validade do paradoxo dos custos. Nesse âmbito, é possível considerar a taxa de lucro normal como sendo a participação dos lucros na economia. Isso resulta em importante síntese entre os modelos kaleckianos e neo-ricardianos denominada por Lavoie (2014) de modelos pós-kaleckianos. Destes modelos, observa-se que o paradoxo da poupança vale, e o paradoxo dos custos pode ou não ocorrer. Se sim, trata-se de uma economia wage-led, caso contrário, a economia é profit-led. Esta interpretação não é consensual, o que resulta na conclusão de que a perfeita interação entre os dois modelos dependerá da relação entre a dinâmica da demanda e a formação de expectativas de longo prazo.

Pasinetti apresenta a alternativa a ser adotada para a síntese entre os dois modelos, mas para isso abandona o caráter institucional relacionado às expectativas dos agentes econômicos e qualifica o comportamento da demanda necessário à manutenção do crescimento no modelo multissetorial. Além do caráter pré-institucional, o modelo de Pasinetti é verticalmente integrado e preocupa-se em adentrar nas características naturais do sistema econômico, isto é, a essência do processo social de produção, o qual vale para qualquer sociedade industrial. Nesse âmbito, Pasinetti apresenta o sistema dual de produção das mercadorias e de preços no modelo estático e de crescimento constante.

Nesses sistemas Pasinetti identifica as condições necessárias para a manutenção do equilíbrio em fluxo e estoque, posição que, por sua vez, representa a manutenção do pleno 
emprego, pleno gasto da renda e plena utilização da capacidade produtiva. Além disso, Pasinetti mostra quais seriam os preços e quantidades caso o equilíbrio fosse mantido. Desta análise depreende-se o quanto é difícil manter o pleno emprego na economia, em especial no modelo dinâmico, no qual está presente o tempo, pois a cada período variam as variáveis fundamentais da economia e consequentemente dificulta-se a obtenção do equilíbrio.

A partir do sistema dinâmico sem progresso tecnológico de Pasinetti obtém-se a taxa de lucro natural, que é dada pela soma da taxa de variação da demanda e da taxa de crescimento populacional. Esta representa a condição necessária para que, no sistema natural, cada setor produtor de bens de capital cresça a mesma taxa do setor produtor de bens de consumo e assim a mantenha o produto e o nível de emprego crescendo a taxas constantes.

A síntese sugerida na última seção deste capítulo considera cada setor do sistema multissetorial de Pasinetti como sendo a economia kaleckiana. Assim, inserem-se elementos institucionais no modelo e a possibilidade de obtenção do equilíbrio com ausência de plena utilização da capacidade produtiva, além disso, ao se considerar a taxa de lucro de Kalecki como a taxa de lucro natural verifica-se a manutenção do paradoxo da poupança, mas não do paradoxo dos custos. Esta síntese, no entanto, é preliminar, pois aborda apenas um setor. No próximo capítulo expande-se esta análise para o sistema com dois ou mais setores. 


\section{CAPÍTULO 4 - O MODELO KALECKIANO MULTISSETORIAL E A SÍNTESE DE PASINETTI}

\subsection{INTRODUÇÃO}

No final do capítulo anterior interpretaram-se os resultados obtidos a partir do modelo de Kalecki ao se considerar a taxa de lucro normal como sendo a taxa de lucro natural proposta por Pasinetti. No entanto, o modelo descrito na ocasião aborda apenas um setor verticalmente integrado, isso impossibilita verificar os efeitos das diferentes taxas de lucro entre os setores, se há tendência à equalização dos lucros e o que está pressuposto para que essa equalização ocorra.

Neste capítulo pretende-se abordar essas questões e para isso o ponto de partida é trabalhar com os modelos multissetoriais, para isso recorre-se ao modelo de Pasinetti com capital e trabalho e sempre que for aconselhável para critério de simplificação adota-se o modelo de puro trabalho de Pasinetti.

$\mathrm{Na}$ segunda subseção discorre-se sobre o modelo kaleckiano de dois setores apresentado por Park (1995) e Dutt (1997), os quais são verticalmente integrados e puxados pela demanda. Observa-se que Park (1995) identifica a sobre determinação nesse modelo e desqualifica todas as soluções para eliminar essa sobre determinação. Dutt (1997), por sua vez, afirma que a sobre determinação ocorre apenas no curto prazo, mas no longo prazo ela é eliminada caso assuma-se a existência de deslocamento de capital entre os setores equalizando a taxa de lucro e de acumulação.

A solução adotada por Dutt (1977) para resolver a sobre determinação é ad hoc, uma vez que não se apresenta a dinâmica de transição do curto para o longo prazo. Para compreender essa dinâmica propõe-se a adoção do modelo de Pasinetti que também é verticalmente integrado e puxado pela demanda. De toda forma é necessário verificar se as equações de Pasinetti são semelhantes ao modelo de Kalecki. A semelhança é comprovada na terceira e quarta subseção deste capítulo.

A quinta subseção discorre especificamente sobre a transição do curto para o longo prazo. Uma vez que no capítulo anterior endogeneizou-se a taxa de lucro normal em cada setor, a proposta aqui é endogeneizar a taxa de utilização da capacidade, dado que ela determina a dinâmica dos bens de capital em cada setor. Nesse intuito, verifica-se a necessidade de discorrer sobre o comportamento da oferta e não somente da demanda, para 
isso recorre-se o trabalho de Feldman (1929). A endogenização é realizada passo a passo, iniciando no modelo unissetorial até o multissetorial. Nesse processo são obtidas conclusões sobre o padrão de crescimento no longo prazo, as condições para a equalização ou não da taxa de lucro entre os setores e os fatores que determinam a mudança estrutural.

\subsection{O MODELO KALECKIANO DE DOIS SETORES}

O modelo kaleckiano é caracterizado pela endogeinização da taxa de utilização da capacidade produtiva. Isso significa que no modelo multissetorial kaleckiano haverá, no equilíbrio de longo prazo, diferentes graus de utilização da capacidade produtiva, taxas de salários reais, quantidades produzidas e preços entre os diversos setores (PARK, 1995). Em resumo, o modelo possui dois importantes resultados $^{71}$ : a) a taxa de utilização da capacidade produtiva é endógena, de tal forma que pode haver persistentemente excesso de capacidade produtiva no longo prazo; b) a relação entre a taxa de salário real e a taxa de lucro não necessariamente é inversa no longo prazo, pois a economia não permanece na fronteira de possibilidade de produção.

Nesta seção discute-se o modelo kaleckiano com dois setores produtivos verticalmente integrados. As hipóteses adotadas são:

- O setor 1 produz bens de consumo e o setor 2 produz bens de capital;

- Os setores 1 e 2 são verticalmente integrados;

- Para a produção dos respectivos bens, cada setor utiliza trabalho e capital a partir de coeficientes fixos de produção;

- Assume-se a tecnologia de produção com retornos constantes de escala;

- Existem duas classes sociais, os trabalhadores que auferem salário e gastam toda a sua renda em bens de consumo, os capitalistas que auferem lucro e o poupam totalmente;

- O salário auferido pelos trabalhadores é igual em ambos os setores.

A partir destas hipóteses, Park (1995) apresenta as seguintes equações:

$$
p_{1}=p_{2} r\left(\frac{v_{1}}{u_{1}}\right)+W l_{1}
$$

\footnotetext{
${ }^{71}$ Ver o primeiro capítulo deste trabalho, no qual se descreve com detalhes esse modelo.
} 


$$
p_{2}=p_{2} r\left(\frac{v_{2}}{u_{2}}\right)+W l_{2}
$$

$$
\begin{gathered}
1=w\left(l_{1}+l_{2} x\right) \\
x=g_{1}\left(\frac{v_{1}}{u_{1}}\right)+g_{2}\left(\frac{v_{2} x}{u_{2}}\right)
\end{gathered}
$$

$$
\mathrm{W}=w p_{1}
$$

$$
p_{1}=\left(1+\theta_{1}\right) W l_{1}
$$

$$
p_{2}=\left(1+\theta_{2}\right) W l_{2}
$$

$$
\begin{aligned}
& g_{1}=g_{1}\left(r_{1}, u_{1}\right) \\
& g_{2}=g_{2}\left(r_{2}, u_{2}\right)
\end{aligned}
$$

$$
\begin{aligned}
& r_{1}=r \\
& r_{2}=r \\
& g_{1}=g \\
& g_{2}=g
\end{aligned}
$$

Onde $p_{i}$ representa o preço do produto do setor $i, i=1$ ou $2 ; r_{i}$ é a taxa de lucro do setor $i$; $v_{i}$ consiste na razão entre o estoque de capital do setor e o produto setorial sob plena capacidade produtiva; $u_{i}$ consiste na razão entre o estoque de produto produzido no setor e o 
produto setorial sob plena capacidade produtiva; W é a taxa de salário nominal; w a taxa de salário real; $l_{i}$ consiste na razão entre o estoque de trabalho utilizado no setor e o produto setorial; $x$ é a razão entre o produto do setor 2 e o produto do setor $1 ; g_{i}$ é a taxa de acumulação setorial, a qual é determinada pela taxa de lucro e taxa de utilização da capacidade e $\theta_{i}$ é o mark-up dos preços.

As equações (4.1) e (4.2) representam a decomposição do produto entre salários e lucros em cada setor, a equação (4.3) mostra que o produto do setor de bens de consumo corresponde à soma dos gastos dos trabalhadores dos dois setores, a equação (4.4) mostra que a quantidade produzida de bens de capital corresponde à soma dos investimentos de ambos os setores; a equação (4.5) representa a taxa de salário real; a equações (4.6) e (4.7) representam a determinação dos preços a partir do mark-up dos custos; as equações (4.8) e (4.9) representam a taxa de acumulação de ambos os setores; por fim as equações de (4.10) a (4.13) mostram que as taxas de lucro e as taxas de acumulação entre os setores tendem a se uniformizar $^{72}$.

Nesse sistema observa-se a existência de 13 equações e 12 incógnitas $\left(P_{1}, P_{2}, x, u_{1}, u_{2}, g, r, v_{1}, v_{2}, l_{1}, l_{2}, w\right)$, o que o torna sobre determinado. Esta sobre determinação foi identificada inicialmente por Park (1995), o qual acrescentou como possíveis soluções: a) eliminar a taxa uniforme de lucros; b) eliminar a taxa uniforme de acumulação; e c) eliminar a diferenciação dos preços determinados por mark-up. Dentre essas, Park critica a proposta de Dutt (1990) de adotar a segunda solução. Nesta Dutt argumenta que o investimento não deve ser considerado variável comportamental, mas sim variável fixa para a posição de equilíbrio ${ }^{73}$. Segundo Park (1995), descaracterizar a instabilidade do investimento é abandonar a interpretação kaleckiana sobre a economia capitalista descentralizada.

Two different things appear to be confused here. It is one thing to say, as apparently in the above statement of Dutt's, that the overall rate of accumulation is a final result, so that that rate can ultimately be expressed by various relevant exogenous and endogenous variables. It is another thing to say, and this is our position, that, in a decentralized capitalist economy, that same rate must result from investment behavior in the respective sectors; any degree of autonomy existing in function [4.8] must come from the autonomy of sectorial investment behavior (PARK, 1995, p. 300).

\footnotetext{
${ }^{72}$ Evidentemente percebe-se que de (3.10) e (3.11) se obtém $r_{1}=r_{2}$ e de (3.12) e (3.13) se obtém $g_{1}=g_{2}$. No entanto, mantêm-se as equações como estão para ser fiel à exposição de Park (1995).

73 "Dutt (1990) argues that function [8] should properly be thought of as a reduced-form equation, which shows how investment plans are made in equilibrium, rather than as a behavioral equation" (PARK, 1995, p. 300).
} 
Além disso, Park (1995) também critica as duas outras soluções para resolver a sobre determinação do modelo. No caso de se assumir diferentes taxas de lucro, Park reconhece a possibilidade de divergência no curto prazo, mas afirma que dificilmente se manterá no longo prazo, e, sobre a alternativa de uniformizar o mark-up, Park destaca que, se a taxa de acumulação varia de forma diferente nos diversos setores, consequentemente altera-se o mark-up proporcionalmente.

Since the rates of accumulation change period by period, the mark-up rates will respond to changing short-period data - as a result of cumulative influences over some periods, if not immediately (PARK, 1995, p. 304).

Diante das deficiências decorrentes das possíveis soluções, Park conclui que o modelo de dois setores kaleckiano mantém-se sobre-determinado. Esta conclusão é retratada por Dutt (1997) que afirma haver erro de interpretação na análise de Park (1995), uma vez que não discute a velocidade de circulação do capital entre os setores.

$\mathrm{Na}$ exposição dos seus argumentos, Dutt (1997) substitui as equações (4.10) e (4.11), por (4.14), e as equações (4.12) e (4.13) por (4.15) abaixo $^{74}$ :

$$
\begin{aligned}
& r_{1}=r_{2} \\
& g_{1}=g_{2}
\end{aligned}
$$

Deste modo o novo sistema seria formado pelas equações (4.1) a (4.9), (4.14) e (4.15). Este sistema possui 11 equações e 10 incógnitas $\left(P_{1}, P_{2}, x, u_{1}, u_{2}, g_{1}, g_{2}, r_{1}, r_{2}, w\right)$, o que de fato o torna sobre determinado ${ }^{75}$. No entanto, isso ocorre apenas no curto prazo, mas no longo prazo, caso se adote a hipótese clássica, haverá deslocamento de capital entre os setores de tal forma que haverá equalização da taxa de lucro e de acumulação entre os setores ${ }^{76}$. Assim, (4.8) e (4.9) é substituída por (4.16) e (4.4) é substituída por (4.17):

$$
\begin{gathered}
g=g\left(r, u_{1}, u_{2}\right) \\
r=g
\end{gathered}
$$

\footnotetext{
${ }^{74}$ Tais alterações não são substanciais.

${ }^{75}$ Observa-se aqui uma repetição do argumento de Park, no entanto Dutt o expõe de forma mais elegante.

76 "Classical competition may be incorporated into the model (....) by replacing equations [3.8] and [3.9] and by assuming that investment is determined as follows. Firms are assumed to choose their total rate of investment taking into account average levels of capacity utilization and rates of profit" (DUTT, 1997, p. 447).
} 
Deste modo, no longo prazo o sistema é formado pelas equações (4.1), (4.2), (4.3), (4.17), (4.5), (4.6), (4.7) e (4.16), 8 equações e 8 incógnitas $\left(P_{1}, P_{2}, x, u_{1}, u_{2}, g, r, w\right)$, o que o torna determinado.

Desta solução de Dutt, convém realizar duas observações. A primeira é referente à equação (4.16), isto é, no longo prazo, após ocorrer o deslocamento dos bens de capital entre os setores na economia, haverá apenas uma taxa de investimento que depende da taxa uniforme de lucro e das taxas de utilização da capacidade em cada setor. Conforme mencionado acima, Park critica essa possibilidade, pois significaria descaracterizar a instabilidade do investimento. Por serem setores verticalmente integrados é de se esperar que no longo prazo ambos cresçam na mesma velocidade, e isto não significa que o investimento na economia torna-se fixo, este continua variando $\operatorname{com} r, u_{1}$ e $u_{2}$. Além disso, a priori haveria circularidade entre (4.16) e (4.17), pois, ao mesmo tempo em que o crescimento determina a taxa de lucro, ele é por ela determinado. No entanto, esta circularidade não existe, pois no presente modelo a taxa de lucro é determinada pelo mark up, conforme será apresentado em seguida.

A segunda observação diz respeito à equação (4.17), esta nada mais é do que a equação de Cambridge sob a hipótese de que os capitalistas poupam toda a sua renda, e este resultado provém das equações (4.1) a (4.5) do sistema de curto prazo ${ }^{77}$.

Em resumo, Dutt (1997) divide a análise do sistema Kaleckiano de dois setores entre sistema de curto prazo e de longo prazo. No primeiro há divergência entre as taxas de lucro setoriais e de acumulação, mas no segundo há uniformidade. No curto prazo, obtém-se de (4.1), (4.2), (4.5) e (4.6):

$$
\begin{gathered}
r_{1}=\left(\frac{\theta_{1}}{1+\theta_{2}}\right)\left(\frac{l_{1}}{l_{2}}\right)\left(\frac{u_{1}}{v_{1}}\right) \\
r_{2}=\left(\frac{\theta_{2}}{1+\theta_{2}}\right)\left(\frac{u_{2}}{v_{2}}\right)
\end{gathered}
$$

E de (4.3) a (4.5) obtém-se que:

$$
x=\theta_{1}\left(\frac{l_{1}}{l_{2}}\right)
$$

\footnotetext{
${ }^{77}$ Para se obter o referido resultado, isola-se de (4.1) e (4.2) as relações capital - produto $\frac{v_{1}}{u_{1}} \mathrm{e} \frac{v_{2}}{u_{2}}$ e insere-se estes na equação (4.4). De forma semelhante, de (4.3) e (4.5) se obtém que $p_{1}=W\left(l_{1}+l_{2} x\right)$, substituindo em (4.4) novamente e realizando pequenas derivações obtém-se que $r=g$.
} 
Por sua vez, o resultado de longo prazo depende da função de acumulação g, pois ela determina a taxa de crescimento do estoque de capital na economia e consequentemente determina a taxa de crescimento estacionário no longo prazo. Dutt, por sua vez, não deriva qual seria o resultado de longo prazo, para isso é necessário especificar a natureza da equação (4.16). Neste trabalho adotaremos que a média ponderada de $u_{1}$ e $u_{2}$ determina a taxa de acumulação $^{78}$.

Suponha g dada por:

$$
g=g\left(r, u_{1}, u_{2}\right)=\alpha+\beta u_{1}+(1-\beta) u_{2}+\gamma r
$$

Onde $\alpha, \beta$, e $\gamma$ são parâmetros positivos. De (4.17), (4.16) e (4.21) obtém-se que:

$$
r=\frac{\alpha}{1-\gamma}+\frac{\beta}{1-\gamma}\left(u_{1}-u_{2}\right)+\frac{u_{2}}{1-\gamma}
$$

De (4.2) e (4.7) obtém-se (4.19), deste modo igualando (4.19) à (4.22) e sabendo de (4.20) que $u_{1}=\frac{u_{2}}{\theta_{1}} \frac{l_{2}}{l_{1}}$, chega-se aos pontos de equilíbrio no longo prazo:

$$
\begin{gathered}
u_{2}^{*}=\frac{\alpha l_{1} \theta_{1} v_{2}\left(1+\theta_{2}\right)}{l_{1} \theta_{1} \theta_{2}(1-\gamma)-\left(1+\theta_{2}\right)\left[l_{1} \theta_{1} v_{2}+\beta l_{2} v_{2}+\beta v_{2} l_{1} \theta_{1}\right]} \\
u_{1}^{*}=\frac{\alpha l_{2} v_{2}\left(1+\theta_{2}\right)}{l_{1} \theta_{1} \theta_{2}(1-\gamma)-\left(1+\theta_{2}\right)\left[l_{1} \theta_{1} v_{2}+\beta l_{2} v_{2}+\beta v_{2} l_{1} \theta_{1}\right]} \\
g=r=\alpha^{\prime}+\beta^{\prime} u_{1}^{*}+\gamma^{\prime} u_{2}^{*}
\end{gathered}
$$

Diante dos resultados de (4.23) e (4.24) percebe-se a complexidade de interpretação das posições de longo prazo $^{79}$, em particular da relação entre o curto e o longo prazo.

Nas palavras de Dutt:

Had [Park (1995)] incorporated classical competition by assuming that capital flows instantaneously between sectors, he would have been forced to discard is equations [3.8] and [3.9] and replace them with an aggregate

\footnotetext{
${ }^{78}$ A inspiração pela isto provém de Lima e Setterfield (2016), que o adotam para objetivos completamente opostos ao do presente trabalho.

${ }^{79}$ Este deve ser o motivo pelo qual Dutt (1990) não deriva as posições de longo prazo.
} 
investment function of the type given by equation [3.16] ${ }^{80}$ (DUTT, 1997, p. 448).

Diante das críticas de Dutt à Park, percebe-se que existe diferenciação entre as posições de equilíbrio de curto e longo prazo. No entanto, é necessário compreender a dinâmica da transição ("traverse") entre os dois períodos. Essa transição é interpretada por Lavoie (1994) como o tempo histórico de Joan Robinson:

Plusiers complications doivent être ajoutées au modéle simple de Kalecki pour analyser une économie moderne, mais les fondaments sont là. Il est êgalement possible de construire une version de cette théorie qui soit située dans la longue période, une version où l'accumulation se déroule de façon régulière. Ceci, cependant, ne constitue qu'une première étape, à la-quelle on ne devrait attacher que peu d'importance. En réalité, toutes les questions substantielles et intéressantes se sittuent à cheval entre l'analyse pure de courte période et celle de longue période (ROBINSON, 1997, p. 369-70; apud LAVOIE, 1994, p. 03).

Segundo Lavoie (1994) nada garante no modelo kaleckiano de múltiplos setores que haverá uniformização da taxa de lucro no longo prazo. Esta é hipótese ad hoc baseada no pressuposto clássico de que haverá deslocamentos dos bens de capital para os setores com maior taxa de lucro. Entretanto, viu-se no segundo capítulo que Kalecki trabalha com a economia composta por setores verticalmente integrados, no qual os bens de capital são especializados, o que dificulta o deslocamento entre os setores. Assim, assumir a equalização dos juros somente fará sentido se for exposta a dinâmica de transição entre o curto e o longo prazo.

In the meantime, we believe, as do Halevi and Kriesler [1991], that an analysis based on various variants of profit rate equalization or on steady growth models set at normal use of capacity is doubtful unless 'some coherent dynamics adjustment process is specified which can describe the traverse from one equilibrium position to another, without the traverse itself influencing the final equilibrium position, that is, without the equilibrium being path determined' (LAVOIE; RAMIREZ-GASTÓN; 1997, p. 166167).

Neste capítulo propõem-se a utilização do modelo de Pasinetti discutido no capítulo anterior para compreensão dessa dinâmica no âmbito do modelo de crescimento. Para isso, inicialmente serão expostas as semelhanças entre o modelo de Pasinetti e o modelo kaleckiano de dois setores, posteriormente verificar-se-á as tendências de longo prazo.

\footnotetext{
${ }^{80}$ Adiante neste capítulo, veremos que de fato no longo prazo $g_{1}=g_{2}$, mas isso ocorre não porque exista uma única função de acumulação na economia dada por $g=g\left(r, u_{1}, u_{2}\right)$, mas sim por que é a produção de bens de capital em cada setor que determina o crescimento deste no longo prazo. Verificar-se-á também que ao contrário do preconizado por Dutt, há sim relação definida entre a taxa de lucro e a taxa de acumulação no longo prazo.
} 


\subsection{O MODELO PASINETTIANO DE CURTO PRAZO COM DOIS SETORES SEM PROGRESSO TECNOLÓGICO}

Conforme descrito no segundo capítulo, o modelo de Pasinetti é pré-institucional e verticalmente integrado, tendo como foco as características naturais do processo de acumulação de qualquer sociedade industrial. A partir das mesmas hipóteses descritas na seção 3.4.2, considera-se a existência de somente dois setores, de forma semelhante ao modelo kaleckiano, o setor 1 produtor de bens de consumo e o setor 2 produtor de bens de capital.

Dado que o setor é verticalmente integrado, para manter a semelhança com o modelo de Kalecki, os fluxos existentes na economia de Pasinetti são: i) fluxo de bens de capital para o setor de bens de consumo; ii) fluxo de bens de consumo para os trabalhadores; iii) fluxo de trabalhadores para ambos os setores.

As variáveis utilizadas são:

- $X_{i}$ : quantidade produzida do bem final $i$;

- L: quantidade total de trabalhadores utilizados na produção;

- $X_{i n}$ : quantidade demandada do bem final i pelo $n$-ésimo setor;

- $X_{n i}$ : quantidade de trabalho fornecido ao setor $i$;

- $a_{n i}=X_{n i} / X_{i}$ : coeficiente de produção (inverso da produtividade) per capita no setor de bens finais;

- $a_{\text {in }}=X_{\text {in }} / X_{n}$ : coeficiente de consumo (demanda) per capita;

- $p_{i}$ : preço do bem final do setor $i$;

- w: salário nominal.

Assim, no curto prazo (apenas um período), com $a_{n i}>0$ e $a_{i n}>0$, para $\mathrm{i}=1,2$. Temse o sistema de produção de mercadorias e de preços dados por:

$$
\begin{gathered}
\left\{\begin{array}{c}
X_{1}-\left(a_{1 n}\right) L=0 \\
X_{2}-\left(a_{2 n}\right) L=0 \\
L-\sum_{i=1}^{n-1} a_{n i} X_{i}=0
\end{array}\right. \\
\left\{\begin{array}{c}
p_{1}-a_{n 1} w-r_{1} p_{2}=0 \\
p_{2}-a_{n 2} w-r_{2} p_{2}=0 \\
w+\sum_{i=1}^{n-1} p_{2} r_{i}-\sum_{i=1}^{n-1} a_{i n} p_{i}=0
\end{array}\right.
\end{gathered}
$$


$\mathrm{Na}$ forma matricial tem-se:

$$
\begin{gathered}
{\left[\begin{array}{ccc}
-1 & 0 & a_{1 n} \\
0 & -1 & a_{2 n} \\
a_{n 1} & a_{n 2} & -1
\end{array}\right]\left[\begin{array}{c}
X_{1} \\
X_{2} \\
L
\end{array}\right]=\left[\begin{array}{l}
0 \\
0 \\
0
\end{array}\right]} \\
{\left[\begin{array}{ccc}
-1 & 0 & a_{n 1} \\
0 & -1 & a_{n 2} \\
a_{1 n} & a_{2 n} & -1
\end{array}\right]\left[\begin{array}{l}
p_{1} \\
p_{2} \\
W
\end{array}\right]+\left[\begin{array}{c}
r_{1} p_{1} \\
r_{1} p_{2} \\
\sum_{i=1}^{n-1} p_{2} r_{i}
\end{array}\right]=\left[\begin{array}{l}
0 \\
0 \\
0
\end{array}\right]}
\end{gathered}
$$

Observa-se a realização de pequena modificação no sistema de preços frente ao apresentado na seção 3.4.2. Em (4.27), a produção de bens de capital não depende apenas do trabalho, mas também dos bens de capital, isso é assumido para manter a semelhança frente ao modelo kaleckiano de dois setores sem contudo prejudicar a essência do modelo de Pasinetti.

Adota-se a convenção que $l_{2}=a_{n 2}$ e $l_{1}=a_{n 1}$, deste modo é possível relacionar $p_{2}=\frac{a_{n 2} W}{1-r_{2}}$, do sistema de Pasinetti, com $p_{2}=\left(1+\theta_{2}\right) W l_{2}$, do modelo de Kalecki. Substituindo tem-se:

$$
r_{2}=\frac{\theta_{2}}{1+\theta_{2}}, \text { ou } \theta_{2}=\frac{r_{2}}{1-r_{2}}
$$

Em (4.28) obtém-se a relação entre o mark-up de Kalecki e a taxa de lucro setorial de Pasinetti. Realizando o mesmo exercício para o primeiro setor, tem-se:

$$
p_{1}=\left[1+\frac{r_{1}}{1-r_{2}} \frac{a_{n 2}}{a_{n 1}}\right] a_{n 1} W
$$

Deste modo, sob o modelo pré-institucional de Pasinetti é possível obter que o markup de Kalecki para o primeiro setor é dado por:

$$
\frac{r_{1}}{1-r_{2}} \frac{a_{n 2}}{a_{n 1}}=\theta_{1}
$$

Substituindo (4.28) em (4.30), obtém-se: 


$$
r_{1}=\frac{\theta_{1}}{1+\theta_{2}} \frac{a_{n 1}}{a_{n 2}} \quad \text { ou } \frac{a_{n 2}}{a_{n 1}}=\frac{\theta_{1}}{1+\theta_{2}} \frac{1}{r_{1}}
$$

Diante dos resultados acima, é possível concluir que a partir do modelo de Pasinetti se obtém as conclusões de Kalecki. Observe que (4.28) e (4.31) nada mais são que (4.18) e (4.19) quando se assume, conforme Pasinetti, a plena utilização da capacidade produtiva, $\frac{u_{1}}{v_{1}}=\frac{u_{2}}{v_{2}}=181$.

A dedução dos resultados do modelo kaleckiano a partir do modelo de Pasinetti também pode ser visualizada por meio do profit share. Neste se faz o caminho inverso, isto é, parte-se de Pasinetti para Kalecki. Veja inicialmente o profit share do setor de bens de capital:

$$
h_{2}=\frac{p_{2} r_{2} K_{2}}{p_{2} X_{2}}=r_{2} \frac{K_{2}}{X_{2}^{*}} \frac{X_{2}^{*}}{X_{2}}=r_{2} v_{2} u_{2}^{-1}, \text { portanto, } r_{2}=\frac{h_{2} u_{2}}{v_{2}}
$$

A equação (4.32) é exatamente a curva de profit-cost do modelo de Kalecki discutida no primeiro capítulo. Para o setor de bens de consumo tem-se:

$$
h_{1}=\frac{p_{2} r_{1} K_{1}}{p_{1} X_{1}}=\frac{p_{2}}{p_{1}} r_{1} \frac{K_{1}}{X_{1}^{*}} \frac{X_{1}^{*}}{X_{1}}=\frac{p_{2}}{p_{1}} r_{1} v_{1} u_{1}^{-1}, \text { portanto, } r_{1}=\left(\frac{p_{2}}{p_{1}}\right) \frac{h_{1} u_{1}}{v_{1}}
$$

A equação (4.33) não é exatamente a curva de profit-cost do modelo de Kalecki, devido à razão $\frac{p_{2}}{p_{1}}$. Essa razão existe, pois no primeiro setor o insumo de produção não é igual ao produto como no segundo setor, logo existem preços relativos. No entanto, se substituirmos (4.6), (4.7) e (4.31) em (4.33) verifica-se que $\frac{u_{1}}{v_{1}}=1$. Isto é, (4.33) é o resultado de Kalecki caso o sistema esteja em plena capacidade produtiva.

De modo a podermos afirmar que o modelo de Pasinetti contém em si todas as equações de Kalecki resta derivar as equações (4.3) e (4.4). A equação (4.3) é facilmente identificada, adotando a nomenclatura de Pasinetti têm-se:

$$
1=W\left(a_{n 1}+a_{n 2} \frac{X_{2}}{X_{1}}\right), \log o, X_{1}=W\left(a_{n 1} X_{1}+a_{n 2} X_{2}\right), \text { portanto, } X_{1}=\left(x_{n 1}+x_{n 2}\right) W
$$

\footnotetext{
${ }^{81}$ Este pressuposto é extremamente importante no modelo de Pasinetti e será discutido com detalhes adiante.
} 
Assim como (4.3), (4.34) mostra que a quantidade total de bens de consumo produzida na economia é igual aos gastos dos trabalhadores empregados nos setores 1 e 2 . Por fim, para discorrer sobre (4.4), o qual mostra que a quantidade produzida de bens de capital é igual à soma dos investimentos em ambos os setores, é necessário introduzir o modelo de Pasinetti de crescimento. Isto é realizado na próxima seção.

\subsection{O MODELO PASINETTIANO DE CRESCIMENTO COM DOIS SETORES SEM PROGRESSO TECNOLÓGICO}

O modelo de Pasinetti de crescimento nada mais é do que o modelo de crescimento discutido na subseção 3.4.3 do capítulo anterior. A característica fundamental deste é a inclusão do tempo, agora não se trata de apenas um período, mas sim vários, sendo o tempo contínuo.

As hipóteses adicionadas ao modelo são ${ }^{82}$ :

- No tempo zero há pleno emprego da força de trabalho e plena utilização da capacidade produtiva;

- A população cresce à taxa constante $\eta$ e a população total é igual à população trabalhadora;

- Não há progresso tecnológico, desta forma os coeficientes técnicos $a_{n 1}$ e $a_{n 2}$ são constantes;

- O padrão de consumo altera-se à taxa $\varphi$.

Analiticamente:

$$
\begin{gathered}
X_{n_{(t)}}=X_{n_{(0)}} e^{\eta t} \\
a_{1 n(t)}=a_{1 n(0)} e^{\varphi_{i} t} \\
a_{2 n(t)}=a_{2 n(0)} e^{\varphi_{i} t} \\
a_{n 1(t)}=a_{n 1(0)} \\
a_{n 2(t)}=a_{n 2(0)}
\end{gathered}
$$

\footnotetext{
${ }^{82}$ Estas hipóteses encontram-se no Capítulo 3, aqui são repetidas para facilitar a leitura do texto.
} 
A equação (4.35) mostra que a população cresce a taxa constante $\eta$; as equações (4.36) e (4.37) mostram que a demanda pelos bens 1 e 2 variam de acordo com $\varphi$; e (4.38) e (4.39) evidenciam a ausência de progresso tecnológico.

Adotando as variáveis descritas na seção anterior, o sistema dual é dado por:

$$
\begin{gathered}
\left\{\begin{array}{c}
X_{1(t)}-a_{1 n(0)} L_{(0)} e^{\left(\varphi_{i}+\eta\right)(t)}=0 \\
X_{2(t)}-a_{2 n(0)} L_{(0)} e^{\left(\varphi_{i}+\eta\right)(t)}=0 \\
L_{(t)}-\left(a_{n 1(0)} X_{1(t)}+a_{n 2(0)} X_{2(t)}\right)=0
\end{array}\right. \\
\left\{\begin{array}{c}
p_{1(t)}-a_{n 1(0)} w-r_{1(t)} p_{2(t)}=0 \\
p_{2(t)}-a_{n 1(0)} w-r_{2(t)} p_{2(t)}=0 \\
W+\left(r_{1} p_{2(t)}+r_{2} p_{2(t)}\right)-\left(a_{1 n(0)} p_{1} e^{\varphi_{1}(t)}+a_{2 n(0)} p_{2} e^{\varphi_{2}(t)}\right)=0
\end{array}\right.
\end{gathered}
$$

$\mathrm{Na}$ forma matricial tem-se:

$$
\begin{gathered}
{\left[\begin{array}{ccc}
-1 & 0 & a_{1 n} e^{\varphi_{1}(t)} \\
0 & -1 & a_{2 n} e^{\varphi_{2}(t)} \\
a_{n 1(0)} & a_{n 2(0)} & -1
\end{array}\right]\left[\begin{array}{c}
X_{1(t)} \\
X_{2(t)} \\
L_{(0)} e^{\eta(t)}
\end{array}\right]=\left[\begin{array}{l}
0 \\
0 \\
0
\end{array}\right]} \\
{\left[\begin{array}{ccc}
-1 & 0 & a_{n 1(0)} \\
0 & -1 & a_{n 2(0)} \\
a_{1 n} e^{\varphi_{1}(t)} & a_{2 n} e^{\varphi_{2}(t)} & -1
\end{array}\right]\left[\begin{array}{l}
p_{1} \\
p_{2} \\
W
\end{array}\right]+\left[\begin{array}{c}
r_{1} p_{1} \\
r_{1} p_{2} \\
\sum_{i=1}^{2} p_{2} r_{i}
\end{array}\right]=\left[\begin{array}{l}
0 \\
0 \\
0
\end{array}\right]}
\end{gathered}
$$

De modo semelhante ao realizado na subseção anterior, a equação (4.41) é diferente da (3.26), pois nesta última somente o insumo trabalho é utilizado para a produção dos bens de capital. A introdução do bem de capital como insumo no segundo setor é novamente realizada para manter a semelhança frente o modelo Kaleckiano.

Nestes sistemas de dois setores é importante lembrar que do total de bens de capital produzidos no setor 2, uma parte é reempregada no mesmo setor e outra parte é alocada para a produção dos bens do setor 1. Esta alocação diversa dos bens de capital foi inicialmente incorporada nos modelos de crescimento por Feldman ${ }^{83}$ (1928) e Mahalanobis (1953). Estes

\footnotetext{
${ }^{83}$ Feldman foi um engenheiro-economista russo que trabalhou na Comissão de Planejamento do Estado Soviético (Gosplan). Seu modelo foi base para o desenvolvimento dos planos de desenvolvimento de dez a vinte anos da antiga União Soviética (JONES, 1979).
} 
autores adotaram o importante pressuposto de que, uma vez instalado, o capital não é reaproveitado em outro setor (nonshifitability assumption).

O modelo de Feldman adota as seguintes hipóteses (JONES, 1979):

a) a economia é dividida em dois setores, o setor 1 de bens de consumo e o setor 2 de bens de capital;

b) não há deslocamento de bens de capital de um setor para o outro;

c) uma proporção $\lambda$ de bens de capital é alocada para o setor 2 e (1- $\lambda$ ) para o setor 1

d) setores possuem tecnologia com coeficientes fixos de tal forma que $X_{1}=$ $\min \left[\frac{K_{1}}{v_{1}}, \frac{L_{1}}{u_{1}}\right]$ e $X_{2}=\min \left[\frac{K_{2}}{v_{2}}, \frac{L_{2}}{u_{2}}\right]$, como não se supõe restrições do lado da oferta em relação aos trabalhadores, logo os limites ao crescimento são dados pela quantidade de bens de capital, de tal forma que $X_{1}=\frac{K_{1}}{v_{1}}$ e $X_{2}=\frac{K_{2}}{v_{2}}$;

e) o estoque de bens de capital não se deprecia de tal forma que o investimento total da economia é dado por $X_{2}$;

f) a economia é fechada;

g) a produção de bens de consumo é independente da produção de bens de capital, ou seja, mesmo que não haja produção de bens de consumo, a produção de bens de capital pode continuar inalterada.

A partir destas hipóteses, Feldman observa que o investimento total na economia é dado por $\mathrm{I}=X_{2}=\frac{K_{2}}{v_{2}}$ (produção dos bens de capital), ao longo do tempo $\dot{I}=\frac{\dot{K}_{2}}{v_{2}}$. Dado que $\dot{K}_{2}=I_{2}=\lambda$ I, tem-se que $\frac{\dot{I}}{I}=\frac{\lambda}{v_{2}}$, isto é, o investimento total na economia depende diretamente da porção de bens de capital alocada para o setor 2 e indiretamente da razão capital-produto para o setor 2. Para o setor de bens de consumo, Feldman conclui que $\mathrm{C}=X_{1}=\frac{K_{1}}{v_{1}}$, pelas hipóteses sabe-se que $\dot{K}_{1}=I_{1}=(1-\lambda) \mathrm{I}$, assim $\frac{\dot{C}}{C}=\frac{(1-\lambda)}{v_{2}} \frac{I}{C}$.

Percebe-se que praticamente todas as hipóteses adotadas por Feldman coadunam com o modelo de Pasinetti, a exceção da última. No capítulo anterior mostrou-se que a condição subjacente ao equilíbrio de estoques no modelo de Pasinetti é dada por $K_{i}=X_{i}$, isto é, o estoque de capital no início do período deve ser igual ao estoque de bens de consumo final produzidos no período em cada setor verticalmente integrado. Ou seja, se não houver produção de bens de capital no longo prazo não se manterá o equilíbrio de estoques proposto por Pasinetti. Com o tempo contínuo essa condição é dada por: 


$$
\dot{X}_{i}=\dot{K}_{i}
$$

O valor de $\dot{X}_{i}$ é facilmente obtido a partir de (4.40), resta obter $\dot{K}_{i}$. Este provém do modelo de Feldman (1928), segundo o qual a taxa de mudança do estoque de capital em cada setor depende da proporção do produto total de bens de capital alocado a este. No presente modelo tem-se:

$$
\begin{gathered}
\dot{K}_{1}=(1-\lambda) X_{2} \\
\dot{K}_{2}=\lambda X_{2}
\end{gathered}
$$

Deste modo, de (4.44), (4.45) e (4.46) obtém-se para cada setor os seguintes resultados:

$$
\begin{gathered}
X_{1}\left(\varphi_{1}+\eta\right)=(1-\lambda) X_{2} \\
X_{2}\left(\varphi_{2}+\eta\right)=\lambda X_{2}
\end{gathered}
$$

Sabe-se do capítulo anterior que $\left(\varphi_{i}+\eta\right)$ nada mais é do que a taxa de variação do produto ao longo do tempo, isto é $g_{i}$ do modelo de Kalecki. Deste modo, pode-se reescrever (4.47) e (4.48) como:

$$
\begin{gathered}
X_{1} g_{1}=(1-\lambda) X_{2} \\
X_{2} g_{2}=\lambda X_{2}
\end{gathered}
$$

Ao somar-se (4.49) a (4.50) tem-se:

$$
x=g_{1}+g_{2} x
$$


O resultado (4.51) nada mais é do que a equação (4.4) do modelo kaleckiano de dois setores quando $\frac{v_{1}}{u_{1}}=\frac{v_{2}}{u_{2}}=1$, que como afirmamos acima é a condição subjacente para o equilíbrio de estoques no modelo de Pasinetti.

A partir da seção 4.2 e na presente seção 4.3 mostram-se que todas as equações do modelo de dois setores kaleckiano são obtidas do modelo de dois setores pasinettiano, lembrando que neste está sempre presente a hipótese de que $K_{i}=X_{i}$. Isto ocorre, pois, como destacado no capítulo anterior, o objetivo de Pasinetti era obter as condições para a manutenção do crescimento em equilíbrio no longo prazo.

Importante destacar que o longo prazo de Pasinetti não é o longo prazo dos primeiros modelos keynesianos. Nestes últimos vimos no primeiro capitulo que no longo prazo o produto é dado sendo $u=1$, o que em tese significa assumir a validade da Lei de Say. O longo prazo de Pasinetti não adota esta hipótese, mas sim destaca que a manutenção do equilíbrio depende da igualdade representa por (4.44), isto é, em cada setor a variação do produto deve crescer juntamente com a variação do estoque de capital para aquele setor em específico $\left(\frac{u_{1}}{v_{1}}=\frac{u_{2}}{v_{2}}=1\right)$. Percebe-se também que isto não significa assumir a hipótese clássica de deslocamento dos bens de capital entre os diversos setores de tal forma que a taxa de investimento se iguale no longo prazo.

Como visto, em Pasinetti, os bens de capital são específicos para cada setor e não se assume o deslocamento, mas mostra-se à qual taxa o bem de capital deve crescer para que o setor se mantenha em equilíbrio no longo prazo. Ou seja, Pasinetti não adota o deslocamento de bens de capital entre os setores, mas somente intrassetores, isto é, há deslocamento dos bens de capital da indústria produtora desta para a indústria produtora de bens de consumo.

A taxa de crescimento dos bens de capital é determinada pela demanda e foi derivada no capítulo anterior, ela corresponde à taxa de crescimento natural de Pasinetti, $\varphi_{\mathrm{i}}+\eta$. Portanto, no modelo de Pasinetti o produto de longo prazo não é dado pela oferta conforme preconizado na Lei de Say, mas pela demanda.

Além de mostrarmos que a partir do modelo de Pasinetti é possível obter o modelo de Kalecki de dois setores, afirmou-se na primeira subseção deste capítulo a necessidade de se obter as tendências de longo prazo. No capítulo anterior, uma dessas tendências foi obtida a partir de Pasinetti, que endogeneizou a taxa de lucro natural por meio da taxa de variação da demanda setorial e da taxa de crescimento da população. Resta, então, endogeneizar a taxa de utilização da capacidade natural. 


\subsection{A ENDOGENIZAÇÃO DA TAXA NATURAL DE UTILIZAÇÃO DA CAPACIDADE}

\subsubsection{Endogenizando no modelo de apenas um bem}

Para facilitar a compreensão, inicialmente aborda-se o modelo com uma firma representativa, cujo produto é bem de capital e consumo simultaneamente nos moldes do modelo de Kalecki discutido no segundo capítulo. Para endogeneizar a taxa natural de longo prazo leva-se em consideração não somente os fatores determinantes da demanda, mas também da oferta. Isso é relevante, pois a taxa de utilização da capacidade natural é aquela que mantém a economia em equilíbrio, conforme demonstrado por Pasinetti, $\dot{X}=\dot{K}$. No primeiro capítulo verifica-se que no modelo de Kalecki as considerações sobre o lado da oferta estão representadas na curva de profit-cost, a qual representa os microfundamentos do modelo por meio da representação agregada dos custos de produção. No modelo a ser apresentado nesta seção, o lado da oferta corresponde ao montante de estoque de capitais, fator determinante do crescimento de longo prazo na economia sem progresso tecnológico.

Analisar o lado da oferta não significa afirmar que é a oferta que determina a demanda, mas sim reconhecer que a manutenção da taxa de crescimento de longo prazo exige que os insumos produzidos acompanhem pari passu o crescimento do produto no setor verticalmente integrado. No entanto, continua sendo a demanda pelo bem de consumo final que determina a produção dos insumos.

Para realizar a análise do lado da oferta retoma-se o modelo de Feldman (1929) apresentado na subseção anterior, no qual $X=\min \left[\frac{K}{v}, \frac{L}{u}\right]$. Como se assume abundância de trabalhadores, o insumo necessário a ser produzido para que não haja descompasso entre a demanda pelo bem final e a capacidade produtiva da economia é o bem de capital.

Deste modo, no longo prazo o lado da oferta é dado por:

$$
\dot{K}=I
$$

Dado que estamos considerando nesta subseção apenas um setor, no longo prazo igualamos a poupança ao investimento, $I=S=s X$, onde $\mathrm{s}=$ taxa de poupança da economia $^{84}$. Assim, se dividirmos (4.52) por K, temos:

\footnotetext{
${ }^{84}$ Aqui não se faz a distinção entre a taxa de poupança dos trabalhadores e dos capitalistas. No entanto, para manter a semelhança com o modelo de Kalecki, pode-se assumir que os trabalhadores não poupam, $\log \mathrm{s}=\mathrm{s}_{\mathrm{p}}$.
} 


$$
\frac{\dot{K}}{K}=\frac{\dot{X}}{X}=\frac{s}{v}=g
$$

Interessante observar que (4.53) nada mais é do que a equação fundamental de Harrod, (2.5). Logo, a oferta de bens de capital é determinada pela taxa de crescimento efetiva de Harrod. Este resultado é qualificado a partir da próxima subseção, pois se passa a discutir o modelo com mais de um setor. De toda forma, é interessante observar que a partir de Feldman chega-se a Harrod.

Com relação ao lado da demanda, retoma-se a curva de demanda efetiva (investimento) do modelo de Kalecki abaixo reescrita:

$$
\mathrm{g}=\alpha+\beta r+\gamma \mu
$$

Igualando-se (4.54) à (4.53), obtém-se a taxa natural de utilização da capacidade:

$$
u^{N}=\left[\frac{s}{v}-\alpha-\beta r\right] \gamma^{-1}
$$

O resultado (4.55) é interessante, pois mostra exatamente o valor da taxa de utilização da capacidade normal compatível com a plena utilização da capacidade. Sabendo que $r=\frac{h u}{v}$, percebe-se também que esse resultado de longo prazo depende do comportamento da taxa de utilização da capacidade de curto prazo obtida por Kalecki, $\mu^{*}$. Ou seja, $u^{N}$ não é uma variável ad hoc conforme assumido na maioria dos modelos pós-keynesianos.

Este importante resultado, (4.55), foi obtido a partir da curva de demanda efetiva do modelo de Kalecki. Se adotarmos a do modelo de Bhaduri e Marglin (1990), que se aproxima da interpretação neo-ricardiana, tem-se resultado diverso para a taxa de utilização da capacidade normal, que seria dada por:

$$
u^{N^{\prime}}=\left[\frac{s}{v}-\alpha-\beta h\right] \gamma^{-1}
$$

Observa-se que os resultados da endogenização são diferentes a depender da função de demanda efetiva utilizada. No entanto, ao nível natural $\frac{u}{v}=1, \operatorname{logo} r=h$. Isso significa que no equilíbrio natural de longo prazo não há diferença em se considerar o investimento 
determinado pela taxa de lucro ou pelo profit share, ou seja, ao trabalhar com a economia em estágio natural resolve-se a discordância entre o modelo kaleckiano canônico e o modelo póskaleckiano.

Além disso, mostra-se que a taxa de utilização da capacidade natural é diferente da endogeinização de curto prazo obtida no modelo kaleckiano representada em (2.46). Esta diferença era esperada, devido à consideração do lado da oferta a partir do modelo de Feldman ao invés dos custos de produção (profit-cost) e por $\frac{u}{v} \neq 1$.

Uma vez obtida a taxa de utilização da capacidade natural e dada a taxa de lucro natural de Pasinetti, obtém-se a taxa de crescimento natural, que nada mais é do que a taxa de crescimento de Harrod. Em resumo, tem-se (4.56), (3.37) e (4.53) $)^{85}$ :

$$
\begin{gathered}
u^{N}=\left[\frac{s}{v}-\alpha-\beta h\right] \gamma^{-1} \\
r_{i}^{N A}=\eta+\varphi_{\mathrm{i}} \\
g^{N}=\frac{s}{v}
\end{gathered}
$$

Comparando estes resultados com os obtidos no modelo kaleckiano descrito no primeiro capítulo, a priori poder-se-ia questionar o motivo da não existência do paradoxo da poupança, elemento fundamental dos modelos pós-keynesianos. Para compreender o resultado obtido, basta rever as equações (4.52) e (4.53). Nessas equações verifica-se que a poupança, a qual é determinada pelo investimento, está representando o estoque de capital que constitui o "teto" de crescimento da economia (ver Gráfico 4.1). Portanto, a ampliação da taxa de poupança, não significa redução do consumo (o que ocorre no curto prazo), mas sim a elevação do investimento para se manter a taxa de crescimento da economia ano nível natural $^{86}$.

Em adendo, é interessante observar que a endogeinização da taxa de utilização da capacidade natural elimina a instabilidade da taxa de crescimento da economia identificada por Harrod, pois as variáveis que compõem o investimento se ajustam de modo a, no máximo, atingirem o crescimento dado pela equação fundamental de Harrod.

\footnotetext{
${ }^{85}$ Repetiu-se a numeração das equações da forma como apresentadas anteriormente.

${ }^{86}$ Este argumento é esclarecido nas subseções seguintes, nas quais se mostra que a propensão a poupar é substituída pela proporção dos bens de capitais que são empregados na produção de novos bens de capitais.
} 
Gráfico 4.1 - Taxa de crescimento natural e taxa de crescimento de curto prazo

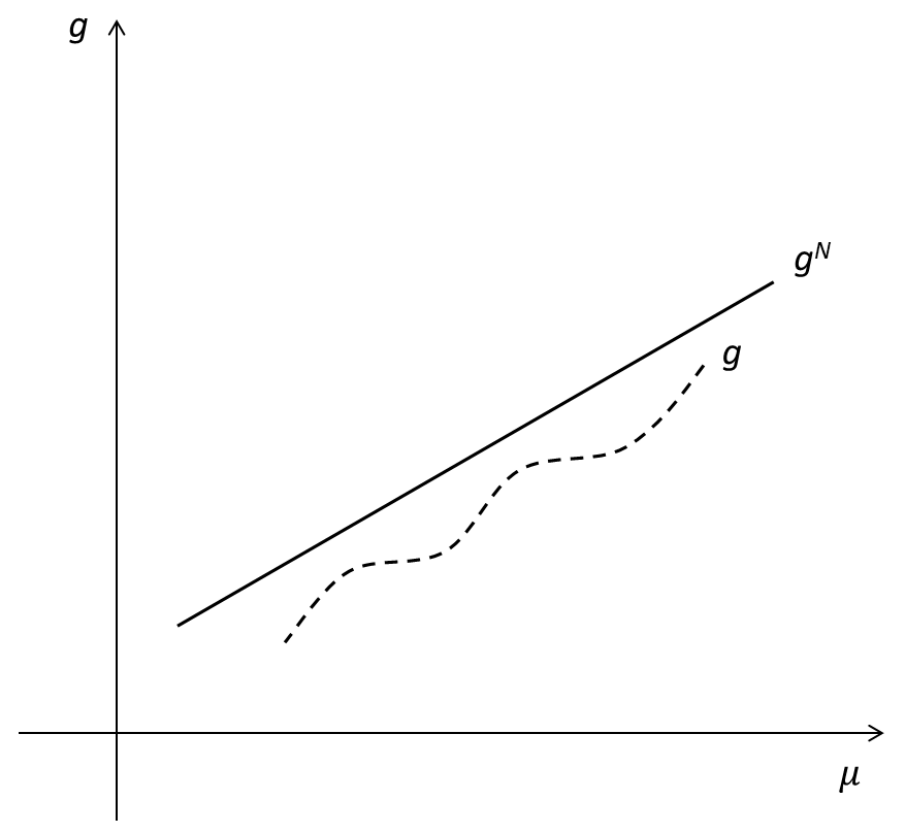

\subsubsection{Endogenizando no modelo de dois bens}

Inicialmente discute-se o modelo de dois setores, no qual o setor 1 é produtor de bens de consumo e o setor 2 de bens de capital. Assim como na seção anterior, procura-se analisar o lado da oferta a partir do modelo de Feldman (1929), de tal forma que $X_{1}=\min \left[\frac{K_{1}}{v_{1}}, \frac{L_{1}}{u_{1}}\right]$ e $X_{2}=\min \left[\frac{K_{2}}{v_{2}}, \frac{L_{2}}{u_{2}}\right]$.

Dada a abundância de trabalhadores, para que a economia permaneça em equilíbrio no longo prazo é a produção do setor 2 que deve acompanhar a demanda do bem final produzida pelo setor 1 .

No equilíbrio de longo prazo, o lado da oferta é dado por:

$$
\begin{aligned}
& \dot{K}_{1}=I_{1}=X_{1} \\
& \dot{K}_{2}=I_{2}=X_{2}
\end{aligned}
$$


Dado que somente o setor dois produz bens de capital, conforme destacado por Feldman, a taxa de crescimento de cada setor depende da proporção do bem de capital a este alocado $^{87}$, isto é representado por (4.45) e (4.46) dos quais se obtém:

$$
\begin{gathered}
\frac{\dot{K_{1}}}{K_{1}}=\frac{(1-\lambda) X_{2}}{K_{1}}=\frac{1-\lambda}{v_{2}} \frac{K_{2}}{K_{1}} \\
\frac{\dot{K_{2}}}{K_{2}}=\frac{\lambda X_{2}}{K_{2}}=\frac{\lambda}{v_{2}}
\end{gathered}
$$

Sendo $\lambda$ o percentual de bens de capital alocado para a produção de novos bens de capital.

Igualando (4.57) a (4.59) e (4.58) a (4.60) verifica-se que:

$$
\begin{gathered}
g_{1}=\frac{1-\lambda}{v_{2}} \frac{K_{2}}{K_{1}} \\
g_{2}=\frac{\lambda}{v_{2}}
\end{gathered}
$$

Aplicando o limite à (4.61), verifica-se que $g_{1}=\frac{1-\lambda}{v_{2}} \frac{\lambda}{1-\lambda}=\frac{\lambda}{v_{2}}=g_{2}$, isto é, no longo prazo (período de investimento) é o crescimento da produção de bens de capital que determina a taxa de crescimento total da economia. Tal fato coaduna com a hipótese de setores verticalmente integrados adotada neste trabalho e com o princípio do crescimento natural de Pasinetti. Este resultado, obtido inicialmente no modelo de Feldman (1929), é importante, pois soluciona uma das fragilidades identificadas por Park (1995) em Dutt (1990). Conforme descrito na segunda subseção deste capítulo, Dutt afirma que no longo prazo a função de acumulação será a mesma para os dois setores e dada por (4.16), eliminando-se assim a instabilidade do investimento presente em Kalecki. No entanto, a partir de Feldman percebe-se que não é necessário abandonar (4.8) e (4.9) em prol de (4.16), pode-se continuar considerando a diferença entre as taxas de acumulação entre os setores, mas no longo prazo o que limita o crescimento é o comportamento do setor de bens de capital.

Veja-se agora o lado da demanda. Iniciando pelo modelo de Kalecki tem-se:

\footnotetext{
${ }^{87}$ Importante relembrar que estamos trabalhando com modelo sem progresso tecnológico e sem depreciação, por isso o crescimento é dado pela ampliação do estoque de capital.
} 


$$
\begin{aligned}
& g_{1}=\alpha_{1}+\beta_{1} r_{1}+\gamma_{1} \mu_{1} \\
& g_{2}=\alpha_{2}+\beta_{2} r_{2}+\gamma_{2} \mu_{2}
\end{aligned}
$$

Igualando (4.61) a (4.63) e (4.62) a (4.64), obtém-se a taxa natural de utilização da capacidade em cada setor, de forma semelhante ao realizado na subseção anterior.

$$
\begin{aligned}
& u_{1}^{N}=\left[\frac{\lambda}{v_{2}}-\alpha_{1}-\beta_{1} r_{1}\right] \gamma_{1}^{-1} \\
& u_{2}^{N}=\left[\frac{\lambda}{v_{2}}-\alpha_{2}-\beta_{2} r_{2}\right] \gamma_{2}^{-1}
\end{aligned}
$$

A endogeinização da taxa de utilização da capacidade normal em cada setor pode ser melhor compreendida se relembrarmos os seguintes resultados obtidos no capítulo:

$$
\begin{gathered}
r_{1}=\left(\frac{\theta_{1}}{1+\theta_{2}}\right)\left(\frac{l_{1}}{l_{2}}\right)\left(\frac{u_{1}}{v_{1}}\right) \\
r_{2}=\left(\frac{\theta_{2}}{1+\theta_{2}}\right)\left(\frac{u_{2}}{v_{2}}\right) \\
\left(\varphi_{2}+\eta\right)=\lambda
\end{gathered}
$$

Substituindo estes resultados em (4.65) e (4.66) obtém-se respectivamente:

$$
\begin{aligned}
& u_{1}^{N}=\left[\frac{\varphi_{2}+\eta}{v_{2}}-\alpha_{1}-\beta_{1}\left(\frac{\theta_{1}}{1+\theta_{2}}\right)\left(\frac{l_{1}}{l_{2}}\right)\left(\frac{u_{1}}{v_{1}}\right)\right] \gamma_{1}^{-1} \\
& u_{2}^{N}=\left[\frac{\varphi_{2}+\eta}{v_{2}}-\alpha_{2}-\beta_{2}\left(\frac{\theta_{2}}{1+\theta_{2}}\right)\left(\frac{u_{2}}{v_{2}}\right)\right] \gamma_{2}^{-1}
\end{aligned}
$$

Essas equações são interessantes, pois demonstram que a taxa de crescimento da demanda por bens de capital determina o "teto" da taxa de utilização da capacidade em ambos os setores, além disso, verifica-se que a taxa de utilização da capacidade de curto prazo afeta o valor da taxa de utilização da capacidade natural de longo prazo conforme preconizado por Kalecki. 
Essa endogeinização poderia ser realizada a partir do modelo de Bhaduri e Marglin, mas como $h_{1}$ e $h_{2}$ são exógenos, dados respectivamente por $h_{1}=\left(\frac{\theta_{1}}{1+\theta_{2}}\right)\left(\frac{l_{1}}{l_{2}}\right)$ e $h_{2}=\frac{\theta_{2}}{1+\theta_{2}}$, ao substituirmos $h_{1}$ e $h_{2}$ em (4.65) e (4.66), iremos obter o mesmo resultado de (4.67) e (4.68), desde que $\frac{u_{1}}{v_{1}}=\frac{u_{2}}{v_{2}}=1$. Entretanto, esta é exatamente a condição exposta por Pasinetti para que se mantenha o equilíbrio natural no longo prazo. Assim, novamente demonstra-se que no longo prazo, seja no modelo kaleckiano seja no modelo neo-ricardiano, os resultados da taxa de utilização natural da capacidade são similares.

Em resumo, no modelo com dois setores, o resultado da endogeinização da taxa de crescimento natural é dado por (4.67), (4.68), (3.37) e (4.62):

$$
\begin{gathered}
u_{1}^{N}=\left[\frac{\varphi_{2}+\eta}{v_{2}}-\alpha_{1}-\beta_{1}\left(\frac{\theta_{1}}{1+\theta_{2}}\right)\left(\frac{l_{1}}{l_{2}}\right)\left(\frac{u_{1}}{v_{1}}\right)\right] \gamma_{1}^{-1} \\
u_{2}^{N}=\left[\frac{\varphi_{2}+\eta}{v_{2}}-\alpha_{2}-\beta_{2}\left(\frac{\theta_{2}}{1+\theta_{2}}\right)\left(\frac{u_{2}}{v_{2}}\right)\right] \gamma_{2}^{-1} \\
r_{1}^{N}=\varphi_{1}+\eta \\
r_{2}^{N}=\varphi_{2}+\eta=\lambda \\
g_{1}^{N}=g_{2}^{N}=\frac{\lambda}{v_{2}}=\frac{\varphi_{2}+\eta}{v_{2}}
\end{gathered}
$$

As taxas naturais representadas acima nos permitem tirar diversas conclusões:

1. Relação entre a taxa de lucro natural de Pasinetti e o profit share em cada setor $^{88}, r_{1}^{N}=\varphi_{1}+\eta=\left(\frac{\theta_{1}}{1+\theta_{2}}\right)\left(\frac{l_{1}}{l_{2}}\right)$ e $r_{2}^{N}=\varphi_{2}+\eta=\left(\frac{\theta_{2}}{1+\theta_{2}}\right)$;

2. O crescimento da economia é dado pela ampliação da demanda por bens de capital;

3. A ampliação da demanda por bens de capital, ao elevar a taxa de lucro natural, mantém constante a taxa de utilização da capacidade deste setor. No entanto, se houver ampliação da demanda por bens de consumo, ao se ampliar a taxa de lucro natural verifica-se a redução da taxa de utilização natural deste setor.

\footnotetext{
${ }^{88}$ Este resultado é interessante, pois mostra que se pode relacionar a taxa de lucro natural de Pasinetti a fatores institucionais, no caso a existência de mercados oligopolizados adotada por Kalecki.
} 
Tais conclusões nos direcionam para o tema abordado na introdução deste capítulo, no qual se afirmou que no modelo de dois ou mais setores seria possível identificar os efeitos das diferentes taxas de lucro entre os setores e os pressupostos que garantem a tendência à equalização dos lucros no longo prazo assumida pelos clássicos e nos modelos de Park e Dutt.

Do modelo de Feldman percebe-se que, sob dois setores verticalmente integrados, a taxa de crescimento da economia no longo prazo é dada pela taxa de crescimento do setor produtor de bens de capital $\left(g_{1}=\frac{1-\lambda}{v_{2}} \frac{\lambda}{1-\lambda}=\frac{\lambda}{v_{2}}=g_{2}\right)$. No entanto, de (4.63) e (4.64) inferese que as variáveis que determinam o investimento não necessariamente serão iguais entre os setores, ou seja, é possível que no longo prazo os profit-share (ou as taxas de lucro) e as taxas de utilização da capacidade sejam diferentes entre os setores. Isto também é evidenciado a partir das taxas endógenas obtidas anteriormente.

Em particular, as equações (4.65) e (4.66) mostram que existe relação entre o profit share (ou taxa de lucro) e o comportamento da taxa natural de utilização da capacidade. Deste modo, é possível identificar três comportamentos de ambos os setores, nos quais inicialmente estamos supondo que os parâmetros do investimento são iguais, $\alpha_{1}=\alpha_{2}, \beta_{1}=\beta_{2}$ e $\gamma_{1}=$ $\gamma_{2}$ :
a) $u_{1}^{N}=u_{2}^{N}$, logo $r_{1}=r_{2}$;
b) $u_{1}^{N}<u_{2}^{N}$, logo $r_{1}>r_{2}$;
c) $u_{1}^{N}>u_{2}^{N}, \log 0 r_{1}<r_{2}$

De (4.69) interpreta-se respectivamente que:

1. O pressuposto necessário para a equalização das taxas de lucro entre os setores é a igualdade entre as taxas normais de utilização da capacidade entre os setores;

2. Caso a taxa normal de utilização da capacidade do setor de bens de capital seja superior à do setor de bens de consumo, a taxa de lucro no setor de bens de consumo será superior ao setor de bens de capital;

3. Caso a taxa normal de utilização da capacidade do setor de bens de consumo seja superior à do setor de bens de capital, a taxa de lucro no setor de bens de consumo será inferior ao setor de bens de capital.

Sabendo que o crescimento natural da economia é dado por $\frac{\lambda}{v_{2}}$, e que $r_{2}^{N}=\varphi_{2}+\eta=$ $\lambda$, dentre as situações expressas em (4.69) espera-se que a segunda conclusão não se perpetue, pois em certo momento para se manter o crescimento do setor de bens de consumo será 
necessário ampliar a produção de bens de capital e isso somente ocorrerá se houver demanda. Ou seja, esse caso é insustentável em longo prazo.

Observe que os resultados presentes em (4.69) foram obtidos a partir da hipótese de que $\alpha_{1}=\alpha_{2}, \beta_{1}=\beta_{2}$ e $\gamma_{1}=\gamma_{2}$. Essa hipótese pode ser relaxada, o que generaliza as conclusões. Esse relaxamento envolve certa complexidade, pois é necessário adotar hipóteses a respeito do comportamento dos parâmetros. A título de exemplificação supõe-se que $\alpha_{1}<\alpha_{2}, e \gamma_{1}>\gamma_{2}$, nesse caso verifica-se que para obter-se $u_{1}^{N}=u_{2}^{N}$ é necessário que $\beta_{1}>\beta_{2} \frac{h_{2}}{h_{1}} \frac{\gamma_{2}^{-1}}{\gamma_{1}^{-1}}+\frac{\lambda_{2}}{v_{2} h_{1}}-\frac{\lambda_{2}}{v_{2} h_{1}} \frac{\gamma_{2}^{-1}}{\gamma_{1}^{-1}}$.

Conclui-se que as condições para que a taxa de lucro seja equalizada entre os setores são particulares e dadas por: 1) $u_{1}^{N}=u_{2}^{N}$ se $\alpha_{1}=\alpha_{2}, \beta_{1}=\beta_{2}$ e $\gamma_{1}=\gamma_{2}$;2) da produção de bens de capital, $\left(\varphi_{2}+\eta\right)=\lambda$ seja realocado para a produção de novos bens de capital e $\left(1-\left(\varphi_{2}+\eta\right)\right)=1-\lambda$ seja alocado para a produção de bens de consumo. Ou seja, não é o diferencial de taxa de lucro que determina o deslocamento dos bens de capital de modo a igualar a taxa de lucro entre os setores, mas sim a igualdade das taxas normais de utilização da capacidade, uma vez que a alocação de bens de capital entre os setores é exogenamente determinada por $\varphi_{2}+\eta$. Esta conclusão é interessante, pois se mostra a possibilidade de manutenção do diferencial entre a taxa de lucro dos setores sem que ocorra tendência a sua equalização.

No que diz respeito aos regimes de crescimento, (4.69) nos mostra que à taxa natural, para a economia como um todo, é a ampliação do profit-share no setor de bens de capital que promove o crescimento. Isso porque é o estoque de bens de capital que limita o crescimento na economia em discussão. Tem-se, assim, que a economia é profit-led à taxa natural. No entanto, mostrou-se que não há garantia de equalização da taxa de lucro entre os setores, assim, de (4.69) tem-se que para o setor de bens de consumo quanto maior o wage share, maior o crescimento. Isso significa que os resultados obtidos no capítulo anterior continuam válidos na ausência de manutenção do equilíbrio natural, ou seja, interpretando-se a taxa de lucro a partir da taxa de lucro natural, no longo prazo a economia somente será profit-led caso haja a equalização da taxa de lucro entre os setores. Caso contrário a economia pode ser wage-led ou profit-led. Uma vez que as condições para equalização da taxa de lucro são restritivas, é de se esperar a predominância de diversos regimes de crescimento.

Na próxima subseção a discussão é estendida para o modelo multissetorial. 


\subsubsection{Endogeneizando no modelo multissetorial}

Nesta subseção retoma-se o modelo multissetorial pasinettiano discutido na seção 3.4 do capítulo anterior, em particular a subseção 3.4.2 na qual se expõe o modelo de produção sem progresso tecnológico. Para facilitar a compreensão repetem-se abaixo as hipóteses adotadas no modelo:

- Economia desenvolvida, fechada e sem governo;

- Trabalhadores uniformemente qualificados (recebem o mesmo salário);

- $\quad N$ setores na economia, sendo o $n$-ésimo a força de trabalho;

- A economia produz bens de capital e bens de consumo;

- Na produção de bens de capital utiliza-se apenas o trabalho como insumo (esta hipótese é importante, pois permite reduzir todos os insumos a trabalho economia de puro trabalho);

- Para cada bem de consumo final existe um bem de capital específico;

- Não há depreciação do estoque de capital ${ }^{89}$.

Para expor este modelo multissetorial devemos adequar a notação de modo a manter a similaridade frente às duas subseções anteriores, assim denominamos $X_{1}=$ a quantidade produzida do bem de consumo final no primeiro setor e $X_{K_{1}}=$ a quantidade de bens de capital utilizado na produção do bem $X_{1}$ e no próprio $X_{K_{1}}$. Conforme o modelo de Pasinetti, teremos $X_{1}, \ldots \ldots \ldots, X_{(n-1)}$ bens de consumo finais e respectivamente $X_{K_{1}}, \ldots \ldots \ldots \ldots, X_{K_{(n-1)}}$ bens de capital.

O setor $X_{n}$ corresponde à oferta de trabalho que ao mesmo tempo entra na produção dos diversos bens de capital e consumo e consiste no setor que demanda os bens de consumo finais. Como destacado, percebe-se das hipóteses elencadas acima que no modelo original de Pasinetti para a produção de $X_{K_{1}}, \ldots \ldots \ldots \ldots \ldots, X_{K_{(n-1)}}$ utiliza-se apenas o insumo trabalho. No entanto, de forma semelhante ao assumido na subseção 4.3 deste capítulo, esta hipótese é abandonada e assume-se que para a produção de bens de capital são utilizados os mesmos bens de capital e trabalho.

O Gráfico 4.2 abaixo apresenta a relação multissetorial proposta no modelo. Pasinetti, de modo semelhante a Kalecki, assume a oferta determinada pela demanda. Nesta subseção, assim como nas anteriores, recorre-se ao modelo de Feldman (1929) para analisar o lado da

\footnotetext{
${ }^{89}$ Esta hipótese não é adota por Pasinetti (1981), no entanto a utilizamos para facilitar a compreensão do modelo e atingir o objetivo deste capítulo.
} 
oferta de tal forma que $X_{1}=\min \left[\frac{K_{1}}{v_{1}}, \frac{L_{1}}{u_{1}}\right], \quad X_{K_{1}}=\min \left[\frac{K_{K_{1}}}{v_{K_{1}}}, \frac{L_{K_{1}}}{u_{K_{1}}}\right], \ldots \ldots .$. $X_{n-1}=\min \left[\frac{K_{(n-1)}}{v_{(n-1)}}, \frac{L_{(n-1)}}{u_{(n-1)}}\right], X_{K_{n-1}}=\min \left[\frac{K_{K_{(n-1)}}}{v_{K_{(n-1)}}}, \frac{L_{K_{(n-1)}}}{u_{K_{(n-1)}}}\right]$.

Gráfico 4.2 - Modelo multissetorial

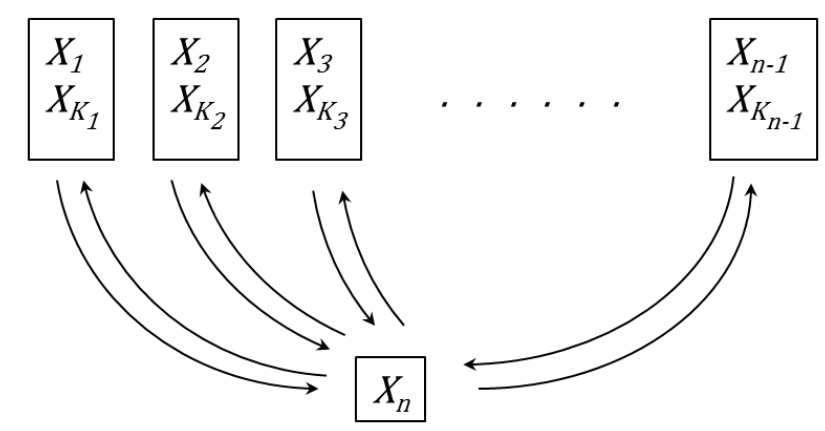

Assume-se que não há restrição por parte do setor trabalho de tal forma que é a ausência de bens de capital que pode limitar a expansão da produção desta economia e sabe-se que a manutenção do crescimento em equilíbrio de cada setor exige que $\dot{X}_{n-1}=\dot{X}_{K_{n-1}}$.

Desta forma, no equilíbrio de longo prazo, para cada setor teríamos:

$$
\begin{gathered}
\dot{X}_{1}=I_{1}=X_{1} \\
\dot{X}_{K_{1}}=I_{K_{1}}=X_{K_{1}} \\
\vdots \\
\vdots \\
X_{n-1}^{\cdot}=I_{n-1}=X_{n-1} \\
\dot{X}_{K_{n-1}}=I_{K_{n-1}}=X_{K_{n-1}}
\end{gathered}
$$

Importante destacar que (4.70) a (4.73) estão representando setores verticalmente integrados, os quais são compostos por duas indústrias, uma que produz o bem de consumo final e outra que produz o bem de capital. Na subseção anterior assumimos que $X_{1}$ é verticalmente integrado a $X_{2}$. Agora na representação acima isso não ocorre, pois $X_{1}$ é 
verticalmente integrado a $X_{K_{1}}, X_{2}$ a $X_{K_{2}}$ e assim por diante. Não há relação estabelecida entre $X_{1}, X_{2} \ldots$. e $X_{n-1}{ }^{90}$.

De modo semelhante ao realizado na subseção anterior, pode-se obter a taxa de crescimento de cada indústria deste modelo. Para isso basta obter a taxa de crescimento dos bem de capital utilizado em cada indústria, o que é realizado da seguinte forma:

$$
\begin{gathered}
\frac{\dot{K}_{1}}{K_{1}}=\frac{\left(1-\lambda_{1}\right) X_{K_{1}}}{K_{1}}=\frac{1-\lambda_{1}}{v_{1}} \\
\frac{\dot{K}_{K_{1}}}{X_{K_{1}}}=\frac{\lambda_{1} X_{K_{1}}}{K_{K_{1}}}=\frac{\lambda_{1}}{v_{K_{1}}} \\
\vdots \\
\frac{\dot{K}_{n-1}}{K_{n-1}}=\frac{\left(1-\lambda_{n-1}\right) X_{K_{(n-1)}}}{K_{n-1}}=\frac{1-\lambda_{n-1}}{v_{K_{n-1}}} \frac{K_{K_{(n-1)}}}{K_{n-1}} \\
\frac{\dot{K}_{K_{n-1}}}{X_{K_{n-1}}}=\frac{\lambda_{n-1} X_{K_{(n-1)}}}{K_{K_{(n-1)}}}=\frac{\lambda_{n-1}}{v_{K_{(n-1)}}}
\end{gathered}
$$

Como os diversos setores são verticalmente integrados, naturalmente espera-se que $g_{(n-1)}=g_{K_{n-1}}$. Para verificar essa igualdade novamente recorre-se a Feldman, dado que somente uma indústria em cada setor é produtora de bens de capital, no caso $X_{K_{(n-1)}}$, e esta aloca bens de capital para a sua própria produção, $\lambda_{n-1}$, e o restante, $\left(1-\lambda_{n-1}\right)$ é alocado para a produção do bem de consumo final $X_{n-1}$. Assim como na subseção anterior, aplicando-se o limite na equação (4.76) verifica-se que $g_{(n-1)}=\frac{1-\lambda_{n-1}}{v_{K_{n-1}}} \frac{\dot{K}_{K_{n-1}}}{\dot{K}_{n-1}}=\frac{1-\lambda_{n-1}}{v_{K_{n-1}}} \frac{\lambda_{n-1}}{1-\lambda_{n-1}}=\frac{\lambda_{n-1}}{v_{K_{n-1}}}=$ $g_{K_{n-1}}$. Logo, de modo semelhante ao obtido na subseção anterior, é a taxa de crescimento do setor de bens de capital que determina a taxa de crescimento natural da economia.

Uma vez discutido o lado da oferta a partir do modelo de Feldman, torna-se necessário analisar o lado da demanda, o qual seja no modelo de Pasinetti seja no kaleckiano determina o comportamento da oferta. No modelo multissetorial de Pasinetti de (3.11) sabe-se que a demanda é determinada pelos gastos da população $\left(X_{n}\right)$ seja no setor de bens de consumo

\footnotetext{
${ }^{90}$ Trata-se apenas de modificação na notação.
} 
quanto nos setores de bens de capital, em particular tem-se respectivamente $\left(a_{i n}\right) X_{n}$ e $\left(a_{k i n}\right) X_{n}$, nos quais $a_{i n}$ e $a_{k i n}$ representam os coeficientes de consumo.

Pasinetti não detalha a natureza do comportamento dos coeficientes de consumo. Isso é compreensível, pois o seu modelo como visto no segundo capítulo é pré-institucional ${ }^{91}$. No entanto, mostrou-se neste capítulo que o modelo multissetorial de Pasinetti é semelhante ao modelo de Kalecki, isso significa que as características institucionais kaleckianas podem ser inseridas no modelo multissetorial de Pasinetti. Identificar essa funcionalidade é fundamental para o propósito deste capítulo, pois torna-se possível assumir o comportamento do consumo dos trabalhadores.

Conforme exposto no segundo capítulo, a economia de Kalecki é constituída por trabalhadores e capitalistas. Os trabalhadores auferem salários e os capitalistas lucros, de tal forma que a dinâmica da economia é determinada pelos gastos dos capitalistas. Os trabalhadores gastam o que ganham e os capitalistas ganham o que gastam ${ }^{92}$. Desta forma, de modo a manter a coerência dos procedimentos realizados nas subseções anteriores, considerase como coeficiente de consumo a função investimento de Kalecki. O argumento para tal é que os capitalistas, ao decidirem investir, contratam trabalhadores, os quais por sua vez auferem renda e consomem o que necessitam, logo é o gasto em investimento que determina o consumo de bens de capital e de bens de consumo. Deste modo, as funções de demanda são:

$$
\begin{gathered}
g_{1}=\alpha_{1}+\beta_{1} r_{1}+\gamma_{1} \mu_{1} \\
g_{K_{1}}=\alpha_{K_{1}}+\beta_{K_{1}} r_{K_{1}}+\gamma_{K_{1}} \mu_{K_{1}} \\
\vdots \\
\vdots \\
g_{(n-1)}=\alpha_{(n-1)}+\beta_{(n-1)} r_{(n-1)}+\gamma_{(n-1)} \mu_{(n-1)} \\
g_{K_{n-1}}=\alpha_{K_{n-1}}+\beta_{K_{n-1}} r_{K_{n-1}}+\gamma_{K_{n-1}} \mu_{K_{n-1}}
\end{gathered}
$$

Logo, a taxa natural de utilização da capacidade em cada indústria é obtida ao se igualar (4.74) a (4.77) com (4.78) a (4.81):

\footnotetext{
91 Esta afirmação deve ser relativizada, pois Pasinetti apesar de não expor formalmente as variáveis que determinam os coeficientes de consumo afirma que a economia segue a Lei de Engel. Isto é, à medida que renda aumenta, eleva-se o consumo de bens de maior valor agregado.

${ }^{92}$ Ver seção 2.4 .
} 


$$
\begin{gathered}
u_{1}^{N}=\left[\frac{\lambda_{1}}{v_{K_{1}}}-\alpha_{1}-\beta_{1} r_{1}\right] \gamma_{1}^{-1} \\
u_{K_{1}}^{N}=\left[\frac{\lambda_{1}}{v_{K_{1}}}-\alpha_{K_{1}}-\beta_{K_{1}} r_{K_{1}}\right] \gamma_{K_{1}}^{-1} \\
\vdots \\
\vdots \\
u_{(n-1) 1}^{N}=\left[\frac{\lambda_{n-1}}{v_{K_{n-1}}}-\alpha_{(n-1)}-\beta_{(n-1)} r_{(n-1)}\right] \gamma_{(n-1)}^{-1} \\
u_{K_{n-1}}^{N}=\left[\frac{\lambda_{n-1}}{v_{K_{n-1}}}-\alpha_{K_{n-1}}-\beta_{K_{n-1}} r_{K_{n-1}}\right] \gamma_{K_{n-1}}^{-1}
\end{gathered}
$$

Caso se adote a função investimento de Bhaduri e Marglin, o resultado seria semelhante, pois como demonstramos na subseção anterior sob a hipótese de equilíbrio no modelo multissetorial a taxa de lucro se iguala ao profit-share. E como seria de se esperar, os resultados da endogeinização para cada setor são semelhantes aos obtidos na subseção anterior:

$$
\begin{gathered}
u_{(n-1)}^{N}=\left[\frac{\lambda_{n-1}}{v_{K_{n-1}}}-\alpha_{(n-1)}-\beta_{(n-1)} r_{(n-1)}\right] \gamma_{(n-1)}^{-1} \\
u_{K_{n-1}}^{N}=\left[\frac{\lambda_{n-1}}{v_{K_{n-1}}}-\alpha_{K_{n-1}}-\beta_{K_{n-1}} r_{K_{n-1}}\right] \gamma_{K_{n-1}}^{-1} \\
r_{(n-1)}^{N}=\varphi_{(n-1)}+\eta \\
r_{K_{n-1}}^{N}=\varphi_{K_{n-1}}+\eta=\lambda_{n-1} \\
g_{(n-1)}^{N}=g_{K_{n-1}}^{N}=\frac{\lambda_{1}}{v_{K_{n-1}}}=\frac{\varphi_{K_{n-1}+\eta}}{v_{K_{n-1}}}
\end{gathered}
$$

Compete-nos destacar os efeitos das diferentes taxas de lucro entre os setores, que no modelo multissetorial proporciona resultados mais interessantes do que o presente no modelo de dois setores. Assim como na subseção anterior, dado que as variáveis que determinam o investimento não são iguais entre os setores é factível que no longo prazo as taxas de lucros se 
mantenham diferentes entre cada indústria a qual compõe os $(n-1)$ setores de produção. Mas supondo que as variáveis sejam iguais, $\alpha_{(n-1)}=\alpha_{K_{n-1}}, \beta_{(n-1)}=\beta_{K_{n-1}}$ e $\gamma_{(n-1)}=\gamma_{K_{n-1}}$, obtém-se a mesma conclusão que (4.74), isto é, a condição para a equalização da taxa de lucro em cada indústria, $r_{(n-1)}=r_{K_{n-1}}$, é a igualdade entre as taxa de utilização normal da capacidade, $u_{(n-1)}^{N}=u_{K_{n-1}}^{N}$. Pois bem, desde a subseção anterior estão identificados os condicionantes para a equalização da taxa de lucros intra indústria, e viu-se que eles são restritivos, uma vez que dificilmente deve ocorrer a igualdade dos parâmetros. Todavia, a título de elucidação das conclusões, vamos manter esta hipótese e analisar o comportamento da equalização da taxa de lucro entre os setores com o intuito de contribuir para a compreensão da dinâmica entre o curto e o longo prazo. A priori, é importante relembrar que tanto no modelo de Pasinetti quanto no de Kalecki, os bens de capital são específicos ao setor, ou seja, o diferencial de lucro não implica a transferência de bens de capital de um setor para o outro, mas como visto influencia na elevação ou redução da produção destes em cada setor. Apesar disto, não se exclui a possibilidade de equalização da taxa de lucro entre os diversos setores, o que ocorreria quando a taxa de lucro natural de cada setor se igualizasse, o que por sua vez significa a existência da mesma demanda por bens de capital e consequentemente o mesmo nível de crescimento natural em todos os $n-1$ setores.

Para analisar essa dinâmica são estudadas separadamente diversas situações analisando dois setores, representados no Gráfico 4.3 , dos $n-1$ setores do modelo ${ }^{93}$. Nesta situação tem-se a existência de quatro taxa de lucro $r_{1}, r_{2}, r_{K_{1}}$ e $r_{K_{2}}$.

Gráfico 4.3 - Taxas de lucro presentes no modelo verticalmente integrado de dois setores

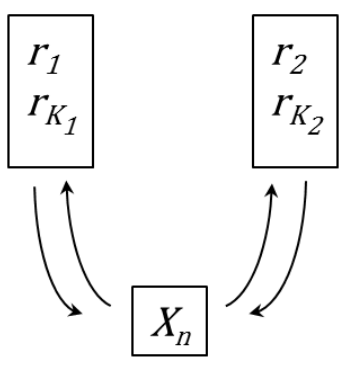

Se $r_{1}=r_{K_{1}}, r_{2}=r_{K_{2}}$ teríamos que cada setor encontra-se ao seu nível de crescimento natural com $u_{1}^{N}=u_{K_{1}}^{N}$ e $u_{2}^{N}=u_{K_{2}}^{N}$. No entanto, isso não significa que ambos os setores

\footnotetext{
${ }^{93} \mathrm{O}$ mesmo exercício poderia ser realizado para três ou mais setores, mas isto tornaria apenas mais complexa a exposição. Com apenas dois setores é possível obter as conclusões relevantes. No quinto capítulo apresenta-se uma aplicação do modelo com três setores.
} 
crescem à mesma taxa. Este resultado dependeria da demanda em cada setor e seria representado por $r_{K_{1}}>r_{K_{2}}$, maior crescimento no primeiro setor e o contrário ocorrendo quando $r_{K_{1}}<r_{K_{2}}$. Nesta situação ter-se-ia também que ambos os setores são profit-led, conforme exposto anteriormente.

A hipótese de que a economia situa-se ao nível natural é bastante restritiva de tal forma que é de se esperar que isso não ocorra. Assim, vejamos o caso em que $r_{1}>r_{K_{1}}$ e $r_{2}>r_{K_{2}}$. Conforme exposto na subseção anterior isso significa que $u_{1}^{N}<u_{K_{1}}^{N}$ e $u_{2}^{N}<u_{K_{2}}^{N}$. Naquela situação em que a economia é constituída por apenas dois setores verticalmente integrados, dada a menor demanda por bens de capital essa situação seria insustentável em longo prazo, pois faltariam bens de capital para atender a demanda pelo bem de consumo final em cada setor. No entanto, no modelo multissetorial tal conclusão não é verdadeira, pois os diferentes regimes de crescimento afetam o comportamento de cada setor. No exemplo em questão as possibilidades são:

1. Se ambos os setores forem wage-led. Neste caso, como o profit-share na indústria produtora de bens de capital é inferior a indústria de bens de consumo, é possível supor que haveria tendência à equalização da taxa de lucro em ambos os setores dado o maior crescimento na indústria produtora de bens de capital;

2. Se o primeiro setor for wage-led e o segundo profit-led. Neste caso, haveria uma tendência à equalização do lucro no primeiro setor, mas não no segundo. Entretanto, isso não significa a eliminação do segundo setor, havendo demanda por esse bem ele permanecerá. A diferença, por sua vez, ocorrerá nas taxas de crescimento setoriais $^{94}$.

3. Se o primeiro setor for profit-led e o segundo for wage-led. Análise é idêntica ao item dois, somente invertendo os setores.

4. Se ambos os setores forem profit-led. Neste caso não haverá tendência à equalização da taxa de lucro em cada setor, pois a indústria produtora de bens finais crescerá mais do que a produtora de bens de capital.

Os quatro casos expostos acima seriam os mesmos caso adotássemos que $r_{1}<r_{K_{1}}$ e $r_{2}<r_{K_{2}}$. Agora vejamos o caso de $r_{1}>r_{K_{1}}$ e $r_{2}<r_{K_{2}}$, nessa situação ter-se-ia $u_{1}^{N}<u_{K_{1}}^{N} \mathrm{e}$ $u_{2}^{N}>u_{K_{2}}^{N}$. Assim:

1. Se ambos os setores forem wage-led. Neste caso, no primeiro setor o profitshare na indústria produtora de bens de capital é inferior a indústria de bens de

\footnotetext{
${ }^{94} \mathrm{Na}$ discussão sobre estagnação a ser apresentada no último capítulo verifica-se a ocorrência desta situação.
} 
consumo. Desta forma é possível supor que haveria tendência à equalização da taxa de lucro. No segundo setor também poder-se-ia esperar a equalização, mas agora seria a indústria produtora do bem final que se igualaria a do bem de capital;

2. Se o primeiro setor for wage-led e o segundo profit-led. Neste caso, haveria uma tendência à equalização do lucro no primeiro setor, mas não no segundo. Entretanto, isso não significa que eliminação do segundo setor, havendo demanda por esse bem ele permanecerá. Em comparação ao item 2 anterior, neste não se pode afirmar a tendência em relação às taxas de crescimento setoriais $^{95}$

3. Se o primeiro setor for profit-led e o segundo for wage-led. Análise é idêntica ao item dois, somente invertendo os setores;

4. Se ambos os setores forem profit-led. Análise é similar ao item 1, mas ao contrário.

Os últimos quatro itens seriam idênticos se assumíssemos $r_{1}<r_{K_{1}}$ e $r_{2}>r_{K_{2}}$. No exercício acima se identificou as condições para equalização dos lucros intrassetoriais no modelo multissetorial. No que diz respeito à equalização da taxa de lucros interssetorial, ao nível natural mostrou-se que isso significa a equalização das taxas de crescimento entre os $n-1$ setores. Ou seja, a equalização da taxa de crescimento interssetores é extremamente improvável e ocorre quando $r_{1}=r_{K_{1}}=r_{2}=r_{K_{2}}$ independentemente do regime de crescimento.

Em resumo, obtêm-se as seguintes conclusões: a) o que limita o crescimento de cada setor é a produção de bens de capital; b) como os bens de capital são específicos, não há deslocamento entre os setores, somente entre as respectivas indústrias; c) é possível a manutenção de diversos setores na economia, cada um deles com taxas de lucro divergentes; d) a condição para equalização da taxa de lucro entre os setores depende do ponto de partida inicial, como visto acima, se este for o crescimento natural em cada setor, essa equalização independe do regime de crescimento.

A partir destas conclusões mostra-se o quão restritivas são as condições necessárias para a equalização da taxa de lucro entre os setores. Além disso, mostra-se que é possível haver no longo prazo divergências entre as taxas de lucro em cada setor, sem que haja eliminação de um setor em prol do outro. Havendo demanda pelos bens finais é perfeitamente

\footnotetext{
${ }^{95}$ Vide referência 92.
} 
factível que todos os setores se mantenham na economia. Esta dedução é importante, pois nos permite adentrar em outro tema presente nas análises multissetoriais que é a relação entre regime de crescimento e perfil da demanda. Até o momento, o perfil da demanda foi considerado exógeno e mostrou-se no terceiro capítulo que ele afeta a definição do regime de crescimento setorial, o wage-led, se $\beta T_{i}<\gamma \Omega_{i}$, ou o profit-led, se $\beta T_{i}>\gamma \Omega_{i}$. Neste caso, a causalidade é do perfil da demanda para o regime de crescimento. Entretanto, a causalidade inversa também está presente na economia, isto é como o regime de crescimento afeta o perfil da demanda. As duas causalidades são importantes para compreender a mudança estrutural.

Segundo Pasinetti (1981) as economias seguem a Lei de Engel, isto é, à medida que a renda cresce as pessoas tendem a consumir bens de maior valor agregado, isto é, reduz-se o gasto com bens inferiores. De modo semelhante, pode-se afirmar que, ao longo do processo de acumulação, os capitalistas irão investir nos setores que possuírem maior demanda, em particular nos setores que possuirem maior demanda por bens de capital, que consequentemente são os bens de maior valor agregado.

Pasinetti chegou a essa conclusão, pois, como mostramos no terceiro capítulo, ele estava preocupado em identificar as condições para o crescimento em equilíbrio e para isto não era necessário qualificar o comportamento da demanda e nem a presença de diferentes regimes de crescimento. Na síntese proposta neste trabalho, a demanda dos trabalhadores presente em Pasinetti foi substituída (aproximada) pela decisão de investimento dos capitalistas (ver argumento acima). Isto de certa forma introduz caráter institucional, mas como visto nas subseções 4.2 e 4.3, estas características institucionais são compatíveis com o modelo de Pasinetti. Desta forma, a partir das hipóteses institucionais de Kalecki é possível complementar a causalidade que não está presente em Pasinetti, em particular, pode-se afirmar que nos setores com regimes de crescimento wage-led predomina-se inicialmente a produção de bens de baixo valor agregado (a medida que a renda cresce isso se altera por meio da Lei de Engel), e nos setores com regime de crescimento profit-led deve-se predominar os bens de maior valor agregado, pois o seu consumo provém da classe mais abastada.

Diante do exposto, sob uma economia fechada, sem governo e sem progresso tecnológico, tem-se que a mudança estrutural está estritamente relacionada ao comportamento da demanda, pois à medida que forem demandados bens de maior valor agregado se processa a transição da preponderância do setor de menor crescimento para o setor de maior crescimento, e nesse processo como visto não há necessidade de equalização da taxa de lucro e deslocamento de capital entre o setores. 
Pois bem, no modelo apresentado pode-se pressupor que para todos os países, à medida que ocorre o processo de acumulação, automaticamente a renda se eleva e consequentemente a demanda por bens de maior valor agregado se efetua. Evidentemente, analisando as economias nacionais isso não ocorre de modo tão simples, em particular destacam-se três empecilhos. O primeiro é evidenciado no próprio modelo, o segundo e o terceiro decorrem de suas limitações.

Conforme destacado, podem predominar na economia diversos regimes de crescimento, sem tendência à equalização da taxa de crescimento entre os setores. No entanto, para aquelas situações em que houver tendência à equalização no nível natural de crescimento, viu-se que se deve predominar o padrão de crescimento wage-led, ou seja, para que o país apresente altas taxas de crescimento em todos os setores é necessário que sua estrutura social seja o mais igualitária possível, isto é, que a renda seja distribuída de modo que os salários absorvam a maior parcela. Isso não é a realidade de boa parte dos países em desenvolvimento ${ }^{96}$. Logo, para que haja a referida mudança estrutural física, é necessário $a$ priori a alteração na estrutura social, isto corresponde ao primeiro empecilho.

No modelo, adota-se que o capital é o fator de produção limitador do crescimento e que cada capital é específico para cada setor, de tal forma que não é possível o deslocamento do capital de um setor para o outro devido a essa especificidade. Sabe-se que os países não possuem todos os bens de capital, assim caso se eleve a demanda pelo bem $X_{n-1}$ é possível que a estrutura produtiva do país não possua o bem de capital $X_{K_{(n-1)}}$ necessário a sua produção. Desta forma haveria importação deste bem final e, dependendo das circunstâncias, seria necessário importar o bem de capital para a posterior produção interna do bem de consumo final. No entanto, trata-se aqui de um modelo fechado. Assim, considerar a economia fechada corresponde ao segundo empecilho.

Independentemente do crescimento da renda, a mudança estrutural pode ocorrer caso haja progresso tecnológico, este pode elevar a produtividade em cada setor e até mesmo resultar na introdução de novos bens e serviços finais na economia. Pasinetti (1981) introduz no seu modelo o progresso tecnológico e destaca o papel deste na mudança estrutural. Para os objetivos deste trabalho, não há necessidade de discorrer sobre o progresso tecnológico, mas reconhece-se que sua ausência limita a interpretação aqui realizada de como se efetua a mudança estrutural, tem-se então o terceiro empecilho.

\footnotetext{
${ }^{96}$ Inclusive nos países desenvolvidos tem-se observado nos últimos anos a elevação da concentração de renda (PIKETY, 2015).
} 


\subsection{RESUMO DO CAPÍTULO}

Neste capítulo inicialmente expõe-se o modelo kaleckiano de dois setores de Park (1995) e Dutt (1990). Mostra-se que Park identificou uma sobre determinação no modelo devido à existência de 13 equações e 12 incógnitas. As soluções para isso seriam: a) eliminar a taxa uniforme de lucros; b) eliminar a taxa uniforme de acumulação; e c) eliminar a diferenciação dos preços determinados por mark-up. Park mostra que não é possível adotar nenhuma dessas soluções, logo o sistema mantém-se sobre determinado.

Dutt (1990) reconhece a sobre determinação, mas afirma que esta ocorre apenas no curto prazo, no qual há divergência entre as taxas de lucros setoriais e de acumulação. No longo prazo haveria equalização entre essas taxas e o sistema tornar-se-ia determinado. No entanto, frente às posições de equilíbrio no longo prazo propostas por Dutt, não se pode obter uma relação entre a taxa de lucro e a taxa de acumulação. Além disso, Dutt não expõe o processo de uniformização da taxa de lucro no longo prazo, ao contrário assume ad hoc que haverá deslocamentos dos bens de capital para os setores com maior taxa de lucro. Isso é problemático, pois Kalecki trabalha com a economia composta por setores verticalmente integrados, na qual os bens de capital são especializados, o que dificulta o deslocamento entre os setores.

Para enfrentar as deficiências identificadas no modelo kaleckiano utiliza-se o modelo de Pasinetti. No entanto, para se adotar esse procedimento é necessário comprovar as semelhanças entre os modelos, isto é realizado mostrando-se que é possível obter a partir do modelo de Pasinetti: a decomposição do produto entre salários e lucros; que a soma dos gastos dos trabalhadores dos dois setores corresponde ao produto do setor de bens de consumo; que os investimentos de ambos os setores correspondem à quantidade de bens de capital produzida e que os preços são determinados por mark-up. Em particular, convém destacar que para demonstrar que a quantidade produzida de bens de capital corresponde à soma dos investimentos dos dois setores recorreu-se ao modelo de Feldman (1929).

Além de destacar as semelhanças, mostra-se também que o longo prazo natural pasinettiano é diferente do longo prazo dos primeiros modelos keynesianos em que se assume

$u=1$. Pasinetti adota $\frac{v_{1}}{u_{1}}=\frac{v_{2}}{u_{2}}=1$, isto é, a produção de bens de consumo final acompanha a capacidade produtiva, e isso não significa assumir que a produção de bens finais será igual ao produto de pleno emprego da economia.

Assim, após demonstrar a equivalência entre os modelos, torna-se necessário explicitar como a partir do modelo de Pasinetti é possível compreender a dinâmica entre o curto e o 
longo prazo que não está explicita nos modelos kaleckianos. Para isso, é necessário endogeneizar as variáveis naturais do modelo. Conforme exposto no terceiro capítulo deste trabalho, Pasinetti (1981) endogeniza a taxa de lucro natural, resta então endogeneizar a taxa de utilização da capacidade natural $\left(u^{N}\right)$.

$\mathrm{Na}$ exposição deste processo destaca-se que se deve levar em consideração não somente o lado da demanda, mas também o lado da oferta, pois a taxa de utilização da capacidade natural é aquela que mantém a economia em equilíbrio, $\dot{X}=\dot{K}$. Na introdução do lado da oferta, utiliza-se o referido modelo de Feldman. De modo a facilitar a compreensão, inicia-se endogenizando o modelo unissetorial, posteriormente os modelos bissetoriais e multissetoriais.

O resultado do modelo unissetorial nos mostra que, ao considerar o lado da oferta a partir do modelo de Feldman, o "teto" de crescimento da economia é fornecido pela equação fundamental de Harrod. Este resultado é interessante, pois elimina a instabilidade identificada no modelo de Harrod, além disso, a obtenção de $u^{N}$ nos mostra que esta não é uma variável ad hoc, pois depende do comportamento da taxa de utilização da capacidade de curto prazo.

As conclusões identificadas no modelo unissetorial em linhas gerais se repetem no modelo bissetorial, mas neste torna-se explicito que a taxa de utilização normal da capacidade é determinada pela demanda por bens de capital e, seja utilizando o modelo kaleckiano seja o neo-ricardiano, os resultados são similares. De forma complementar, a partir do modelo bissetorial é possível analisar a tendência à equalização da taxa de lucro entre os dois setores. Vê-se que as condições para essa equalização são restritivas e não estão relacionadas ao deslocamento de bens de capital, mas sim à igualdade das taxas normais de utilização da capacidade.

Os resultados obtidos no modelo bissetorial são interessantes, mas limitados ao fato de que se discute a situação de dois setores verticalmente integrados. Isso é superado ao se discutir o modelo multissetorial, no qual se tem $n-1$ setores compostos por duas indústrias verticalmente integradas, o produtor de bens finais e o produtor de bens de capital. O modelo multissetorial de referência é o de Pasinetti, por isso realizam-se certas modificações na nomenclatura e fazem-se alguns ajustes devidamente justificados, como, por exemplo, considerar a demanda por consumo da população como as decisões de investimento dos capitalistas.

Ao discorrer sobre o modelo bissetorial, verificou-se as restrições à equalização entre as taxas de lucro intra indústrias. No modelo multissetorial mostra-se que a equalização da taxa de juros inter indústrias é possível, e que está relacionada à equalização da taxa de 
crescimento entre os setores. No entanto, dadas as restrições para equalização da taxa de lucro, tem-se que no longo prazo há divergência de taxa de lucro entre as indústrias e isso não significa que uma será eliminada em prol da outra. Se houver demanda pelos diferentes bens finais é factível que todos os diversos setores se mantenham na economia. Isto nos permite analisar a mudança estrutural através da relação entre o regime de crescimento e o perfil da demanda. Tratando-se de uma economia fechada, sem governo e sem progresso tecnológico, a mudança estrutural está estritamente relacionada ao comportamento da demanda, em particular à Lei de Engel.

Desta conclusão, evidencia-se que o primeiro empecilho ao constante crescimento no longo prazo é a modificação da estrutura distributiva em cada país. Naquele em que a renda for mais bem distribuída, maior a possibilidade de manutenção da taxa de crescimento natural entre todos os setores da economia. Além disso, como os países não produzem internamente todos os produtos é possível que a demanda por certo bem final não seja satisfeita devido exatamente à inexistência da produção desse bem. Caso o modelo fosse aberto, esse segundo empecilho seria resolvido pela importação do bem final, ou até mesmo pela importação do bem de capital necessário à sua produção. Por fim, convém destacar a ausência do progresso tecnológico que atua elevando a produtividade e criando novos bens finais (novas indústrias) na economia.

Essas limitações não invalidam as conclusões presentes nesse capítulo, além disso, vão além do objetivo deste trabalho. A superação dos empecilhos identificados exige grande esforço analítico, em especial se for formalizado, e diante da natureza destes percebe-se que a melhor abordagem envolve caraterísticas históricas e institucionais de cada país, as quais permitem identificar o desenvolvimento ou subdesenvolvimento.

A escola estruturalista latino-americana destaca-se na compreensão do caráter histórico institucional que explica o subdesenvolvimento latino-americano. No próximo capítulo discorre-se sobre algumas teses historicamente datadas de autores estruturalistas destacando-se os seus argumentos analíticos com o intuito de identificar as semelhanças com os pressupostos e conclusões do presente modelo. 


\section{CAPÍTULO 5 - UM BREVE EXERCÍCIO SOBRE HISTÓRIA DO PENSAMENTO ECONÔMICO: APLICAÇÃO DO MODELO SÍNTESE KALECKI-PASINETTI}

\subsection{INTRODUÇÃO}

Ao final do quarto capítulo são elencadas três limitações do modelo síntese KaleckiPasinetti proposto neste trabalho, elas são: a) alteração da estrutura social, em particular uma distribuição igualitária da renda de modo a gerar a tendência de equalização da taxa de crescimento intrassetor; b) considerar a economia fechada, o que impossibilita analisar a possibilidade de importação de bens de capital por parte dos países em crescimento; c) ausência de progresso tecnológico, o qual constitui importante fator no processo de mudança estrutural.

Além de destacar as limitações, observa-se que a superação destas exigiria grande esforço analítico, os quais envolveriam características históricas e institucionais de cada país, elementos estes que fogem ao escopo deste trabalho. No entanto, avanços significativos sobre as limitações apresentadas foram realizados pela escola estruturalista latino-americana, que desenvolveu diversas teses ao longo do século passado para a compreensão do subdesenvolvimento dos países latinos.

Neste capítulo não se pretende discorrer detalhadamente sobre o pensamento estruturalista latino-americano, mas sim expor duas teses historicamente datadas presentes no debate estruturalista e destacar as semelhanças com o modelo apresentado neste trabalho. Nesse intuito, na segunda seção destacam-se algumas características gerais do pensamento estruturalista, em particular a especificidade do subdesenvolvimento latino-americano, a concepção centro-periferia e a necessidade de industrialização. Em seguida, passa-se à discussão das duas teses. A terceira seção discorre sobre a tendência à estagnação proposta por Furtado (1968) e a quarta seção discorre sobre a crítica à tendência à estagnação de Furtado elaborada por Tavares e Serra (1974). A quinta seção mostra como ambas as teses podem ser formalizadas a partir do modelo síntese Kalecki-Pasinetti. A partir disto verifica-se que o modelo é passível de diversos desdobramentos.

Estas duas teses foram selecionadas para discussão neste capítulo, pois os principais argumentos de ambas podem ser visualizados a partir de uma economia fechada, elemento 
essencial para se atingir o objetivo deste capítulo. Entretanto, é importante frisar que essas teses foram apresentadas para economias abertas. Importantes teses estruturalistas como a tendência a deterioração dos termos de troca e o estrangulamento externo dos países subdesenvolvidos não são aqui analisadas, pois não é possível visualizar os argumentos sob economia fechada.

\subsection{O ESTRUTURALISMO LATINO-AMERICANO}

O pensamento econômico denominado estruturalismo latino-americano está intrinsicamente relacionado à Comissão Econômica para a América Latina e Caribe das Nações Unidas (Cepal), pois a maioria dos economistas ligados a essa corrente em algum momento participaram da Cepal e os seus trabalhos foram publicados sob o seu patrocínio (RODRIGUES, 2009). Estes autores tinham como objetivo identificar os principais problemas ao desenvolvimento econômico dos países da América Latina e Caribe, isso é evidenciado no título do texto de Raul Prebisch de 1949, The economic development of Latin America and its principal problems, o qual ficou reconhecido como "manifesto" do estruturalismo.

Neste trabalho Prebisch, juntamente com os demais autores cepalinos, observa que o subdesenvolvimento é um processo de desenvolvimento que merece ser teorizado especificamente. Esta teorização, por sua vez, deve focar na análise das forças produtivas e na transformação das estruturas sociais e institucionais nas quais as forças atuam ${ }^{97}$.

A formação das modernas sociedades industriais é mais facilmente compreendida quando estudamo-la simultaneamente do ângulo de desenvolvimento de suas forças produtivas e do da transformação das estruturas sociais e do marco institucional dentro dos quais operam essas forças. O afastamento crescente desses dois enfoques, causado pela falsa especialização das ciências sociais, é responsável pelas dificuldades que hoje enfrentamos para equacionar problemas de desenvolvimento com respeito aos quais perdem validez os critérios tradicionais que permitiam diferenciar variáveis econômicas e não econômicas. Os obstáculos opostos por esse inadequado enfoque metodológico à captação da realidade social avolumamse no caso do estudo das estruturas subdesenvolvidas, nas quais a diferenciação do especificamente econômico muitas vezes se encontra em fase não muito avançada. $\mathrm{Na}$ análise que se segue, trataremos de captar o problema do subdesenvolvimento como uma realidade histórica, decorrente da propagação de técnica moderna do processo de constituição de uma economia de escala mundial. (FURTADO, 1968, p. 3).

\footnotetext{
${ }^{97} \mathrm{O}$ detalhamento do carácter estruturalista da escola cepalina é encontrado em Palma (1987) e Rodríguez (2009) entre outros. Sobre o método histórico-estruturalista na obra de Furtado especificamente ver Boianovsky (2015).
} 
Observa-se que Furtado identifica o desenvolvimento e o subdesenvolvimento como fenômenos interdependentes que surgem no processo de evolução do capitalismo industrial $\left(\right.$ BOIANOVSKY, 1987) ${ }^{98}$. No âmbito desse processo, os cepalinos destacam o papel do progresso técnico e desta análise concebem o sistema centro-periferia, introduzida inicialmente por Prebisch (1949). Os países centrais são aqueles em que se origina o progresso técnico e onde se concentra os frutos da crescente produtividade da economia decorrente deste. Isto é, nos centros os métodos de produção se difundem de forma relativamente breve entre os diversos setores da economia, e dada a ampliação da demanda que acompanha a elevação da produtividade tende-se a gerar um ciclo virtuoso de inovações tecnológicas, diversificando ainda mais a produção de bens e serviços. Como resultado, a estrutura produtiva dos países centrais é diversificada e homogênea, não havendo distinção nítida entre os setores exportadores e os voltados para o mercado interno.

La indole centripeta del capitalismo se manifiesta persistentemente en las relaciones entre los centros y la periferia. En los primeros se origina el progreso técnico y tiende a concentrarse en ellos el fruto de la creciente que acompaña al incremento de productividad se concentra también alli la industrialización, aguijada por incesantes innovaciones tecnológicas que diversifican más y más la producción de bienes y servicios (PREBISCH, 1981, p. 37)

Os países periféricos por sua vez são aqueles em que o progresso tecnológico penetra somente em setores exportadores de produtos primários ou setores cujas atividades estejam diretamente relacionadas à exportação, que constituem o setor dinâmico da economia (RODRÍGUEZ, 2009). Há, portanto, nesses países a nítida distinção entre setores focados na exportação e setores voltados ao mercado interno. Desta forma, nos países periféricos coexistem setores de alta produtividade com setores atrasados tecnologicamente, desenvolvese assim uma estrutura produtiva especializada e heterogênea ${ }^{99}$.

Heterogeneous because economic activities with remarkably different productivity-growth dynamics existed side by side - namely, a modern export sector coexisting with a backward agriculture and an undersized manufacturing sector. Over-specialized because the range of exports was limited to just a few (homogenous, unbranded and price-volatile) commodities, and their process of production had very limited backward and forward-linkages with the rest of the economy (PALMA, 1987, p. 573).

\footnotetext{
98 "From de very beginning ECLAC's analysis was structuralist in the sense that it was associated with both a view of the world economy as a system within which the center and the periphery are intrinsically related to one another, and the most economic problems of the periphery (...) derive from the specific economic structure that emerged from that interaction" (BLANKENBUR, PALMA, TREGENNA, 1987, p. 71).

${ }^{99} \mathrm{O}$ conceito de hetoregeneidade estrutural foi concebido por Furtado (2009).
} 
No manifesto, Prebisch (1949) destacou também que os argumentos favoráveis à divisão internacional do trabalho e ao livre comércio entre os países baseiam-se na hipótese de que o progresso técnico tende a difundir-se de forma a beneficiar a todos. Essa difusão ocorreria da seguinte forma: diante do progresso tecnológico, seria de se esperar que os preços dos bens manufaturados reduzissem mais do que o preço dos bens primários. Desta forma, os países periféricos se apropriariam do progresso técnico de forma semelhante aos países centrais. No entanto, isso não ocorria e os fatos estilizados identificados para as economias primário-exportadoras eram: (a) menor crescimento da renda frente aos países industrializados; (b) recorrentes problemas de balanço de pagamentos; (c) tendência à deterioração dos termos de troca; e (d) desemprego persistente (PALMA, 1987).

Prebisch e os demais autores da escola estruturalista não visualizavam a possibilidade de manter-se o desenvolvimento periférico baseado na especialização primário-exportadora. A industrialização seria indispensável.

Ela [a industrialização] não é um fim em si mesma, mas o único meio de que se dispõe para captar uma parte do fruto de progresso técnico e elevar progressivamente o nível de vida das massas (PREBISCH, 1949, p. 48).

No intuito de explicar os fatos estilizados ora mencionados e outras características do processo desenvolvimento dos países latino-americanos, a escola estruturalista desenvolveu amplo arcabouço teórico ao longo do século XX. Nesta breve seção discorreu-se sobre aspectos gerais da escola, que perpassam as obras de diversos autores cepalinos, como a mencionada especificidade do subdesenvolvimento latino-americano, a concepção centroperiferia e a necessidade de industrialização.

\subsection{A TESE DA TENDÊNCIA À ESTAGNAÇÃO}

A tese de que as economias latino-americanas tenderiam à estagnação foi apresentada por Furtado no livro Subdesenvolvimento e Estagnação na América Latina de 1968. Neste Furtado discorre sobre dois modelos, um referente à fase primário-exportadora e outro à fase de industrialização por substituição de importações.

A primeira fase seria marcada pelas seguintes características: a) terra e oferta de mãode-obra abundante ${ }^{100}$; b) baixo nível de salários; c) deterioração dos termos de troca; d) economia composta por três setores, o de subsistência, o exportador e o provedor de capacidade produtiva para o setor exportador. Segundo Furtado, no início do processo de

\footnotetext{
${ }^{100}$ A oferta de mão-de-obra ilimitada nos países latino-americanos e caribenhos é analisada com detalhe em Lewis (1958).
} 
desenvolvimento desta fase, os trabalhadores excedentes seriam absorvidos com produtividade marginal zero. No entanto, à medida que a demanda pelos bens exportados se elevasse, seria necessário ampliar o investimento no terceiro setor. Surge então, o questionamento se essa fase de desenvolvimento geraria os recursos necessários à ampliação da capacidade produtiva. Furtado afirma que a resposta é positiva, pois os recursos provenientes da exportação gerariam a poupança necessária à ampliação dos investimentos ${ }^{101}$.

(..) no modelo agroexportador, a própria expansão da atividade exportadora assegura a poupança necessária, uma vez que a produção [do terceiro setor], não podendo ser consumida ou exportada, tem como destino obrigatório a incorporação à capacidade produtiva (COUTINHO, 2015, p. 459).

Tem-se, portanto, que uma vez mantidas as exportações de bens primários, esta fase resultaria em ciclo virtuoso, pois se elevaria ao mesmo tempo a produtividade do capital e a taxa de poupança ${ }^{102}$. Mas, uma vez cessadas as exportações, haveria excesso de oferta de bens primários no mercado, queda dos preços e redução dos investimentos. Nessa situação dar-seia início à segunda fase.

Historicamente, o processo de substituição de importações foi alavancado a partir da crise dos anos 1930, que afetou negativamente as receitas de exportações dos países da América Latina consequentemente dificultando a sua capacidade de importar. Nesse cenário adotaram-se medidas de restrições à importação como controle quantitativo (quotas), desvalorização da moeda, compra de excedentes e financiamento de estoques de produtos primários etc ${ }^{103}$. Tais medidas evitaram a queda da renda interna e permitiram que as divisas fossem direcionadas a importações dos bens de capital necessários ao processo de industrialização.

Em suma, o processo de substituição de importações pode ser entendido como um processo de desenvolvimento parcial e fechado que, respondendo às restrições do comércio exterior, procurou repetir aceleradamente, em condições históricas distintas, a experiência de industrialização dos países desenvolvidos (TAVARES, 1974, p. 35).

Importante observar que a substituição de importações não consistia simplesmente em passar a produzir internamente produtos importados e assim reduzir o montante de importação. Pelo contrário, à medida que a industrialização avançava, superando o setor de

\footnotetext{
${ }^{101}$ Identifica-se aqui uma diferença fundamental entre Furtado e Kalecki, pois como destacado na primeira seção para o segundo o investimento precede a poupança e não o contrário.

102 “(...) um aspecto interessante do modelo agrícola multissetorial é a conclusão de que o aumento da concentração de renda não impede o crescimento econômico, uma vez que a composição da demanda necessariamente envolve investimentos [no setor provedor de capacidade produtiva ao setor exportador]" (COUTINHO, 2015, p. 459).

${ }^{103}$ Prebisch (1981), apesar de reconhecer a necessidade de proteção ao mercado interno para a industrialização por substituição de importações, afirma que estes foram exagerados devido à influência de poderosos interesses.
} 
bens de consumo e passando para o setor de bens intermediários, a demanda por bens de capital importados se elevava, retroalimentando esse ciclo o qual tenderia ao estrangulamento seja em caráter absoluto (redução da capacidade total de importar) ou relativo (crescimento lento da capacidade de importar).

Furtado (1968) reconhece os argumentos acima descritos e destaca que as políticas restritivas sustentaram a renda interna e impulsionaram o processo de industrialização por substituição de importações. A manutenção da renda interna não só criou o mercado para os bens manufaturados como elevou os preços destes.

Segundo Furtado, a substituição de importações de bens de consumo não duráveis seria fácil, dados os menores preços dos bens e a existência de amplo mercado, mas tais fatores não estariam presentes na posterior substituição de bens de consumo duráveis. Furtado (1968) destaca que diferentemente dos países centrais, nos quais o desenvolvimento tecnológico era o resultado endógeno das mudanças sociais, nos países periféricos a técnica produtiva era um fator exógeno introduzido numa sociedade contendo marco social e institucional inadequado para a sua plena absorção.

Ao contrário dos países que se desenvolveram na fase clássica, durante a qual o avanço da técnica estava intimamente relacionado com os demais fatores causantes da aceleração do processo de desenvolvimento econômico e de mudança social, no atual processo de transformação das estruturas subdesenvolvidas a tecnologia constitui um fator exógeno de reduzida flexibilidade (FURTADO, 1968, p. 9).

As técnicas de produção necessárias para a produção de bens intermediários eram intensivas em capital, desta forma a sua produção não resultava em absorção de grande contingente de trabalhadores, assim havia uma redução da massa de salários na economia e ampliação dos lucros, aumentando a concentração de renda. Em adendo, isso resultava na redução do mercado consumidor tanto de bens primários quanto de bens manufaturados. Diante da redução do mercado, para se estimular a produção interna dos bens de capital, os preços deste deveriam ser mais elevados do que os preços médios da economia. Furtado (1968) conclui que o resultado dessa dinâmica seria a ampliação da relação capital-trabalho e redução da relação produto-capital na economia, o que consequentemente levaria a economia para estagnação.

Na medida em que a demanda se inclina em favor de indústrias produtoras de bens de consumo duráveis ou de capital, privilegia setores que operam com uma relação produto-capital inferior à média da economia, fortalecendo a tendência à estagnação (COUTINHO, 1980, p. 143). 
Conforme Tavares e Serra (1974) observam, os salários são estáveis nas economias latino-americanas devido à heterogeneidade estrutural, pois grande contingente populacional continua empregado em setores de baixa produtividade (baixa remuneração). Nos argumentos de Furtado percebe-se que a dinâmica do processo de substituição de importações, ao invés de reduzir, alavanca essa heterogeneidade estrutural, que se agrava à medida que não apenas o setor de bens de capital de mecaniza, mas também o setor agrícola, reduzindo ainda mais a sua capacidade de absorção de mão-de-obra. O resultado inevitável seria a estagnação.

A queda na taxa de crescimento seria estimulada pelo declínio da relação produto-capital "tecnológica", inerente ao setor de bens de consumo duráveis e equipamentos (em condições de mercado restrito), e também pela perda de dinamismo da agricultura moderna, que reduz sua capacidade de absorção de renda (COUTINHO, 2015, p. 464).

Para os objetivos deste trabalho é explicito que Furtado desenvolve os seus argumentos a partir da concepção do um regime de crescimento wage-led. O processo de industrialização ao adotar técnicas de capital intensiva reduzia a demanda por trabalhadores e consequentemente reduzia a massa salarial da economia. Isso, por sua vez, significava redução do consumo total da economia (bens de consumo não duráveis e duráveis). Conforme Coutinho (2015) observa, a concentração de renda é um dos argumentos centrais da tese estagnacionista de Furtado. A redução do mercado de consumo fazia com que os bens de capital necessitassem ter preços elevados, caso contrário não seriam produzidos. Todos esses fatores atuavam para que houvesse a tendência à redução da relação produto-capital.

Nos argumentos de Furtado percebe-se a semelhança com o modelo multissetorial síntese Kalecki-Pasinetti exposto no capítulo anterior ${ }^{104}$. Furtado reconhece de forma semelhante ao modelo que a continuidade do crescimento seria dada pela acumulação de capital, no caso os bens de consumo duráveis. No entanto, dadas às características institucionais dos países latino-americanos, a absorção destes se realizava com redução da massa de trabalhadores e, consequentemente, redução do wage share, o que por fim reduziria a consumo dos bens finais. Ou seja, no argumento de Furtado evidencia-se uma desproporção entre a demanda por bens de consumo e a produção de bens de capital decorrente da redução da massa de salários.

Importante frisar que a tendência à estagnação para Furtando era inerente ao processo de industrialização dos países latino-americanos, pois como se destacou estes adotavam técnicas para um marco social e institucional inadequado. Segundo Furtado (1968), a alteração desse quadro envolvia modificar esse marco institucional em três direções: a) evitar

\footnotetext{
${ }^{104} \mathrm{Na}$ última seção deste capítulo isso é exposto com maiores detalhes.
} 
tecnologias que provoquem concentração de renda; b) ampliar as dimensões potenciais e atuais do mercado por meio da integração econômica regional; c) orientar o progresso tecnológico às necessidades da economia. Nestas direções sugeridas por Furtado, novamente percebe-se a concepção de um regime de crescimento wage-led, pois o fundamental seria ampliar o mercado de consumo.

\subsection{A CRÍTICA AO ESTAGNACIONISMO}

Tavares e Serra (1974) no importante ensaio, Além da Estagnação de 1971, afirmam que a relação produto-capital não explica a dinâmica da acumulação capitalista, pelo contrário é o resultado desta. Para os autores, a dinâmica capitalista é explicada pelo investimento, o qual depende primordialmente do lucro esperado e não da relação capital-produto ${ }^{105}$.

A mencionada relação inversa entre as razões capital-trabalho e produto-capital somente ocorreria se a taxa de lucro de todos os setores da economia fosse igual, o que para Tavares e Serra era um pressuposto por demais irrealista.

Furtado parte de um suposto quanto à igualização das taxas de lucro que nos parece irreal, visto que em condições de mercado acentuadamente imperfeito, com alguns ramos dominados por grandes unidades de produção que além disso possuem forte grau de monopólio tecnológico, não há por que admitir que se igualem as taxa de lucro das diferentes indústrias (TAVARES; SERRA, 1974, p. 163).

Os autores frisam também que Furtado não levou em consideração o papel do progresso tecnológico. Por exemplo, se o progresso fosse poupador de capital, à medida que a economia se industrializasse a relação capital-trabalho não cresceria a ponto de reduzir a relação produto-capital. Por outro lado, se o progresso tecnológico fosse poupador de trabalho, a relação produto-capital somente se reduziria caso o aumento relativo da produtividade do trabalho fosse inferior ao aumento relativo da relação capital-trabalho. A critica de Tavares e Serra é resumida abaixo.

(...) trabalhar com "categorias resultado", na consideração das taxas de lucro das diferentes indústrias que tenderiam a igualar-se do mesmo modo que os salários, ao superar a intensificação do uso do capital da penetração do progresso técnico e, além disso, não considerar os efeitos destes sobre a produtividade dos investimentos nem os efeitos das diversas modalidades de economias externas, Furtado parece ter vestido a "camisa de força" de um modelo neoclássico de equilíbrio geral - elegante mas ineficaz para explicar a dinâmica de uma economia capitalista (TAVARES, SERRA, 1974, p. 167).

\footnotetext{
${ }^{105}$ Ao se comparar este parágrafo com o segundo capítulo deste trabalho, percebe-se a influência kaleckiana no trabalho de Tavares e Serra.
} 
A afirmação de que Furtado não considerou os efeitos do progresso tecnológico não é verídica, ele analisou o caso em que o progresso é neutro, isto é, eleva tanto a produtividade do capital quanto do trabalho de forma igual. Nessa situação, dado que normalmente a inovação ocorre no setor de manufaturas, haveria redução dos preços desses bens, o que beneficiaria a classe social consumidora destes (FURTADO, 1968). Ou seja, a redução dos preços dos bens manufaturados não resultaria em elevação da massa de salários reais da economia, pois esses bens têm pequena participação na cesta de consumo do montante total de trabalhadores. Desta forma, o progresso tecnológico não reduziria, mas sim agravaria a heterogeneidade estrutural das economias periféricas.

Apesar desta análise, é fato que Furtado não considerou os pontos levantados por Tavares e Serra decorrentes dos progressos capital intensivo ou trabalho intensivo. De toda forma, para o objetivo deste trabalho o que convém destacar é a concepção diversa de regimes de crescimento nestas duas obras. Enquanto em Furtado predomina a concepção de regime wage-led, para Tavares e Serra a economia cresce sob regime profit-led. Ou seja, o processo de substituição de importações não tenderia à estagnação dada a redução da massa de salários na economia, ao contrário, a economia continuaria crescendo devido à elevação da participação dos lucros. Enquanto para Furtado, a concentração de renda era o problema, em Tavares e Serra esta era fundamental para a manutenção do crescimento, pois estimulava o consumo e o investimento em bens de alto valor agregado.

A interpretação ora apresentada não significa que Tavares e Serra identificassem a concentração de renda como um resultado benéfico para a sociedade, pelo contrário, mas o foco da análise para a compreensão do processo de acumulação de capital era o investimento. Segundo os autores, o capitalismo latino-americano, e o brasileiro em particular, apresentava sérios problemas, pois ao mesmo tempo em que era excludente, enfrentava escassez de oportunidade de investimento, o que está diretamente relacionado à heterogeneidade estrutural dessas economias.

Os autores discutem também se haveria possibilidade de homogeneização produtiva na América Latina. Segundo eles, isso ocorreria caso houvesse investimentos nos setores não modernos, de modo a elevar a produtividade destas. Entretanto, tais investimentos não ocorreriam, pois como destacado, eles se direcionam para os setores que possuem elevadas taxas de lucro, que por natureza são os setores modernos. Logo, a heterogeneidade tende a se acentuar. 
Novamente, percebe-se na argumentação de Tavares e Serra a respeito da manutenção da heterogeneidade estrutural que eles sustentam sua análise a partir da concepção de regime de crescimento profit-led.

\subsection{APLICANDO O MODELO SÍNTESE KALECKI-PASINETTI AO DEBATE SOBRE O ESTAGNACIONISMO E POSSÍVEIS DESDOBRAMENTOS}

De modo a representar por meio do modelo síntese Kalecki-Pasinetti a discussão sobre o estagnacionismo na escola estruturalista, o Gráfico 5.1 representa a estrutura proposta por Furtado (1968):

\section{Gráfico 5.1 - Estrutura de Furtado pré-industrialização}

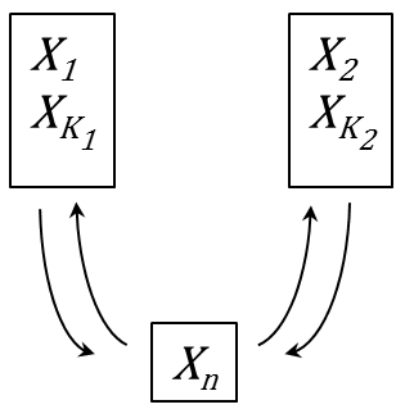

Na Seção 5.3 observa-se que Furtado apresenta seu argumento a partir de três setores, mas o mesmo no modelo síntese multissetorial deste trabalho é visualizado em apenas dois setores. O primeiro setor verticalmente integrado produz o bem final $X_{1}$, que são os bens de subsistência, e $X_{K_{1}}$ representa os bens de capital necessários à produção dos bens de subsistência. Tais bens de capital, de acordo com os argumentos de Furtado, seriam bem rústicos (pás, enxadas, insumos naturais etc). O segundo setor, por sua vez, seria o setor produtor de commodities exportáveis, no qual $X_{2}$ representa esse bem e $X_{K_{2}}$ consiste no bem de capital necessário à produção do bem final a ser comercializado internacionalmente. A diferença entre o modelo síntese e o modelo de Furtado reside exatamente na representação deste bem de capital, que para Furtado seria um novo setor, mas, como ele é verticalmente integrado à $X_{2}$ no modelo síntese, encontra-se representado no mesmo setor hiper verticalmente integrado.

Segundo Furtado (1968), esta estrutura representada no Gráfico 5.1 seria a fase préindustrialização dos países latino-americanos. Interessante observar que, apesar de Furtado 
não explicitar, a partir de seus argumentos pode-se afirmar que o primeiro setor é wage-led e o segundo profit-led. Isso porque a ampliação da produção no primeiro decorre fundamentalmente da renda dos trabalhadores e, no segundo, decorre da demanda externa, ou seja, neste não é a ampliação da demanda interna proveniente da renda dos trabalhadores que promove o crescimento, mas sim a renda externa que amplia os lucros dos capitalistas, que estimula tanto a produção de $X_{2}$ quanto de $X_{K_{2}}$. Nos argumentos de Furtado, esta fase préindustrialização seria sustentável à medida que houvesse demanda por $X_{2}$.

Agora para representar a fase de industrialização dos países latino-americanos, no modelo síntese é de fato necessário introduzir um terceiro setor conforme o Gráfico 5.2.

Gráfico 5.2 - Fase da industrialização

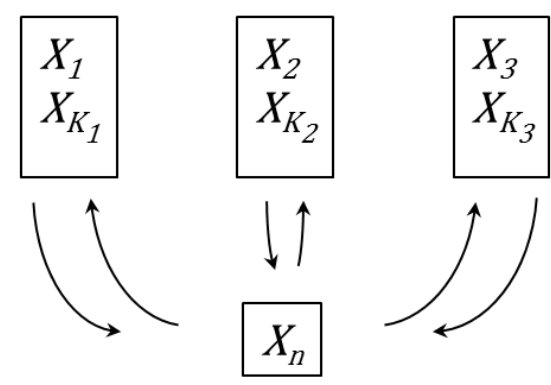

Neste os dois primeiros setores são semelhantes à fase anterior, e o terceiro setor representa aquele que não existia na fase anterior, isto é, são os bens finais $X_{3}$ e bens de capital $X_{K_{3}}$ que antes eram importados, mas, com a adoção de políticas de restrição à importação, passaram a ser produzidos internamente ${ }^{106}$. Conforme Furtado demonstra tais políticas foram necessárias diante da queda da demanda externa pelos bens do segundo setor.

Resta, por sua vez, identificar a tendência à estagnação no modelo síntese. De acordo com Furtado, o terceiro setor seria wage-led, mas altamente intensivo em capital, de tal forma que, à medida que se amplia a produção, mais capital era utilizado e menos trabalho. Isto é, a elevação da produção não demandaria a totalidade disponível de $X_{n}$, além disso, dada a heterogeneidade produtiva entre os três setores, a maior produtividade do terceiro setor não representaria a elevação dos salários ${ }^{107}$. O resultado disto seria a redução da demanda não

\footnotetext{
${ }^{106}$ Nos argumentos de Furtado apresenta-se a distinção entre bens de consumo duráveis e não duráveis. Essa distinção é possível de ser realizada no modelo síntese, mas para isso seria necessário introduzir um quarto setor. De modo a facilitar a exposição, resume-se tudo no terceiro setor que representa os bens anteriormente importados.

${ }^{107}$ Devido aos baixos salários auferidos pelos trabalhadores dos outros dois setores.
} 
apenas do terceiro setor, $\varphi_{3}$, quanto também do primeiro, $\varphi_{1}$. Assim, diante redução da demanda, a economia tenderia à estagnação.

A crítica ao estagnacionismo de Furtado elaborada por Tavares e Serra (1974) inicialmente questiona a afirmação de que o terceiro setor seria intensivo em capital. No entanto, independente desta primeira observação, a diferença essencial dos autores frente a Furtado é considerar o terceiro setor profit-led e não wage-led. Ou seja, mesmo que haja redução do wage share na economia esta seria necessária para a ampliação do investimento e consequentemente manutenção do crescimento da economia. A economia continuaria crescendo apesar da concentração de renda, esta manteria elevada a demanda no terceiro setor, $\varphi_{3}{ }^{108}$.

Pelo que foi exposto, percebe-se que o modelo síntese Kalecki-Pasinetti é apto a representar de forma sintética o debate estruturalista das décadas de 1960 e 1970 a respeito da tendência ou não à estagnação da economia. Debate este que envolvia não somente a relação entre o perfil da demanda e o regime de crescimento, mas também, conforme mencionado no capítulo anterior, a relação entre o regime de crescimento e o perfil da demanda.

Em linhas gerais se discutia a viabilidade ou não de manutenção do processo de industrialização. De acordo com Furtado (1968), haveria estagnação, pois os novos setores industriais eram intensivos em capital e não absorviam a classe trabalhadora. Isso resultava na concentração de renda e consequentemente no subconsumo. De fato há evidências da concentração de renda no período.

(...) a participação na receita nacional de $40 \%$ dos que pertencem aos grupos de renda mais baixa caiu de 11,2\% em 1960 para 9\% em 1970; a dos seguintes $40 \%$ caiu de $34,4 \%$ para $27,8 \%$, enquanto os $5 \%$ pertencentes aos grupos de renda mais alta aumentaram sua fatia de $27,4 \%$ para $36,3 \%$. Há também evidências consideráveis de que o salário real tenha primeiro declinado na segunda metade da década de 1960 para então subir a uma taxa significativamente menor que a dos aumentos de produtividade (BAER, 2009, p. 100).

Os críticos ao estagnacionismo por sua vez aproximam-se da proposta de Anibal Pinto, que considerava o estudo da heterogeneidade estrutural o ponto de partida para a compreensão do subdesenvolvimento. Segundo Pinto (1976), a distribuição de renda não é o resultado da relação entre estrutura produtiva e perfil da demanda, ao contrário, é a estrutura produtiva que determina a distribuição da renda necessária à formação de um mercado para os seus produtos. Ou seja, para Pinto é o regime de crescimento que determina o perfil da

\footnotetext{
${ }^{108}$ Subjacente a este argumento, encontra-se o fato de que os autores supõem que no terceiro setor a principal demanda é proveniente dos capitalistas, pois são eles que consomem os bens de capital anteriormente importados.
} 
demanda. Tais argumentos foram apropriados por Tavares e Serra (1974) e assemelham-se a adoção da Lei de Engels por Pasinetti, pois à medida que o crescimento se realiza eleva-se a demanda por bens de maior valor agregado proveniente das classes mais abastadas.

Não é o objetivo deste texto discutir a validade das teorias apresentadas neste debate, mas o fato é que o estagnacionismo não se realizou, ao contrário, no caso brasileiro, verificouse anos de alto crescimento econômico. Tal fato fez com que Furtado revisse seus argumentos:

A concentração na distribuição de renda no Brasil ocasionou um perfil de demanda no qual os bens de indústrias tecnologicamente avançadas estão fortemente representados, fato que também se reflete na estrutura produtiva do país. Assim, o contínuo dinamismo desse tipo de indústrias depende da manutenção ou mesmo de um aumento na concentração de renda (FURTADO, 1974, apud, BAER, 2009, p. 104).

Observa-se então que, apesar da simplicidade, o modelo síntese Kalecki-Pasinetti é capaz de expressar o debate que envolvia elementos históricos e institucionais. Mas, dado que se apresentou a fase pré-industrialização e o processo de industrialização, o que o modelo nos forneceria para a fase atual das economias latino-americanas?

No intuito de responder essa pergunta, inicialmente reinterpretam-se os três setores apresentados no Gráfico 5.2. O primeiro consiste no setor de primário produtor de commodities, o segundo é o setor secundário produtor de bens de capital e o terceiro é o setor de serviços. Nesta breve exposição de possíveis desdobramentos do modelo tem-se como parâmetro a economia brasileira e adotam-se algumas hipóteses:

a) O principal componente da demanda do primeiro setor $\left(\varphi_{1}\right)$ é a demanda externa, desta forma é factível assumir que em geral esse setor é profit-led, uma vez que a demanda é determinada preferencialmente pela demanda externa;

b) O Brasil não é um grande exportador de máquinas, assim pode-se supor que a demanda que sustenta o crescimento do setor secundário é basicamente a demanda interna. Deste modo, é factível assumir que este setor é wage-led. Não obstante, se assumirmos que a demanda por máquinas na economia provém da classe abastada, é factível considerar este setor profit-led ${ }^{109}$.

c) $\mathrm{O}$ setor de serviços em sua maioria ${ }^{110}$ não é exportável, mas sim consumido internamente, assim é factível assumir que o seu regime de crescimento é wage-

\footnotetext{
${ }^{109}$ Argumento este que se aproxima do utilizado por Tavares e Serra (1974).

${ }^{110}$ Existem serviços exportáveis como os de engenharia e de tecnologia da informação, no entanto, eles não possuem grande participação no setor de serviços brasileiros.
} 
led. No Brasil esse setor é intensivo em mão-de-obra de baixa qualificação e seu produto em geral é de baixa intensidade tecnológica.

No capítulo anterior discutiram-se extenuadamente as condições para equalização da taxa de lucro intrassetores, desta forma aqui se assume que cada setor encontra-se ao seu nível natural $r_{n-1}=r_{K_{n-1}}$. Passa-se então à discussão das trajetórias de crescimento a partir das três hipóteses descritas acima.

No Brasil, em particular, nos últimos anos o setor primário tem sido o mais dinâmico. Como esse setor é capital intensivo e voltado para a demanda externa, o seu regime de crescimento profit-led resulta na redução do wage share da economia. Isso por sua vez afeta a demanda dos bens dos demais setores. Com destaque para o segundo setor, no qual a natureza do bem produzido resulta no emprego de poucos trabalhadores, logo não há uma demanda endógena elevada ${ }^{111}$. No setor terciário, dado que este emprega grande parte de $X_{n}$, a redução da massa salarial decorrente do dinamismo do primeiro setor teria menor efeito e, portanto, seria de se esperar certa constância com tendência à queda na sua taxa de crescimento, uma vez que o regime de crescimento é wage-led.

Agora, supondo que o segundo setor seja profit-led, a ampliação do profit share da economia resultaria na elevação da demanda por esses bens e à medida que esse processo se sucedesse poder-se-ia esperar um processo de transferência do maior crescimento do primeiro para o segundo setor. No entanto, dada a esperada redução do wage share, o crescimento do terceiro setor se reduziria comprometendo o resultado líquido para a economia como um todo.

Este exercício para a economia brasileira tem o intuito de exemplificar as diversas possibilidades de análise que o modelo síntese Kalecki-Pasinetti permite elucidar. E assim demonstrar as conclusões obtidas no terceiro capítulo deste trabalho, no qual se mostrou o quanto restritivas são as condições para que haja equalização da taxa de lucro intrassetores e interssetores.

\subsection{RESUMO DO CAPÍTULO}

Conforme exposto não é o objetivo deste trabalho emitir considerações sobre a validade ou não das teses apresentadas. De toda forma, cabe frisar que a economia brasileira não entrou em estágio de estagnação na década de 1970 como previa Furtado. Ao contrário, houve forte crescimento caracterizando o que foi denominado "milagre econômico".

\footnotetext{
${ }^{111}$ No setor de subsistência de Furtado visualiza-se uma demanda endógena elevada.
} 
Em linhas gerais, mostra-se que é a concepção de crescimento sob o regime wage-led que permeia os argumentos utilizados por Furtado para justificar a tendência à estagnação no processo de industrialização por substituição de importação. Dado que este adotava técnicas intensivas em capital, a consequente diminuição da massa salarial resultaria na redução do mercado de consumo (ampliando a concentração de renda). Desta forma, para que houvesse substituição no mercado de bens intermediários, diante da reduzida escala do mercado, os preços desses bens tendiam ser elevados. Esses fatores resultavam na redução da relação produto-capital e consequente estagnação.

De modo contrário, na segunda tese predomina a concepção de regime de crescimento profit-led. Segundo Tavares e Serra as economias latino-americanas não tendiam à estagnação, pois na dinâmica do processo de substituição de importações, a constituição da indústria de bens de capital exigia a concentração de renda, pois os bens desse setor são de alto valor agregado (consumidos por pequena parcela da população) e exigem alto montante de investimento. Ou seja, segundo os autores, o crescimento ocorreria devido à concentração de renda. Esse argumento foi desenvolvido a partir das teses de Aníbal Pinto sobre o papel da heterogeneidade estrutural no subdesenvolvimento e em anos posteriores foi apropriado por Delfim Neto, que afirmou ser necessário inicialmente crescer o "bolo" para posteriormente o distribuir.

Em seguida, na quinta subseção mostra-se que ambas as teses podem ser formalizadas a partir do modelo síntese Kalecki-Pasinetti desenvolvido neste trabalho. Ou seja, a partir da junção entre os pressupostos institucionais de Kalecki e o modelo multissetorial préinstitucional de Pasinetti é possível compreender e explicitar teses estruturalistas, cujo esforço analítico almejava elucidar fatos muito além da meta do presente trabalho.

Os desdobramentos no modelo síntese apresentado neste trabalho são inúmeros e ao final do quarta seção apresenta-se um breve exemplo a partir do caso brasileiro das conclusões que se pode obter a respeito de trajetórias de crescimento e mudança estrutural na economia. 


\section{CAPÍTULO 6 - CONCLUSÃO}

Dado que em cada capítulo expõem-se as conclusões dos argumentos apresentados, neste capítulo final faremos um resumo dos principais pontos levantados ao final dos quatro capítulos de desenvolvimento deste trabalho e a relação destes com a discussão apresentada na introdução.

No segundo capítulo dado o intuito de apresentar os modelos de crescimento e distribuição pós-keynesianos, inicialmente expõem-se o princípio da demanda efetiva de Keynes e mostra-se que a dedução de Keynes deste princípio é realizada no âmbito da rejeição da Lei de Say, fato este estritamente relacionado às características peculiares da moeda.

A partir desse princípio mostra-se que Harrod propôs um modelo de crescimento baseado na interação do multiplicador e do acelerador keynesiano com o objetivo de determinar as condições necessárias para o equilíbrio entre poupança e investimento ao longo de vários períodos, o que resultaria no estado de equilíbrio estacionário. No entanto, a partir desse modelo mostrou-se que não é possível garantir: 1) o crescimento estacionário em pleno emprego; 2) a estabilidade do crescimento. Domar, por sua vez, não almejou desenvolver uma teoria do crescimento, mas sim apresentar um modelo que contivesse as condições necessárias para manutenção infinita da igualdade entre demanda e oferta a pleno emprego, e as fragilidade de seu modelo são semelhantes às de Harrod, em particular o pressuposto de que o investimento é exogenamente determinado.

Kaldor e Pasinetti expandem os modelos de tradição keynesiana introduzindo a distribuição funcional da renda. Ambos deduzem o que ficou denominado de equação de Cambridge, esta afirma que a taxa de lucro e a participação dos lucros no produto (profit share) são determinados pelo investimento. O resultado de Pasinetti é particularmente interessante, pois, ao contrário de Kaldor, ele assume que os trabalhadores possuem participação nos lucros ${ }^{112}$. No entanto, no longo prazo é somente a poupança dos capitalistas que influencia na determinação da taxa de lucro e do profit share, resultado semelhante ao obtido por Kaldor.

\footnotetext{
${ }^{112}$ Kaldor (1956) também assume a possibilidade da poupança dos trabalhadores ser positiva, no entanto, não reconhece que isto levaria aos trabalhadores serem proprietários de bens de capital juntamente com os capitalistas.
} 
Robinson adiciona aos modelos de tradição keynesiana a função investimento, nos autores citados anteriormente o investimento é dado. De modo original, Robinson resolve a seguinte circularidade: o investimento determina a taxa de lucro, mas é determinado pela própria taxa de lucro. A solução de Robinson consistiu em adotar o investimento como função da taxa de lucro esperada pelos empresários, ou seja, ela endogenizou a taxa de lucro.

A particularidade dos modelos de Kaldor, Pasinetti e Robinson é assumir no longo prazo a utilização plena da capacidade produtiva, o que significa retornar à Lei de Say. Esta fragilidade é superada nos modelos kaleckianos que endogenizam o investimento por meio da taxa de utilização da capacidade e da taxa de lucro. Essa hipótese permite aos modelos kaleckianos identificarem dois importantes resultados, o paradoxo da poupança e o paradoxo dos custos.

Após a exposição do modelo kaleckiano e de seus principais resultados no segundo capítulo, observa-se que não há menção a preços naturais e centro de gravitação predeterminado na economia. Ao contrário, no modelo de Kalecki o longo prazo consiste na sucessão de curtos prazos.

A concepção de preços naturais como variáveis de longo prazo determinadas pelas condições gerais da economia é discutida no terceiro capítulo. Neste mostra-se que essa concepção provém dos autores clássicos Smith, Ricardo e Marx e foi apropriada pelos neoricardianos. No entanto, há autores, a exemplo Vianelo (1985), que interpretam o estado natural como a posição de pleno ajuste da economia, nesta a taxa de utilização da capacidade produtiva é unitária, o que aproxima esta interpretação dos modelos dos primeiros póskeynesianos discutidos no segundo capítulo. Por outro lado, autores como Ciccone (1986) interpretam a taxas naturais de longo prazo como taxa esperadas pelos agentes econômicos, deste modo a taxa normal de longo prazo não é pré-determinada e varia a cada alteração das expectativas, o que evidencia o path dependence no que diz respeito aos preços e quantidades normais. Esta segunda interpretação se aproxima do modelo kaleckiano, e também se evidenciam outras semelhanças como: a) adoção do princípio da demanda efetiva; b) importância das análises de curto prazo assim como as análises de longo prazo; c) path dependence.

Inicia-se assim, no terceiro capítulo, a discussão sobre o estereótipo neo-ricardiano que o impede de considerá-lo no âmbito da escola pós-keynesiana. Uma alternativa de síntese seria interpretar a taxa de lucro normal sendo o profit-share. Esta interpretação resulta no modelo de Bhaduri e Marglin (1990), no qual o paradoxo da poupança é válido e o paradoxo dos custos pode ou não ocorrer. Se ocorrer, trata-se de uma economia wage-led, caso 
contrário, a economia é profit-led. Ou seja, identificam-se diferentes regimes de crescimento para as economias a depender dos valores dos parâmetros.

Considerar o lucro normal como o profit-share não é consenso, pois para alguns autores não há relação direta entre o profit-share e a expectativa de lucro, e para outros, a taxa de lucro presente continua sendo o melhor indicador do investimento. De toda forma, reconhece-se que a integração entre os modelos ocorrerá quando se relacionar a dinâmica da demanda e a formação de expectativas no longo prazo. Isso é realizado por Pasinetti que integra a variação da demanda com a dinâmica de acumulação de capital.

Pasinetti apresenta a alternativa a ser adotada para a síntese entre os dois modelos, mas para isso abandona o caráter institucional relacionado às expectativas dos agentes econômicos e qualifica o comportamento da demanda necessário à manutenção do crescimento no modelo multissetorial. Além do caráter pré-institucional, o modelo de Pasinetti é verticalmente integrado e preocupa-se em adentrar nas características naturais do sistema econômico, isto é, a essência dos processos social de produção, o qual vale para qualquer sociedade industrial. Nesse âmbito, Pasinetti apresenta o sistema dual de produção das mercadorias e de preços no modelo estático e de crescimento.

Nesses sistemas Pasinetti identifica as condições necessárias para a manutenção equilíbrio em fluxo e estoque, posição que por sua vez representa a manutenção do pleno emprego, pleno gasto da renda e plena utilização da capacidade produtiva. Além disso, Pasinetti mostra quais seriam os preços e quantidades caso o equilíbrio fosse mantido. Desta análise depreende-se o quanto é difícil manter o pleno emprego na economia, em especial no modelo dinâmico, no qual está presente o tempo, pois a cada período modificam-se as variáveis fundamentais da economia e consequentemente dificulta-se a obtenção do equilíbrio.

A partir do sistema dinâmico sem progresso tecnológico de Pasinetti obtém-se a taxa de lucro natural, que é dada pela soma da taxa de variação da demanda e da taxa de crescimento populacional. Esta representa a condição necessária para que no sistema natural cada setor produtor de bens de capital cresça à mesma taxa do setor produtor de bens de consumo e assim mantenha o produto e o nível de emprego crescendo a taxas constantes.

Além do sistema dual com capital e trabalho de Pasinetti, no terceiro capítulo discorrese sobre o sistema dual de puro trabalho, pois este é útil no desenvolvimento do quarto capítulo.

Após a exposição do modelo multissetorial de Pasinetti, desmistifica-se outro argumento componente do estereótipo neo-ricardiano, uma vez que se observa a importância 
da determinação do nível de emprego e da taxa de crescimento do produto. Ou seja, os neoricardianos não consideram a determinação dos preços relativos e a distribuição social do produto como o núcleo exclusivo da análise econômica.

Ao final do terceiro capítulo, mostra-se que, ao invés de considerar a taxa de lucro de Kalecki sendo o profit-share, caso seja introduzida a taxa de lucro natural de Pasinetti, verifica-se a manutenção do paradoxo da poupança e a existência de dois regimes de crescimento. Esta análise é realizada para apenas um setor neste capítulo e no Capítulo 4 discute-se o caso de $n$ setores.

No intuito de transpor a discussão de um modelo verticalmente agregado para o modelo multissetorial, o início do quarto capítulo expõe o modelo kaleckiano de dois setores de Park (1995) e Dutt (1990). Mostra-se que Park identificou uma sobre determinação no modelo devido à existência de 13 equações e 12 incógnitas. As soluções para isso seriam: a) eliminar a taxa uniforme de lucros; b) eliminar a taxa uniforme de acumulação; e c) eliminar a diferenciação dos preços determinados por mark-up. Park mostra que não é possível adotar nenhuma dessas soluções, logo o sistema mantém-se sobre determinado.

Dutt (1990) reconhece a sobre determinação, mas afirma que esta ocorre apenas no curto prazo, no qual há divergência entre as taxas de lucros setoriais e de acumulação. No longo prazo haveria equalização entre essas taxas e o sistema tornar-se-ia determinado. No entanto, frente às posições de equilíbrio no longo prazo propostas por Dutt não se pode obter uma relação entre a taxa de lucro e a taxa de acumulação, além disso, Dutt não expõe o processo de uniformização da taxa de lucro no longo prazo, ao contrário assume-se ad hoc que haverá deslocamentos dos bens de capital para os setores com maior taxa de lucro. Isso é problemático, pois Kalecki trabalha com a economia composta por setores verticalmente integrados, nos quais os bens de capital são especializados, o que dificulta o deslocamento entre os setores.

Para enfrentar as deficiências identificadas no modelo kaleckiano utiliza-se o modelo de Pasinetti. Como primeiro passo demonstra-se que é possível obter todas as equações de Kalecki a partir do modelo de Pasinetti, utilizando como "ponte" o modelo de Feldman (1929). Nesse processo mostra-se também que o longo prazo natural pasinettiano é diferente do longo prazo dos primeiros modelos keynesianos em que se assume $u=1$. Pasinetti adota $\frac{v_{1}}{u_{1}}=\frac{v_{2}}{u_{2}}=1$, isto é, a produção de bens de consumo final acompanha a capacidade produtiva, e isso não significa assumir que a produção de bens finais será igual ao produto de pleno emprego da economia. 
De modo a expor a dinâmica entre o curto e longo prazo ausente nos modelos kaleckianos, recorre-se ao modelo síntese Kalecki-Pasinetti, endogeneizando não apenas a taxa de lucro, mas também a taxa natural de utilização da capacidade. Isto é realizado para o modelo com um, dois e $n$ setores.

O resultado do modelo unissetorial nos mostra que, ao considerar o lado da oferta a partir do modelo de Feldman, o "teto" de crescimento da economia é fornecido pela equação fundamental de Harrod. Este resultado é interessante, pois elimina a instabilidade identificada no modelo de Harrod, além disso, a obtenção de $u^{N}$ nos mostra que esta não é uma variável ad hoc, pois depende do comportamento da taxa de utilização da capacidade de curto prazo.

No modelo bissetorial torna-se explicito que a taxa de utilização normal da capacidade é determinada pela demanda por bens de capital. De forma complementar vê-se que as condições para a equalização das taxas de lucro intrassetores estão relacionadas à igualdade entre as taxas normais de utilização da capacidade, e quanto a taxas de lucro interssetores vêse que as condições para essa equalização são muito restritivas.

Os resultados obtidos no modelo bissetorial são interessantes, mas limitados ao fato de que se discute a situação de dois setores verticalmente integrados. Isso é superado, ao se discutir o modelo multissetorial, no qual se tem $n-1$ setores compostos por duas indústrias verticalmente integradas, o produtor de bens finais e o produtor de bens de capital. Assim, como no caso bissetorial mostram-se as restrições à equalização da taxa de lucro intra e interssetores, de tal forma que no longo prazo mantém-se a divergência. O ponto a se destacar é que tal divergência não significa que uma será eliminada em prol da outra. Se houver demanda pelos diferentes bens finais é factível que todos os diversos setores se mantenham na economia e cada setor pode assumir um regime de crescimento diferente. Isto nos permite analisar a mudança estrutural através da relação entre o regime de crescimento e o perfil da demanda. Tratando-se de uma economia fechada, sem governo e sem progresso tecnológico, a mudança estrutural está estritamente relacionada ao comportamento da demanda, em particular à Lei de Engel.

A discussão apresentada no quarto capítulo resulta no importante reconhecimento da possibilidade de existência de diversos regimes de crescimento numa única economia. Esta conclusão é diversa da proposta pelos kaleckianos, em grande parte devido à ausência da análise multissetorial, a qual é sanada como o modelo síntese.

O desenvolvimento da síntese também permite identificar as suas limitações para a compreensão do crescimento em longo prazo, que são: a) ausência de modificação da 
estrutura produtiva; b) pressuposto de economia fechada; c) ausência de progresso tecnológico.

A superação dos empecilhos identificados exige grande esforço analítico, em especial se for formalizado, e diante da natureza destes percebe-se que a melhor abordagem envolve caraterísticas históricas e institucionais de cada país, as quais permitem identificar o desenvolvimento ou subdesenvolvimento. Tal esforço foi realizado no século XX pela escola estruturalista latino-americana.

As deficiências do modelo não significam a inutilidade do modelo síntese para compreensão do comportamento de uma economia fechada, sem governo e sem progresso tecnológico. O quinto capítulo possui o intuito de mostrar essa aplicabilidade do modelo, para isso recorre-se ao debate estruturalista sobre o estagnacionismo da economia brasileira ao final da década de sessenta. Neste capítulo mostra-se que os argumentos favoráveis e contrários ao estagnacionismo podem ser facilmente formalizados por meio do modelo síntese Kalecki-Pasinetti. Esse exercício permite evidenciar importantes desdobramentos do modelo, os quais são brevemente expostos para o caso brasileiro a partir de hipóteses sobre os setores primário, secundário e terciário. Nesse exemplo, demonstra-se o quão restritivas são as condições para equalização da taxa de lucro intra e interssetores e mostra-se como a economia de um país pode assumir diferentes trajetórias de crescimento a partir das características dos seus diversos setores.

À guisa de conclusão, o presente trabalho mostra que para os neo-ricardianos: a) não apenas os preços relativos e a distribuição social do trabalho constituem o core da economia; b) as posições normais de longo prazo não são independentes do comportamento do curto prazo. Tais pontos permitem aproximar a escola neo-ricardiana junto às pós-keynesiana, e isso é realizado por meio do modelo multissetorial de Pasinetti.

Após demonstrar as similaridades entre os dois modelos, se verifica que a concepção agregada do modelo kaleckiano pode ser desagregada na análise multissetorial de Pasinetti. Além disso, observa-se que a análise ao nível natural de Pasinetti pode ser institucionalizada à la Kalecki, obtendo-se, em especial, a possibilidade de existência de diferentes regimes de crescimento na mesma economia, o que afeta a sua trajetória de mudança estrutural. 


\section{BIBLIOGRAFIA}

AMADEO, E. The Role of Capacity Utilization in Long Period Analysis. Political Economy: Studies in the Surplus Approach, v. 2, n. 2, 1986.

ARAUJO, J. T. Modelos de Crescimento de Inspiração Keynesiana: Uma Apreciação. Estudos Econômicos, São Paulo, v. 28, n.1, p. 5-32, 1998.

ARAÚJO, R; TEIXEIRA, J. A multi-sectoral version of the Post-Keynesian growth model. Estudos Econômicos, v. 45, n. 1, 2014.

ARAÚJO, R; TEIXEIRA, J. Structural change and decisions on investment allocation. Sctrutural Change and Economic Dynamics, v. 13, n. 2, p. 249-258, 2013.

ARAÚJO, R; TEIXEIRA, J. Structural economic dynamics: an alternative approach to NorthSouth models. Cambridge Journal of Economics, v. 28, n. 5, p. 705-717, 2004.

ASIMAKOPULOS, A. Keynes's General Theory and Accumulation. Cambridge University Press, UK, 225 p., 1991.

BHADURI, A.; MARGLIN, S. Profit Squeeze and Keynesian Theory. In: MARGLIN, S. A.; SCHOR, J. B. (eds.) The Golden Age of Capitalism: Reinterpreting the Postwar Experience. Oxford: Clarendon Press, 1995.

BHADURI, A.; MARGLIN, S. Unemployment and the real wage: the economic basis for contesting political ideologies. Cambridge Journal of Economics, v.14, n.4, p. 375-393, 1990.

BLANKENBURG, S., PALMA, J.G., TREGENA, F. Structuralism. In: The New Palgrave: a dictionary of economics. London, Macmillan, 1987.

BOIANOVSKY, M. Modeling economic growth: Domar on moving equilibrium. CHOPE Working Paper, 2015.

BOIANOVSKY, M. Beyond capital fundamentalism: Harrod, Domar and the history of developmente economics. SSRN, 2015.

BOIANOVSKY, M. Celso Furtado. In: The New Palgrave: a dictionary of economics. London, Macmillan, 1987.

BORTIS, H. Shackle's Years of High Theory 1926-1939 and the Making of ClassicalKeynesian Policital Economy - From the Exchange Paradigm to a Monetary Theory of Production. $\mathbf{1}^{\text {st }}$ World Keynes Conference, Izmir University of Economics, Turkey, 2013.

BORTIS, H. Structural economic dynamics and technical progress in a pure labour economy. Structural Change and Economic Dynamics, v. 7, n. 2, p. 135-146, 1996. 
CARVALHO, F.J.C. Mr Keynes and the Post Keynesians. Vermont, USA: Edward Elgar Publishing Limited, 1992.

CICCONE, R. Accumulation and Capacity Utilization: Some Critical Considerations on Joan Robinson's Theory of Distribution. Political Economy: Studies in the Surplus Approach, v.2, n.1, p.17-36, 1986.

COUTINHO, M. Distribuição de renda e padrões de consumo: alguns autores em torno da tradição cepalina. Ensaios FEE, v.1, n. 1, p. 14, 1980.

COUTINHO, M. Subdesenvolvimento e estagnação na América Latina, de Celso Furtado. Revista de Economia Contemporânea, n. 19, v.3, p. 448-474, 2015.

D'AGATA, A; FRENI, G. The structure of growth models: a comparative survey. In: SALVADORI, N. (ed.). The Theory of Economic Growth, UK, 2003.

DAVIDSON, P. Financial Markets, Money and the Real World. Edward Elgar, Cheltenham, UK, Northampton, MA, USA, 2002.

DEPREZ, J. Vertical integration and the problem of fixed capital. Journal of Post Keynesian Economics, v. 13, n. 1, p. 47-64, 1990.

DOMAR, E. Capital, expansion, rate of growth and employment. Econometrica, v. 14, p. 137-147, 1946.

DOW, S. Post Keynesian Methodology. In: DAVIS, J.B.; HANDS, D.W.; MAKI, U (ed). The Handbook of Economic Methodology. Elgar ed., Cheltenham, p. 378-381, 1988.

DOWNWARD, P. A realist appraisal of post-Keynesian pricing theory. Cambridge Journal of Economics, v. 24, n. 2, march, p. 211-214, 2000.

DUPERTUIS, M.; SINHA, A. A Sraffian critique of the classical notion of centre of gravitation. Cambridge Journal of Economics, v. 33, n. 6, 2009.

DUTT, A. Profit-rate equalization in the Kalecki-Steindl model and the "over-determination" problem. The Manchester School, v. 65, n. 4, p. 443-451, 1997.

DUTT, A. Growth, Distribution and Uneven Development. Cambridge, Cambridge University Press, 1990.

FEL'DAM, A.G. On the theory of growth rates of national income. Translated in Foudations of Soviet strategy for economic growth, p. 174-99, ed. Indiana University Press, [1928], 1964.

FONSECA, P. A retomada da eficácia da política monetária anti-inflacionário no Brasil pós-Plano Real (1995-2007). Dissertação de Mestrado, UFRJ, 2010.

FURTADO, C. Desenvolvimento e Subdesenvolvimento. Rio de Janeiro: Contraponto. Centro Internacional Celso Furtado, 2009. 
FURTADO, C. O mito do desenvolvimento econômico. Rio de Janeiro: Paz e Terra, 1974.

FURTADO, C. Subdesenvolvimento e Estagnação na América Latina. Rio de Janeiro: Civilização Brasileira, 1966.

GARBELlinI, N.; WIRKIERMAN, A. Pasinetti's 'Structural Change and Economic Growth': A Conceptual Excursus. Review of Political Economy, v. 26, n. 2, p. 234-57, 2014. First version, 2010.

GURLEZI, D. Natural dynamics, endogenous structural change and the theory of demand: A comment on Pasinetti. Structural Change and Economic Dynamics, v. 7, n. 2, p. 147-162, 1996.

HALEVI, J. The significance of the theory of vertically integrated process for the problem of economic development. Structural Change and Economic Dynamics, v. 7, n. 2, p. 163-171, 1996

HARROD,R. An essay in dynamic theory. In: Sen, A. (org.) Growth economics. Middlesex: Penguim Books, 1970.

HEIN, E.; OCHSEN, C. Regimes of Interest Rates, Income Shares, Savings, and Investment: A Kaleckian Model and Empirical Estimations for some Advanced OECD-Economies. Metroeconomica, February, 2003.

HEIN, E.; VAN TREECK, T. Financialisation in Post-Keynesian models of distribution and growth - a systematic review. IMK Working Paper, $\mathrm{n}^{\mathrm{o}}$ 10, 2008.

HEIN, E. Money, Distribution Conflict and Capital Acumulation: Contributions to Monetary Analysis. New York: Palgrave macmillan, 2008.

HISHIYAMA, I. Appraising Pasinetti's structural dynamics. Structural Change and Economic Dynamics, v. 7, n. 2, p. 127-134, 1996

JONES, H.G. Modernas teorias do crescimento econômico: uma introdução. São Paulo, Ed. Atlas, 1975.

KALDOR, N. A model of economic growth. Economic Journal, 67, p. 591-624, 1957.

KALECKI, M. Teoria da Dinâmica Econômica: Ensaio sobre as mudanças cíclicas e a longo prazo da economia capitalista. São Paulo: Abril S.A, 1983.

KEYNES, J. M. A Teoria Geral do Emprego, do Juro e da Moeda. Ed. Atlas, São Paulo, 328 p., 2007.

KURZ, H. 'Normal' Positions and Capital Utilization. Political Economy: Studies in the Surplus Approach, v. 2, n. 1, 1986.

LAVOIE, M. Sraffians, other Post-Keynesians, and the Controversy over Centers of Gravitation. In: Levrero, E.; Palumbo, A.; Stirati, A (org.). Sraffa and the Reconstruction of Economic Theory: volume three. Palgrave macmillan, 2013. 
LAVOIE, M.; STOCKHAMMER, E. Wage-led growth: concept, theories and policies. International Labour Organization, Genebra, 2012.

LAVOIE, M. The Kaleckian model of growth and distribution and its neo-Ricardian and neoMarxian critiques. Cambridge Journal of Economics, v.35, n.5, p.1333-1350, 1995.

LAVOIE, M. La traverse kaleckienne dans un modèle d'accumulation à deux secteurs avec cout complet : à la recherche d'une synthèse post-classique. Cahiers d'economie politique, n. 26, p. 127-164, 1996.

LAVOIE, M. Foundations of Post-Keynesian Economic Analysis. Edward Elgar: New Directions in Modern Economics, 1992.

LEE, F. Theory creation and the methodological foundations of Post Keynesian economics. Cambridge Journal of Economics, v.26, n.6, November, p. 789-804, 2002.

LEE, F. Post Keynesian Price Theory. Cambridge University Press, 1999.

LEWIS, A. Economic development with unlimited supplies of labour. In: Agarwala and Singh. The economics of underdevelopment, 1958.

LIMA, G; SETTERFIEL, M. Expectations and Stability in the Kaleckian Growth Model. Brazilian Keynesian Review, v.2, n.1, p. 11-25, 2016.

LOPES, J; ASSOUS, M. Michal Kalecki. Great Thinkers in Economics, series editor: A.P. Thirlwall, 2010.

MAHALANOBIS, P.C. Some observations on the process of growth of national income. Sankhya, v. 12, p. 307-12, 1953.

MALINVAUD, E. A Gap in the Social Doctrine of the Church about the Priority of Labour Over Capital: The Proper Role of Finance. Rivista Internazionale di Scienze Sociali, v. 110, n. 3, p. 303-322, 2002.

MARX, K. O Capital. Ed. Abril, São Paulo, v. 3, 1984.

MINSKY, H. John Maynard Keynes. London MacMillan Press, 1975.

MONGIOVI, G. Sraffian economics. In: KING, J.E (ed.), Post Keynesian Economics, 2ed., Cheltenham, UK: Edward Elgar, p. 499-504, 2012.

OCAMPO, J. Economia poskeynesian (Lecturas de EI Trimestre Economico). Fondo de Cultura Economica, Mexico, 1988.

PALMA, J.G. Raul Prebisch. In: The New Palgrave: a dictionary of economics. London, Macmillan, 1987.

PARK, M-S. A note on the "Kalecki-Steindl" steady-state approach to growth and income distribution. The Manchester School, v. 63, n. 3, p. 297-310, 1995. 
PASINETTI, L. An "analytical" approach to the "just" rate of interest: the priority of labour over capital. Rivista Internazionale di Scienze Sociali, v. 110, n. 3, p. 323-329, 2002.

PASINETTI, L. Structural economic dynamics: A theory of the economic consequences of human learning. New York: Cambridge University Press, 1993.

PASINETTI, L. Vertical integration and capital theory: a comment. Journal of Post Keynesian Economics, v. 13, n. 1, p. 65-70, 1990.

PASINETTI, L. Structural Change and Economic Growth: A theoretical essay on the dynamics of the wealth of nations. New York: Cambridge University Press, 1981.

PASINETTI, L. Rate of profit and income distribution in relation to rate of economic growth. Review of Economic Studies, 29, p. 267-279, 1962.

PIKETTY, T. O Capital no século XXI. Ed. Intrínseca, Rio de Janeiro, 2014.

PINTO, A. Heterogeneidade estrutural e modelo de desenvolvimento recente. In: SERRA, José, coord. América Latina, ensaios de interpretação econômica. Rio de Janeiro, Paz e Terra, 1976. p. 44-82.

POSSAS, M. Dinâmica da Economia Capitalista: Uma abordagem teórica. Ed. Brasiliense, SP, 1987.

POSSAS, M.; BALTAR, P. Demanda efetiva e dinâmica em Kalecki. Pesquisa e Planejamento Econômico, v. 11, n. 1, RJ, 1981.

PREBISCH, R. O desenvolvimento econômico na America Latina e algum de seus principais problemas. Cepal, 1949.

RICARDO, D. Princípios de Economia Política e Tributação. Ed. Abril, São Paulo, 1983.

ROBINS, L. An Essay on the Nature and Significance of Economic Science. London, Macmillan, 1932 ( $3^{\mathrm{a}}$ ed. 1984).

ROBINSON, J. Essays in the theory of economic growth. London: Macmillan, 1962.

ROBINSON, J. Acumulação de Capital. Ed. Abril, Coleção os Economistas, São Paulo, 1956.

RONCAGLIA, A. Pierro Sraffa and the reconstruction of political economy. In: WOOD, J. C. (ed.). Pierro Sraffa: Critical Assessments, ed. Routledge, UK, 1995.

SCAZZIERI, R. Vertical integration in Economic Theory. Journal of Post Keynesians Economics, v. 13, n. 1, p. 20-46, 1990.

SEN, A. Growth Economics. Harmondsworth, Penguin Books, 1970. 
SMITH, A. A Riqueza das Nações - Investigação sobre a sua natureza e suas causas. Ed. Abril, São Paulo, 1983.

SOLOW, R. A contribution to the theory of economic growth. Quartely Journal of Economics, v. 70, p. 65-94, 1956.

TAVARES, M., SERRA, J. Além da estagnação. In: Tavares, M. Da substituição de Importações ao Capitalismo Financeiro: ensaios sobre economia brasileira. Rio de Janeiro, ed. Zahar, p. 155-207, 1971/1976.

TRIGG, A. B. Quantity and price systems: toward a framework for coherence between postKeynesian and Sraffian economics. In: HAREY, J.T e GANETT, R.F (eds), Future Directions for Heterodox Economics. Arbor, Michigan Press, p. 127-141, 2008.

VIANELlO, F. Natural (or Normal) Prices: Some Pointers. Political Economy: Studies in the Surplus Approach, v. 5, n. 2, 1989.

VIANEllo, F. The Pace of Accumulation. Political Economy: Studies in the Surplus Approach, v. 1, n. 1, 1985.

WHITE, G. Normal Prices and the Theory of Output: Some Significant Implications of Recente Debate. Political Economy: Studies in the Surplus Approach, v. 5, n. 2, 1989. 